OSWALDO CABRAL DE VASCONCELLOS NETO

ANÁLISE DE DISPONIBILIDADE EM SISTEMAS DE SOFTWARE NA WEB 
OSWALDO CABRAL DE VASCONCELLOS NETO

\title{
ANÁLISE DE DISPONIBILIDADE EM SISTEMAS DE SOFTWARE NA WEB
}

\author{
Dissertação apresentada à escola \\ Politécnica da Universidade de São \\ Paulo para a obtenção do título de \\ Mestre em Engenharia.
}

Área de Concentração: Sistemas Digitais

Orientador: Prof. Dr. Paulo Sérgio Muniz Silva 
Este exemplar foi revisado e alterado em relação à versão original, sob responsabilidade única do autor e com a anuência de seu orientador.

São Paulo, 17 de dezembro de 2009.

Assinatura do autor

Assinatura do orientador

FICHA CATALOGRÁFICA

Vasconcellos Neto, Oswaldo Cabral de

Análise de disponibilidade em sistemas de software na Web / O.C. de Vasconcellos Neto. -- ed.rev. -- São Paulo, 2009.

$152 \mathrm{p}$.

Dissertação (Mestrado) - Escola Politécnica da Universidade de São Paulo. Departamento de Engenharia de Computação e Sistemas Digitais.

1. Arquitetura de software 2. Engenharia de software 3. Qualidade de software I. Universidade de São Paulo. Escola Politécnica. Departamento de Engenharia de Computação e Sistemas Digitais II. t. 


\section{AGRADECIMENTOS}

Agradeço ao professor Dr. Paulo Sérgio Muniz Silva pelas contribuições realizadas durante a orientação deste trabalho, por todo incentivo e confiança ao longo de todo o mestrado.

Ao professor Dr. Reginaldo Arakaki, pelas oportunidades e contribuições ao longo dos últimos anos.

Aos professores da Escola Politécnica da Universidade de São Paulo com os quais tive contato nos últimos anos, que contribuíram para a realização deste trabalho.

À minha família, por todo o apoio recebido durante toda a minha vida.

A todos que contribuíram, direta ou indiretamente, para a realização deste trabalho. 


\section{RESUMO}

A utilização da Internet como um meio de automação de serviços de e-business tem sido adotada como estratégia por empresas em vários ramos da economia, diminuindo custos e propiciando uma melhoria no relacionamento com o cliente. Um requisito não-funcional importante a ser considerado no desenvolvimento de sistemas de software que possibilita esta automação é a disponibilidade. O nível de disponibilidade de um sistema pode ser influenciado pela arquitetura do sistema, e, em particular, pela arquitetura de software, pois as decisões arquitetônicas devem considerar aspectos relacionados à disponibilidade. No método de avaliação de arquitetura ATAM (Architecture Tradeoff Analysis Method - Método de Análise de Compromissos de Arquitetura), esse requisito é analisado através da utilização de cenários de disponibilidade. Como a avaliação da disponibilidade é normalmente uma tarefa complexa, requerendo dos analistas a identificação de numerosos itens interdependentes, a geração e, conseqüentemente, a análise de cenários de disponibilidade na maioria das vezes não é uma tarefa trivial. O presente trabalho tem como objetivo elaborar uma técnica de análise de disponibilidade em sistemas de software para a Web, que auxilie a geração sistemática de cenários de disponibilidade requeridos no método ATAM. Para a elaboração da proposta, o trabalho aborda métodos para a elicitação, representação e análise de requisitos não-funcionais em uma determinada arquitetura de software, bem como conceitos e taxonomias relacionadas à dependabilidade. Ao final, a técnica é exercitada em um exemplo simplificado de sistema de software bancário na Web.

Palavras-chaves: Arquitetura de software. Dependabilidade de sistemas de software. Requisitos não-funcionais. ATAM. Cenários de disponibilidade. 


\begin{abstract}
The use of Internet for e-business service automation has been adopted as a strategy by organizations in several sectors of the economy, reducing costs and providing a better relationship with the customer. Availability is an important nonfunctional requirement to be considered in the development of software systems offering this type of automation. The level of system availability may be affected by the system architecture, and, especially, by the software architecture, as architectural decisions must take availability-related aspects into account. In the ATAM (Architecture Tradeoff Analysis Method) architecture evaluation method, this requirement is analyzed by means of availability scenarios. As availability evaluation is normally a complex task, requiring analysts to identify several interdependent items, the generation and, consequently, the analysis of availability scenarios is often not a trivial task. This work aims to elaborate an availability technique analysis for web-based software systems, to aid in the systematic generation of availability scenarios required in the ATAM method. To elaborate the proposal, the work covers methods for elicitation, representation and analysis of non-functional requirements in a specific software architecture, as well as concepts and taxonomies related to dependability. In the end, the technique is applied on a simplified example of web banking software system.
\end{abstract}

Keywords: Software architecture. Software systems dependability. Non-functional requirements. ATAM. Availability scenarios. 


\section{LISTA DE ILUSTRAÇÕES}

Figura 1 - Representação Gráfica de um Softgoal de Requisito não-funcional.........12

Figura 2- Decomposição por tipo - Contribuição AND...........................................14

Figura 3 - Decomposição por tópico.............................................................15

Figura 4 - Contribuições definidas no framework NFR ..........................................17

Figura 5 - Relação entre táticas, estímulo e resposta ...........................................24

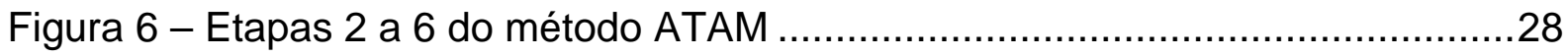

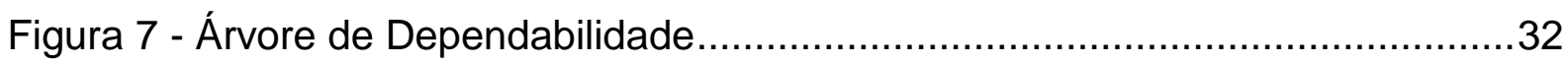

Figura 8 - Relação entre MTBF, MTTF e MTTR.................................................34

Figura 9 - Relação de Causa-Efeito entre Defeitos, Erros e Falhas...........................36

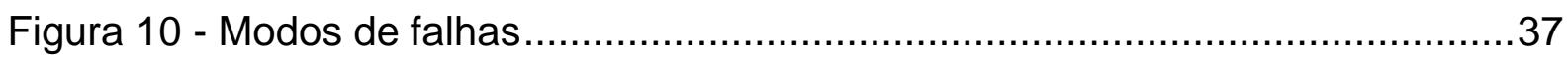

Figura 11 - Modos de falhas de serviço em relação ao domínio de falhas.................38

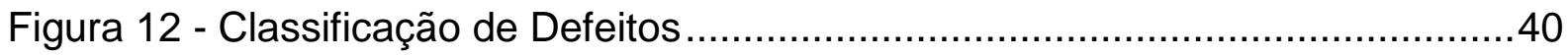

Figura 13 - Técnicas de tolerância a defeitos......................................................47

Figura 14 - Integração de meios de tolerância a defeitos ........................................47

Figura 15 - Táticas para alcançar disponibilidade ..............................................54

Figura 16 - Conceitos que contribuem para a técnica ADSSW ...............................58

Figura 17 - Divisão em Camadas ....................................................................60

Figura 18 - Elementos de uma arquitetura Web...............................................61

Figura 19 - Módulos do Servidor de Aplicação.....................................................62

Figura 20 - Elementos que compõem o servidor de banco de dados ......................64 
Figura 21 - Catálogo de tipos de requisitos não-funcionais, aplicados ao conceito de dependabilidade e seus atributos.

Figura 22 - Decomposição por tipo de dependabilidade 68

Figura 23 - Descrição hierárquica de sistemas de e-business. 70

Figura 24 - Decomposição por perfil de usuário .72

Figura 25 - Priorização para perfil de acesso 73

Figura 26 - Decomposição por tópico - funcionalidade 75

Figura 27 - Decomposição por tópico - camadas .77

Figura 28 - Decomposição por tópico baseada em componentes. 78

Figura 29 - Decomposição por tópico relacionada à camada de regra de negócio...80

Figura 30 - Decomposição por tópico relacionada a camada de integração. .81

Figura 31 - Decomposição por tópico - Fluxo Alternativo 82

Figura 32 - Representação de ameaças de dependabilidade no método 83

Figura 33 - Contribuição ALGO- de Falha para disponibilidade 85

Figura 34 - Catálogo de tipos de falhas definido na técnica ADSSW 86

Figura 35 - Decomposição por tipo de falhas. 89

Figura 36 - Representação de Falha Temporal com refinamentos e contribuições ..90

Figura 37 - Refinamentos e contribuições associadas a falhas de conteúdo..... .92

Figura 38 - Representação de encadeamento entre defeitos, erros e falhas na técnica 92

Figura 39 - Geração de Cenários com o auxílio da técnica ADSSW. 112

Figura 40 - Aplicação da decomposição SistemaSoftwareWebDependabilidadeViaSubTipo 118 
Figura 41 - Aplicação da decomposição

SistemaSoftwareWebDisponibilidadeViaPerfil

Figura 42 - Aplicação da decomposição

SistemaSoftwareWebDisponibilidadeViaFuncionalidade

Figura 43 - Aplicação da decomposição

SistemaSoftwareWebDisponibilidadeFuncViaCamada.

Figura 44 - Decomposição por tópico relacionada à camada de negócio no exemplo - Funcionalidade Pagamento de Tributos

Figura 45 - Decomposição por tópico relacionada à camada de integração no exemplo - Funcionalidade Pagamento de Tributos

Figura 46 - Representação de possíveis falhas relacionadas ao componente Sistema Gerenciador de Banco de Dados

Figura 47 - Representação entre falhas e softgoals de acurácia e tempo de resposta

Figura 48 - Representação da contribuição entre falha e softgoal de disponibilidade associado ao componente SGBD.

Figura 49 - Exemplo de Encadeamento de ameaças a dependabilidade, com respectivas contribuições.

Figura 50 - Inserção de rótulo no estímulo a ser considerado 130

Figura 51 - Representação de propagação de rótulos 131

Figura 52 - Propagação de rótulos para ameaças encadeadas. 132

Figura 53 - Marcação do softgoal Disponibilidade [SGBD] 133

Figura 54 - Propagação de rótulos nos componentes da camada de integração ...134

Figura 55 - Marcação do rótulo associado ao softgoal relacionado à funcionalidade de Pagamento de Tributos 
Figura 56 - Marcação de rótulos associados aos softgoals relacionados a perfis operacionais e ao sistema de software como um todo

Figura 57 - Inclusão de nó correspondente a falha temporal no Sistema

Gerenciador de Banco de Dados na árvore de utilidades.

Figura 58 - Árvore de utilidades em seu quarto nível - com inserção dos cenários

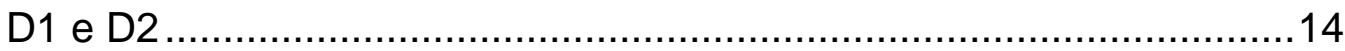




\section{LISTA DE TABELAS}

Tabela 1 - Custo de uma Transação Bancária por canal de distribuição 1

Tabela 2 - Custo por minuto de indisponibilidade. 3

Tabela 3 - Modelo para análise de uma abordagem arquitetônica. .30

Tabela 4 - Tabela para geração de cenários gerais de disponibilidade 51

Tabela 5 - Impacto de contribuições individuais segundo o procedimento de avaliação presente no framework NFR

Tabela 6 - Impacto de contribuições individuais segundo o procedimento de avaliação presente na técnica ADSSW

Tabela 7 - Tabela representando falha com softgoals e ameaças relacionadas

Tabela 8 - Modelo para análise de abordagens arquitetônicas em cenários de disponibilidade gerados com o auxílio da técnica ADSSW 113

Tabela 9 - Início de procedimento - inserção de falha no catálogo 130

Tabela 10 - Inserção de ameaças encadeadas. 132

Tabela 11 - Inserção do softgoal Disponibilidade [SGBD]. 133

Tabela 12 - Inserção de softgoals associados a componentes da camada de integração.

Tabela 13 - Inclusão de softgoal relacionado à funcionalidade de Pagamento de Tributos

Tabela 14 - Inserção de softgoals relacionados a perfis operacionais e ao sistema de software como um todo, com marcação de priorização

Tabela 15 - Modelo para análise do cenário D1.

Tabela 16 - Modelo para análise de cenário D2. 


\title{
LISTA DE ABREVIATURAS E SIGLAS
}

\author{
ABAS Attribute-Based Architectural Styles \\ ADD Attribute Driven Design \\ ADSSW Análise de disponibilidade de Sistemas de Software na \\ Web \\ ATAM Architecture Tradeoff Analysis Method \\ ERP Enterprise Resource Planning \\ HTTP Hypertext Transfer Protocol \\ ISO International Organization for Standardization \\ NFR Non-Functional Requirements \\ PAKME Process-centric Architecture Knowledge Management \\ Environment \\ QAW Quality Attribute Workshop \\ SGBD Sistema Gerenciados de Banco de Dados \\ SIG Softgoal Interdependency Graph \\ UML Unified Modeling Language \\ WSSAA Web Software Systems Availability Analysis
}




\section{SUMÁRIO}

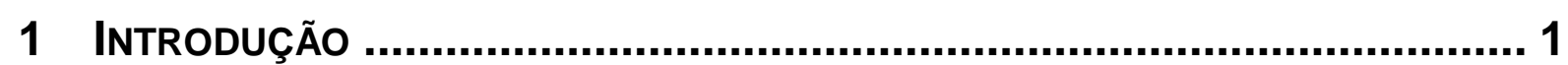

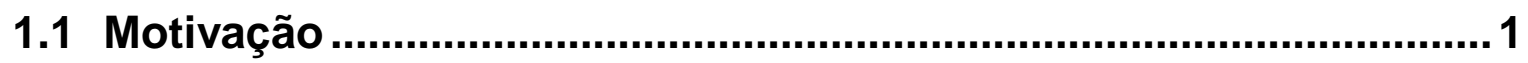

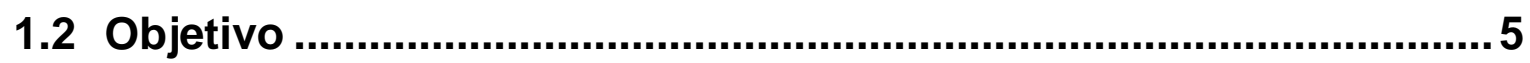

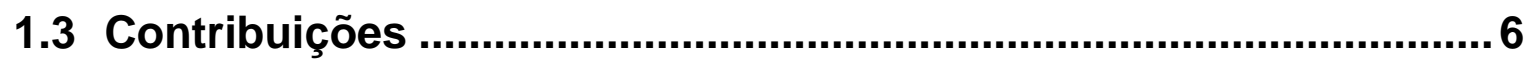

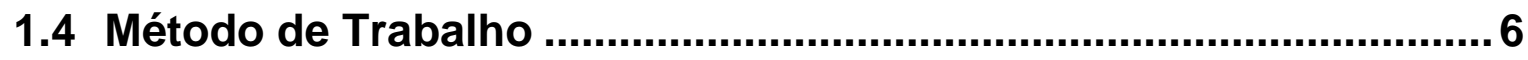

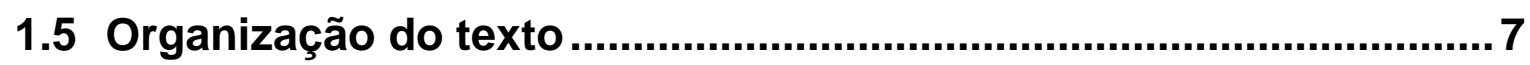

2 Requisitos Não-funcionais e Arquitetura de SoftWARE ................. 9

2.1 Representação de requisitos não-funcionais...................................

2.2 Cenários de atributos de qualidade ...............................................19

2.3 Requisitos não-funcionais e arquitetura de software ....................22

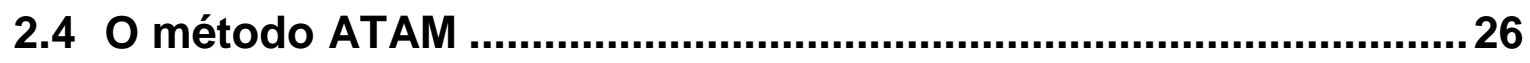

3 ConcEITOS E TAXONOMIA DE DEPENDABILIDADE .................................. 31

3.1 Conceitos fundamentais de dependabilidade .................................31

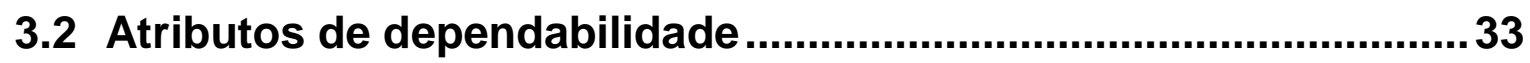

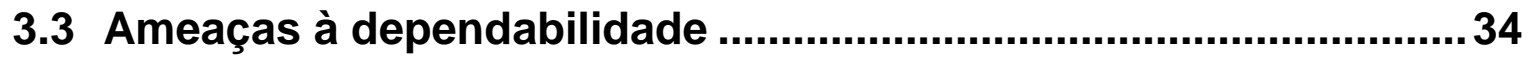

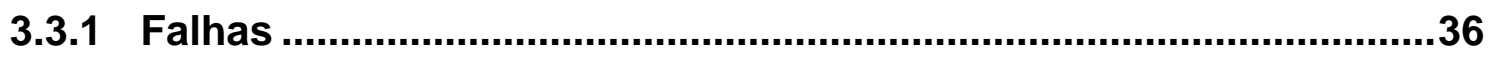

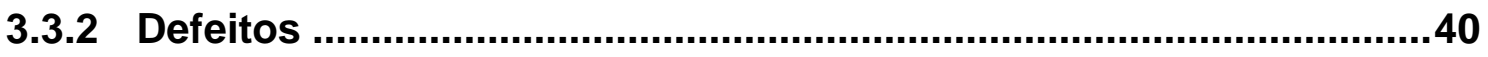

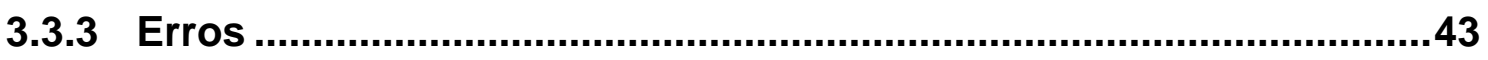

3.4 Meios para se atingir dependabilidade ............................................4 44

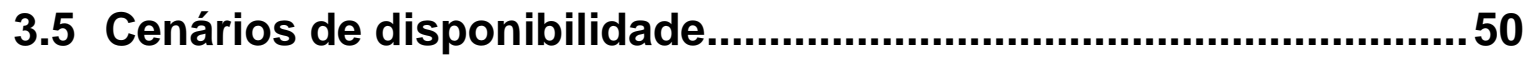

3.6 Táticas arquitetônicas relacionadas à disponibilidade .................53 
4 Proposta de uma técnica para a geração de cenários de DISPONIBILIDADE DE SISTEMAS DE SOFTWARE PARA A WEB NO MÉTODO ATAM

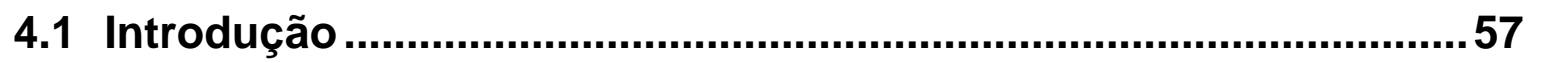

4.2 Caracterização de sistemas distribuídos na Web.........................59

4.3 Descrição de elementos da técnica ADSSW ...............................65

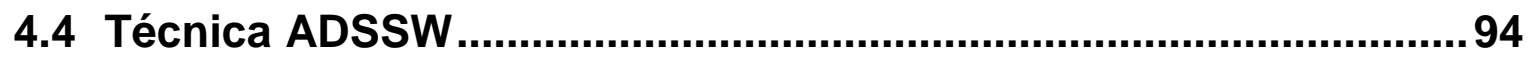

4.4.1 Primeira Etapa - Geração do Grafo ..................................................96

4.4.2 Segunda etapa - Aplicação do procedimento de avaliação .............98

4.5 Geração de cenários de disponibilidade e integração com o ATAM 109

5 APLICAÇÃO DA TÉCNICA ADSSW.................................................... 116

5.1 Etapa 1 - Construção do Grafo …….............................................118

5.2 Etapa 2 - Aplicação do procedimento de avaliação ......................129

5.3 Geração de cenários de disponibilidade ...................................137

6 ConSIDERAÇÕES FInAIS ........................................................ 144

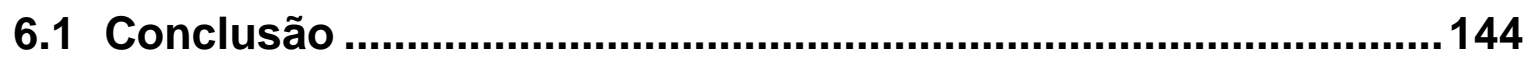

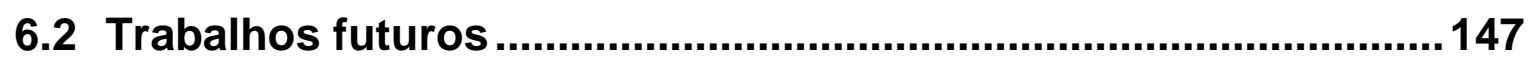

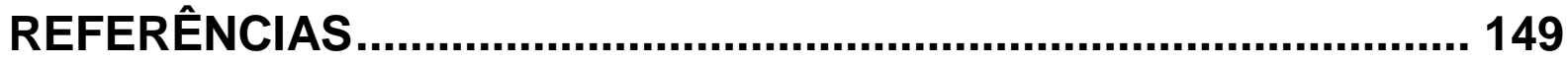




\section{INTRODUÇÃO}

\subsection{Motivação}

A utilização da Internet como um meio de automação de serviços de e-business tem sido adotada como estratégia por empresas em vários ramos da economia. Esta estratégia permite, por exemplo, no ramo financeiro, uma redução de custos, podendo chegar, em alguns casos, a 1\% do custo de uma transação financeira realizada em uma agência bancária, conforme informações presentes na Tabela 1, extraída de (FORTUNA, 2008), que contém dados divulgados pela empresa de consultaria Booz Allen em 1999.

Tabela 1 - Custo de uma Transação Bancária por canal de distribuição

\begin{tabular}{cc}
\hline Canal de Distribuição & Custo por transação (em US\$) \\
\hline Agências & 1,07 \\
Telefone & 0,54 \\
ATM & 0,27 \\
Home-Banking & 0,02 \\
Internet Banking & 0,01 \\
\hline
\end{tabular}

Além de proporcionar uma redução significativa de custos, a disponibilização de serviços de e-business através da Internet propicia às instituições financeiras uma melhoria de relacionamento com o cliente, possibilitando um conforto maior na utilização de serviços bancários, sem a necessidade de se dirigir a agências ou centrais de auto-atendimento, e também sem restrições de horários e datas.

Para extrair o máximo rendimento desse canal de distribuição, é de fundamental importância a disponibilidade de serviços de e-business através da Internet. A expectativa para os usuários deste canal de distribuição é que estas aplicações estejam disponíveis 24 horas por dia, durante sete dias por semana. As aplicações estão sujeitas a ocorrências de defeitos em servidores de aplicação, servidores de bancos de dados, redes de comunicação, entre outros defeitos de hardware, software, ou até mesmo causado por fatores humanos, como um erro de 
configuração durante, por exemplo, um procedimento de instalação de uma aplicação. Os sistemas devem ser capazes de maximizar o tempo em que estão disponíveis mesmo na ocorrência desses defeitos, através de técnicas de prevenção de defeitos e de recuperação destes defeitos, sendo de fundamental importância a freqüência de ocorrência dos defeitos, e o tempo médio necessário para recuperação do sistema após a detecção deles. Para aplicações bancárias, o período de indisponibilidade desejado deve ser de apenas 5 minutos ao ano, correspondendo à disponibilidade de 99,999\% (AL-KHATEEB, F.; AL-IRHAYIM; ALKHATEEB, A., 2003).

Períodos de indisponibilidade em serviços de e-business na Web podem causar prejuízos para a instituição financeira e para quem utiliza estes serviços. O primeiro prejuízo está relacionado ao baixo custo operacional de uma transação realizada na Internet. Se uma operação bancária de transferência de valores não está disponível na Web e o cliente se vê obrigado a realizar esta operação em uma agência, por exemplo, o custo desta operação torna-se muitas vezes maior para a instituição bancária.

Outro prejuízo para a instituição bancária origina-se no fato de que a indisponibilidade de fornecimento de serviços está relacionada a danos da imagem da instituição em relação ao cliente. Clientes podem sofrer perdas financeiras com a indisponibilidade de serviços. Um exemplo está relacionado a um cliente investidor do mercado de ações. Um período de indisponibilidade de um serviço de investimento na Internet com a duração de alguns minutos pode representar prejuízos significativos nas operações de compras e vendas de ações. Prejuízos a clientes e empresas parceiras de instituições bancárias prejudicam o relacionamento entre as partes, podendo causar danos à imagem da instituição, que podem acarretar na perda de clientes, ou na diminuição do número de novos clientes.

De acordo com (PEÑALOZA, 2003), um estudo realizado pelo Standish Group tentou estimar os custos por minuto de indisponibilidade por aplicação nos Estados Unidos, apresentados na Tabela 2 . 
Tabela 2 - Custo por minuto de indisponibilidade

\begin{tabular}{cc}
\hline Aplicação & $\begin{array}{c}\text { Custo indisponibilidade por } \\
\text { minuto (US\$) }\end{array}$ \\
\hline ERP (Enterprise Resource Planning- & $13.000,00$ \\
Planejamento de Recursos Empresariais) & \\
Gerenciamento de Cadeia de Suprimentos & $11.000,00$ \\
Comércio Eletrônico & $10.000,00$ \\
Internet Banking & $7.000,00$ \\
Centro de Atendimento ao Consumidor & $3.700,00$ \\
\hline
\end{tabular}

Embora o nível de disponibilidade de software e hardware apresente um aumento considerável nos últimos anos, a heterogeneidade de sistemas que estão disponibilizados através da Internet, a complexidade de interconexões destes sistemas e as dependências entre componentes aumentaram consideravelmente (MISHRA; TRIVEDI, 2006). Como conseqüência, existe a necessidade de se considerar aspectos relacionados a esta complexidade durante o ciclo de vida de desenvolvimento de software, de tal forma que o projeto de software considere aspectos relacionados à complexidade para a construção de sistemas com um nível desejado de disponibilidade.

A disponibilidade, um requisito não-funcional, pode ser definida como a prontidão para o serviço correto (AVIŽIENIS et al., 2004). Corresponde a um atributo de dependabilidade, a qual pode ser definida como a capacidade de o sistema disponibilizar serviços em que se possa justificadamente confiar (LAPRIE, 1992). Tal capacidade tem forte dependência da arquitetura do sistema e, em particular, do software, cuja construção deve considerar, portanto, aspectos relacionados aos atributos de dependabilidade, tais como confiabilidade, segurança (safety), disponibilidade e integridade.

Um modo de se analisar soluções para a construção de arquiteturas de sistemas computacionais é a avaliação do projeto arquitetônico através de cenários de atributos de qualidade (BASS; CLEMENTS; KAZMAN, 2003). Um cenário é constituído por um estímulo, que representa um evento ou uma condição à qual arquitetura deve responder, e por uma resposta, que corresponde à atividade realizada após a ocorrência de um determinado estímulo. Para o atributo de 
qualidade disponibilidade, (BASS; CLEMENTS; KAZMAN, 2003) apresentam características que podem ser mapeadas em elementos de cenários de disponibilidade.

Um método de avaliação de arquitetura que tem como base a utilização de cenários de atributos de qualidade é o ATAM (Architecture Tradeoff Analysis Method) (KAZMAN; KLEIN; CLEMENTS, 2000). Esse método consiste na avaliação arquitetônica baseada em requisitos não-funcionais, ou atributos de qualidade. Seu principal objetivo é mapear as conseqüências de decisões arquitetônicas nos atributos de qualidade do sistema, identificando possíveis tradeoffs entre os diferentes atributos de qualidade. Na aplicação do método, é destacada a importância do envolvimento de stakeholders - partes interessadas no sistema em questão - durante a geração de cenários de atributo de qualidade. Em (CLEMENTS; KAZMAN; KLEIN, 2002), é citado que a qualidade da avaliação de uma arquitetura de software depende em grande parte da capacidade dos stakeholders que participam da avaliação de identificar cenários de atributos de qualidade eficientes.

Para auxiliar a geração de cenários de atributos de qualidade, em (BASS; CLEMENTS; KAZMAN, 2003) são definidos elementos para a geração de cenários gerais, que são independentes de sistema e descrevem características relacionadas ao atributo de qualidade em questão. De acordo com (BASS; KLEIN; MORENO, 2001), cenários gerais podem ser utilizados no processo de avaliação de arquitetura de software ATAM como um guia ou uma lista de verificação para a geração de cenários específicos da arquitetura sob análise. Embora cenários gerais auxiliem a geração de cenários específicos para uma dada arquitetura de software, a geração de cenários específicos baseia-se fundamentalmente no conhecimento e na experiência de stakeholders relacionados ao sistema de software em questão. Em (DOBRICA; NIEMELÃ, 2002), é citado que o resultado de uma avaliação baseada em cenários de atributos de qualidade depende da seleção dos cenários e de sua relevância para identificar suposições críticas a respeito da arquitetura de software. $\mathrm{Na}$ obra de (KAZMANN; CARRIÈRE; WOODS, 2000) é citado que embora experiências realizadas em avaliações de arquitetura indiquem que cenários sejam úteis para o entendimento da arquitetura, a identificação de suas limitações e requisitos, a elicitação de cenários baseada somente na experiência de stakeholders pode não ser adequada em razão da crescente complexidade dos sistemas de 
software, existindo a necessidade de um procedimento organizado de análise. Em (BABAR; CAPILLA, 2008), é citado que embora existam diversas abordagens para elicitar, estruturar e organizar cenários de atributos de qualidade como, por exemplo, a estrutura de cenários gerais proposta em (BASS; CLEMENTS; KAZMAN, 2003), estas abordagens não provêem um suporte sistemático para utilizar todo o conhecimento necessário para a geração de cenários de atributos de qualidade para um domínio específico. Como conseqüência da ausência deste suporte, os autores de (BABAR; CAPILLA, 2008) citam que existe uma forte dependência do nível de conhecimento dos stakeholders na avaliação de uma arquitetura de software.

Em suma, a avaliação de uma arquitetura de software é uma tarefa complexa, pois lida com uma rede de relações entre requisitos não-funcionais e funcionais sintetizadas em decisões arquitetônicas. Caso não exista uma técnica que permita guiar a avaliação de modo sistemático, a avaliação da arquitetura exclusivamente baseada na experiência dos stakeholders pode ficar comprometida, uma vez que cenários importantes relacionados a requisitos não-funcionais podem não ser considerados, possíveis estímulos podem ser ignorados, ou respostas associadas a um estímulo podem não ser identificadas.

\subsection{Objetivo}

O objetivo deste trabalho é propor uma técnica para auxiliar a geração de cenários de disponibilidade no método ATAM, em sistemas de software que fornecem serviços através da Internet, denominada Análise de Disponibilidade de Sistemas de Software na Web - ADSSW (em inglês Web Software Systems Availability Analysis - WSSAA). A técnica proposta visa prover, de uma forma organizada e detalhada, um catálogo de elementos utilizados na caracterização de cenários de disponibilidade, minimizando riscos decorrentes da dependência do nível de conhecimento dos stakeholders na avaliação da disponibilidade. A técnica proposta deverá identificar estímulos para a criação de cenários de disponibilidade e auxiliar a identificação de possíveis respostas que a arquitetura de software provê para cada estímulo. 
A técnica considera somente aspectos relacionados a características dos sistemas de software descritos neste trabalho, bem como conceitos relacionados ao requisito não-funcional disponibilidade. Ela utiliza elementos da elicitação, análise e representação de requisitos não-funcionais em sistemas de software, e as relações entre requisitos não-funcionais e arquitetura de software.

\subsection{Contribuições}

A principal contribuição deste trabalho consiste na proposição de uma técnica de análise de disponibilidade que identifique e caracterize falhas para a construção de cenários de disponibilidade, preconizados pelo método ATAM, em arquiteturas de sistema de software que seguem a arquitetura descrita no trabalho.

Outra contribuição que este trabalho apresenta consiste em um mapeamento dos conceitos de dependabilidade apresentados em (LAPRIE, 1992) e (AVIŽIENIS et al., 2004) no framework NFR (CHUNG et al., 2000), utilizado para representação e análise de requisitos não-funcionais. Como resultado deste mapeamento, obtém-se a representação destes conceitos de dependabilidade na perspectiva do framework NFR e um catálogo de métodos de refinamento que permitem uma análise de disponibilidade em sistemas de software que disponibilizam serviços na Web. A técnica também apresenta um procedimento de avaliação, baseado no procedimento de avaliação presente no framework NFR, que permite a análise qualitativa das conseqüências de estímulos que podem constituir cenários de disponibilidade.

\subsection{Método de Trabalho}

O método de pesquisa empregado tem caráter exploratório, sendo realizado através de pesquisa bibliográfica sobre o tema e da experiência do autor em análise de arquiteturas de software. A pesquisa procurou, inicialmente, obter o embasamento teórico referente aos seguintes tópicos: 
- Elicitação, análise e representação de requisitos não-funcionais no ciclo de desenvolvimento de software baseadas, sobretudo, no framework NFR (CHUNG et al., 2000). Para avaliação arquitetônica de sistemas, em particular de sistemas de software, descreve-se o método de avaliação de arquitetura ATAM.

- Conceitos e taxonomia utilizados para a caracterização da dependabilidade, conceito definido como a capacidade de o sistema disponibilizar serviços de forma justificadamente confiável (LAPRIE, 1992). O conceito de disponibilidade insere-se na conceituação de dependabilidade, em que a disponibilidade é definida como um atributo de dependabilidade.

- Caracterização de sistemas de software que fornecem serviços através da Internet, com a identificação de elementos presentes nas arquiteturas destes sistemas, e possíveis fatores de risco que podem comprometer a disponibilidade destes sistemas.

A proposição da técnica para a análise de disponibilidade decorre da descoberta de relações entre os temas pesquisados na etapa de embasamento teórico. A técnica é exercitada em um exemplo simplificado, mas realista, que representa os elementos arquitetônicos que compõem uma arquitetura de sistema bancário na Internet. $\mathrm{O}$ exemplo será tratado em um nível de abstração arquitetônico, ou seja, o sistema de software será apresentado através de configurações arquitetônicas baseadas em componentes e conectores, sem considerar configurações específicas de hardware e software.

\subsection{Organização do texto}

A estrutura deste trabalho é composta por seis capítulos. Inicialmente, um capítulo introdutório - o presente capítulo -, seguido de um capítulo que apresenta o resultado da pesquisa bibliográfica para a elicitação, análise e representação de requisitos não-funcionais, sendo abordadas diferentes metodologias e possíveis mapeamentos de requisitos não-funcionais para decisões arquitetônicas. 
O terceiro capítulo apresenta uma determinada conceituação de dependabilidade, permitindo a caracterização do requisito não-funcional disponibilidade, que terá um enfoque maior neste trabalho.

O quarto capítulo descreve a técnica de análise de disponibilidade proposta neste trabalho, tratando características de sistemas de software que disponibilizam serviços através da Internet, conceitos relevantes para o entendimento da técnica.

O quinto capítulo aplica a técnica descrita no capítulo anterior em um exemplo de sistema de software bancário que disponibiliza serviços na Web. Por fim, o sexto capítulo apresenta considerações finais sobre o trabalho, apresentando conclusões e algumas direções para uma continuidade da pesquisa realizada. 


\section{Requisitos Não-funcionais e Arquitetura de SoftWare}

Neste capítulo são apresentados conceitos utilizados para elicitação, análise e representação de requisitos não-funcionais, e relações entre requisitos nãofuncionais e arquitetura de software. Inicialmente este capítulo aborda a representação de requisitos não-funcionais, com um enfoque maior na descrição do framework NFR segundo (CHUNG et al., 2000). Em seguida, o capitulo apresenta conceitos relacionados a cenários de atributos de qualidade segundo (BASS; CLEMENTS; KAZMAN, 2003). Este capítulo também aborda a relação entre requisitos não-funcionais e arquitetura de software, e por fim apresenta uma descrição resumida do método de avaliação de arquitetura ATAM.

\subsection{Representação de requisitos não-funcionais}

Para a realização deste trabalho, foram analisadas abordagens para a análise e representação de requisitos não-funcionais. A complexidade de um software é determinada não somente por seus requisitos funcionais, definidos em (IEEE, 1998) como as ações fundamentais que ocorrem no software ao aceitar e processar entradas e processar e gerar saídas, mas também por seus requisitos nãofuncionais ou atributos de qualidade.

Os requisitos não funcionais, tais como desempenho, disponibilidade, usabilidade, modificabilidade, entre outros, devem ser considerados durante o processo de desenvolvimento de sistemas, constituindo um importante critério para decisões de projeto. Para (CHUNG et al., 2000), no contexto de engenharia de software, um requisito não-funcional consiste em um requisito que não descreve as funcionalidades que o software realiza, mas como o software as realiza. Cabe ressaltar que a importância de um determinado requisito não-funcional pode ser considerada relativa, dependendo do sistema a ser considerado. A prioridade atribuída a um requisito não-funcional depende da importância deste requisito em relação ao contexto onde o software está inserido.

Os requisitos não-funcionais não podem ser analisados isoladamente. Uma solução que vise maximizar um determinado requisito não-funcional pode trazer 
conseqüências negativas em relação a outros requisitos não-funcionais. Um exemplo que representa esta situação seria a relação entre os requisitos nãofuncionais portabilidade e desempenho. Mecanismos que permitam a portabilidade de uma aplicação em relação ao sistema operacional podem afetar negativamente o desempenho, por exigirem operações adicionais de processamento.

Existem basicamente duas formas de abordagem para caracterizar a análise de requisitos não-funcionais em um sistema de software: a abordagem orientada a produto e a abordagem orientada a processos (CHUNG et al., 2000). A abordagem orientada a produto tem por objetivo desenvolver um enfoque formal para a avaliação do produto final de software em relação aos níveis desejados relacionados a métricas associadas a requisitos não-funcionais. As abordagens orientadas a processo, que são exploradas neste trabalho, consistem na utilização de técnicas que justifiquem decisões de projeto durante o processo de desenvolvimento de software, visando racionalizá-lo considerando aspectos relacionados aos requisitos não-funcionais (CHUNG et al., 2000).

Neste trabalho, utiliza-se o framework de requisitos não-funcionais (framework NFR), descrito em (CHUNG et al., 2000). O objetivo desta abordagem orientada a processo é a descrição de um framework qualitativo para a representação e análise de requisitos não-funcionais. Um conceito necessário para o entendimento deste framework consiste no conceito de softgoal', ou seja, um objetivo que não possui definições e/ou critérios claros para garantir se estão satisfeitos ou não. $O$ framework NFR provê um tratamento qualitativo para representar e analisar requisitos não-funcionais baseado na premissa de que tais requisitos nem sempre são satisfeitos no sentido absoluto. Para expressar tal premissa, ele representa os requisitos não-funcionais como softgoals, os quais podem refinados, interrelacionados e analisados através um grafo: o SIG (Softgoal Interdependency Graph - gráficos de interdependência entre softgoals). O refinamento, no essencial, reflete o conhecimento, o processo de raciocínio e as decisões de projeto sobre os requisitos não-funcionais. No refinamento, um softgoal derivado pode contribuir - ou impactar - positiva ou negativamente no grau de satisfação de um softgoal em um

\footnotetext{
${ }^{1}$ Optou-se, neste trabalho, pelo emprego da palavra em inglês por motivos de concisão, assim como outros termos sem correspondência direta no português. Do mesmo modo, optou-se por escrever framework NFR ao invés de, por exemplo, arcabouço RNF (requisitos não-funcionais), em referência ao framework (arcabouço) descrito em (CHUNG et al., 2000).
} 
nível mais alto da cadeia de refinamento. Assumindo-se que a satisfação não seja absoluta, mas ocorra em limites aceitáveis interpretados qualitativamente, diz-se que um softgoal pode ser satisficed. A análise da satisficeability dos softgoals é realizada por um procedimento de avaliação que semi-automaticamente determina o impacto das decisões de projeto no atendimento aos requisitos não-funcionais. Este framework auxilia os desenvolvedores a produzirem soluções personalizadas, considerando-se características de um domínio em particular e sistemas em fase de desenvolvimento. Estas características, incluindo requisitos não-funcionais, requisitos funcionais e prioridades, influenciam a escolha de alternativas de desenvolvimento para um sistema em particular. Para lidar com um grande número de alternativas possíveis de desenvolvimento, existe a possibilidade de consulta a um catálogo de decisões de projeto que este framework provê. Os catálogos são gerados através da organização de experiências passadas, técnicas padronizadas, conhecimentos adquiridos sobre requisitos não-funcionais e suas interdependências, e balanceamento entre requisitos.

O processo de utilização do framework NFR permite a aquisição ou acesso às informações sobre o domínio em particular do sistema a ser construído, bem como aos tipos particulares de requisitos não-funcionais, além de técnicas de desenvolvimento associadas a estes requisitos. Permite também a identificação de possíveis requisitos não-funcionais para o domínio, a decomposição de requisitos não-funcionais e a operacionalização de requisitos não-funcionais, ou seja, a definição de possíveis técnicas de desenvolvimento ou decisões de projeto para satisfazer aos requisitos não-funcionais do sistema. Possibilita também que se lide com ambigüidades, tradeoffs, prioridades e interdependências entre requisitos nãofuncionais e operacionalizações, possibilitando o suporte a decisões de projeto com racionalização e auxiliando a avaliação de impacto das decisões em relação a requisitos não-funcionais. A operação desse framework pode ser descrita através de operações incrementais e interativas, tais como a construção, elaboração, análise e revisões do SIG. Nesta representação gráfica em grafo, os softgoals são representados através de nuvens, sendo conectados através de ligações de interdependência, representados através de linhas. No grafo são representados três tipos de softgoals: 
- Softgoals de requisitos não-funcionais: representam os requisitos nãofuncionais a serem analisados na análise de um sistema de software. Através de operações de decomposição, é possível a definição de tipos e sub-tipos de requisitos não-funcionais. A notação utilizada no framework NFR para a representação de softgoals de requisitos não-funcionais no SIG corresponde a uma representação gráfica de uma nuvem, como mostra a Figura 1. Na Figura 1, observa-se que o softgoal apresenta uma descrição Tipo[Tópico], em que Tipo representa o requisito não-funcional a ser analisado e Tópico representa alguma característica relacionada à aplicação que será analisada em relação ao requisito não-funcional representado pelo Tipo. Embora o conceito de tópico assemelhe-se ao conceito de parâmetros utilizados na descrição de funções em linguagens de programação, tópicos e parâmetros não são conceitos equivalentes, e o número de tópicos pode variar para um mesmo tipo de softgoal, dependendo da análise efetuada.

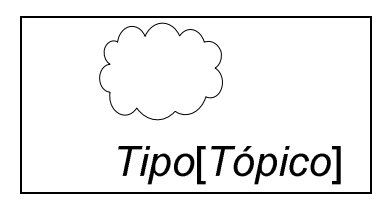

Figura 1 - Representação Gráfica de um Softgoal de Requisito não-funcional

- Softgoals de operacionalização: representam técnicas de desenvolvimento e decisões de projeto que visam satisfazer um determinado requisito nãofuncional.

- Softgoals de argumentação: visam registrar as razões da justificativa de tomada de decisões em virtude do requisito não-funcional sob análise.

O framework de requisitos não-funcionais é composto basicamente de cinco componentes principais (CHUNG et al., 2000):

1. Softgoals de requisitos não-funcionais, operacionalização e de argumentação.

2. Interdependências entre softgoals: refinamentos de softgoals em outros softgoals e contribuições entre softgoals. 
3. Um procedimento de avaliação que determina o grau em que um dado requisito não-funcional é satisfeito por um conjunto de decisões de projeto.

4. Métodos de refinamento de softgoals, que correspondem a procedimentos gerais para um softgoal ou uma interdependência em um ou mais itens.

5. Correlações que permitem a inferência de possíveis interações, positivas ou negativas, entre softgoals.

No framework NFR, softgoals são inter-relacionados por meio de refinamentos e contribuições. Refinamento de um softgoal corresponde a um processo no qual um softgoal existente é refinado em um ou mais softgoals. Técnicas de decomposição são uma forma de refinamento de requisitos não-funcionais, permitindo que se originem sub-softgoals a partir de um softgoal analisado. $O$ processo de decomposição corresponde a um refinamento e, no grafo de interdependências de softgoals do framework NFR, esta operação ocorre quando se observa um processo no qual a análise parte de um softgoal para um sub-softgoal. O processo inverso, ou seja, quando ocorre um processo em que a análise parte de um sub-softgoal para um softgoal, corresponde a um processo de análise de contribuição, na qual um softgoal pode contribuir positiva ou negativamente para se atingir um softgoal. Em uma operação de decomposição, quando todos os sub-softgoals são necessários para que o softgoal acima seja satisfeito, diz-se no framework que os softgoals gerados na etapa de decomposição realizam uma contribuição $A N D$. Esta relação entre softgoals pode ser representada graficamente como na Figura 2. O arco que relaciona os softgoals na figura denota uma contribuição $A N D$. Outra contribuição existente é a $O R$, indicando que apenas um dos sub-softgoals é necessário para que o softgoal acima seja considerado satisfatório. A representação da contribuição $O R$ assemelha-se à notação da contribuição $A N D$, diferenciando-se pela presença de um arco duplo na ligação entre os softgoals.

No framework NFR, existem basicamente dois tipos de decomposição entre softgoals de requisitos não-funcionais: decomposição por tipo e decomposição por tópico. A decomposição por tipo, ilustrada na Figura 2, representa um refinamento com características relacionadas a requisitos não-funcionais. A Figura 2(a) representa a estrutura de representação desta decomposição, enquanto a Figura 
2(b) apresenta um exemplo retirado de (CHUNG et al., 2000) relacionado ao requisito não-funcional desempenho, que pode ser caracterizado através de espaço e tempo.

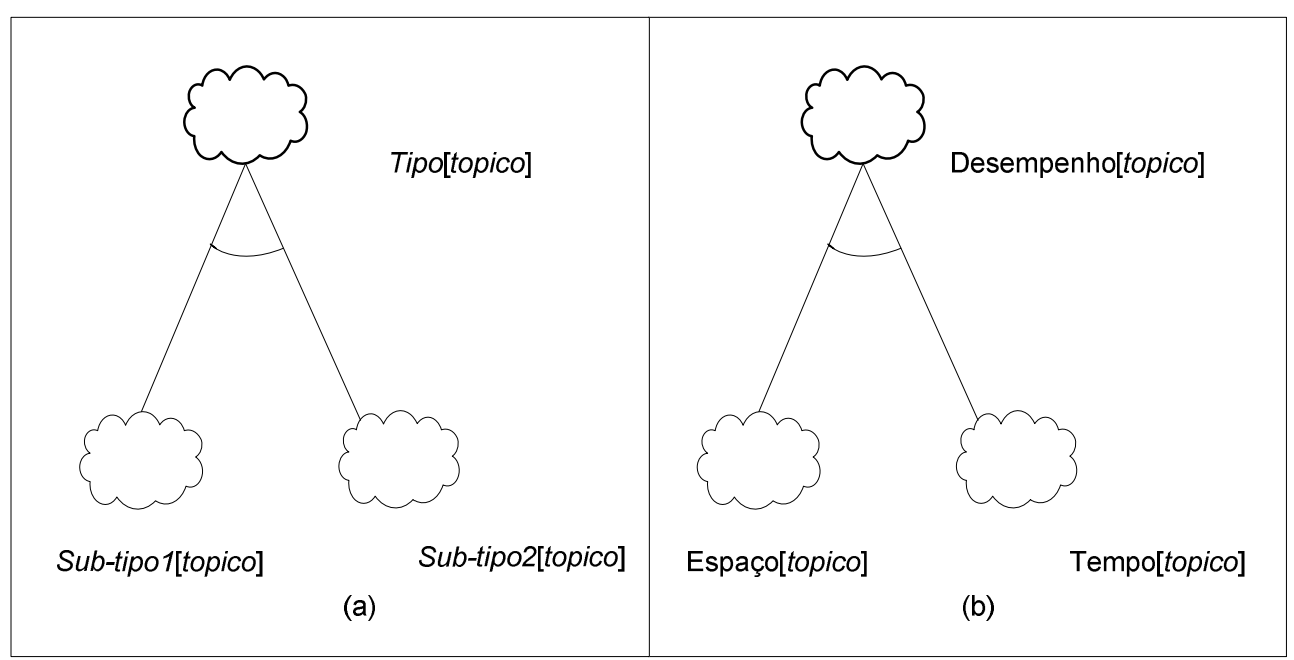

Figura 2- Decomposição por tipo - Contribuição AND

Outro tipo de decomposição utilizado no framework NFR corresponde a uma decomposição por tópico. Este tipo de decomposição é representado graficamente como na Figura 3. A Figura 3(a) apresenta a estrutura de decomposição, enquanto a Figura 3(b) apresenta um exemplo retirado de (CHUNG et al., 2000). No exemplo, existe a entidade Conta, definida para um determinado sistema de software. Há uma especialização para esta entidade, resultando em dois tipos de Conta: conta Ouro, relacionada a clientes com um determinado perfil, e conta Regular. A Figura 3(b) indica que para o desempenho atingir um nível satisfatório para a entidade Conta, é necessário que as especializações Conta Ouro e Conta Regular sejam capazes de atingir um nível satisfatório. Em (CHUNG et al., 2000) são descritas técnicas de decomposição de softgoals de requisitos não-funcionais por tópico, incluindo subclasses das classes do softgoal principal (como no exemplo da figura), e através de atributos da entidade sob análise. 


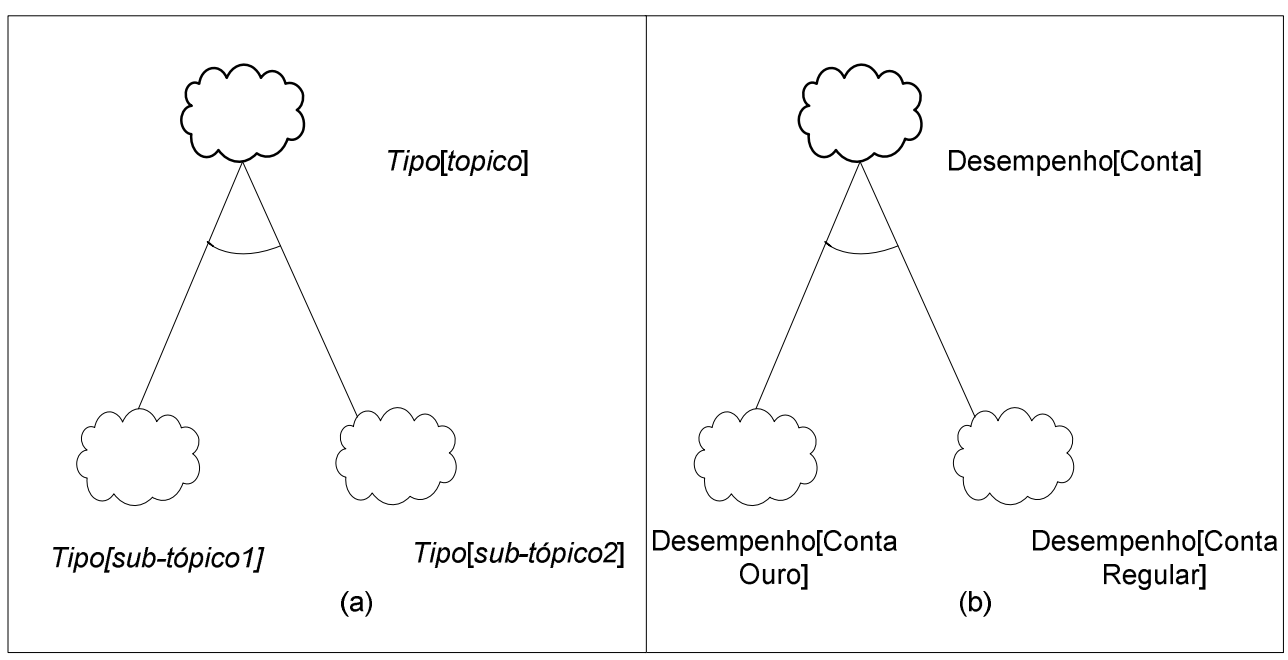

Figura 3 - Decomposição por tópico

Para a representação das contribuições presentes em decomposições por tipo e por tópico no framework NFR, em (CHUNG et al., 2000) os autores apresentam suas descrições sintáticas. Supondo uma decomposição com uma contribuição AND onde $n$ sub-softgals contribuem com um softgoal, de acordo com (CHUNG et al., 2000), esta contribuição pode ser representada através da seguinte descrição sintática:

sub-softgals_1 AND sub-softgals_2 ... AND sub-softgals_n SATISFAZEM softgoal

Nesta notação, o exemplo da Figura 2(b) pode ser assim representado:

\section{Espaço [Tópico] AND Tempo[Tópico]}

SATISFAZEM Desempenho [Tópico]

Outra representação sintática de contribuições $A N D$ presentes em decomposição por tipo e por tópico tem a seguinte forma:

AND (\{sub-softgals\}) SATISFAZEM softgoal

Com esta notação, o exemplo da Figura 2(b) pode ser representado como:

AND (\{Espaço [Tópico], Tempo [Tópico]\}) SATISFAZEM Desempenho [Tópico]

As notações utilizadas para a representação de contribuições $O R$ utilizadas em decomposições por tópico e por tipo assemelham-se às notações utilizadas para a representação de contribuições $A N D$, sendo possível apresentá-las nas seguintes notações: 
sub-softgals_1OR sub-softgals_2 ... OR sub-softgals_n SATISFAZEM softgoal

\section{OR (\{sub-softgals\}) SATISFAZEM softgoal}

Para relacionar a contribuição de somente um softgoal em relação a outro, existem outros tipos de contribuição definidos por (CHUNG et al., 2000). Um par de contribuições definido no framework NFR é utilizado em situações em que os tipos de contribuições provêem total suporte para que o softgoal de nível superior seja totalmente satisfeito ou negado. $O$ framework NFR define este par com as seguintes contribuições: MAKES (traduzida neste trabalho como REALIZA) em situações nas quais a contribuição atua positivamente; e BREAKS (traduzida neste trabalho como QUEBRA), em situações nas quais a contribuição atua negativamente. Com a contribuição REALIZA, se um softgoal for considerado satisfatório, o softgoal para o qual ela contribui também pode ser considerado satisfatório. Com a contribuição QUEBRA, se um softgoal for considerado satisfatório, o softgoal para o qual este contribui não é considerado satisfatório.

Outro par de contribuições definido por (CHUNG et al., 2000). diz respeito a contribuições que provêem um suporte parcial. $O$ par é definido com a contribuição positiva HELPS (traduzida neste trabalho como AUXILIA), e com a contribuição negativa HURTS (traduzida neste trabalho como FERE). Se um softgoal for considerado satisfatório, e este se relaciona com outro softgoal através de uma contribuição AUXILIA, o softgoal a ser analisado possui uma tendência a ser satisfatório, mas este fato não indica necessariamente que o softgoal que recebe a contribuição seja satisfatório. O mesmo raciocínio se aplica à contribuição FERE. Se o softgoal que provê tal contribuição for considerado satisfatório, o softgoal que recebe esta contribuição possui uma tendência a não ser satisfatório, mas esta contribuição não indica necessariamente que o softgoal que recebe esta contribuição não seja considerado satisfatório. Existe também uma contribuição conhecida como UNKNOWN (DESCONHECIDO), indicando um relacionamento entre softgoals em que não se tem conhecimento sobre o efeito da contribuição (se positiva ou negativa) e a sua influência (se parcial ou suficiente). Outra forma de representação de contribuições ocorre através de contribuições SOME+ e SOME(traduzidas neste trabalho como $A L G O+$ e $A L G O$-, respectivamente). Estas formas de contribuição ocorrem quando se deseja indicar somente o efeito da contribuição, 
se positiva ou negativa, não sendo relevante a indicação de que se trata de uma contribuição parcial ou suficiente. A Figura 4(a) representa as contribuições envolvendo somente um softgoal, com suas respectivas representações gráficas. $\mathrm{Na}$ Figura 4(a), observa-se que a contribuição QUEBRA é representada no grafo de interdependência de softgoals com a utilização de dois sinais negativos, a contribuição FERE é representada no grafo com um sinal negativo, a contribuição AUXILIA é representada no grafo com um sinal positivo e a contribuição REALIZA é representada no grafo com dois sinais positivos. A Figura 4 (b) representa um exemplo de contribuição AUXILIA entre softgoals.

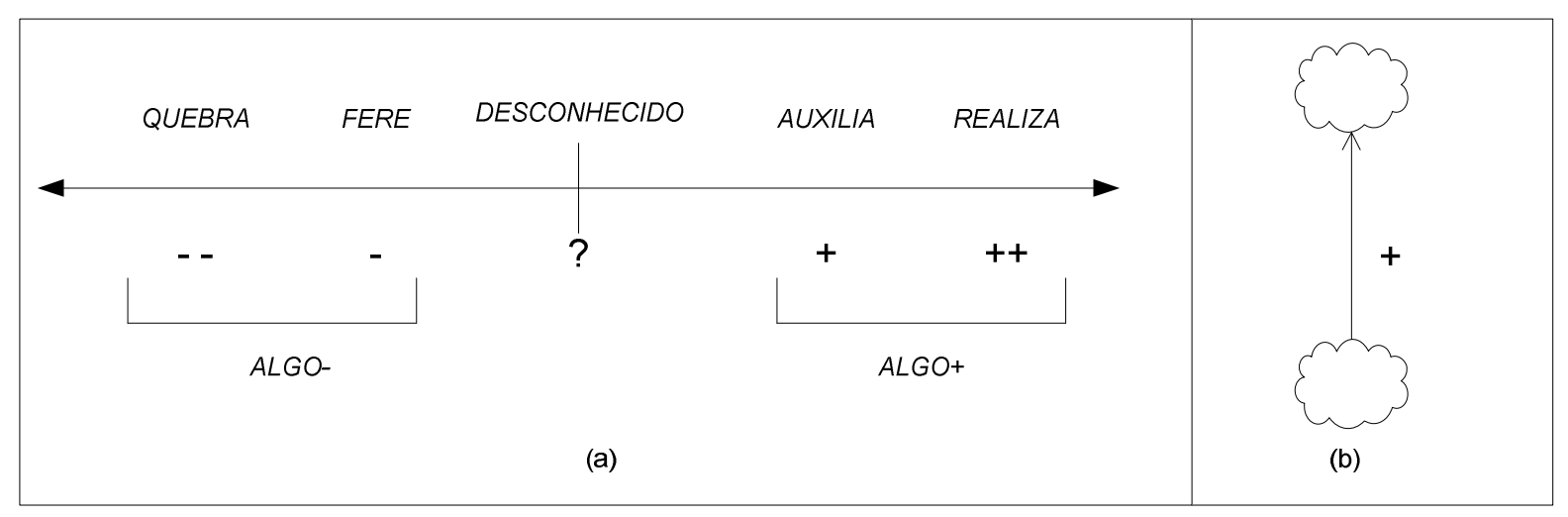

Figura 4 - Contribuições definidas no framework NFR

Fonte: (Chung et al., 2000)

Em (CHUNG et al., 2000) também são apresentadas descrições sintáticas para contribuições que envolvem somente um sub-softgoal. As contribuições QUEBRA, FERE, AUXILIA e REALIZA podem ser representadas através das seguintes descrições sintáticas:

\section{Sub_softgoal QUEBRA Softgoal \\ Sub_softgoal FERE Softgoal \\ Sub_Softgoal AUXILIA Softgoal \\ Sub_softgoal REALIZA Softgoal}

Contribuições $A L G O$ - e $A L G O+$ podem ser representadas através das descrições sintáticas a seguir: 


\begin{tabular}{|c|c|c|c|c|c|}
\hline Sub_softgoal & ALGO- & Softgoal & $\begin{array}{l}\equiv \text { Sub_softgoal } \\
\text { ou Sub_Softgoa }\end{array}$ & $\begin{array}{l}\text { QUEBRA } \\
\text { FERE Softg }\end{array}$ & Softgoal \\
\hline Sub_softgoal & $A L G O+$ & Softgoal & $\begin{array}{l}\equiv \quad \text { Sub_softgoal } \\
\text { ou Sub_Softgoal }\end{array}$ & $\begin{array}{l}\text { AUXILIA } \\
\text { REALIZA Sof }\end{array}$ & $\begin{array}{l}\text { Softgoal } \\
\text { al }\end{array}$ \\
\hline
\end{tabular}

A notação utilizada descreve que uma contribuição $A L G O$ - é caracterizada pela ocorrência de uma contribuição negativa, mas não é possível definir de forma precisa quando se trata de contribuições QUEBRA ou FERE. A mesma abordagem é adotada na representação de uma contribuição $A L G O+$, caracterizada pela ocorrência de uma contribuição positiva, não sendo possível definir de forma precisa quando se trata de contribuições AUXILIA ou REALIZA.

Métodos de refinamento e correlações auxiliam a geração de um SIG, através de um catálogo conhecido de requisitos não-funcionais e técnicas de desenvolvimento de software. Em (CHUNG et al., 2000), foram definidos catálogos relacionados a três requisitos não-funcionais: acurácia, segurança (security) e desempenho. Os catálogos apresentam a representação destes requisitos não-funcionais através de um conjunto de softgoals, sendo descritos métodos para a decomposição e a análise destes requisitos. O requisito não-funcional que terá maior ênfase neste trabalho, disponibilidade, não é analisado detalhadamente em (CHUNG et al., 2000), sendo considerado um atributo presente no catálogo de segurança (security) definido pelos autores, juntamente com confidencialidade e integridade.

Outro enfoque relacionado a requisitos não-funcionais é descrito em (CYSNEIROS; LEITE; SABAT NETO, 2001), utilizando o framework NFR para a construção de um léxico e a definição de um modelo de dados, integrando requisitos não-funcionais no modelo Entidade-Relacionamento. Uma continuação deste enfoque (CYSNEIROS; LEITE, 2004), realiza a integração de requisitos não-funcionais no modelo orientado a objetos. 


\subsection{Cenários de atributos de qualidade}

Outro trabalho desenvolvido com foco em requisitos não-funcionais é (BARBACCI ET AL., 1995). Este trabalho, com o objetivo de descrever as características inerentes a cada atributo de qualidade, estabelece uma conexão entre os diversos atributos de qualidade, apresentando uma taxonomia geral para a descrição de desempenho, dependabilidade e segurança (safety e security). Esta taxonomia identifica os seguintes conceitos:

- Interesses (Concerns): representam os parâmetros que serão julgados, especificados e mensurados. Os requisitos não-funcionais são representados por meio de interesses.

- Fatores específicos relacionados aos atributos: propriedades do sistema (tais como políticas e mecanismos adotados na construção de sistema) e seu contexto têm impacto nos interesses. Dependendo do atributo de qualidade, fatores específicos de atributos e propriedades internas e externas do sistema afetam os interesses. Fatores podem não ser independentes e podem ter uma relação causa-efeito. Os fatores e seus relacionamentos podem ser considerados na arquitetura de um sistema de software.

- Métodos: representam como endereçar os interesses e podem ser processos de análise e síntese durante o desenvolvimento do sistema, procedimentos adotados na execução do sistema, treinamento de usuários e operadores.

Outro enfoque utilizado na análise e representação de requisitos não funcionais consiste na utilização de cenários de atributos de qualidade (BASS; CLEMENTS; KAZMAN, 2003). Esta abordagem visa caracterizar um requisito não-funcional através da utilização de cenários de atributos de qualidade.

Um cenário de atributo de qualidade consiste de seis elementos:

- Fonte do estímulo: Alguma entidade (um ser humano, um sistema, ou qualquer outro atuador) que gera o estímulo. Na geração de cenários, este fator torna-se relevante em situações em que existe um tratamento diferenciado em relação à fonte do estímulo. Um exemplo em que a fonte de estímulo pode ser um fator relevante é o de cenários de segurança, no qual 
uma fonte de um estímulo provocado por uma entidade confiável pode ser tratado de forma diferente em relação a um estímulo provocado por uma entidade que não seja confiável.

- Estímulo: evento ou condição que deve ser considerado pelo sistema.

- Ambiente: representa as condições sob as quais o sistema encontra-se na ocorrência do estímulo.

- Artefato: representa o item sob o qual o estímulo ocorre. Pode ser o sistema como um todo ou algum módulo específico.

- Resposta: é a atividade realizada após a ocorrência de um determinado estímulo.

- Medições da resposta: representam medidas relacionadas à resposta.

Também segundo (BASS; CLEMENTS; KAZMAN, 2003), existem dois tipos de cenários: cenários gerais e cenários concretos. Cenários gerais são independentes de sistema e podem, potencialmente, pertencer a qualquer sistema. Já cenários concretos de atributos de qualidade são específicos para um sistema em particular. Caracterizações de atributos de qualidade são apresentadas como uma coleção de cenários gerais. No entanto, para se considerar a caracterização do atributo de um sistema em particular, os cenários devem ser mais específicos, sendo utilizados cenários concretos. Cada cenário concreto pode ser significativo no projeto de software e detalhes de resposta para estímulos são suficientes para possibilitar a execução de testes em relação a um determinado requisito não-funcional. A elicitação de requisitos pode ocorrer através de cenários gerais de atributos de qualidade, em que cenários gerais podem indicar possíveis aspectos a serem considerados para avaliar um determinado requisito não-funcional.

Cenários gerais provêem um framework para a geração de um número elevado de cenários específicos para um determinado atributo de qualidade. Cada cenário geral é potencialmente, mas não necessariamente, relevante para o sistema que será construído. Para que um cenário geral seja útil em um sistema em particular, o cenário deve ser mais específico. Cenários concretos são gerados a partir de cenários gerais, e assumem uma importância para a especificação de requisitos 
não-funcionais similar à utilização de casos de uso em uma especificação de requisitos funcionais (BASS; CLEMENTS; KAZMAN, 2003).

Um dos usos de cenários gerais é habilitar a comunicação entre stakeholders sobre atributos de qualidade. Stakeholders são pessoas (ou grupos de pessoas) afetadas por decisões de arquitetura. Podem ser considerados stakeholders: representantes dos clientes, o arquiteto do projeto, operadores, equipes de desenvolvimento, gerentes de projeto, etc.

Cada atributo de qualidade possui um vocabulário próprio para descrever seus conceitos básicos. Isto pode acarretar problemas de comunicação. Através da descrição de cenários, é possível a realização de discussões a respeito de quais cenários podem ser considerados importantes para decisões de arquitetura.

Em (BASS; CLEMENTS; KAZMAN, 2003), são definidas tabelas com características relacionadas aos atributos de qualidade disponibilidade, desempenho, modificabilidade, segurança (security) e testabilidade. As características presentes nas tabelas têm como objetivo permitir a criação de cenários gerais de atributos de qualidade, sendo os cenários gerais a base para a criação de cenários concretos específicos do sistema analisado. As tabelas apresentam um conjunto de itens de verificação para que características importantes na análise de um determinado requisito não-funcional sejam consideradas na geração de cenários.

Em (ZHU; HUANG; MEI, 2004) cenários de atributos de qualidade são utilizados para prever situações de adaptações em tempo de execução, por meio de medições de resposta. Trata-se de uma forma prática de prover a informação de quando e porquê um sistema pode adaptar-se, permitindo também identificar ações de adaptação para a fase de projeto, adicionando flexibilidade para a tomada de decisões de adaptabilidade. Cabe ressaltar, aqui, que nem todos os cenários de atributos de qualidade podem ser associados a potenciais adaptações em tempo de execução. Requisitos operacionais, tais como desempenho e disponibilidade, são diretamente relacionadas à auto-adaptação, enquanto que requisitos relacionados a desenvolvimento, como modificabilidade, são menos propensos a serem aplicados em mudanças de configuração em tempo de execução. 


\subsection{Requisitos não-funcionais e arquitetura de software}

Os requisitos não-funcionais identificados na construção de um software devem ser considerados no projeto de arquitetura de software. A arquitetura de software de um programa ou de um sistema pode ser definida, segundo (BASS; CLEMENTS; KAZMAN, 2003), como a(s) estrutura(s) do sistema, constituído(s) de elementos de software, das propriedades externas e visíveis destes elementos e de seus interrelacionamentos. Outra definição de arquitetura de software está presente no documento IEEE Std. 1471-2000 (IEEE, 2000), que define arquitetura de software como sendo a organização fundamental de um sistema, englobando os componentes e seus relacionamentos, o ambiente e os princípios que governam o projeto (design) e a evolução da arquitetura. Este documento, inclusive, descreve um modelo conceitual que estabelece a distinção entre uma arquitetura e sua descrição. A descrição arquitetônica é organizada por um conjunto de visões que são regidas pelos pontos de vista (viewpoints).

De acordo com (CLEMENTS; KAZMAN; KLEIN, 2002), uma arquitetura de software constitui um conjunto coerente de decisões de projeto antecipadas no ciclo de desenvolvimento. Estas decisões têm um papel fundamental na satisfação dos requisitos funcionais e não-funcionais durante a construção do software.

No contexto da arquitetura de software, segundo (SHAW; GARLAN, 1996), dois conceitos são importantes. O primeiro conceito está relacionado ao padrão de arquitetura. Um padrão para uma arquitetura de software descreve um problema particular recorrente em projetos de software, que surgem em um contexto específico e apresenta uma solução genérica para solucioná-lo. A solução é especificada através da descrição dos componentes que a constituem, suas responsabilidades e relacionamentos, assim como a forma em que eles colaboram entre si. Outro conceito importante é o de estilo arquitetônico. Um estilo arquitetônico descreve uma categoria de sistemas de software em termos de sua estrutura organizacional. Um estilo arquitetônico é composto por um conjunto de componentes e sua topologia, um conjunto de conectores, que possibilitam a integração entre componentes, restrições que definem como os componentes podem ser integrados, juntamente com benefícios e desvantagens na utilização deste estilo. 
Existem métodos para mapearem requisitos não-funcionais em decisões de arquitetura. Uma abordagem utilizada em (CHUNG et al., 2000) consiste na aplicação do framework NFR para a seleção de decisões arquitetônicas. Neste enfoque, as alternativas arquitetônicas a serem consideradas são tratadas como softgoals de operacionalização no SIG, e a aplicação do método associado ao framework NFR auxilia a avaliação dos impactos das decisões nos requisitos nãofuncionais analisados.

Os cenários de atributos de qualidade também possibilitam a análise de possíveis soluções arquitetônicas. Para a avaliação de decisões arquitetônicas aplicadas a determinados cenários de atributos de qualidade, (BACHMANN et al., 2005) destaca a importância de modelos de atributos de qualidade na avaliação de solução arquitetônica. Modelos de atributos de qualidade correspondem a um conjunto de métricas relacionadas, além de métodos utilizados para mensurar estas métricas. A ISO 9126 (ISO, 2001) enumera uma multiplicidade de métricas para uma série de requisitos não-funcionais. Dentre exemplos de modelos de atributos de qualidade, podem ser citados modelos relacionados à teoria de filas para a análise do requisito não-funcional desempenho e cadeias de Markov, utilizadas como modelo para os requisitos não-funcionais disponibilidade e desempenho. Modelos de atributos de qualidade expressam relações definidas entre conceitos definidos em teorias relacionadas a requisitos não-funcionais. Tais relacionamentos podem ser expressos a partir de fórmulas matemáticas, ou modelos de simulação. Modelos de atributos de qualidade podem ser utilizados para prever uma medida relacionada à resposta de uma arquitetura na ocorrência de um determinado estímulo.

Um conceito importante associando estilos arquitetônicos a modelos de atributos de qualidade é o conceito de ABAS (Attribute-Based Architectural Styles, traduzido como Estilos Arquitetônicos Baseados em Atributos). O ABAS, segundo (KAZMAN; KLEIN, 1999), pode ser definido como um conjunto de três elementos, composto por um estilo arquitetônico, um modelo de um atributo de qualidade específico, que provê um método de racionalização sobre o comportamento dos tipos de componente que interagem no padrão definido no estilo, e os resultados da aplicação do modelo do modelo no estilo proposto. O objetivo principal do ABAS é identificar estilos arquitetônicos em modelos de um determinado atributo de qualidade. 
Em (BASS; CLEMENTS; KAZMAN, 2003) os autores descrevem como cenários de atributos de qualidade podem ser utilizados para a descrição de requisitos nãofuncionais a serem considerados na avaliação ou construção de uma arquitetura de software. Para alcançar uma resposta adequada em relação um requisito nãofuncional, eles descrevem táticas utilizadas pelo arquiteto para a construção de padrões de projeto, padrões de arquitetura ou estratégias arquitetônicas.

Segundo (BASS; CLEMENTS; KAZMAN, 2003), a tática consiste em uma decisão de projeto que influencia o controle da resposta de um estímulo associado a um cenário de atributo de qualidade. Um conjunto de táticas constitui uma estratégia arquitetônica. No contexto de cenários de atributo de qualidade, as táticas estão associadas à ocorrência de um determinado estímulo com o objetivo de se obter uma resposta desejada. A Figura 5 representa a relação entre estímulo, táticas arquitetônicas e resposta de cenários, indicando que táticas podem ser aplicadas para obtenção da resposta desejada.

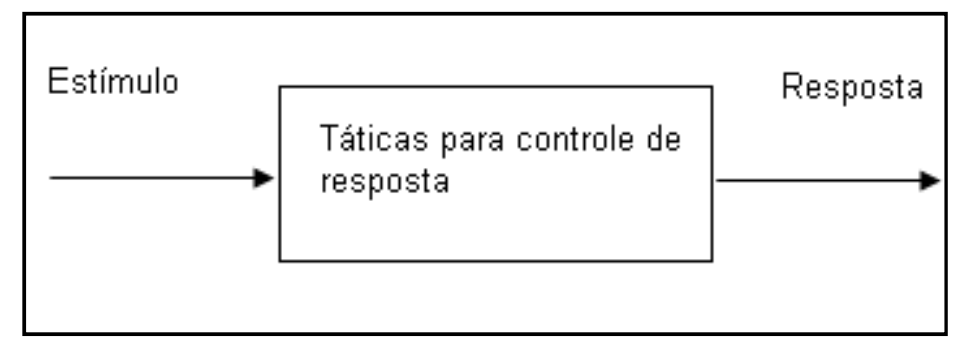

Figura 5 - Relação entre táticas, estímulo e resposta

Também em (BASS; CLEMENTS; KAZMAN, 2003), existe a definição de táticas para os atributos de disponibilidade, modificabilidade, desempenho, segurança, testabilidade e usabilidade.

Há uma série de trabalhos abordando a utilização de cenários como base para a construção e avaliação de arquiteturas de software. Um dos trabalhos (BASS; KLEIN; BACHMANN, 2001) baseia-se no conceito de mecanismos arquitetônicos introduzidos em (BOOCH, 1996). Mecanismos arquitetônicos são estruturas em que objetos colaboram para prover um comportamento que satisfaça um requisito de um problema $(\mathrm{BOOCH}, 1996)$. A partir deste conceito, restringiu-se a definição para um novo conceito, o conceito de primitivas de atributo. Primitivas de atributo correspondem a uma coleção de componentes e conectores que colaboram para alcançar objetivos relacionados a requisitos não-funcionais (expressos como 
cenários gerais de atributos de qualidade), sendo primitivos com respeito ao alcance de atributos de qualidade. Cada primitiva de atributo de qualidade tem como objetivo alcançar um ou mais atributos de qualidade, mas em geral provoca efeitos em outros atributos de qualidade que não foram endereçados como objetivo principal na adoção da primitiva. Portanto, uma atividade de projeto de arquitetura deve considerar primitivas para cada cenário considerado, devendo ser identificados, para cada primitiva adotada, os impactos, sejam positivos ou negativos, em relação aos requisitos não-funcionais do sistema que não estejam relacionados ao cenário analisado.

Em (BARBACCl et al., 2003), é definido um método conhecido como QAW (Quality Attribute Workshop). O QAW corresponde a um método que envolve stakeholders no início do ciclo de vida de desenvolvimento de software para direcionar atributos de qualidade, sendo um meio de descobrir, documentar e priorizar os atributos de qualidade a serem considerados em um sistema. O método QAW objetiva identificar cenários de qualidade através de interação com stakeholders, sendo os cenários priorizados de acordo com regras de negócio pertinentes ao sistema e refinados durante a execução do método. O resultado do QAW é um conjunto de cenários priorizados e refinados.

(BASS; KLEIN; BACHMANN, 2002) descrevem um método para a definição de uma arquitetura de software com base em cenários de atributo de qualidade conhecido como ADD (Attribute-Driven Design - Projeto direcionado a Atributo), um processo recursivo de decomposição do software. As entradas são requisitos funcionais, restrições de projeto, que correspondem a decisões de projeto pré-estabelecidas (por exemplo, disponibilização de serviços utilizando a Internet, escolha préestabelecida de um sistema operacional, de uma plataforma de desenvolvimento, de um sistema gerenciador de base de dados, etc.), e requisitos não-funcionais, representados através de cenários concretos de atributos de qualidade e priorizados de acordo com critérios de negócio (o resultado da aplicação do método QAW pode ser aplicado como entrada para o ADD). As saídas do método são elementos de software (definidos como artefato de desenvolvimento ou computacional, e que se relacionam com outros elementos de software que compõem o sistema), com suas respectivas responsabilidades (funcionalidades, dados, ou informações que cada elemento de software deve prover), papéis (um conjunto de responsabilidades 
relacionadas), propriedades (informações relacionadas a elementos de software como nome, tipo, característica de atributo de qualidade, protocolo), além de relacionamentos com os demais elementos de software.

\subsection{O método ATAM}

Um método de avaliação de arquitetura que tem como base a utilização de cenários de atributos de qualidade é o ATAM (Architecture Tradeoff Analysis Method Método de Análise de Compromissos de Arquitetura) (KAZMAN; KLEIN; CLEMENTS, 2000). O método consiste na avaliação de arquitetura baseando-se em requisitos não-funcionais, ou atributos de qualidade ${ }^{2}$. Seu principal objetivo é identificar as conseqüências de decisões arquitetônicas nos atributos de qualidade do sistema, identificando possíveis tradeoffs entre os diferentes atributos de qualidade do sistema.

O resultado da análise de decisões de arquitetura em relação a um determinado requisito não-funcional, segundo a metodologia ATAM, abrange riscos, não-riscos, pontos de sensibilidade e pontos de tradeoff.

Riscos, no contexto do ATAM, são decisões de arquitetura que podem provocar efeitos negativos em relação a um determinado atributo de qualidade. Não-riscos são decisões de arquitetura que podem provocar efeitos positivos em relação a um determinado atributo de qualidade.

Pontos de sensibilidade de arquitetura são propriedades críticas para alcançar um determinado atributo de qualidade. $\mathrm{Na}$ área de segurança (security), por exemplo, o nível de confidencialidade em uma rede virtual privada pode apresentar como ponto de sensibilidade a quantidade de bits utilizada na criptografia.

Pontos de tradeoff são propriedades de uma decisão de arquitetura que afetam mais de um atributo de qualidade. Pontos de tradeoff são importantes para a análise da arquitetura, pois devem ser analisados os efeitos de uma determinada decisão em mais de um atributo de qualidade.

O ATAM é composto pelas seguintes etapas:

\footnotetext{
${ }^{2}$ Em (KAZMAN; KLEIN; CLEMENTS, 2000), requisitos não-funcionais são também referenciados como atributos de qualidade.
} 
1. Apresentação do ATAM - consiste em reuniões para apresentar a metodologia a todos os envolvidos no projeto.

2. Apresentação dos objetivos de negócio - apresentação dos objetivos de negócio que motivam o desenvolvimento.

3. Apresentação da arquitetura - o arquiteto irá descrever a arquitetura proposta, relacionando-a aos objetivos de negócio e aos respectivos atributos de qualidade.

4. Identificação dos elementos de arquitetura - nesta etapa abordagens de arquitetura são identificadas, mas não são analisadas.

5. Geração da árvore de atributos de qualidade - geração da utility tree (árvore de utilidades) para a elicitação de cenários que permitem caracterizar os atributos de qualidade do sistema. A árvore de utilidades corresponde a um mecanismo top-down utilizado para mapear atributos de qualidade relacionados ao domínio do problema em cenários concretos.

6. Análise de Abordagens Arquitetônicas - a partir dos fatores de qualidade obtidos através da árvore gerada no item anterior, as abordagens de arquitetura que referenciam estes fatores são analisadas. Durante este passo, riscos, pontos de sensibilidade e tradeoffs são analisados.

7. Priorização de cenários (brainstorm) - um número maior de stakeholders é reunido para, através de brainstorming, definir novos cenários e priorizá-los, com o propósito de envolver um número maior de participantes. Nesta etapa podem ser identificados novos cenários de atributos de qualidade, que podem ser incorporados à árvore de utilidades.

8. Análise de Abordagens Arquitetônicas - esta etapa reitera a etapa 6, mas com os cenários priorizados no passo 7 considerados como casos de testes para a análise das abordagens de arquitetura adotadas.

9. Apresentação de Resultados - com base nas informações levantadas nas etapas anteriores, é gerado, nesta fase, um relatório detalhando toda informação e possíveis decisões de arquitetura a serem utilizadas.

A essência do método está contida nas etapas 5, 6 e 7. A etapa 5 do método ATAM corresponde à etapa de geração de cenários de atributos de qualidade, sendo estes agrupados na árvore de utilidades. Nesta etapa, os responsáveis pela avaliação se reúnem com os responsáveis por decisões de projeto, tais como a equipe de 
arquitetos, gerentes e representantes do cliente, para a geração de cenários. Este passo possui importância fundamental no método (CLEMENTS; KAZMAN; KLEIN, 2002), uma vez que são gerados cenários que representam requisitos nãofuncionais a serem considerados na avaliação da arquitetura. A Figura 6 representa, de forma sucinta, a interação entre a etapa cinco e as demais etapas do método. A geração dos cenários de atributos de qualidade baseia-se nos objetivos de negócio e atributos de qualidade de maior relevância identificados na etapa 2, e nas características da arquitetura sob análise identificadas na etapa 4. A partir destas informações são identificados cenários de atributos de qualidade, utilizados no método ATAM de forma simplificada em relação à estruturação de cenários proposta em (BASS; CLEMENTS; KAZMAN, 2003), sendo basicamente compostos por três elementos (CLEMENTS; KAZMAN; KLEIN, 2002):

- Estímulo, que representa um evento ou condição que deve ser considerado pelo sistema;

- Ambiente, que representa as condições sob as quais o sistema encontra-se na ocorrência do estímulo;

- Resposta, que representa a reação do sistema na ocorrência de um determinado estímulo.

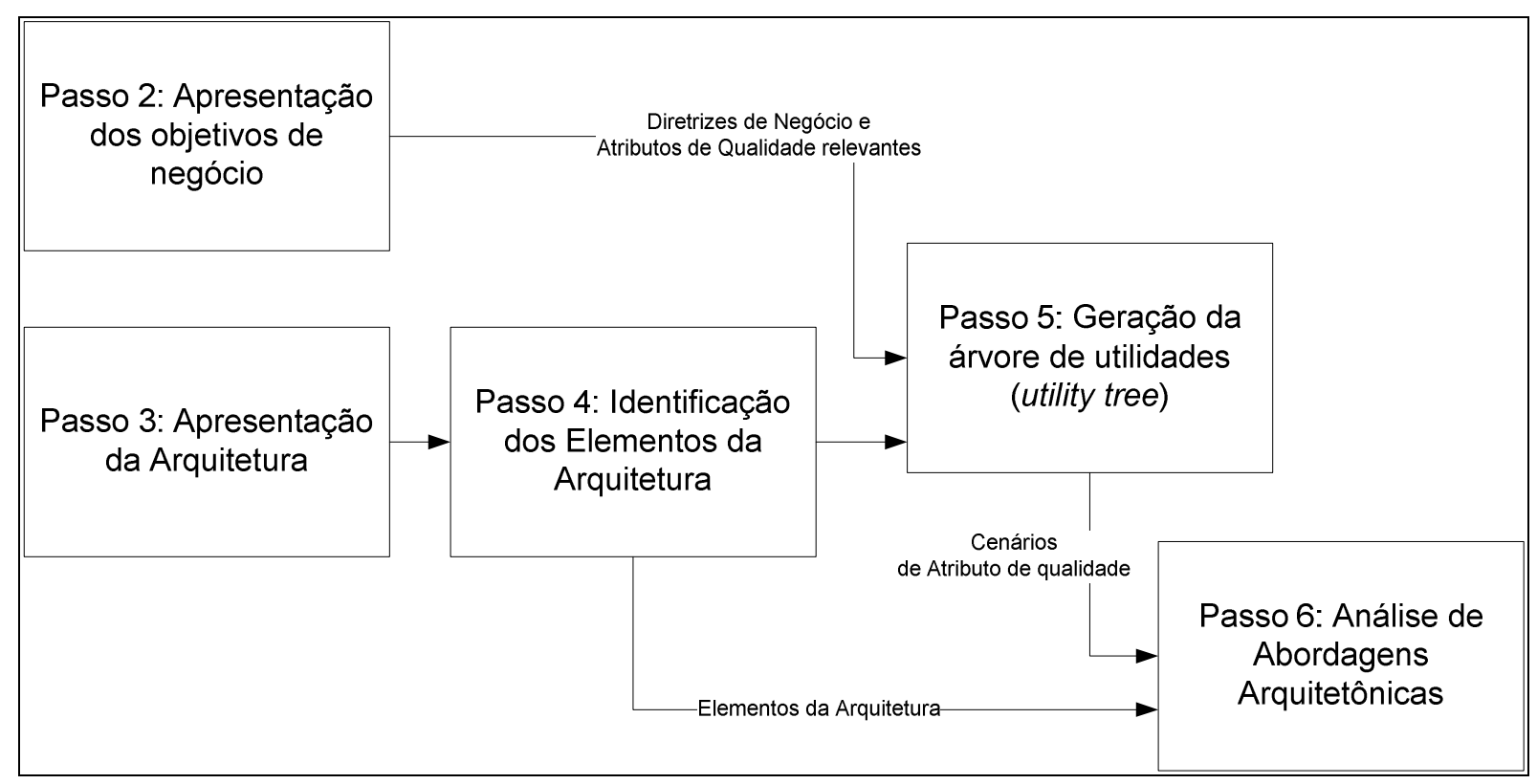

Figura 6 - Etapas 2 a 6 do método ATAM 
Os cenários são priorizados e agrupados em uma estrutura de árvore, a árvore de utilidades. O primeiro nível da árvore (a raiz da árvore de utilidades) equivale à "utilidade" da arquitetura a ser analisada. Os nós do segundo nível equivalem aos atributos de qualidade a serem considerados na avaliação da arquitetura, tais como desempenho, disponibilidade, segurança, entre outros. O terceiro nível da árvore, segundo (CLEMENTS; KAZMAN; KLEIN, 2002), corresponde a refinamentos de atributos de qualidade, considerando características relacionadas a cada requisito não-funcional. Dentre os exemplos deste refinamento presentes em (CLEMENTS; KAZMAN; KLEIN, 2002) são citadas a decomposição do atributo de qualidade desempenho em latência de dados e vazão, e a decomposição do atributo disponibilidade em possíveis categorias de falhas, tais como falhas de hardware e de componentes de software. O último nível da árvore de utilidades, que corresponde às "folhas" da árvore, é composto por cenários concretos associados aos atributos de qualidade. Estes cenários são rotulados com marcações de priorização relativas, segundo dois critérios: o primeiro critério baseia-se na importância de cada cenário para a arquitetura de software sob análise, e o segundo baseia-se no grau de dificuldade para se atender ao cenário, de acordo com a avaliação do arquiteto.

Durante a avaliação, os stakeholders são encorajados a utilizar suas palavras para descrever cenários de atributo de qualidade, uma vez que eles podem não estar familiarizados com taxonomias utilizadas para a descrição de requisitos nãofuncionais, como, por exemplo, a taxonomia definida na ISO 9126 (ISO, 2001) para requisitos não-funcionais. Em (OZKAYA et al., 2008) é citada uma análise das árvores de utilidades de 24 avaliações realizadas pelo SEI de 1999 a 2007. Estas avaliações foram conduzidas por organizações comerciais e empresariais e englobam sistemas de aviação, sistemas de combate, entre outros sistemas. Nesta avaliação observou-se um total de 1072 cenários e, segundo (OZKAYA et al., 2008) as descrições obtidas relacionadas a requisitos não-funcionais não seguem padrões relacionados a taxonomias utilizadas para a descrição de requisitos não-funcionais. Os cenários que apresentarem uma prioridade maior são selecionados para serem analisados na etapa 6 do ATAM. Nesta etapa, as abordagens arquitetônicas identificadas na etapa 4 são analisadas com base nos cenários selecionados. Para cada cenário analisado, os elementos que o compõem e as decisões arquitetônicas 
que o afetam são agrupados conforme modelo apresentado na Tabela 3. Para cada cenário, são identificados riscos, não-riscos, pontos de sensibilidade e tradeoffs.

Tabela 3 - Modelo para análise de uma abordagem arquitetônica

Cenário: Texto do cenário pertencente à árvore de utilidades.

Atributo: Atributo de qualidade ao qual o cenário está relacionado.

Ambiente: Premissas sobre o ambiente computacional e as condições relevantes nas quais 0 cenário é caracterizado.

Estímulo: uma declaração precisa do estímulo no qual o cenário de atributo de qualidade é construído (por exemplo, uma função invocada, uma falha, uma ameaça, uma modificação, etc.).

Resposta: uma declaração precisa da resposta do cenário (por exemplo, tempo de resposta, medida da complexidade de modificação, etc.).

\begin{tabular}{|c|c|c|c|c|}
\hline $\begin{array}{l}\text { Decisões } \\
\text { Arquitetônicas }\end{array}$ & $\begin{array}{c}\text { Pontos de } \\
\text { Sensibilidade }\end{array}$ & $\begin{array}{c}\text { Pontos de } \\
\text { Tradeoff }\end{array}$ & Riscos & Não - riscos \\
\hline $\begin{array}{l}\text { Lista de decisões } \\
\text { arquitetônicas } \\
\text { relevantes que afetam } \\
\text { a resposta do cenário } \\
\text { de atributo de } \\
\text { qualidade. }\end{array}$ & $\begin{array}{l}\text { Pontos de } \\
\text { sensibilidade } \\
\text { associados a } \\
\text { cada decisão de } \\
\text { arquitetura no } \\
\text { cenário em } \\
\text { questão }\end{array}$ & $\begin{array}{c}\text { Pontos de } \\
\text { tradeoff } \\
\text { relacionados a } \\
\text { cada decisão, } \\
\text { com o impacto } \\
\text { em relação aos } \\
\text { demais atributos } \\
\text { de qualidade }\end{array}$ & $\begin{array}{l}\text { Descrições } \\
\text { relacionadas } \\
\text { ao efeito } \\
\text { negativo de } \\
\text { uma decisão } \\
\text { arquitetônica } \\
\text { (ou a ausência } \\
\text { da decisão) no } \\
\text { cenário em } \\
\text { questão }\end{array}$ & $\begin{array}{c}\text { Descrições } \\
\text { relacionadas } \\
\text { ao efeito } \\
\text { positivo de } \\
\text { uma decisão } \\
\text { arquitetônica } \\
\text { no cenário } \\
\text { em questão }\end{array}$ \\
\hline
\end{tabular}

Racionalização: racionalização quantitativa e/or qualitativa indicando as razões pelas quais a lista de decisões arquitetônicas contribui para afetar cada requisito de atributo de qualidade representado pelo cenário.

Diagramas de Arquitetura: diagrama ou diagramas de visões arquitetônicas que representam informações arquitetônicas que dão suporte a racionalização acima, acompanhados com um texto explicativo caso seja necessário.

Fonte: (CLEMENTS; KAZMAN; KLEIN, 2002) 


\section{CONCEITOS E TAXONOMIA DE DEPENDABILIDADE}

O requisito não-funcional a ser analisado neste trabalho é o de disponibilidade. Para analisá-lo, este capítulo, com base nas definições descritas em (LAPRIE, 1992) e (AVIŽIENIS et al., 2004), irá tratar conceitos relacionados à dependabilidade.

Este capítulo também apresenta cenários de disponibilidade e táticas arquitetônicas para se atender ao requisito não-funcional disponibilidade, segundo (BASS; CLEMENTS; KAZMAN, 2003).

\subsection{Conceitos fundamentais de dependabilidade}

O conceito de dependabilidade pode ser definido como a capacidade de o sistema disponibilizar serviços de forma que se possa, justificadamente, confiar neles (LAPRIE, 1992). Nesse contexto, os serviços são definidos como o comportamento do sistema percebido por um usuário. Um usuário pode corresponder a um usuário humano do sistema, ou outro sistema com o qual ocorre uma interação e que interage com o sistema através de uma interface de serviço.

Ainda segundo (LAPRIE, 1992), uma conceituação sistemática de dependabilidade consiste basicamente de três partes: as ameaças à dependabilidade de um sistema, os atributos de dependabilidade e os meios utilizados para alcançá-la. A Figura 7 representa uma estruturação destes conceitos segundo (AVIŽIENIS et al., 2004). 


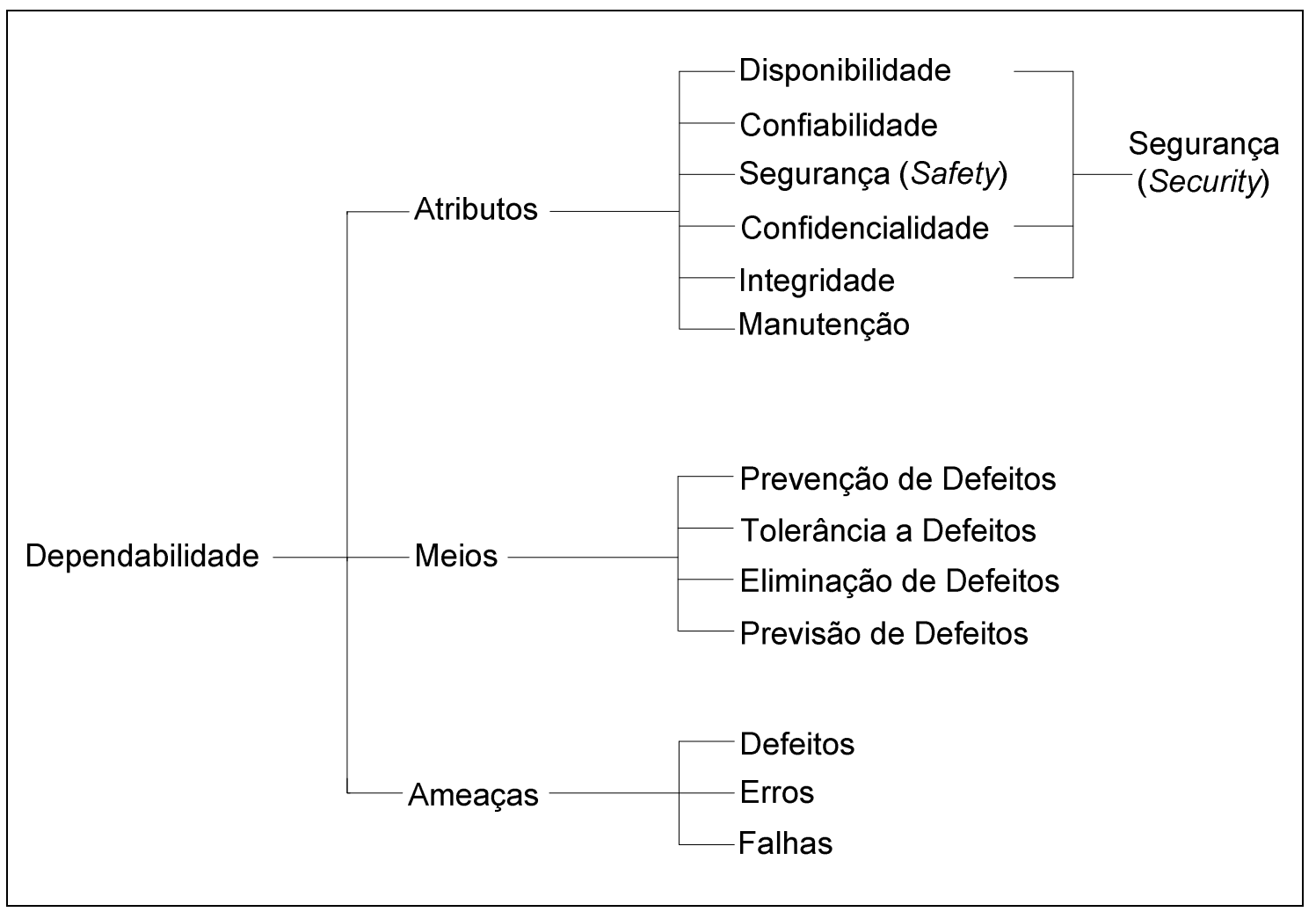

Figura 7 - Árvore de Dependabilidade

Fonte: (AVIŽIENIS et al., 2004)

(LAPRIE, 1992) e (AVIŽIENIS et al., 2004), antes de definir esses atributos, meios e ameaças, definiram alguns conceitos de base. Um sistema é uma entidade que interage com outras entidades, isto é, outros sistemas. O conjunto de outros sistemas com os quais o sistema interage pode ser definido como o ambiente de execução de um dado sistema. A fronteira do sistema corresponde à fronteira comum entre o sistema e seu ambiente de execução. O serviço disponibilizado pelo sistema corresponde ao comportamento observado por usuários do sistema, sendo o usuário a parte do ambiente de execução que interage com o sistema e que utiliza o serviço disponibilizado. A funcionalidade do sistema corresponde ao que 0 sistema se destina a realizar. O comportamento do sistema corresponde ao que o sistema realiza e pode ser descrito através de uma seqüência de estados. Um estado pode ser definido como a condição relacionada a um conjunto de circunstâncias, seja de comportamento ou de estrutura. O estado total de um dado sistema corresponde ao conjunto de estados de computação, comunicação, informação armazenada, interconexões, condições físicas, etc.

A estrutura do sistema possibilita que o sistema seja capaz de gerar seu próprio comportamento. De acordo com uma visão estrutural, o sistema corresponde a um 
conjunto de componentes relacionados entre si para interação, em que cada componente corresponde a outro sistema. Portanto, um componente pode ser descrito por um conjunto de componentes que estão inter-relacionados. A recursividade desta definição se encerra quando um componente pode ser considerado atômico, ou seja, não existe a possibilidade ou a necessidade de se discernir uma nova estrutura interna. Conseqüentemente, o estado atual do sistema corresponde ao conjunto de estados externos de seus componentes atômicos.

\subsection{Atributos de dependabilidade}

O conceito de dependabilidade engloba os seguintes atributos (AVIŽIENIS et al., 2004):

- Disponibilidade: prontidão para o serviço correto; probabilidade de um sistema estar operacional em um dado instante do tempo;

- Confiabilidade: fornecimento contínuo do serviço correto; probabilidade de o sistema funcionar de acordo com as especificações, dentro de certas condições, em um certo período de tempo;

- Segurança (safety): ausência de consequências catastróficas para os usuários e o contexto onde estes estão inseridos;

- Integridade: ausência de alterações impróprias do sistema;

- Manutenção: habilidade de executar reparos e modificações.

Os atributos integridade e disponibilidade (relacionados somente a ações autorizadas), juntamente com confidencialidade, que corresponde à ausência de divulgação de informação não autorizada, constituem características do requisito não-funcional segurança (security) (AVIŽIENIS et al., 2004).

Dependendo da aplicação, um atributo de dependabilidade pode possuir uma importância maior em comparação com os demais atributos de dependabilidade. Nas aplicações envolvidas em situações que envolvem riscos para a vida humana, por exemplo, o atributo segurança (safety) se sobressai, enquanto que em aplicações bancárias e de comércio eletrônico o atributo disponibilidade normalmente é considerado. 
Em relação ao atributo disponibilidade, algumas medidas são importantes. Uma delas é o MTTF (Mean Time to Failure), definido como o tempo médio esperado para que um sistema apresente falhas. Outra medida importante é o MTTR (Mean Time To Repair), definido como o tempo médio requerido para reparar um sistema quando existe a ocorrência de falhas. O tempo médio entre a ocorrência de falhas é o MTBF (Mean Time Between Failure), correspondendo à soma do MTTF com MTTR. A Figura 8 mostra a relação entre MTTF, MTTR e MTBF.

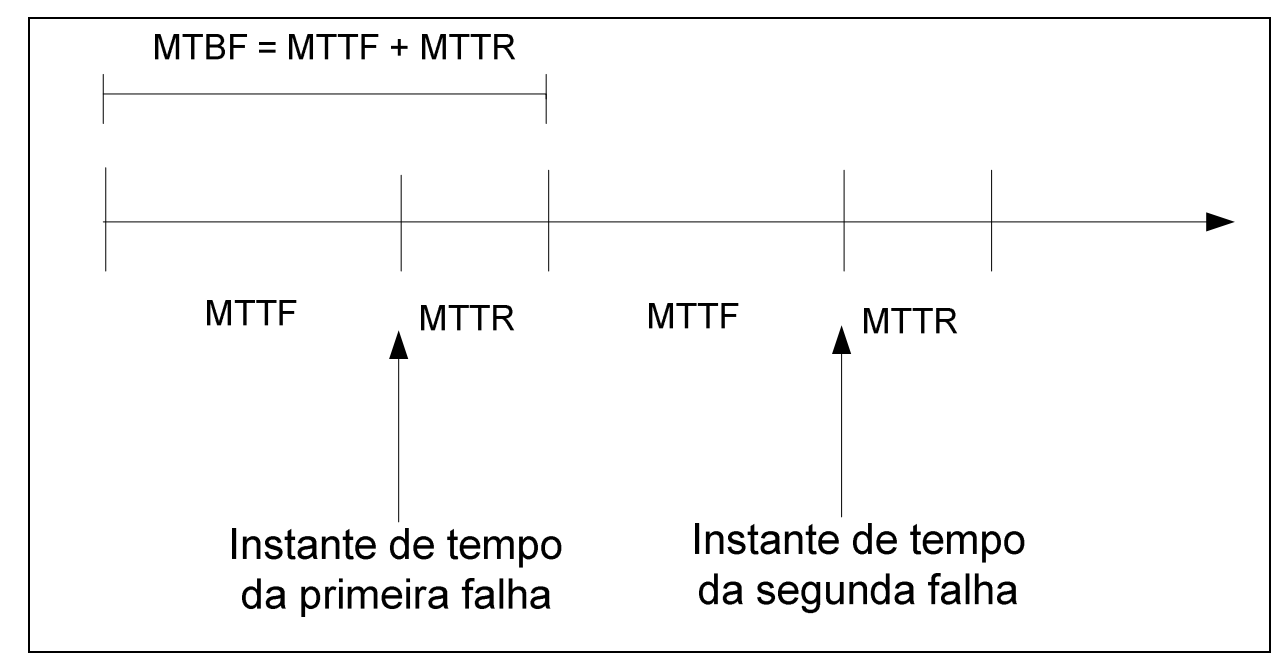

Figura 8 - Relação entre MTBF, MTTF e MTTR

Dentre as medidas para caracterizar 0 atributo disponibilidade existe a medida disponibilidade assintótica, definida como a probabilidade de um sistema estar disponível quando o instante de tempo $t$ tende ao infinito. É definida como:

$$
A=\frac{M T T F}{M T T F+M T T R}
$$

\subsection{Ameaças à dependabilidade}

Em relação às ameaças de dependabilidade, cabe ressaltar os conceitos de defeito (fault), erro (error) e falha (failure). Um serviço correto, segundo (LAPRIE, 1992), corresponde ao comportamento do sistema percebido pelo usuário quando o sistema provê uma funcionalidade. Uma falha no serviço corresponde a um evento associado à ocorrência de um desvio do que seria o serviço correto, devido ao fato 
de que não atende à sua especificação, ou devido ao fato de que a especificação não descreva corretamente a funcionalidade do sistema (AVIŽIENIS et al., 2004). Uma falha no serviço pode ser definida como a transição de um serviço correto para um serviço incorreto, ou seja, o serviço não realiza sua funcionalidade corretamente (AVIŽIENIS et al., 2004). A transição do serviço incorreto para o serviço correto corresponde à recuperação do serviço. $O$ intervalo de tempo em que o serviço é disponibilizado de forma incorreta corresponde a uma interrupção de serviço. De acordo com (LAPRIE, 1992), um erro consiste em uma manifestação de defeito no sistema, correspondendo a um estado de parte do sistema que pode causar uma falha subseqüente. Um defeito pode ser considerado a causa de um erro, sendo um defeito ativo quando este causa um erro, e considerado um defeito dormente quando não causa um erro.

(LAPRIE, 1992) aponta que as ameaças à dependabilidade de um sistema podem surgir durante o ciclo de vida de desenvolvimento de software, podendo ocorrer na fase de utilização do sistema quando este é executado para fornecer serviços. Durante esta fase, o sistema interage com o ambiente de execução, podendo ser afetado por defeitos. O meio com o qual o sistema interage é composto de elementos tais como:

- Área física onde o sistema está em execução;

- Administradores do sistema, podendo ser outros sistemas ou humanos que são capazes de gerenciar, modificar, reparar e utilizar o sistema;

- Usuários, que utilizam os serviços do sistema;

- Infra-estrutura de hardware e software, como sistemas operacionais, redes de comunicação, entre outros fatores;

- Invasores, que consistem em entidades (humanas ou outros sistemas) que podem invadir o sistema com a finalidade de alterar sua funcionalidade ou desempenho.

De acordo com (JOHNSON, 1989), o defeito pode ser físico, ou imperfeições que ocorrem em componentes de hardware ou software. Defeitos ocorrem no domínio de componentes. Erros acontecem no domínio da informação, onde ocorrem erros 
em valores que o sistema trabalha. Erros são causados por defeitos de componentes. Por fim, falhas ocorrem no domínio externo do sistema, ou seja, são perceptíveis por quem interage com o sistema. Falhas são causadas por erros.

De acordo com (JOHNSON, 1989) existem duas categorias de defeitos: defeito de hardware e defeito de software. Problemas na especificação, ou problemas na implementação de determinado componente, são possíveis causas tanto de defeitos de hardware quanto de defeitos de software. Desgaste de componentes e interferências externas ao sistema também podem ser possíveis causas de defeitos de hardware. A Figura 9, baseada em (JOHNSON, 1989), exibe as relações entre defeitos, erros e falhas.

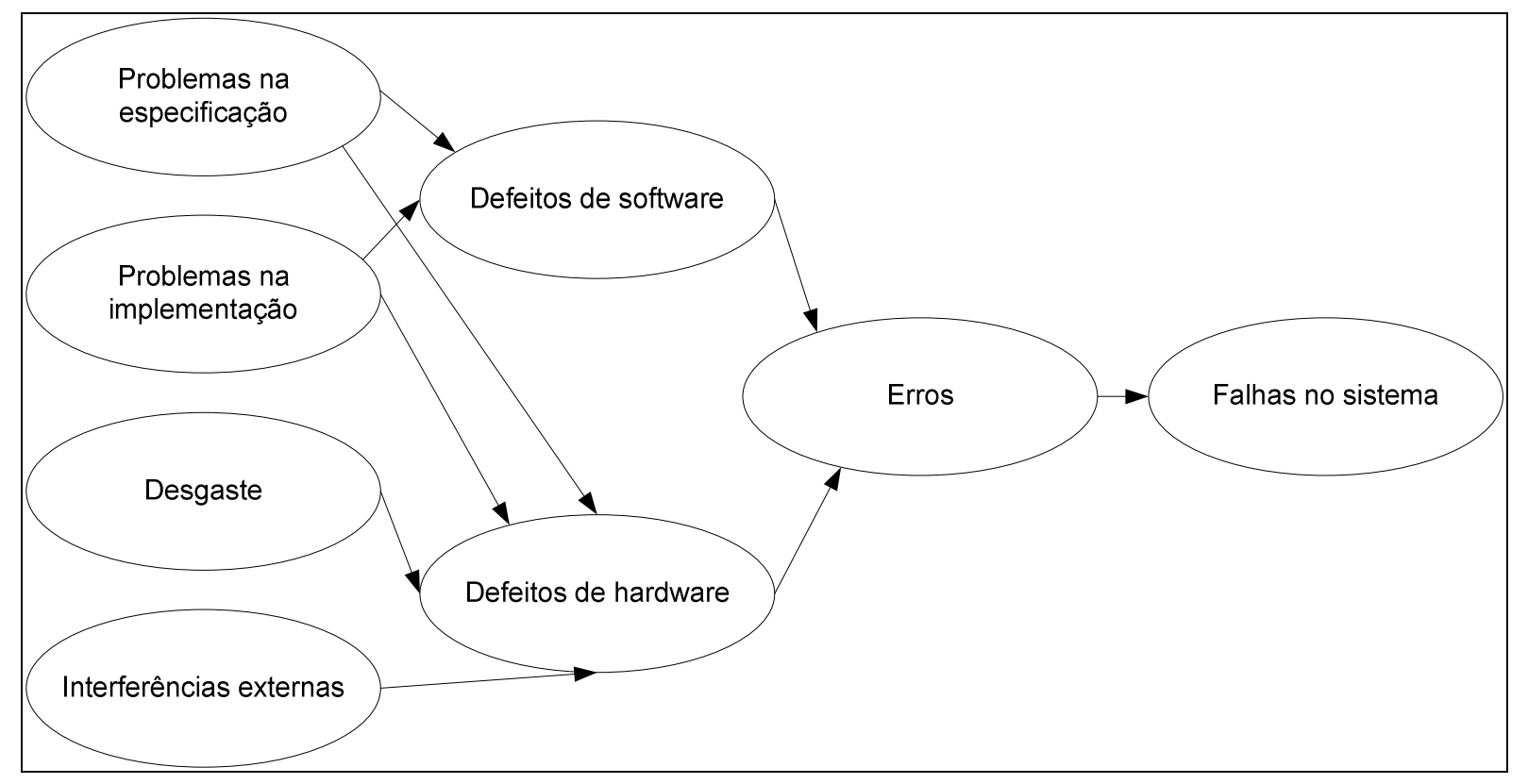

Figura 9 - Relação de Causa-Efeito entre Defeitos, Erros e Falhas

Fonte: (JOHNSON, 1989)

\subsubsection{Falhas}

Um serviço nem sempre apresenta falhas da mesma forma. Os diferentes modos que um sistema pode apresentar falhas são conhecidos como modos de falhas. Conforme Figura 10, extraída de (AVIŽIENIS et al., 2004), os modos de falha são caracterizados através de quatro pontos de vista: o domínio de falha, detecção de falhas, consistência de falhas e conseqüências das falhas no ambiente. 


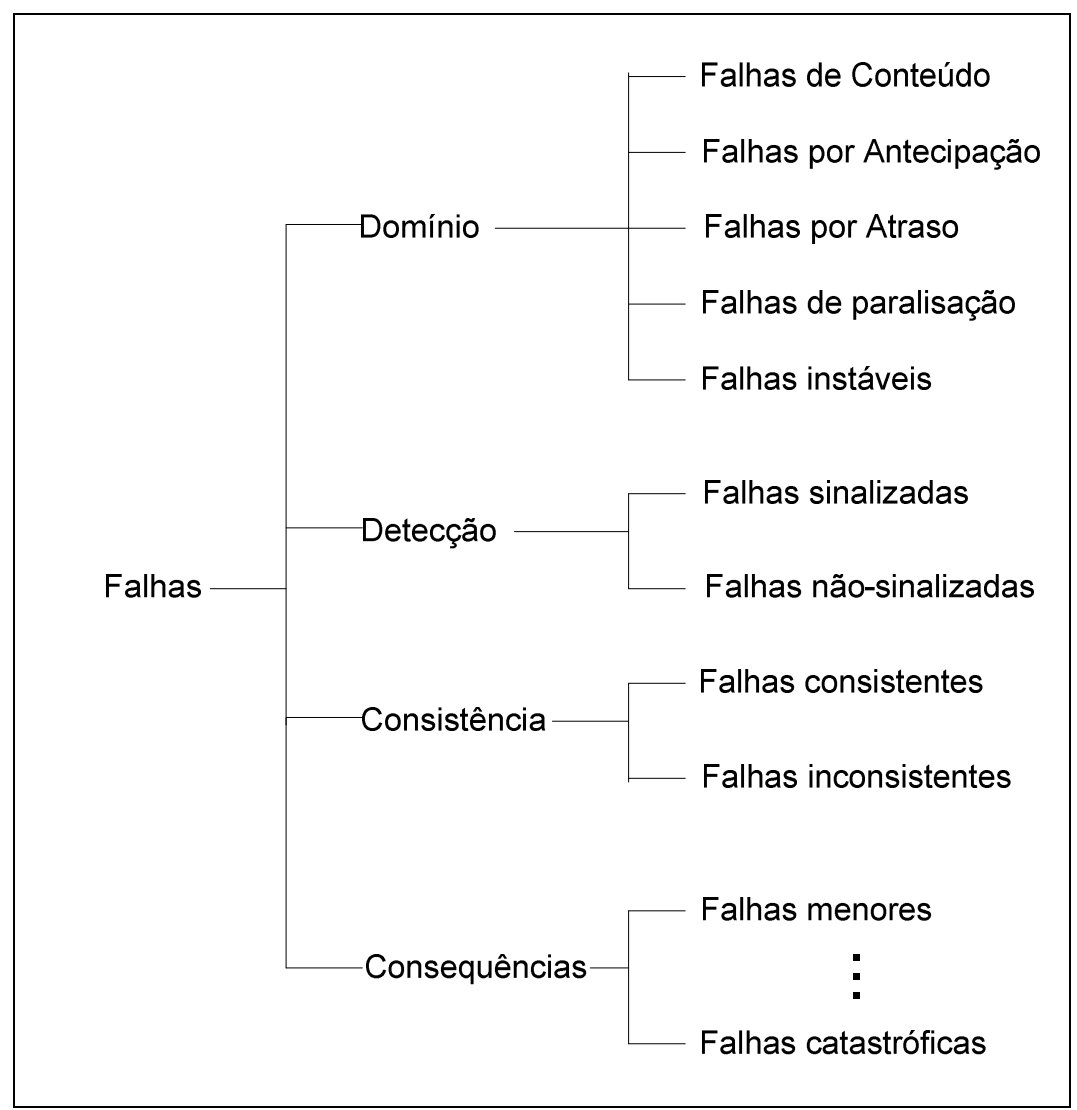

Figura 10 - Modos de falhas

Fonte: (AVIŽIENIS et al., 2004)

A visão de domínio de falhas permite que as falhas possam ser classificadas em falhas de conteúdo, em que o conteúdo disponibilizado pela interface do sistema difere do conteúdo esperado, e em falhas temporais, em que o tempo de duração de um determinado serviço difere do tempo especificado, seja por antecipação ou por atraso. Quando tanto a informação quanto o valor são incorretos, existem duas possíveis classes indicando modos de falhas. Uma delas corresponde a falhas de paralisação, que em (LAPRIE, 1992) recebeu o nome de stopping failures, enquanto que em (AVIŽIENIS et al., 2004) foi denominada halt failure. Neste trabalho adota-se a tradução "falhas de paralisação", que são caracterizadas quando o estado externo do sistema se torna constante, ou seja, as atividades do sistema, se ainda estiverem sendo executadas, não são mais perceptíveis aos usuários. Um caso especial de falhas de paralisação corresponde a falhas de omissão, que em (LAPRIE, 1992) recebeu o nome de omission failures, enquanto que em (AVIŽIENIS et al., 2004) recebeu o nome de silent failure. Neste trabalho adota-se a tradução 
"falhas de omissão", em que nenhum serviço é disponibilizado na interface do serviço.

Outra classe, aplicada nas situações em que ocorrem falhas relacionadas à informação e falhas temporais, corresponde à classe de falhas instáveis, que em (AVIŽIENIS et al., 2004) foi definida como erratic failures quando um serviço é disponibilizado sem paralisação, mas de maneira instável. A Figura 11, extraída de (AVIŽIENIS et al., 2004), representa os modos de falhas de serviço em relação ao domínio de falhas.

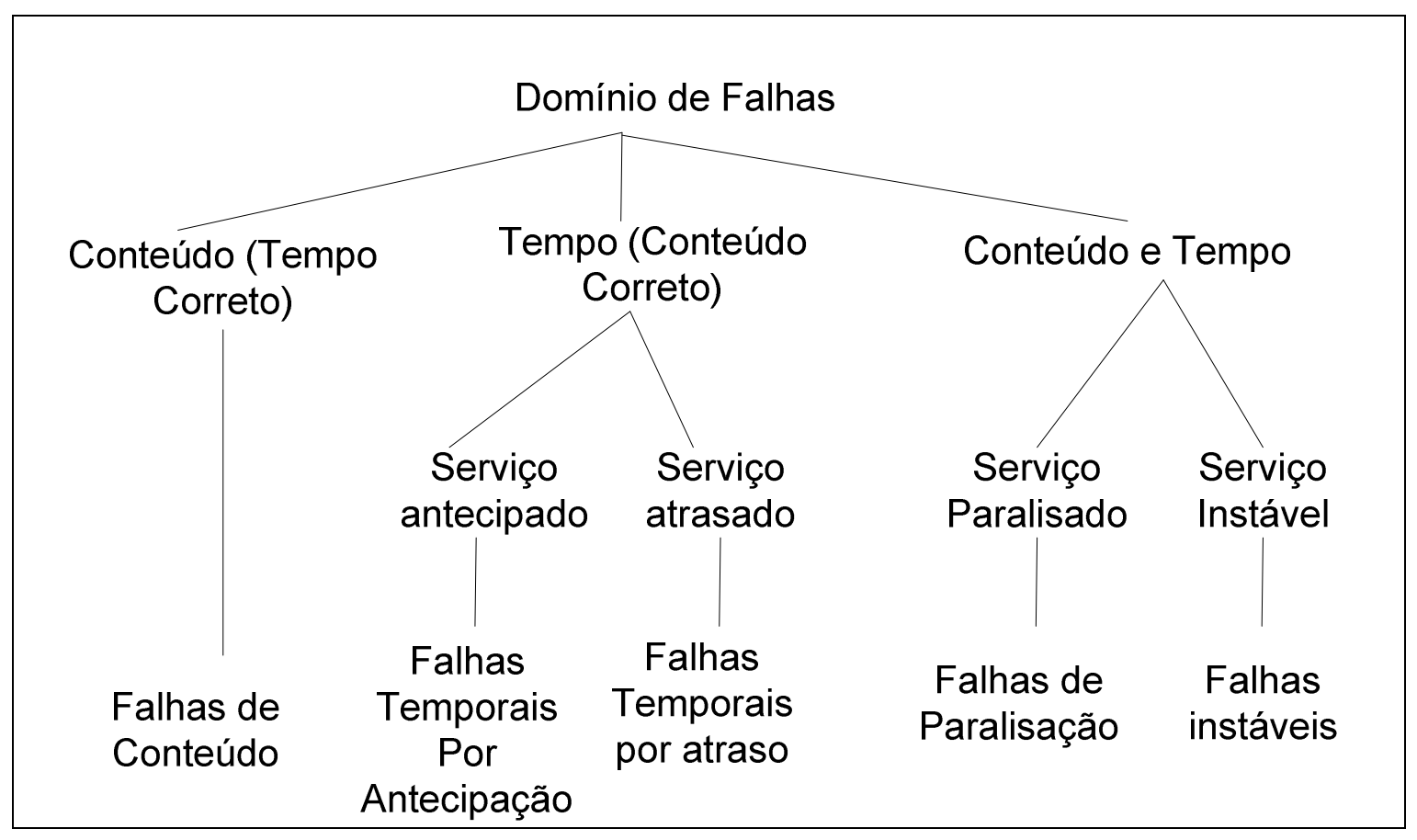

Figura 11 - Modos de falhas de serviço em relação ao domínio de falhas

Fonte: (AVIŽIENIS et al., 2004)

O ponto de vista de detecção trata a sinalização de falhas de serviço para o usuário. A sinalização através da interface de serviço envolve a utilização de mecanismos de deteç̧ão que permitem a verificação se o serviço está operando de forma correta. Quando são detectadas e sinalizadas perdas, então ocorre uma falha sinalizada. Os mecanismos de deteç̧ão podem apresentar duas falhas em seu comportamento: quando sinaliza uma perda de funcionalidade sem que necessariamente a falha tenha ocorrido, representando um alarme falso, ou quando não é possível identificar uma perda de funcionalidade, constituindo uma falha não sinalizada. Quando a 
ocorrência de falhas de serviço resulta em modos reduzidos de serviço, o sistema deve sinalizar que um modo degradado de serviço está sendo fornecido ao usuário. A visão de consistência de falhas permite a distinção entre falhas consistentes, em que o serviço disponibilizado de forma incorreta é identificado por todos os usuários do sistema, e falhas inconsistentes, em que diferentes usuários possuem percepções diferentes do serviço incorreto. Falhas inconsistentes são conhecidas também como falhas Bizantinas.

A partir da visão de conseqüências das falhas, existe a possibilidade de se verificar as severidades de cada falha. Os modos de falha são ordenados em níveis de severidade, com cada nível sendo associado a uma probabilidade máxima aceitável de ocorrências. O número e a definição de níveis de severidade, assim como as probabilidades aceitáveis de ocorrências, são relacionados à aplicação e envolvem atributos de dependabilidade. Em (AVIŽIENIS et al., 2004) são citados exemplos de critério para determinarem-se as classes de severidades de falha. Para o atributo disponibilidade, a duração de interrupção do serviço foi considerada como critério; para segurança (safety) o critério considerado consiste na possibilidade de vidas humanas estarem em risco; para confidencialidade, considera-se o tipo de informação que será exposta; e para integridade considerou-se a extensão dos dados corrompidos e a habilidade de recuperá-los.

De uma maneira geral, ao se analisar falhas de acordo com suas conseqüências, dois níveis de limite podem ser definidos de acordo com a relação entre os benefícios proporcionados por um serviço sem falhas e os custos associados às conseqüências de falhas. De acordo com esta relação, podem ser definidas falhas menores, em que as conseqüências possuem custo similar aos benefícios proporcionados por um serviço sem falhas, e falhas catastróficas, em que o custo de conseqüências é bem maior do que o benefício proporcionado pelo funcionamento correto do serviço (LAPRIE, 1992).

Quando a especificação funcional de um sistema inclui um conjunto de funcionalidades, a ocorrência de falhas em um ou mais serviços pode levar 0 sistema a um modo de degradação, que oferece um subconjunto de serviços necessários para o usuário. As especificações de um sistema podem identificar diversos modos de degradação, como serviços com um tempo de resposta mais 
elevados, redução no conjunto de serviços disponibilizados, disponibilização somente de serviços considerados emergenciais, etc.

\subsubsection{Defeitos}

Em (LAPRIE, 1992) e (AVIŽIENIS et al., 2004), também existe a definição de uma taxonomia para a classificação de defeitos: todos os defeitos que podem afetar um sistema durante seu funcionamento podem ser classificados de acordo com oito classes elementares, como mostra a Figura 12.

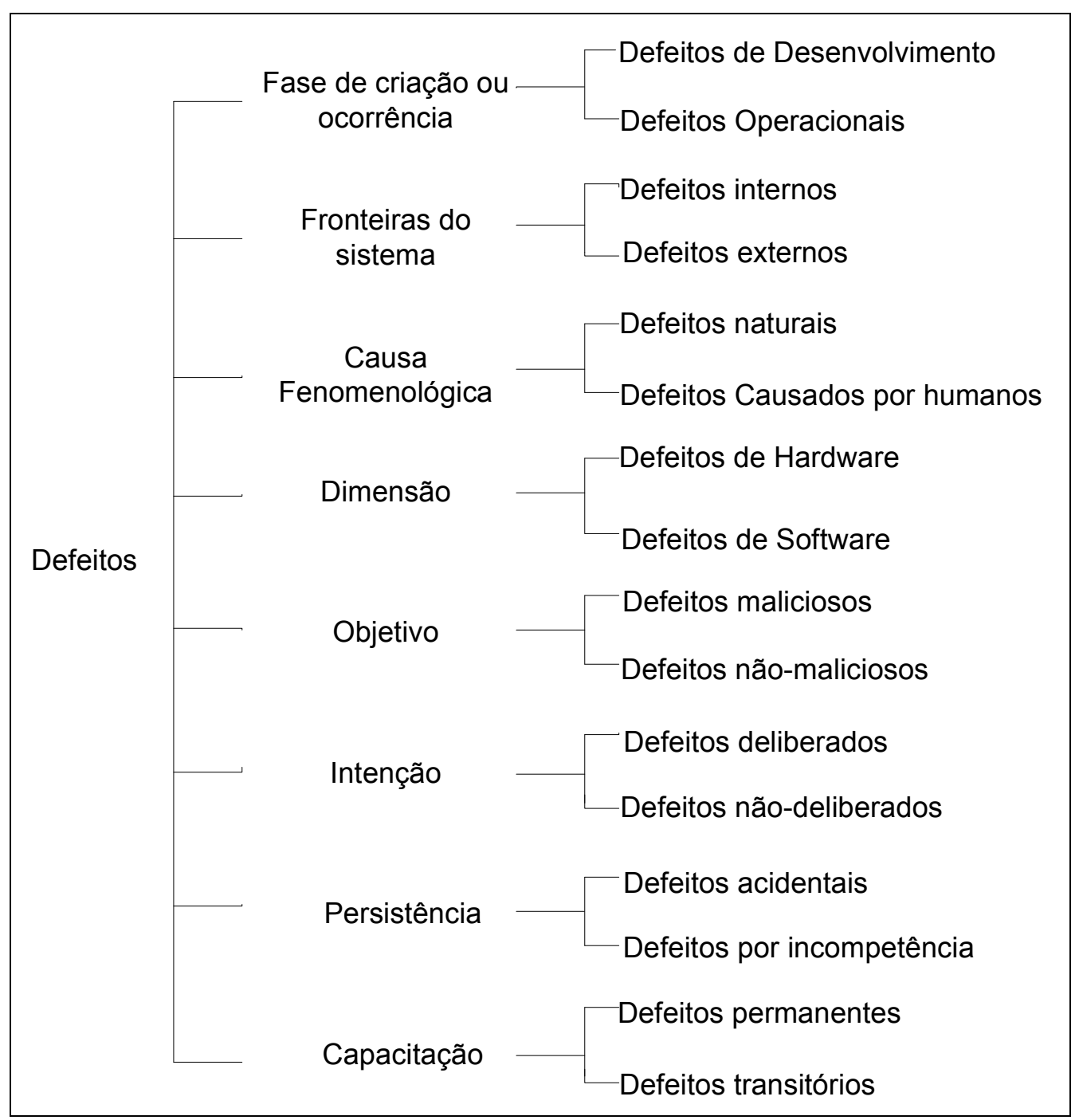

Figura 12 - Classificação de Defeitos

Fonte: (AVIŽIENIS et al., 2004)

Segue uma breve descrição das oito classes de defeitos. 
- Fase de criação e ocorrência. Permite a distinção entre:

- Defeitos de desenvolvimento: ocorrem durante o desenvolvimento do sistema, a manutenção durante a fase de utilização, e durante a geração de procedimentos para operação ou manutenção do sistema;

- Defeitos operacionais: ocorrem durante a execução dos serviços na fase de operação do sistema.

- Fronteiras do sistema. Permite a classificação dos defeitos em:

- Defeitos internos: são aqueles originados internamente no sistema e que, quando invocados, podem produzir um erro;

- Defeitos externos: são aqueles originados externamente ao sistema e que resultam de interação externa ou interferência.

- Causas fenomenológicas. Permitem a distinção entre:

- Defeitos naturais, causados por fenômenos sem a participação humana;

- Defeitos causados por humanos.

- Dimensão. Permitem a distinção entre:

- Defeitos que afetam hardware;

- Defeitos que afetam software.

- Objetivo. Permitem a classificação do defeito em:

- Defeitos maliciosos, introduzidos com objetivos maliciosos para causar danos ao sistema;

○ Defeitos não-maliciosos: introduzidos sem objetivos maliciosos.

- Intenção. Permite a classificação em:

- Defeitos deliberados: resulta de uma decisão intencional de danificar o sistema; 
- Defeitos não-deliberados: resulta de decisões sem intenção de causar defeitos;

- Capacitação. Permite uma distinção entre:

○ Defeitos acidentais: introduzidos inadvertidamente;

- Defeitos por incompetência: causados por falta de capacitação de equipe.

- Persistência. Permite uma distinção entre:

- Defeitos permanentes

- Defeitos transitórios.

Dentre as classes de defeitos, são destacados três grupos principais:

- Defeitos de desenvolvimento: ocorrem na fase de desenvolvimento;

- Defeitos físicos: incluem todas as classes de defeitos que afetam hardware;

- Defeitos de interação: incluem defeitos causados por fatores externos ao sistema.

Dentre as classes de defeitos citadas em (LAPRIE, 1992) e (AVIŽIENIS et al., 2004), destacam-se os defeitos naturais, que correspondem a defeitos físicos causados por fenômenos naturais sem a participação humana. Durante a operação de um componente de hardware, pode ocorrer deterioração física interna, ou externa. Os autores também destacam defeitos causados por humanos, que incluem defeitos por omissão, em que ocorre uma ausência de ações quando estas deveriam ser realizadas. Na categoria de defeitos causados por humanos, estes podem ser classificados como maliciosos e não maliciosos. Dentre as ações não maliciosas, os defeitos podem ser classificados como não deliberados e deliberadas.

Em (LAPRIE, 1992) e (AVIŽIENIS et al., 2004) são citados defeitos de interação, que consistem em defeitos operacionais. Estes defeitos são causados pela interação do sistema com os elementos de contexto de execução. Em (AVIŽIENIS et al., 2004) existe um exemplo desta situação, através de defeitos de configuração inseridos por um operador do sistema. 


\subsubsection{Erros}

Para (AVIŽIENIS et al., 2004) um erro é detectado se sua presença for indicada por uma mensagem ou sinal de erro. Erros que estão presentes, mas não são detectados, são conhecidos como erros latentes. Dado que um sistema consiste em um conjunto de componentes que interagem entre si, o estado total do sistema corresponde ao conjunto de estados dos componentes. Esta definição diz que um defeito originalmente causa um erro em um ou mais componentes, mas a falha de serviço não ocorre caso o estado externo do componente tenha relação direta com o estado externo do sistema. Quando o erro torna-se parte do estado externo do componente, ocorre uma falha de serviço do componente, mas o erro permanece interno ao sistema.

Se o erro pode provocar ou não uma falha de serviço depende basicamente de dois fatores. O primeiro corresponde à estrutura do sistema, especialmente a natureza da redundância existente. $O$ segundo corresponde ao comportamento do sistema, pois a parte que contém o erro pode ou não ser necessária para o serviço, ou então o erro pode ser detectado e eliminado antes de provocar a falha. Uma classificação de erros, segundo (AVIŽIENIS et al., 2004), pode ser descrita de forma semelhante à terminologia utilizada para a descrição de falhas de serviço que estes podem provocar, ou seja, através de erros de conteúdo ou erros de tempo, erros detectados ou erros latentes, erros consistentes ou inconsistentes, erros menores ou catastróficos.

Alguns defeitos podem causar erros em mais de um componente simultaneamente. Estes erros são conhecidos como erros múltiplos relacionados. Erros simples são erros que afetam somente um único componente.

A criação e mecanismos de manifestação de defeitos, erros e falhas podem ser resumidos da seguinte maneira, conforme (LAPRIE, 1992):

1. Um defeito é ativo quando sua ocorrência produz um erro. Um defeito ativo pode ser um defeito interno que estava anteriormente dormente e que foi ativado por um processo computacional, ou um defeito externo. Os defeitos internos geralmente oscilam entre estados dormentes e ativos. Defeitos físicos podem somente afetar diretamente componentes de hardware, 
enquanto defeitos causados por humanos podem afetar qualquer componente.

2. Um erro pode ser latente ou detectado. Um erro é latente quando não é reconhecido como tal. Um erro pode ser detectado através de um mecanismo ou algoritmo de detecção. Um erro pode desaparecer antes de ser detectado, ou propagar-se, sendo transformado em outros erros. A propagação de erros em um dado componente pode ser considerada uma propagação interna. A propagação de erros entre componentes é uma propagação externa, ocorrendo quando um erro se propaga para outro componente através da execução de serviços com erros. Durante a operação de um sistema, a presença de defeitos ativos é determinada através da detecção de erros.

3. Uma falha no serviço ocorre quando um erro é propagado para a interface do serviço e afeta o serviço fornecido. Uma falha de um componente causa um defeito permanente ou transitório no sistema que contém o componente. Nesta situação, os modos de falhas de um componente tornam-se defeitos para os componentes que interagem com o componente que apresenta falhas.

De forma resumida, defeitos ativam erros, que propagam-se em falhas, que causam defeitos, constituindo uma cadeia fundamental de ameaças a dependabilidade (AVIŽIENIS et al., 2004).

\subsection{Meios para se atingir dependabilidade}

Em relação aos meios para se alcançar dependabilidade, (LAPRIE, 1992) define quatro categorias:

- Meios de prevenção de defeitos, que englobam técnicas para prevenir a ocorrência ou introdução de defeitos;

- Meios de tolerância a defeitos, que evitam falhas no serviço mesmo na presença de defeitos; 
- Meios de eliminação de defeitos, responsáveis para redução do número e da severidade dos defeitos;

- Meios de previsão de defeitos, que estimam o número atual, as futuras incidências e as conseqüências de defeitos.

Técnicas de tolerância a defeitos consistem basicamente em técnicas que objetivam evitar falhas, através da detecção de erros e recuperação de sistema (AVIŽIENIS et al., 2004). A recuperação do sistema se baseia em duas atividades principais: processamento de erros e tratamento de defeitos (LAPRIE, 1992). O processamento de erros tem como objetivo a remoção de erros de um estado computacional. Tratamento de falhas tem como objetivo prevenir que defeitos sejam ativados novamente.

O processamento de erros pode se realizar de duas maneiras:

- Recuperação do erro, em que o sistema sai de um estado de erro para um estado sem erros. Esta substituição pode ser realizada de duas formas:

- Recuperação para trás (backward recovery), em que ocorre uma restauração de um estado anterior sem erros, através de pontos de recuperação;

- Recuperação para frente (forward recovery), em que o sistema passa de um estado com erros para um novo estado sem erros, sendo este estado possivelmente um estado que representa um modo de degradação do sistema.

- Compensação do erro, que envolve redundância, permitindo a disponibilização de um serviço sem falhas apesar de um estado interno que apresenta erros.

Para que uma estratégia de recuperação de erros possa ser empregada, existe a necessidade de se realizar uma operação de detecção de erros. A associação, em um componente, de sua capacidade de prover uma funcionalidade com mecanismos de detecção de erros caracteriza um componente capaz de realizar auto-verificação (self-checking). Este tipo de componente pode ser um componente de hardware ou um componente de software (LAPRIE, 1992). 
Estratégias de recuperação de erro para trás e para frente não são exclusivas. Uma primeira tentativa de recuperação para trás pode ser aplicada. Se o erro persistir, uma estratégia de recuperação para frente pode ser utilizada. Na recuperação para frente, é necessário avaliar o dano causado por um erro detectado, ou por erros propagados antes da detecção.

O tempo adicional necessário para o processamento de erros varia de acordo com a forma de processamento de erro adotada. Na recuperação de erro, o tempo adicional necessário é maior na ocorrência de erros, especialmente se for adotada a estratégia de recuperação para trás, pois existe a necessidade de se estabelecer pontos de recuperação. Em caso de compensação do erro, a diferença entre o tempo de processamento na ocorrência de erros e sem ocorrência de erros é menor em relação à diferença verificada na recuperação de erros (LAPRIE, 1992). O tempo de duração de uma estratégia de compensação de erro geralmente é menor se comparada com estratégias de recuperação de erros, devido à redundância estrutural utilizada. Esses aspectos de tempo de processamento devem ser considerados para avaliação de aspectos de desempenho na estratégia de processamento de erros.

Em relação ao tratamento de defeitos, o primeiro passo se realiza através de diagnóstico do defeito, que consiste em determinar a causa dos erros, através de sua localização e natureza. Em seguida, são verificadas as ações que visam a prevenção de uma nova ocorrência do defeito, consistindo em uma operação de inativação ou isolamento de defeitos. Esta operação pode ocorrer através de remoção de componentes identificados como defeituosos. Se o serviço não for mais capaz de disponibilizar o serviço da mesma forma anterior, torna-se necessária uma reconfiguração. Após a etapa de reconfiguração, torna-se necessária uma reinicialização, para atualização de informações relacionadas a configurações decorrentes da etapa de reconfiguração.

A Figura 13 representa uma visão geral de técnicas de tolerância a defeitos, as quais são comentadas aqui. 


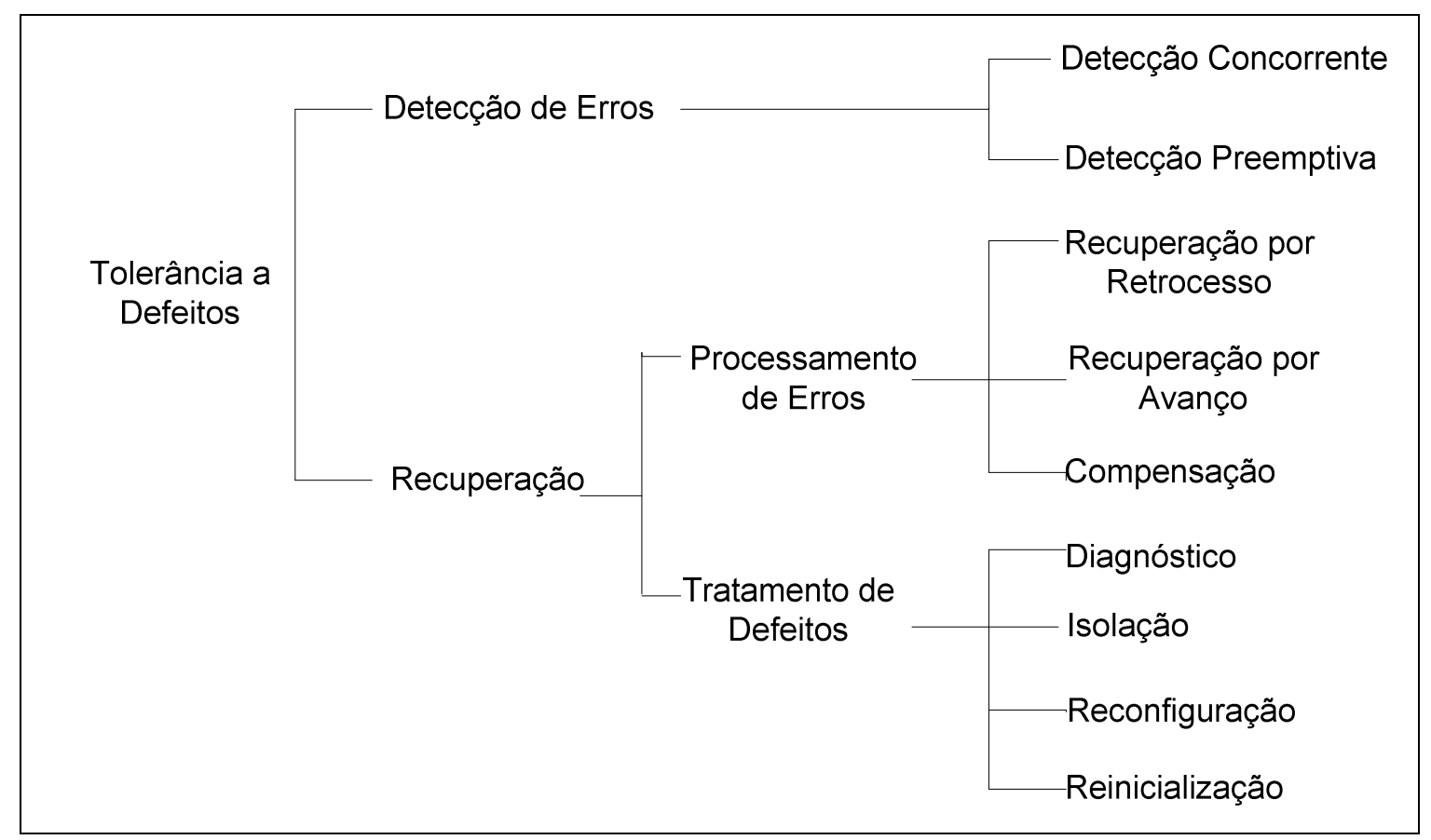

Figura 13 - Técnicas de tolerância a defeitos

Fonte: (AVIŽIENIS et al., 2004)

As técnicas de tolerância a defeitos geralmente são seguidas por manutenções corretivas, tendo como objetivo remover defeitos que são isolados. A Figura 14 representa uma combinação de estratégias para a implantação de tolerância a defeitos:

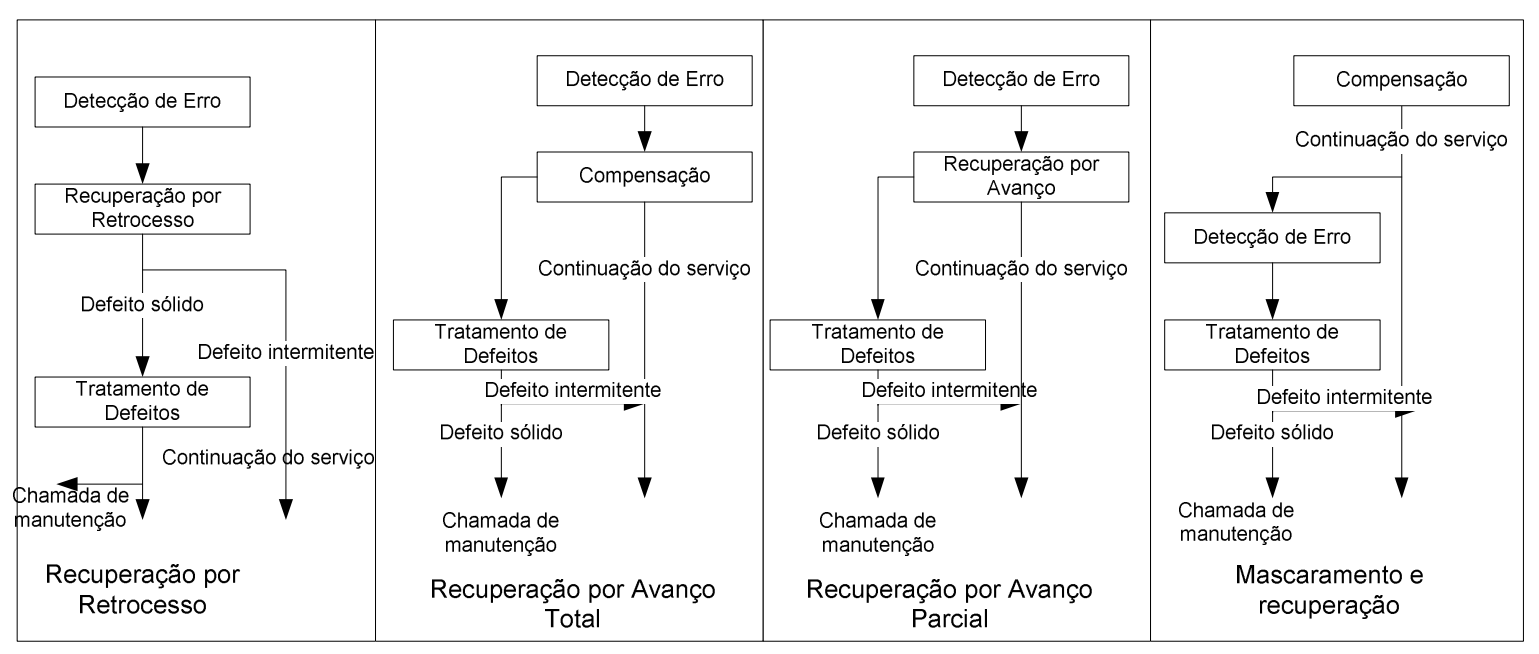

Figura 14 - Integração de meios de tolerância a defeitos

Fonte: Adaptada de (AVIŽIENIS et al., 2004) 
A escolha de estratégias de detecção de erros, processamentos de erros ou tratamento de defeitos e a implementação destas estratégias estão diretamente relacionadas aos defeitos a serem considerados, ou seja, as classes de defeitos que podem ser toleradas dependem dos defeitos que são assumidos no processo de desenvolvimento e independem de redundâncias no que diz respeito ao processo de criação de defeito e ativação.

Nem todas as técnicas de tolerância a defeitos são igualmente efetivas. A medida de efetividade de uma solução de tolerância a defeitos é conhecida como cobertura (coverage). As imperfeições de tolerância a defeitos, isto é, o fator de cobertura de uma estratégia de tolerância a defeitos, constitui uma limitação severa para um incremento de dependabilidade que pode ser atingida. Dentre os possíveis problemas de cobertura destacam-se situações em que os defeitos são considerados para o desenvolvimento de uma estratégia, mas existem dificuldades ao detectar e tratar estes defeitos, e também situações nas quais os defeitos identificados durante a fase de desenvolvimento são diferentes dos defeitos ocorridos na execução do sistema.

Em (LAPRIE, 1992) e (AVIŽIENIS et al., 2004) também são abordadas técnicas de eliminação de defeitos. Uma primeira abordagem consiste na eliminação de defeitos durante 0 processo de desenvolvimento. A eliminação de defeitos nesta fase consiste em três etapas: verificação, diagnóstico e correção. Verificação é o processo de checar se o sistema endereça certas propriedades, conhecidas como condições de verificação. Se estas não estão de acordo, outras duas operações devem ser realizadas: o diagnóstico do defeito que ocasionou a situação e a realização das correções necessárias. Após a correção, deve ocorrer uma verificação conhecida como verificação de regressão para verificar se 0 defeito removido não provocou conseqüências indesejadas. Estas condições se apresentam de duas maneiras: condições gerais, aplicadas a uma classe específica de sistemas, sendo relativamente independentes de especficação (por exemplo, ausência de deadlock e conformidade com as regras relacionadas), e condições específicas para o sistema considerado, diretamente deduzidas da especificação.

As técnicas de verificação podem ser classificadas de acordo com a necessidade de verificação do sistema. Verificar um sistema sem executá-lo consiste em verificação estática. Esta verificação pode ser conduzida por análise estática do sistema, com 
ferramentas de análise, como checagens de compiladores, análise de fluxo de dados, análise de complexidade, ou modelos de comportamento do sistema, tais como redes de Petri, autômatos de estado finito, entre outras técnicas de análise comportamental.

Verificar um sistema através de sua execução constitui uma verificação dinâmica, através de operações de teste de verificação. O teste de um sistema de forma exaustiva em relação a todas as possíveis entradas geralmente possui um custo elevado. Os métodos para a determinação dos padrões de teste podem ser classificados de acordo com dois pontos de vista: critério para seleção das entradas de teste, baseados em seu propósito no modelo do sistema e na existência de um modelo de defeitos, e geração de entradas de teste, que podem ser determinísticas ou geradas estatisticamente.

Outra categoria corresponde à remoção de defeitos durante a fase de operação do sistema, em que a remoção se dá através de manutenção corretiva, com o objetivo de remover defeitos que provocam erros, e manutenção preventiva, que objetiva remover defeitos antes de produzir erros.

Em (LAPRIE, 1992) e (AVIŽIENIS et al., 2004) também é abordado o meio de previsão de falhas, que corresponde a uma avaliação do comportamento do sistema em relação a ocorrência ou ativação de defeitos. Esta avaliação possui um aspecto qualitativo, que objetiva identificar, classificar, e categorizar os modos de falhas do sistema. A avaliação também possui um aspecto quantitativo, ou probabilístico, que objetiva avaliar o sistema de acordo com as probabilidades nos quais os atributos de dependabilidade atingem níveis satisfatórios.

Conforme visto anteriormente, de acordo com (LAPRIE, 1992), uma falha corresponde à transição de um serviço correto para um serviço incorreto. A quantificação dessas alternâncias entre o serviço correto e incorreto permite a obtenção de medidas de confiabilidade, que estão relacionadas ao fornecimento contínuo do serviço correto (tempo para ocorrência de falhas), e de disponibilidade, que estão relacionadas à alternância entre o serviço correto e incorreto. Outra medida está relacionada à manutenção, que pode ser definida como a medida do tempo para recuperação em virtude de ocorrência de um defeito.

Os dois principais enfoques para a previsão de falhas são: modelagem e testes (de avaliação). Eles são complementares, pois a modelagem necessita de dados que 
são obtidos através da realização de testes. A modelagem pode ser conduzida com respeito a defeitos físicos, defeitos de desenvolvimento, ou combinação de ambos.

Durante uma atividade de modelagem, as abordagens podem diferir significativamente de acordo com o sistema a ser modelado. O sistema pode ser considerado como de confiabilidade estável, ou seja, cuja capacidade de prover serviços corretos é preservada, ou como de confiabilidade crescente (ou decrescente, desde que novos defeitos sejam inseridos durante ações corretivas), no qual a capacidade para disponibilizar serviços corretos pode ser melhorada através de reduções sucessivas de tempos de falha.

A modelagem é composta basicamente de duas fases: a construção de um modelo do sistema, através de processos estocásticos elementares que modelam 0 comportamento do sistema e suas interações, e a segunda fase que consiste no processamento do modelo para a obtenção de expressões e valores relacionados a medidas de dependabilidade do sistema.

\subsection{Cenários de disponibilidade}

No capítulo 2, foi apresentada a definição de cenários de atributos de qualidade para análise de requisitos não-funcionais no processo de avaliação de arquiteturas de software. A utilização de cenários de disponibilidade em uma avaliação de arquitetura de software possibilita a caracterização de requisitos de disponibilidade do sistema de software e a avaliação do impacto de decisões arquitetônicas em relação à disponibilidade do sistema de software. Esta seção apresenta a caracterização de cenários de disponibilidade com a utilização dos conceitos de dependabilidade presentes no capítulo 3.

(BASS; CLEMENTS; KAZMAN, 2003) apresenta uma tabela com características relacionadas ao requisito não-funcional disponibilidade que podem ser mapeadas em elementos que compõem cenários de atributo de qualidade. Conforme descrito na seção 2.2, cenários de atributos de qualidade são compostos de seis elementos: fonte do estímulo, estímulo, ambiente, artefato, resposta e medida de resposta. As características que podem ser utilizadas para a geração de cenários de disponibilidade podem ser visualizadas na Tabela 4. 
Tabela 4 - Tabela para geração de cenários gerais de disponibilidade

\begin{tabular}{|c|c|}
\hline Parte do cenário & Valores possíveis \\
\hline Fonte do estímulo & Interna ou externa ao sistema. \\
\hline Estímulo & Defeito: omissão, crash, tempo, resposta. \\
\hline Artefato & $\begin{array}{l}\text { Processadores, canais de comunicação, repositório } \\
\text { armazenamento de dados, processos. }\end{array}$ \\
\hline Ambiente & $\begin{array}{l}\text { Modo normal de operação ou modo degradado (ou seja, com um } \\
\text { grau reduzido de funcionalidades). }\end{array}$ \\
\hline Resposta & $\begin{array}{l}\text { O sistema deve ser capaz de detectar o estímulo e realizar uma ou } \\
\text { mais operações, como, por exemplo: } \\
\text { - Registrar a ocorrência do estímulo; } \\
\text { - Notificar as partes envolvidas, incluindo possíveis usuários } \\
\text { ou outros sistemas; } \\
\text { - Desabilitar possíveis fontes de defeitos; } \\
\text { - Tornar-se indisponível em um intervalo de tempo pré- } \\
\text { determinado, o qual depende da criticidade do sistema; } \\
\text { - Continuar operando em modo normal ou degradado. }\end{array}$ \\
\hline $\begin{array}{l}\text { Medida da } \\
\text { Resposta }\end{array}$ & $\begin{array}{l}\text { - Porcentagem de tempo que o sistema deve estar disponível; } \\
\text { - Tempo de disponibilidade; } \\
\text { - Intervalo de tempo em que o sistema pode estar em modo } \\
\text { degradado; }\end{array}$ \\
\hline
\end{tabular}

Fonte: (BASS; CLEMENTS; KAZMAN, 2003)

De acordo com (BASS; CLEMENTS; KAZMAN, 2003), os itens presentes na Tabela 4 são utilizados para a construção de cenários gerais de disponibilidade, que serão a base para a geração de cenários concretos desse requisito. Segue uma breve descrição dos elementos presentes na Tabela 4:

- Fonte do estímulo: A fonte do estímulo pode ser interna ou externa ao sistema de software analisado. A fonte do estímulo pode ser um fator relevante para se determinar a resposta desejada do cenário.

- Estímulo: Em (BASS; CLEMENTS; KAZMAN, 2003) os autores citam que o estímulo considerado para a geração de cenários de disponibilidade 
corresponde a defeito (fault). Segundo (BASS; CLEMENTS; KAZMAN, 2003), são listados como possíveis estímulos as seguintes classes de defeitos:

- Omissão: o componente não responde a uma determinada entrada;

- Crash: o componente repetidamente sofre defeitos de omissão;

- Temporal: o componente responde, mas a resposta é antecipada ou atrasada;

- Resposta: o componente responde com um valor incorreto.

Nota-se que a classificação utilizada para defeitos na definição de estímulos de cenários de disponibilidade em (BASS; CLEMENTS; KAZMAN, 2003) difere da taxonomia apresentada em (LAPRIE, 1992) e (AVIŽIENIS et al., 2004). A técnica proposta neste trabalho realiza a geração de estímulos para cenários de disponibilidade com base nos conceitos apresentados em (LAPRIE, 1992) e (AVIŽIENIS et al., 2004).

- Artefato: Especifica o recurso sob o qual o estímulo pode ocorrer. Conforme descrição presente na Tabela 4, o artefato para um cenário de disponibilidade pode ser um processador, um canal de comunicação, um processo, ou local de armazenamento.

- Ambiente: corresponde ao estado do sistema de software quando o estímulo ocorre. Segundo (BASS; CLEMENTS; KAZMAN, 2003), o ambiente pode influenciar a resposta do cenário. Como exemplo desta influência, ele cita uma situação na qual a detecção de um defeito ocorre pela primeira vez, em um ambiente considerado normal. Nesta situação, uma possível resposta seria uma degradação de funcionalidades ou tempo de resposta. A detecção do mesmo defeito em um ambiente degradado poderia apresentar uma resposta distinta, como a reinicialização do sistema, por exemplo.

- Resposta: segundo (BASS; CLEMENTS; KAZMAN, 2003), diversas respostas podem ser aplicadas a um estímulo. A Tabela 4 apresenta algumas respostas que caracterizam um cenário de disponibilidade. 
- Medida da resposta: segundo (BASS; CLEMENTS; KAZMAN, 2003), medidas que se aplicam aos cenários de disponibilidade são: disponibilidade assintótica, tempo para reparo, intervalos de tempo em que o sistema deve estar disponível, etc.

Em (OZKAYA et al., 2008) é citada uma análise das árvores de utilidades de 24 avaliações ATAM realizadas pelo SEI de 1999 a 2007. Estas avaliações foram conduzidas por organizações comerciais e empresariais e englobam sistemas de aviação, sistemas de combate, entre outros sistemas. Desta avaliação observou-se um total de 1072 cenários, dentre os quais cenários de disponibilidade correspondem a $6,8 \%$ dos cenários identificados (o requisito não-funcional manutenção apresentou uma maior distribuição, com $14,1 \%$, enquanto que desempenho apresenta uma distribuição de 13,6\%, e usabilidade apresenta uma distribuição de $11,4 \%)$. Os cenários relacionados à recuperação e contenção de falhas (distribuição de 1,9\%), degradação gradual (distribuição de 1,6 \%) e tolerância a defeitos (distribuição de 1,3\%) são os cenários que apresentam uma distribuição maior entre cenários de disponibilidade. Estes números indicam que embora requisitos de manutenção e desempenho sejam os requisitos nos quais stakeholders geram um número maior de cenários, o número de cenários de requisitos nãofuncionais relacionados ao requisito não-funcional disponibilidade pode ser considerado expressivo, indicando o grau de importância do requisito disponibilidade para stakeholders envolvidos em avaliação de arquiteturas de software.

\subsection{Táticas arquitetônicas relacionadas à disponibilidade}

No capítulo 2 foi apresentado o conceito de táticas arquitetônicas, descrito em (BASS; CLEMENTS; KAZMAN, 2003). Estas táticas são aplicadas com o intuito de se obter uma resposta desejada em relação a um determinado estímulo em um determinado cenário. Táticas arquitetônicas relacionadas ao requisito não-funcional disponibilidade baseiam-se em conceitos relacionados a meios de prevenção e tolerância definidos em (LAPRIE, 1992). Esta seção descreve táticas arquitetônicas apresentadas em (BASS; CLEMENTS; KAZMAN, 2003),que visam garantir que para um cenário de disponibilidade, a ocorrência de um estímulo de disponibilidade 
(defeito) produza como resposta o mascaramento ou o reparo deste defeito. Em (BASS; CLEMENTS; KAZMAN, 2003) as táticas arquitetônicas relacionadas à disponibilidade podem ser classificadas em quatro categorias:

- Detecção de defeito;

- Recuperação de defeito;

- Re-introdução;

- Prevenção

A Figura 15 adaptada de (BASS; CLEMENTS; KAZMAN, 2003), exibe uma visão geral das táticas para controle de disponibilidade.

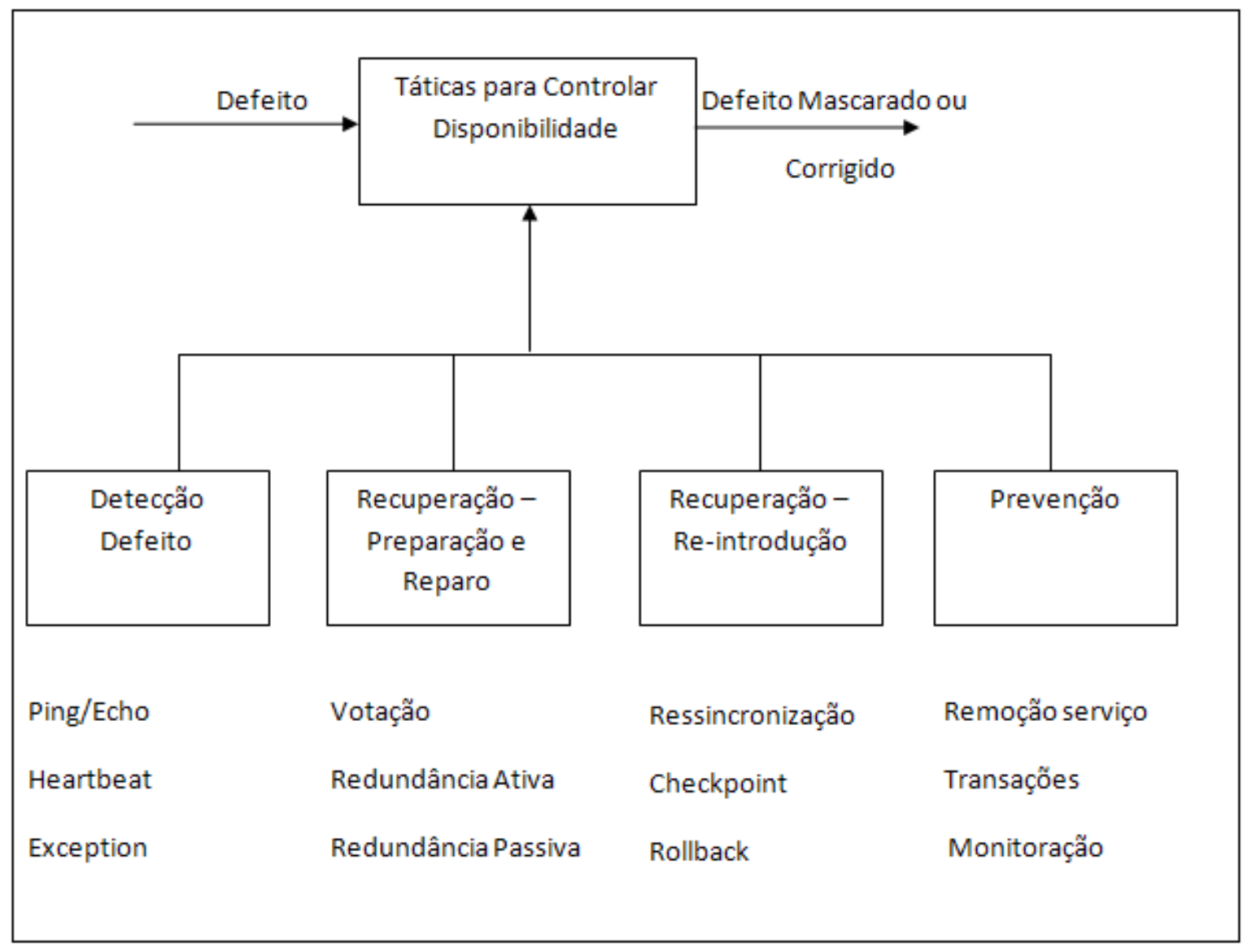

Figura 15 - Táticas para alcançar disponibilidade

Fonte: Adaptada de (BASS; CLEMENTS; KAZMAN, 2003)

Táticas arquitetônicas de detecção de defeitos utilizam mecanismos de monitoração. Com base nas definições de meios de tolerância a defeitos presente em (LAPRIE, 1992), táticas arquitetônicas de monitoração correspondem a operações de detecção de erros ou diagnóstico de defeitos. Em (BASS; CLEMENTS; KAZMAN, 2003) os autores destacam três táticas arquitetônicas para monitoração de defeitos: 
- Ping/echo - Tática utilizada para monitoração, na qual um componente envia um ping, e recebe um echo, em intervalos de tempo pré-definidos. Esta tática pode ser utilizada para detecção de defeitos de comunicação entre componentes.

- Heartbeat - Tática na qual um componente envia periodicamente uma mensagem para um módulo gerenciador de mensagens heartbeat. Caso o módulo gerenciador não receba mais mensagens, o módulo gerenciador assume que ocorreram falhas na comunicação com o componente.

- Exceções - um método utilizado para o reconhecimento de defeitos. O tratamento de exceções corresponde a uma forma efetiva de incorporar tolerância a defeitos em sistemas de software (GUERRA; RUBIRA; DE LEMOS, 2003). A abordagem de tratamento de exceções possibilita aos desenvolvedores a estruturação de componentes adicionais que lidam com condições excepcionais. Quando uma condição de exceção ocorre, o fluxo normal de operação é interrompido, sendo o controle transferido para um módulo responsável por lidar com condições de exceção.

As táticas de re-introdução se referem à re-introdução de um componente em um sistema, após o reparo deste componente. Nesta categoria se destacam as seguintes táticas:

- Ressincronização de estado - utilizada no caso de redundâncias passiva citado anteriormente, em que os estados dos módulos sobressalentes ou que apresentaram reparos devem estar sincronizados com os estados dos demais módulos.

- Checkpoint/rollback - checkpoint (ponto de verificação) corresponde a um estado do sistema criado periodicamente, ou criado em resposta a um determinado evento. Este estado é armazenado, e quando ocorre uma situação de erro, o sistema realiza uma operação de rollback, responsável por reconfigurar o sistema para que este retorne ao estado definido como checkpoint. Esta tática arquitetônica baseia-se na recuperação para trás descrita como meio de tolerância a defeitos (LAPRIE, 1992).

A categoria de táticas de prevenção consiste em táticas arquitetônicas que permitem a prevenção em relação à ocorrência de defeitos. Táticas de prevenção típicas: 
- Remoção de serviço - esta tática retira temporariamente serviços do sistema com o intuito de prevenir a ocorrência de defeitos.

- Transações - uma transação é um conjunto de vários passos seqüenciais que devem ser desfeitos de uma única vez. Transações podem ser utilizadas para prevenir possíveis defeitos relacionados a colisões entre processos concorrentes acessando as mesmas informações;

- Monitoração de processos - uma vez que um defeito em um processo é detectado, outro processo de monitoração pode finalizá-lo e criá-lo novamente.

Existem trabalhos que apresentam soluções de arquitetura baseadas em táticas apresentadas em (BASS; CLEMENTS; KAZMAN, 2003) para a construção de arquiteturas de software. (GUERRA; RUBIRA; DE LEMOS, 2003) definem uma abordagem arquitetônica de tolerância a defeitos baseada na tática de tratamento de exceções. Em (LOOKER; MUNRO; XU, 2005) os autores definem um mecanismo de tolerância a defeitos conhecido como WS-FTM (Web Service-Fault Tolerance Mechanism - Mecanismo de Tolerância a Defeitos em Web Services) com a utilização de tática de votação. 


\section{Proposta de uma técnica para a geração de cenários de disponibilidade de sistemas de Software para a Web no mÉtodo ATAM}

Neste capítulo ocorre a proposição de uma técnica que visa auxiliar a geração de cenários de disponibilidade em sistemas de software que fornecem serviços através da Internet no método ATAM. Esta técnica tem como objetivo prover um catálogo de elementos que permita caracterizar cenários de disponibilidade.

\subsection{Introdução}

No capítulo 2, foi destacada a importância de cenários de atributos de qualidade descritos em (BASS; CLEMENTS; KAZMAN, 2003) em métodos de construção e avaliação de arquitetura de software. A utilização de cenários propicia uma análise de requisitos não-funcionais por meio de requisitos concretos relacionados ao software a ser analisado, permitindo a análise de atributos de qualidade e decisões de arquitetura.

Em (BASS; CLEMENTS; KAZMAN, 2003) são tratados elementos que possibilitam a geração de cenários gerais de disponibilidade. Cenários gerais de disponibilidade servem como base para a geração de cenários concretos de disponibilidade. A identificação de cenários concretos de disponibilidade permite que sejam detectados os principais aspectos relacionados à disponibilidade do sistema de software, de acordo com a visão dos diferentes stakeholders relacionados ao sistema de software sob análise.

Neste capítulo será proposta uma técnica de análise qualitativa para auxiliar, no método de avaliação de arquitetura ATAM, a geração de cenários de disponibilidade em sistemas de software que disponibilizam serviços na Internet. A técnica proposta recebe o nome de ADSSW (Avaliação de Disponibilidade de Sistemas de Software na Web). A Figura 16 ilustra os conceitos que contribuem para a técnica ADSSW. 


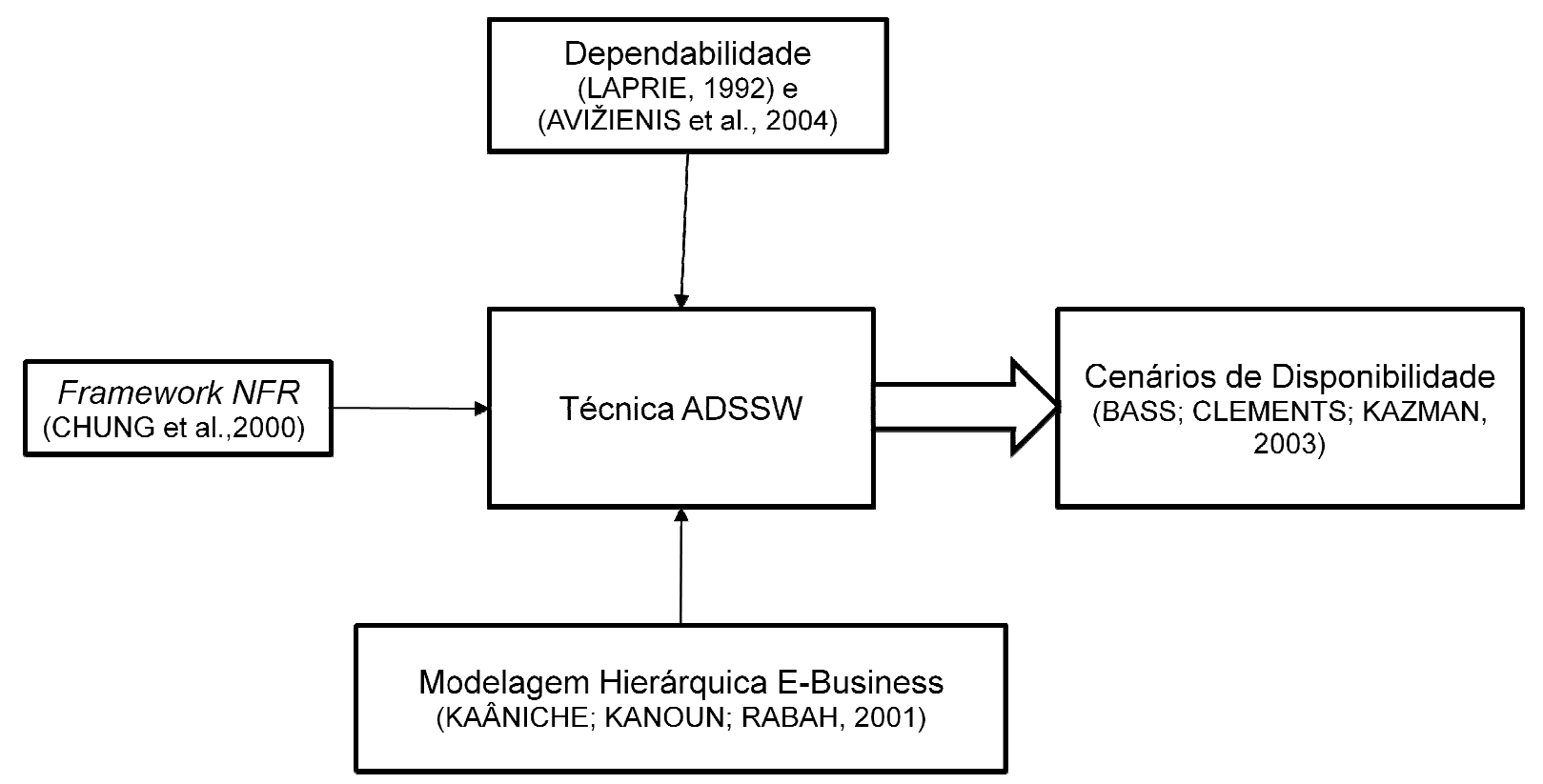

Figura 16 - Conceitos que contribuem para a técnica ADSSW

A técnica ADSSW faz uso de elementos presentes no framework NFR apresentado no capítulo 2 e descrito em (CHUNG et al., 2000) para a estruturação e organização de conceitos de dependabilidade descritos em (LAPRIE, 1992) e (AVIŽIENIS et al., 2004). A modelagem hierárquica de disponibilidade em sistemas e-business proposta em (KAÂNICHE; KANOUN; RABAH, 2001) contribui para a definição de elementos da técnica. A técnica ADSSW tem como objetivo a identificação e caracterização de estímulos para a geração de cenários concretos de disponibilidade, auxiliando a identificar as respostas desejadas aos estímulos considerados, caracterizando desta forma um cenário concreto a ser considerado na avaliação de uma arquitetura de software.

Antes da descrição da técnica proposta, visando uma melhor contextualização dos elementos nela presentes, neste capítulo é abordada a caracterização de sistemas de software que disponibilizam serviços através da Internet, com o objetivo de se verificar as características destes sistemas. Por fim, descreve-se a técnica ADSSW e como esta auxilia na geração de cenários concretos de disponibilidade. 


\subsection{Caracterização de sistemas distribuídos na Web}

Aplicações que disponibilizam serviços através da Web são implementadas em infraestruturas largamente distribuídas, com múltiplas camadas interconectadas de software e hardware, envolvendo vários tipos de servidores, como servidores Web, servidores de aplicação e servidores de banco de dados.

Sistemas distribuídos na Web que provêem serviços de e-business, tais como aplicações de comércio eletrônico e aplicações bancárias, normalmente apresentam as seguintes necessidades em relação a requisitos não-funcionais (OFFUTT, 2002):

- Confiabilidade: como serviços na Web geralmente lidam com informações pessoais de clientes e valores monetários, a confiabilidade destes serviços é essencial para a empresa que disponibiliza estes serviços.

- Desempenho: uma aplicação deve atender um número variável de requisições, com um tempo de resposta na ordem de segundos. Um tempo de resposta elevado pode influenciar na percepção de um usuário ao acessar um serviço, podendo influenciar na escolha de utilizações futuras deste serviço.

- Disponibilidade: Aplicações que provêem serviços na Web devem possuir apenas alguns minutos por ano de indisponibilidade (no setor bancário, por exemplo, o nível de disponibilidade considerado ideal é de 99,999\% (ALKHATEEB, F.; AL-IRHAYIM; AL-KHATEEB, A., 2003)). (OFFUTT, 2002) ressalta que além de medidas relacionadas à ocorrência de falhas e reparos na infra-estrutura utilizada para disponibilização de serviços na Web, a disponibilidade de uma aplicação deve também considerar aspectos de portabilidade no cliente, ou seja, a camada de apresentação do aplicativo, executada no navegador e no sistema operacional do cliente, deve ser implementada de forma que atenda o maior número de sistemas operacionais e navegadores possíveis, evitando assim, se possível, a utilização de recursos específicos para um determinado navegador. Neste trabalho este aspecto não é considerado, restringindo-se a análise da disponibilidade somente a ameaças presentes no fornecedor do serviço, e não no cliente. 
- Segurança (security): aspectos de confidencialidade, integridade e disponibilidade devem ser considerados na construção de sistemas distribuídos na Web. Mecanismos de transporte confiável, como o SSL, são aplicados visando garantir confidencialidade no transporte de informações em aplicações Web.

- Usabilidade: clientes esperam utilizar serviços para a Web sem a necessidade de treinamento, e as funcionalidades disponíveis devem atender às expectativas dos usuários, oferecendo somente as informações necessárias, provendo controles de navegação com clareza.

Aqui serão considerados sistemas de software na Web que apresentem divisão em camadas e, em particular, que tenham um tipo de arquitetura como a ilustrada no diagrama UML representado na Figura 17. Esta arquitetura apresenta uma divisão em camadas, com interfaces e responsabilidades definidas em cada camada, e fluxo de dados ocorrendo entre elas. A primeira camada corresponde à lógica de apresentação e está diretamente relacionada à interação entre componentes responsáveis pela geração da interface do sistema para o usuário, envolvendo aspectos de visualização de páginas e navegação através de um navegador Web. A segunda camada está diretamente relacionada ao processamento de regras de negócio inerentes ao domínio da aplicação. Por fim, a camada de integração está relacionada à comunicação de dados, permitindo a integração com outros sistemas ou bancos de dados.

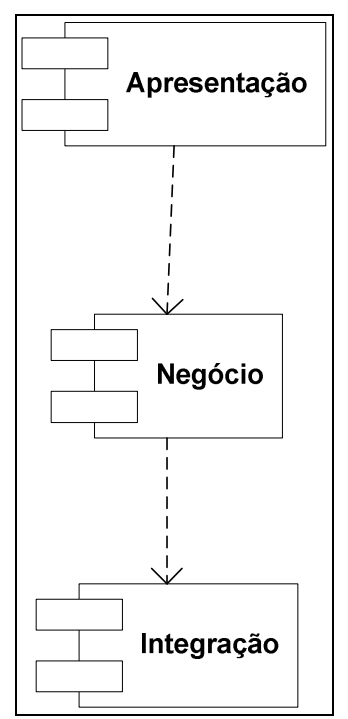

Figura 17 - Divisão em Camadas 
Uma visão modular desta arquitetura pode ser representada a partir do diagrama UML presente na Figura 18.

$\mathrm{Na}$ interação com o cliente, o processamento ocorre através de navegadores Web, envolvendo a utilização de tecnologias como HTML, javascript, etc, para a interação do usuário com a aplicação. Um elemento presente na Figura 18 que tem como objetivo aumentar os níveis de desempenho e disponibilidade em serviços Web trata-se do balanceador de carga. Este elemento tem como objetivo distribuir um volume de requisições entre um conjunto de servidores Web, para obter melhores níveis de desempenho e de disponibilidade, pois se um servidor Web for detectado como indisponível, o balanceador de carga direciona a requisição para outro servidor Web disponível. Os servidores Web correspondem aos elementos do sistema capazes de processar requisições HTTP, enquanto os servidores de aplicações são responsáveis pelo processamento de regras de negócio da aplicação. Por fim, na camada de integração são utilizados também bancos de dados, com o objetivo de gerenciar informações relevantes ao sistema, provendo métodos de consulta e atualização de dados, e acessos a serviços externos ao sistema de software.

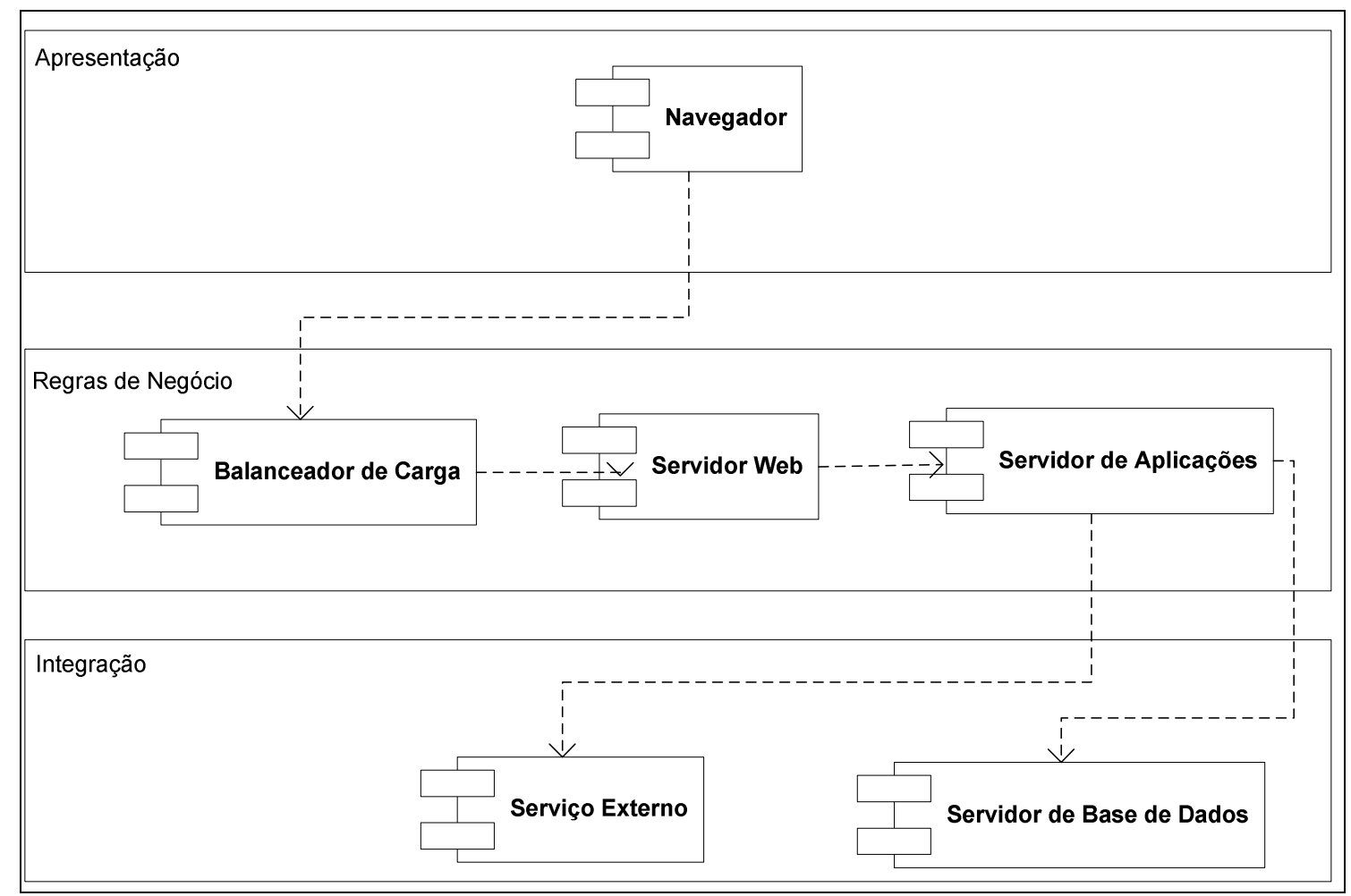

Figura 18 - Elementos de uma arquitetura Web 
No modelo de três camadas para a Web, a comunicação entre as camadas pode ser modelada através do conceito de objetos distribuídos. Cada objeto possui uma interface bem definida, e provê conceitos de encapsulamento e abstração. Segundo (PEACOCK, 2000), para a comunicação entre as camadas distintas, é utilizado o conceito de middleware, consistindo de um software reutilizável que reside entre as aplicações e a infra-estrutura computacional relacionada ao sistema operacional, arquitetura de rede e o hardware utilizados. Um modelo comumente utilizado em aplicações Web é o modelo de middleware baseado no modelo orientado a objetos. O middleware oferece mecanismos de conexão entre componentes, através da ativação de métodos ou troca de mensagens. Como exemplos de implementações de middleware orientados a objetos, (PEACOCK, 2000) cita CORBA, WebServices, e ODBC/JDBC, entre outros.

Em relação aos módulos exibidos na Figura 18, alguns componentes serão decompostos com para propiciar uma análise mais completa. O primeiro item a ser decomposto é o servidor de aplicação. A Figura 19 representa os módulos que compõem o servidor de aplicação.

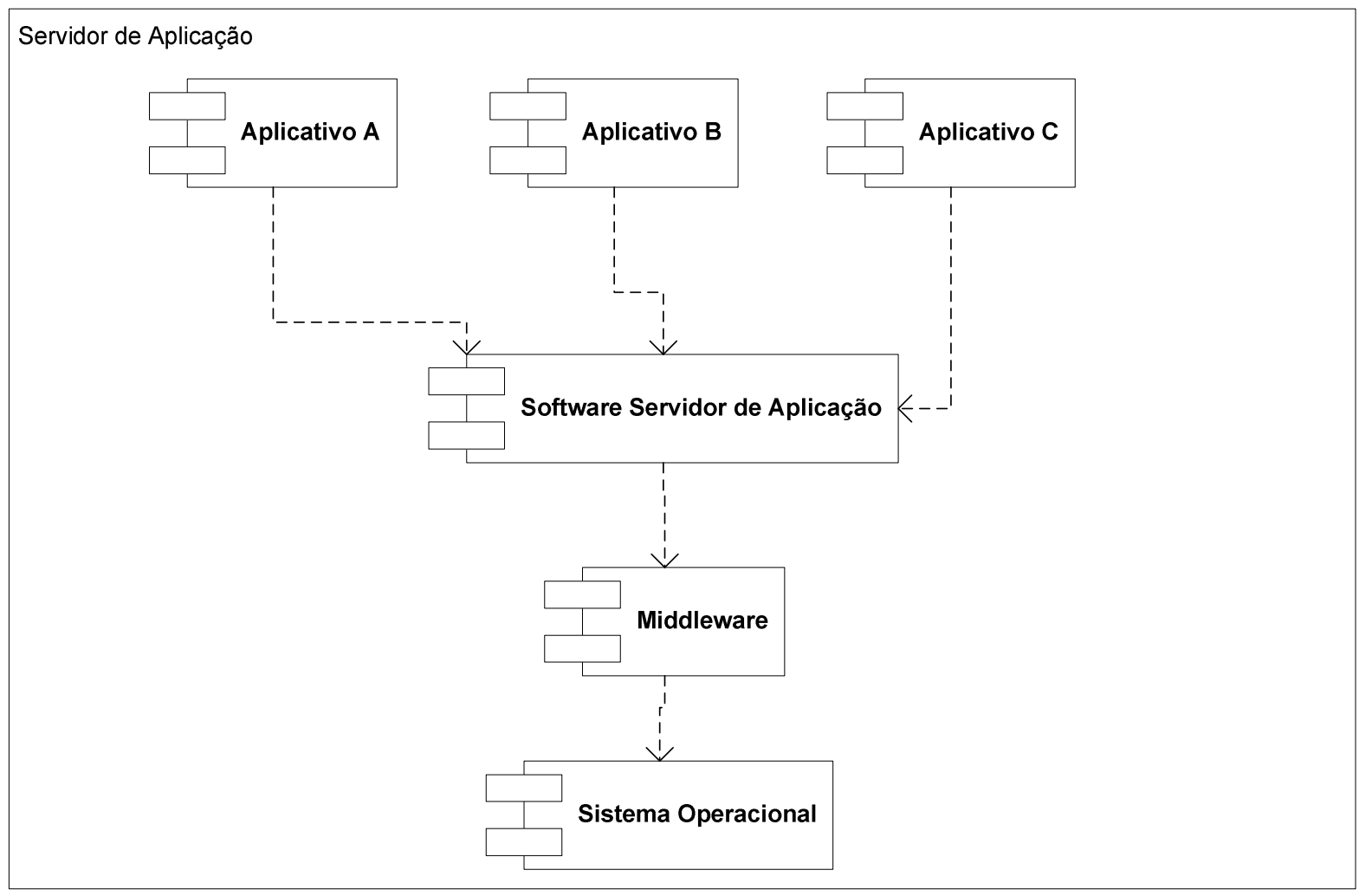

Figura 19 - Módulos do Servidor de Aplicação 
Os itens referenciados como aplicativo A, aplicativo B e aplicativo C na Figura 19 exemplificam componentes relacionados diretamente à aplicação, desenvolvidos para que o sistema possa prover uma determinada funcionalidade. Dentre os exemplos destes componentes, podem ser citados páginas JSP (Java Server Pages) e servlets em aplicações J2EE, páginas ASP em implementações para servidores Windows, etc. Em relação ao software do servidor de aplicação, este corresponde ao componente que cumpre o papel de servidor de aplicação, podendo ser um componente comercializado ou open-source (como exemplo deste software servidor de aplicação open-source pode-se citar o JBoss). O middleware, como dito anteriormente, corresponde a um elemento que provê intercomunicação com a camada de integração. Por fim, considera-se na análise o sistema operacional sob o qual estes componentes estão instalados.

O servidor de banco de dados também pode ser decomposto, conforme verificado na Figura 20. Na Figura 20, os componentes Procedimento Armazenado $\mathrm{A}$ e Procedimento Armazenado $B$ exemplificam procedimentos armazenados (stored procedures), consistindo de um conjunto de instruções de consulta e atualização armazenados no servidor de banco de dados e que estão associadas a uma regra de negócio específica da aplicação. O componente Sistema Gerenciador de Banco de Dados (SGBD) corresponde a um conjunto de programas desenvolvidos para acessar as informações contidas em uma base de dados. Existem sistemas gerenciadores de banco de dados comercializados e open source (como exemplo de SGBG open source, pode se citar o MySQL). No servidor de banco de dados também será considerado o sistema operacional, cabendo ressaltar que ele não necessariamente corresponde ao sistema operacional utilizado no servidor de aplicação, pois tratam-se de sistemas distintos que comunicam-se entre si. 
Servidor de Banco de Dados

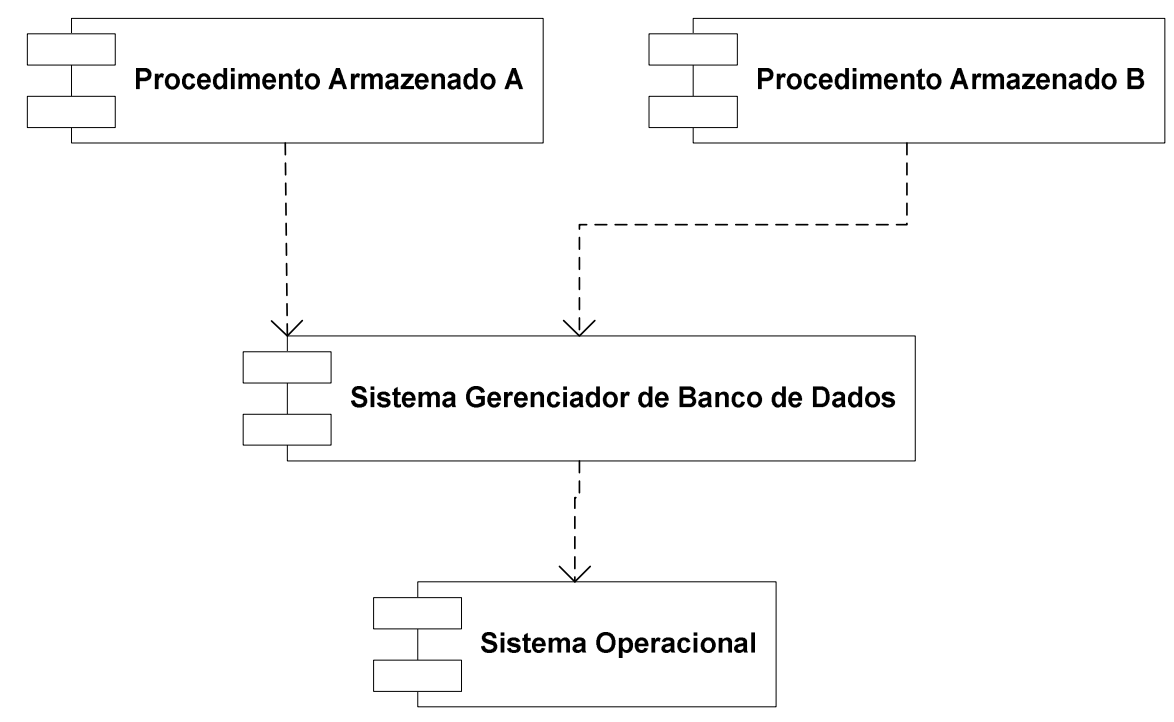

Figura 20 - Elementos que compõem o servidor de banco de dados

Existem alguns trabalhos que abordam aspectos de disponibilidade em aplicações distribuídas que fornecem serviços na Web. Em (OPPENHEIMER; PATTERSON, 2002), foi realizada uma análise de arquitetura e causas de falhas de três aplicações de larga escala na Internet. No artigo, foi destacada a importância de monitoração de serviços, diagnóstico de problemas e reparos para manter uma disponibilidade dos serviços na Web. Para que estas atividades possam ser realizadas, existe a necessidade de se identificar as possíveis ameaças que podem comprometer a disponibilidade de serviços na Web. Em (BREWER, 2001) e (GORBENKO et al., 2006) foram realizadas análises a respeito destas possíveis ameaças. A utilização de cenários de disponibilidade na avaliação arquitetônica possibilita a identificação de ameaças à disponibilidade de um sistema de software, representados por meio de estímulos, e possibilita também a definição de respostas que podem estar relacionadas à monitoração de serviços, diagnósticos de problemas e reparos.

Em (KAÂNICHE; KANOUN; RABAH, 2001) foi definido um modelo hierárquico para a avaliação de disponibilidade em aplicações de negócio disponibilizadas na Web (ebusiness). Este modelo caracteriza a aplicação de forma hierárquica, por meio da identificação das principais funções providas para o usuário e os principais recursos que contribuem para que seja possível a disponibilização destas funções. Com base nestes aspectos, existe a possibilidade de se modelar o impacto de falhas e reparos 
de componentes na qualidade de serviço disponibilizada aos usuários. Alguns aspectos relacionados ao artigo de (KAÂNICHE; KANOUN; RABAH, 2001) são abordados na técnica ADSSW.

\subsection{Descrição de elementos da técnica ADSSW}

Neste trabalho é proposta a técnica ADSSW para análise qualitativa de disponibilidade em sistemas de software que disponibilizam serviços na Internet. Esta técnica tem como objetivo a identificação e caracterização de possíveis falhas no sistema, possibilitando a obtenção de estímulos para a geração de cenários de disponibilidade. A base conceitual para a construção da técnica consiste na aplicação de elementos presentes na notação utilizada pelo framework NFR (CHUNG et al., 2000) a conceitos relacionados à dependabilidade definidos em (LAPRIE, 1992) e (AVIŽIENIS et al., 2004), ambos apresentados nos capítulos 2 e 3. Elementos do framework NFR foram adotados na representação da técnica porque possibilitam uma visão sistemática e global de requisitos não-funcionais, oferecendo uma abordagem sistemática e racional para lidar com atributos de qualidade. Por meio da utilização de elementos do framework, é possível analisar aspectos de disponibilidade, refiná-los, e correlacioná-los com características relacionadas a outros requisitos não-funcionais.

O framework NFR, conforme visto no capítulo 2, apresenta o conceito de softgoal, isto é, um objetivo que não possui definições e/ou critérios claros para garantir se estão satisfeitos ou não. Um tipo de softgoal que será utilizado na aplicação do método corresponde ao softgoal de requisito não-funcional. Este softgoal será utilizado no método para representar requisitos não-funcionais considerados relevantes para o sistema de software a ser analisado. A representação de softgoals apresenta a mesma notação utilizada no framework NFR, com a descrição sintática Tipo[Tópico] e uma representação gráfica de uma nuvem.

Conforme descrito em (CHUNG et al., 2000), o framework NFR é constituído basicamente de softgoals, interdependências entre softgoals, um procedimento de avaliação, métodos de refinamento de softgoals, que correspondem a procedimentos gerais para a decomposição de um softgoal ou a geração de interdependências, e correlações que permitem a inferência de possíveis interações, 
positivas ou negativas, entre softgoals. Todos estes elementos do framework NFR utilizados para análise podem ser organizados sob a estrutura de catálogos, que representam informações relevantes para o projeto de software que podem ser reutilizados em outros projetos de natureza similar. No framework NFR, são definidos três tipos de catálogo:

- Catálogos de tipos de requisitos não-funcionais: catálogos que representam conceitos específicos relacionados a determinados requisitos não-funcionais;

- Catálogos de métodos de refinamento: catálogos que representam informações necessárias para a geração do grafo de interdependência entre softgoals, contendo procedimentos gerais para refinar um softgoal em um ou mais sub-softgoals;

- Catálogos de regras de correlação: estes catálogos representam informações necessárias que auxiliam a detectar interdependências implícitas entre softgoals.

Para estruturar e organizar a análise de disponibilidade em sistemas de software que disponibilizam serviços na Web, a técnica ADSSW disponibiliza um catálogo de tipos de requisitos não-funcionais e um catálogo com métodos de refinamento. $A$ estruturação dos catálogos da técnica baseia-se na estruturação definida para os catálogos presentes no framework NFR.

Catálogos de tipos de requisitos não-funcionais possibilitam que tipos gerais de requisitos não-funcionais sejam especializados, gerando uma hierarquia de subtipos ou requisitos especializados. Esta especialização possibilita uma caracterização dos diversos tipos de requisitos não-funcionais. A técnica proposta provê um catálogo de tipos de requisitos não-funcionais a serem considerados para a análise da dependabilidade de um sistema de software. Este catálogo engloba atributos de dependabilidade descritos em (AVIŽIENIS et al., 2004) e é representado por meio da Figura 21. Este catálogo será utilizado adiante para a geração de softgoals, e em métodos de decomposição por tipo que serão utilizados na técnica. Cabe ressaltar que o catálogo de tipos de requisitos não-funcionais adotado pela técnica ADSSW não pertence aos catálogos de requisitos não-funcionais apresentados na descrição do framework NFR em (CHUNG et al., 2000). No contexto da análise realizada pela técnica, os atributos de dependabilidade são utilizados como tipos de softgoals a 
serem analisados, juntamente com outros tipos de requisitos não-funcionais, tais como desempenho e acurácia.

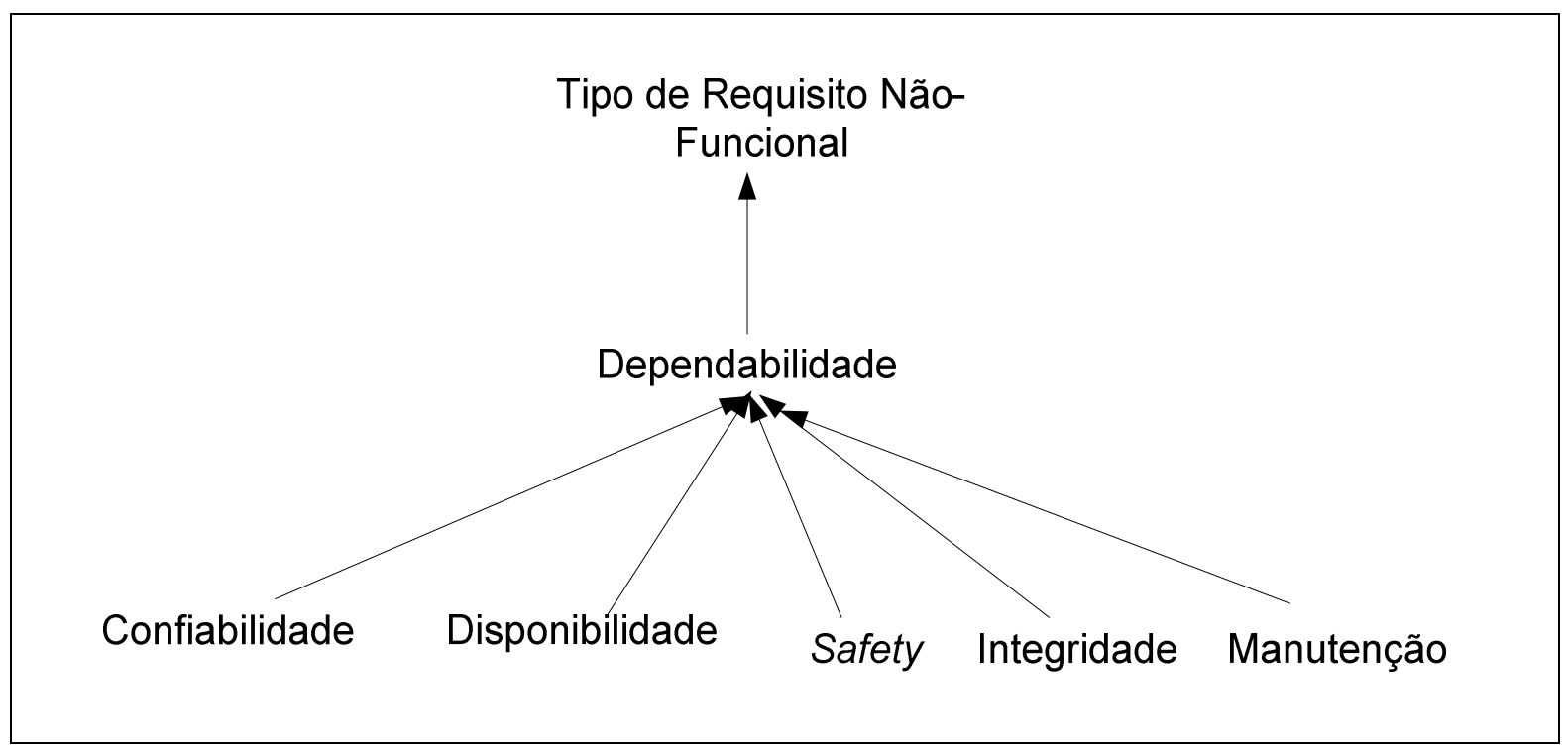

Figura 21 - Catálogo de tipos de requisitos não-funcionais, aplicados ao conceito de dependabilidade e seus atributos

A técnica ADSSW apresenta um catálogo de métodos para refinamento. Dentre os métodos presentes neste catálogo, estão presentes métodos de decomposição. Para representação dos inter-relacionamentos entre os softgoals, a técnica utiliza tipos de decomposição adotados no framework NFR. Métodos de decomposição permitem um refinamento dos requisitos não-funcionais, permitindo que se originem sub-softgoals a partir de um softgoal analisado. Conforme descrito no capítulo 2, no framework NFR existem basicamente dois tipos de decomposição entre softgoals de requisitos não-funcionais: decomposição por tipo e decomposição por tópico. A decomposição por tipo representa um refinamento com características relacionadas a requisitos não-funcionais. No catálogo de métodos de refinamento proposto, a primeira decomposição por tipo corresponde à decomposição de dependabilidade em atributos de dependabilidade. De acordo com (LAPRIE, 1992), cada sistema de software, dependendo de sua aplicação, possui necessidades distintas em relação aos atributos de dependabilidade. Em alguns sistemas, safety representa uma característica relevante a ser considerada no sistema. Em outros sistemas, este atributo pode não ser considerado relevante. Portanto, para cada sistema de software a ser analisado, os atributos necessários para se atingir um nível 
satisfatório de dependabilidade pode variar. A representação desta etapa de decomposição considerando-se todos os atributos de dependabilidade descritos em (LAPRIE, 1992) encontra-se na Figura 22 (a), enquanto que a Figura 22 (b) representa a decomposição dos atributos a serem considerados no sistema de software que serve de exemplo neste trabalho, identificados como relevantes de acordo com (OFFUTT, 2002).

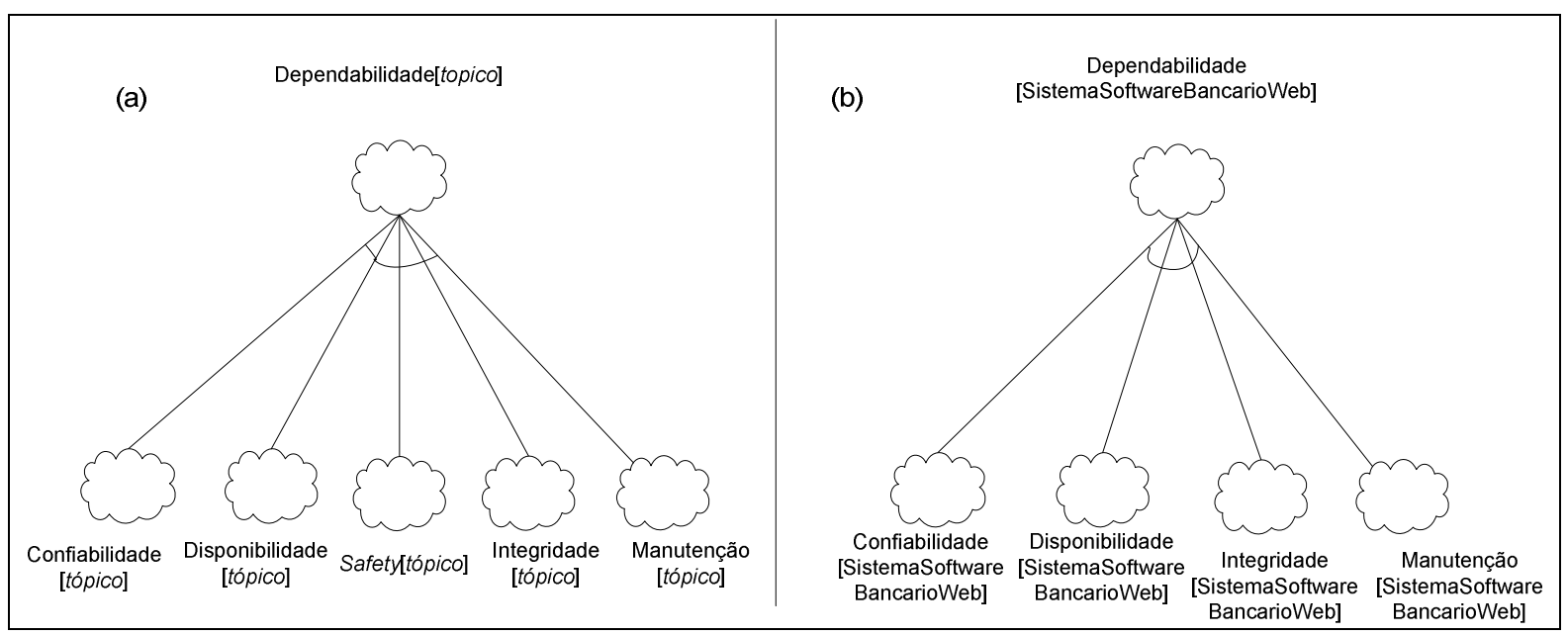

Figura 22 - Decomposição por tipo de dependabilidade

No capítulo 2 foram apresentadas possíveis descrições sintáticas descritas em (CHUNG et al., 2000) para a representação de contribuições $A N D$ e $O R$ em decomposições por tipo e por tópico de softgoals de requisitos não-funcionais. Dentre as descrições sintáticas apresentadas, a técnica ADSSW utiliza a descrição sintática na qual sub-softgoals são representados sob a forma de um conjunto:

AND (\{sub-sofgoals\}) SATISFAZEM softgoal

A escolha dessa notação para representação das contribuições $A N D$ e $O R$ presentes no catálogo de métodos da técnica ADSSW visa uniformizar a representação dos elementos da técnica, sendo possível estabelecer uma notação única que permita especificar a descrição sintática da decomposição e representar exemplos de aplicação da decomposição.

Portanto, seguindo a notação adotada na técnica ADSSW, a decomposição de softgoals de dependabilidade em softgoals de atributos de dependabilidade pode ser representada como segue: 
AND (\{Atributos dependabilidade [Tópico]\}) SATISFAZEM Dependabilidade [Tópico]

$\mathrm{Na}$ Figura 22 (b), considera-se como tópico de dependabilidade um exemplo de sistema bancário, descrito por meio do tópico SistemaSoftwareBancarioWeb. Considera-se também que os atributos de dependabilidade relevantes para 0 sistema sejam confiabilidade, disponibilidade, integridade e manutenção. A técnica abordará inicialmente somente 0 atributo disponibilidade. Seguindo a notação proposta em (CHUNG et al., 2000) utilizada neste trabalho, a decomposição recebe - nome de SistemaSoftwareWebDependabilidadeViaSubTipo, podendo ser representada através da seguinte notação:

AND (\{Confiabilidade [SistemaSoftwareBancarioWeb],

Disponibilidade[SistemaSoftwareBancarioWeb],

Integridade [SistemaSoftwareBancarioWeb],

Manutenção[SistemaSoftwareBancarioWeb]\})

SATISFAZEM Dependabilidade [SistemaSoftwareBancarioWeb]

Outro tipo de decomposição utilizado no framework NFR corresponde a uma decomposição por tópico, apresentada no capítulo 2. As decomposições por tópico presentes no catálogo de métodos de refinamento da técnica ADSSW utilizam uma abordagem semelhante à abordagem adotada em (KAÂNICHE; KANOUN; RABAH, 2001) , considerando-se uma hierarquia com diferentes níveis para a modelagem de disponibilidade em aplicações de e-business através da internet. A hierarquia proposta por (KAÂNICHE; KANOUN; RABAH, 2001) pode ser representada através da Figura 23.

Em (KAÂNICHE; KANOUN; RABAH, 2001), os autores argumentam que para modelar a disponibilidade de sistemas de e-business sob a visão de diversos perfis de usuários, primeiramente é necessário identificar as principais funcionalidades providas e os principais recursos que contribuem para que seja possível cumprir esta finalidade. Com base nesses aspectos, existe a possibilidade de se modelar e verificar o impacto de falhas e reparos de componentes no nível de disponibilidade fornecido a diferentes perfis de usuários. De acordo com (KAÂNICHE; KANOUN; RABAH, 2001), diferentes grupos de usuários podem exibir diferentes comportamentos e podem invocar funcionalidades de um sistema de e-business de 
diversas maneiras. Alguns usuários podem constituir um perfil de usuários que têm acesso a um número maior de funcionalidades, enquanto outros usuários utilizam apenas funcionalidades elementares do sistema de software. Portanto, para cada perfil operacional de usuário as funcionalidades acessadas e os recursos envolvidos não são necessariamente os mesmos. Como conseqüência, a disponibilidade de um sistema de software pode ser percebida de formas distintas por diferentes perfis operacionais de usuários. Portanto, a disponibilidade de um sistema avaliada por um usuário é influenciada por seu perfil operacional e pelo estado dos componentes envolvidos no processamento das funcionalidades invocadas.

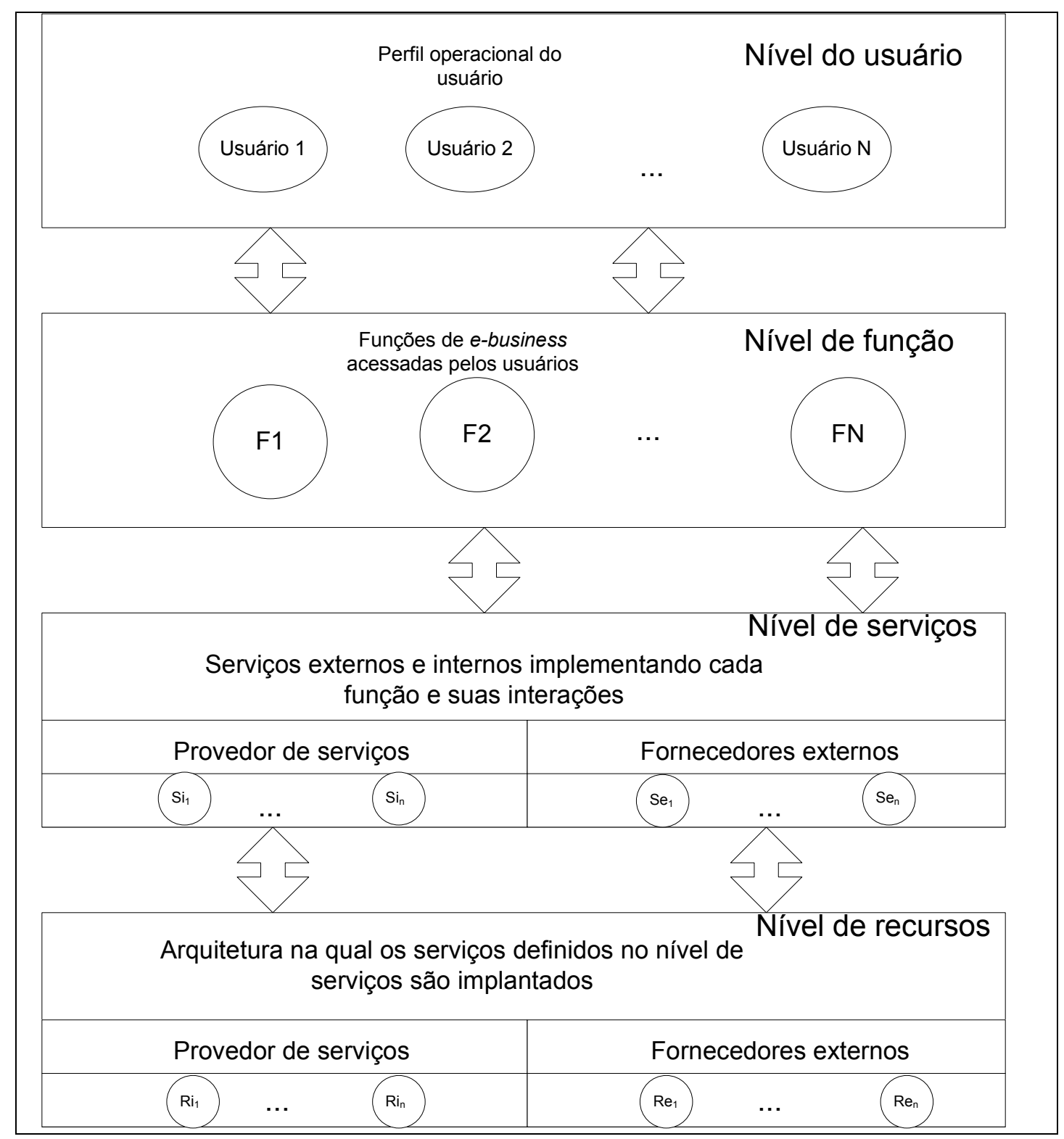

Figura 23 - Descrição hierárquica de sistemas de e-business

Fonte: (KAÂNICHE; KANOUN; RABAH, 2001) 
Como apresentado na Figura 23, em (KAÂNICHE; KANOUN; RABAH, 2001) as informações necessárias para analisar o comportamento de uma aplicação de uma perspectiva do usuário podem ser estruturadas basicamente em quatro níveis:

- O nível do usuário, que descreve seu perfil operacional através de conjuntos de funcionalidades acessadas, com probabilidades associadas a seqüências de acessos a cada funcionalidade;

- O nível funcional, que descreve o conjunto de funcionalidades oferecidas pelo sistema de software;

- O nível de serviço, que descreve o mapeamento entre as funcionalidades oferecidas pelo sistema de software e os serviços oferecidos por entidades de software, como servidores de aplicação, servidores de comunicação com base de dados, entre outros. Nesta classificação, existem serviços internos, providos por elementos internos do sistema de software, e serviços externos, providos por entidades externas ao sistema de software;

- O nível de recursos, que descreve o mapeamento entre os serviços definidos no nível de serviço e os recursos envolvidos, descrevendo a estrutura necessária para atender aos serviços definidos no nível acima, envolvendo possíveis estratégias de redundância utilizadas para prover um nível adequado de disponibilidade.

$\mathrm{Na}$ técnica aqui proposta, o princípio de avaliação de disponibilidade através de diferentes níveis será aplicado nas operações de decomposição por tópico de disponibilidade. Esta abordagem permite que se avalie o impacto da ocorrência de ameaças à disponibilidade em relação às funcionalidades oferecidas pelo sistema e, conseqüentemente, permite que se identifiquem quais perfis operacionais de usuário são prejudicados diante da ocorrência destas ameaças.

Conforme ilustrado na Figura 22, o primeiro softgoal relacionado corresponde à disponibilidade do sistema de software, podendo ser representado como Disponibilidade [SistemaSoftwareBancarioWeb]. O método de decomposição por tópico aplicado a este softgoal está relacionado a perfis operacionais de usuários do sistema. Por exemplo, um sistema de software bancário pode possuir diferentes perfis de usuários, que acessam diferentes grupos de funcionalidades. Uma 
decomposição por tópico através do perfil operacional permite que se analise isoladamente a disponibilidade do sistema para diferentes perfis de usuário, sendo estes perfis definidos através de requisitos funcionais do sistema de software sob análise. Esta etapa de decomposição não é obrigatória na aplicação da técnica, e deve ser adotada somente em situações em que existam diferentes perfis de usuário, em um contexto no qual a análise de disponibilidade para cada perfil de forma isolada torna-se um fator importante a ser considerado. A decomposição por tópico relacionada a perfis operacionais será denominada SistemaSoftwareWebDisponibilidadeViaPerfil. Esta decomposição pode ser definida conforme a notação de (CHUNG et al., 2000) utilizada neste trabalho, sendo representada através da seguinte notação:

\section{AND (\{Disponibilidade [SistemaSoftwareWeb, perfil]\}) \\ SATISFAZEM Disponibilidade [SistemaSoftwareWeb]}

A Figura 24 ilustra um exemplo de decomposição por tópico do atributo de qualidade disponibilidade através de perfis de usuário. No exemplo, foram definidos dois perfis, Perfil_A e Perfil_B.

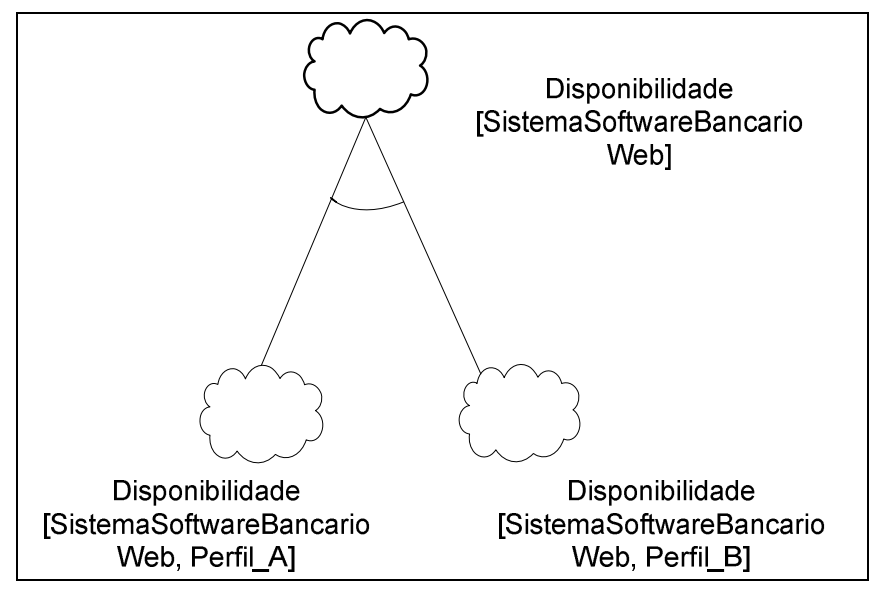

Figura 24 - Decomposição por perfil de usuário

Seguindo a notação adotada para a decomposição SistemaSoftwareWebDisponibilidadeViaPerfil, o exemplo apresentado na Figura 24 pode ser representado como segue: 
AND \{Disponibilidade [SistemaSoftwareBancarioWeb, Perfil_A],

Disponibilidade [SistemaSoftwareBancarioWeb, Perfil_B] \}

SATISFAZEM Disponibilidade [SistemaSoftwareBancarioWeb]

No contexto de sistemas de software com perfis de usuário distintos, regras de negócio associadas a este sistema podem determinar a priorização de um determinado perfil de usuário em relação aos demais. Assim, a disponibilidade associada a um determinado perfil de usuário pode ser mais relevante do que a disponibilidade associada a outros perfis de usuário. Para que a técnica proposta neste trabalho seja capaz de prover um suporte para esta situação, será adotada a mesma notação utilizada para priorização de softgoals de requisitos não-funcionais no framework NFR. A priorização de um determinado softgoal de requisito nãofuncional ocorre, segundo (CHUNG et al., 2000), através de uma contribuição positiva do softgoal priorizado, com um caractere '!' acompanhando a nuvem que o representa. A Figura 25 representa um exemplo desta notação, indicando uma priorização da disponibilidade do sistema para usuários que possuem o Perfil_A.

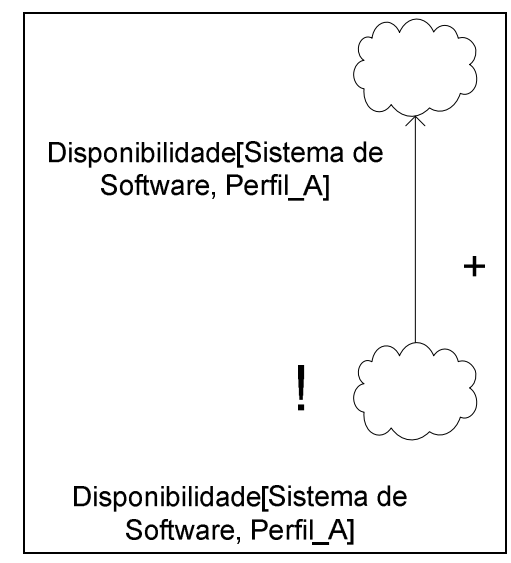

Figura 25 - Priorização para perfil de acesso

Conforme a definição presente em (LAPRIE, 1992), a função do sistema corresponde ao que o sistema se destina a realizar. A função de um sistema pode ser descrita através de um conjunto de funcionalidades que o sistema provê. Por exemplo, na área de sistemas bancários, existe uma variedade de funcionalidades, tais como transferência de valores, pagamento de tributos, pagamentos de título de cobrança, consulta de saldos, etc. Na técnica proposta, propõe-se uma 
decomposição por tópico baseada nas funcionalidades que o sistema provê. Existem duas possibilidades de realização desta decomposição. Uma primeira possibilidade ocorre quando não é realizado o método de decomposição por tópico SistemaSoftwareWebDisponibilidadeViaPerfil. Nesta situação, o softgoal que representa a disponibilidade do sistema de software é decomposto em softgoals que representam tópicos que representam a disponibilidade associada às funcionalidades que o sistema de software disponibiliza. Outra possibilidade de decomposição ocorre após a ocorrência da decomposição SistemaSoftwareWebDisponibilidadeViaPerfil, em que softgoals que representam a disponibilidade de um determinado perfil de usuário podem ser decompostos, por tópico, em softgoals que representam a disponibilidade das funcionalidades às quais os usuários associados ao perfil têm acesso.

A Figura 26 representa métodos de decomposição por tópico relacionados à funcionalidade. A Figura 26(a) representa uma situação na qual o perfil do usuário não é relevante para a avaliação da disponibilidade do sistema. A decomposição ocorre diretamente do sistema para as funcionalidades do sistema. A Figura 26(b) representa uma situação na qual ocorre a decomposição da disponibilidade dos perfis de usuário em disponibilidade de funcionalidades as quais os perfis de usuários têm acesso. Na Figura 26(b), o Perfil $A$ possui acesso às funcionalidades Funcionalidade_ $A$ e Funcionalidade_ $B$, enquanto 0 Perfil $B$ possui acesso as funcionalidades Funcionalidade_B e Funcionalidade_C.

Em um sistema, existe a possibilidade de que uma determinada funcionalidade possua uma prioridade em relação às demais funcionalidades. Para dar suporte a este tipo de situação na técnica ADSSW, de forma semelhante à decomposição por meio de perfis de usuário, também será utilizada a notação que indica prioridades no framework NFR, conforme representação na Figura 26(c). 


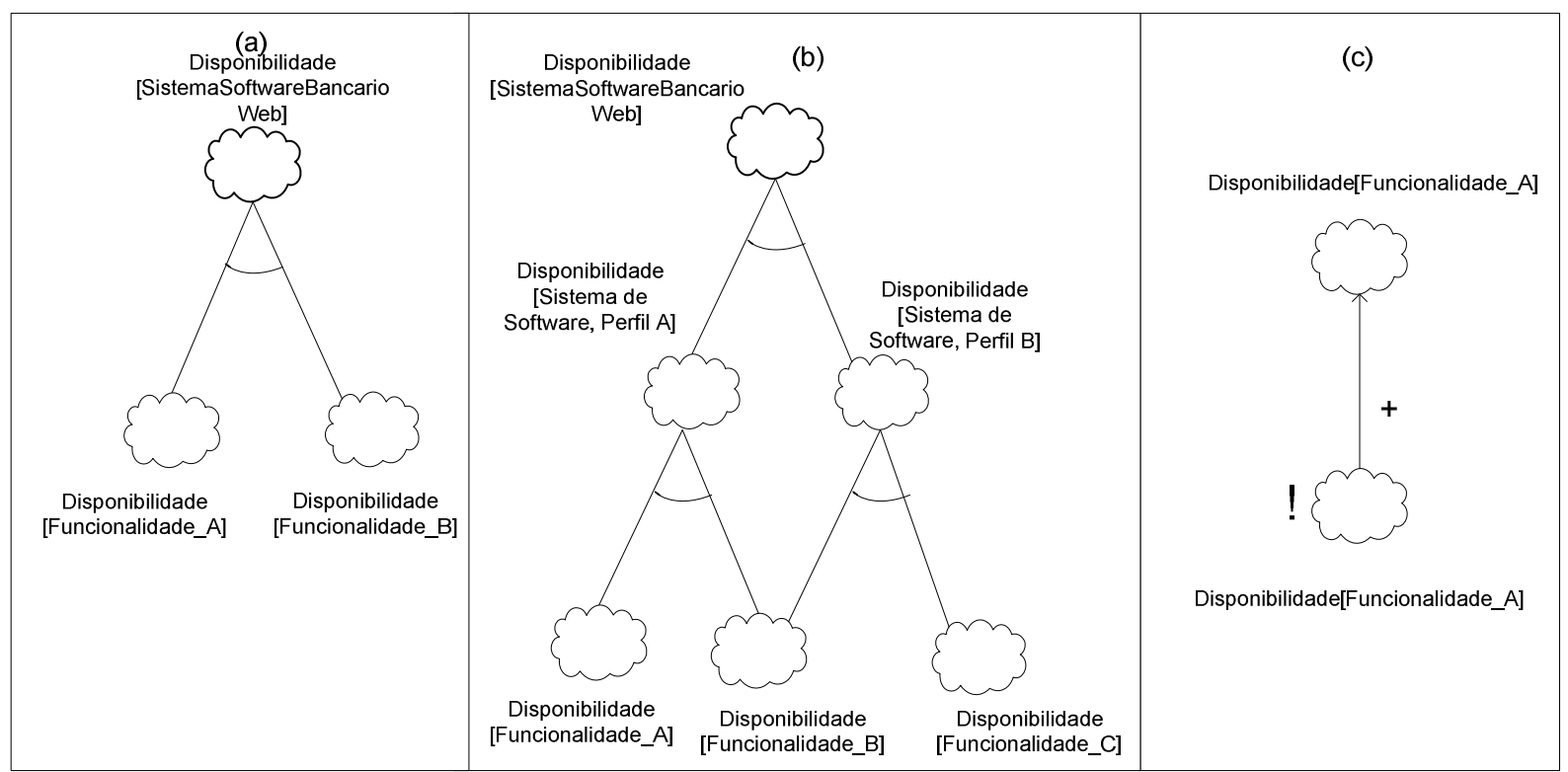

Figura 26 - Decomposição por tópico - funcionalidade

O método de decomposição aplicado na Figura 26(a) neste trabalho será referenciado como SistemaSoftwareWebDisponibilidadeViaFuncionalidade, enquanto que o método aplicado na Figura 26(b) será referenciado como SistemaSoftwareWebDisponibilidadePerfilViaFuncionalidade.

A decomposição por tópico SistemaSoftwareWebDisponibilidadeViaFuncionalidade pode ser representada conforme a seguinte notação:

AND (\{Disponibilidade [Funcionalidades $]\})$

SATISFAZEM Disponibilidade [SistemaSoftwareWeb]

Seguindo a notação proposta para a decomposição SistemaSoftwareWebDisponibilidadeViaFuncionalidade o exemplo presente na Figura 26 (a) pode ser representado como segue:

$$
\text { AND (\{Disponibilidade [Funcionalidade_A], }
$$

Disponibilidade [Funcionalidade_B]\}) SATISFAZEM Disponibilidade

[SistemaSoftwareBancarioWeb]

O método SistemaSoftwareWebDisponibilidadePerfilViaFuncionalidade pode ser representado por meio da seguinte notação: 
AND (\{Disponibilidade [Funcionalidades]\}) SATISFAZEM Disponibilidade [SistemaSoftwareWeb, Perfil]

De acordo com esta notação, um exemplo extraído da Figura 26(b) pode ser representado como segue:

AND (\{Disponibilidade [Funcionalidade_A],

Disponibilidade [Funcionalidade_B]\}) SATISFAZEM Disponibilidade

[SistemaSoftwareWebBancarioWeb, Perfil_A]

Segundo a definição de (LAPRIE, 1992), um serviço corresponde a um comportamento do sistema observado por um usuário. A estrutura do sistema possibilita que o sistema seja capaz de gerar este comportamento. De acordo com uma visão estrutural, o sistema corresponde a um conjunto de componentes relacionados entre si para interação, em que cada componente pode ser considerado outro sistema. Portanto, um componente pode ser descrito por um conjunto de componentes que estão inter-relacionados. A recursividade desta definição se encerra quando um componente pode ser considerado atômico, ou seja, não existe a possibilidade ou a necessidade de se discernir uma nova estrutura interna. Conseqüentemente, o estado atual do sistema corresponde ao conjunto de estados externos de seus componentes atômicos. Com base nestas definições, a técnica proposta considera que existe uma interdependência entre a disponibilidade das funcionalidades e a disponibilidade dos componentes que disponibilizam serviços que possibilitam a execução da funcionalidade. Portanto, propõe-se um método de decomposição por tópico por meio de componentes.

No caso de sistemas de software que disponibilizam serviços na Internet e que adotam a arquitetura descrita na seção 4.2, a primeira decomposição ocorre considerando-se a divisão em camadas. Na técnica proposta, considera-se que para atender as funcionalidades do sistema, existe uma subdivisão de responsabilidades entre três camadas (apresentação, regra de negócio e integração) e que cada camada corresponde a um componente a ser analisado no sistema. Essas considerações definem 0 método de decomposição por tópico SistemaSoftwareWebDisponibilidadeFuncViaCamada, que pode ser representada 
na notação adotada neste trabalho para a decomposição por tópico. A Figura 27 apresenta o diagrama correspondente.

$$
\begin{array}{r}
\text { AND (\{Disponibilidade [Funcionalidade, Apresentacao], } \\
\text { Disponibilidade [Funcionalidade, Negócio], } \\
\text { Disponibilidade [Funcionalidade, Integração]\}) } \\
\text { SATISFAZEM Disponibilidade [Funcionalidade] }
\end{array}
$$

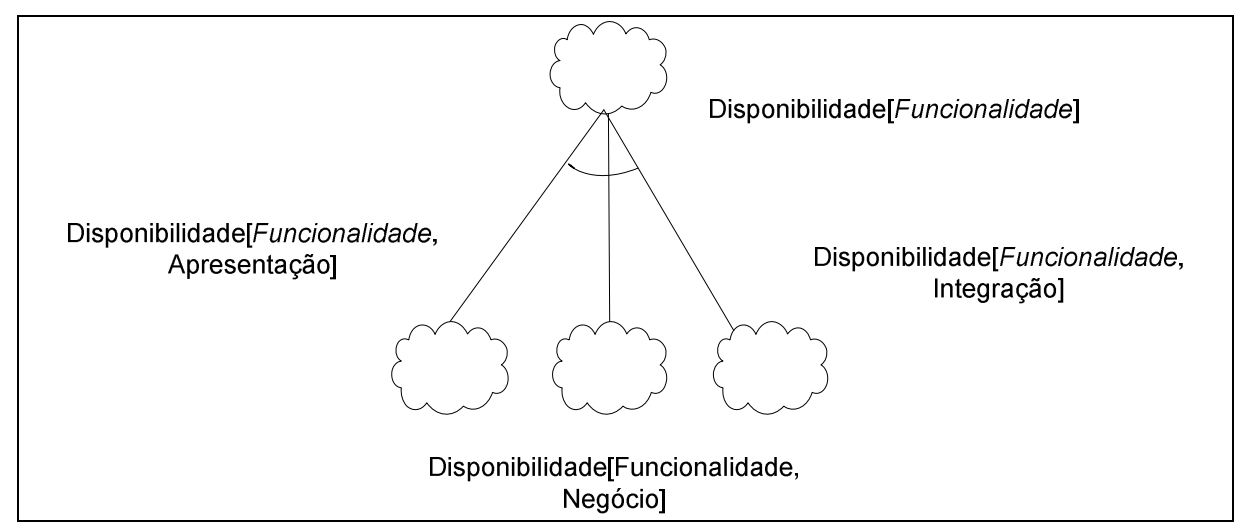

Figura 27 - Decomposição por tópico - camadas

Conforme definições de (LAPRIE, 1992), a estruturação de um sistema baseia-se em componentes, e um componente pode ser construído através da estruturação de outros componentes (para um melhor entendimento, estes outros componentes serão referenciados como sub-componentes). Na técnica proposta, será utilizado um método de decomposição por tópicos, visando decompor softgoals que representem a disponibilidade de um componente através de softgoals que representem a disponibilidade de sub-componentes.

$\mathrm{Na}$ técnica são definidas duas formas de decomposição por tópico considerando-se a estrutura do sistema. A primeira forma de decomposição corresponde à execução de serviços de sub-componentes para prover um serviço de um componente. Como a execução do serviço do componente depende da execução dos sub-componentes envolvidos, utiliza-se uma contribuição $A N D$ dos softgoals que representam a disponibilidade dos serviços dos sub-componentes. A Figura 28 exemplifica esta situação, em que a execução do serviço do componente $C$ ocorre através da execução de um serviço do componente $C 1$, seguida pela execução de um serviço do componente C2. A Figura 28(a) representa a interligação de componentes, e a Figura 28(b) exemplifica a contribuição $A N D$ adotada no refinamento. 


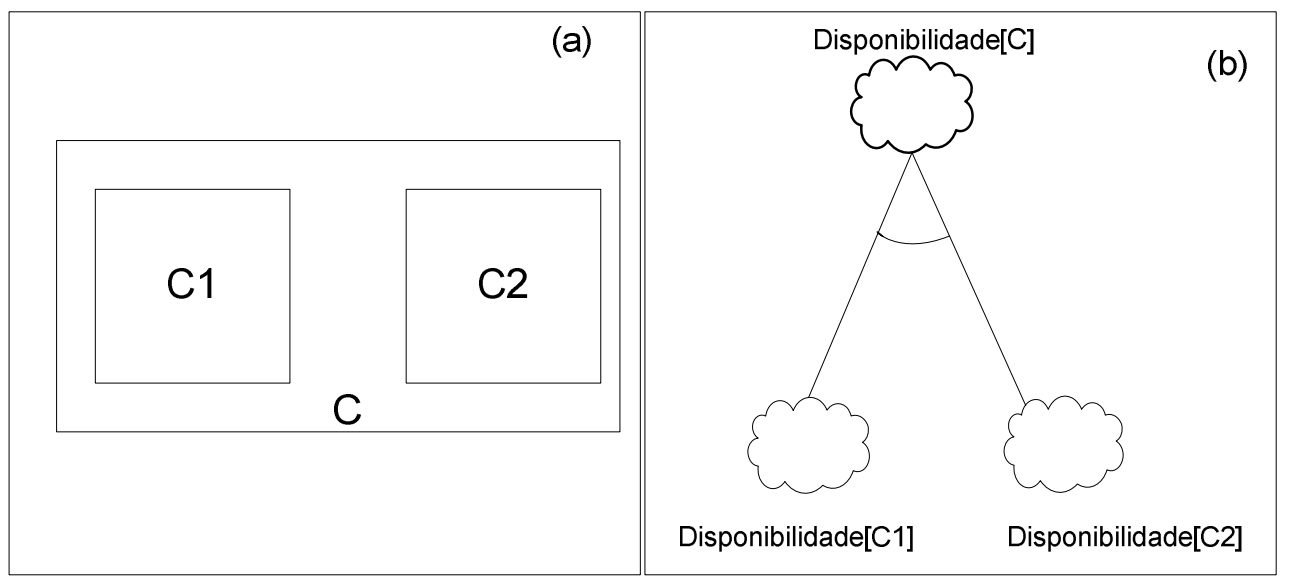

Figura 28 - Decomposição por tópico baseada em componentes

Esta decomposição recebe 0 nome de SistemaSoftwareWebDisponibilidadeComponenteViaComponentes, e pode ser representada através da seguinte notação:

AND (\{Disponibilidade [Componentes]\}) SATISFAZEM Disponibilidade [Componente]

De acordo com a notação proposta para a decomposição SistemaSoftwareWebDisponibilidadeComponenteViaComponentes, 0 exemplo presente na Figura 28(b) pode ser representado como segue:

AND (\{Disponibilidade [C1], Disponibilidade [C2]\}) SATISFAZEM Disponibilidade [C]

Outra possível notação para esta decomposição assume que o softgoal que apresenta como tipo Disponibilidade e como tópicos a funcionalidade e a camada, pode ser decomposto em softgoals que representam a disponibilidade associada a cada componente que compõe a camada responsável por seu processamento na execução da funcionalidade. Esta notação pode ser representada como segue:

AND (\{Disponibilidade [Componentes]\})

SATISFAZEM Disponibilidade [Funcionalidade, Camada]

Este método pode ser aplicado no contexto de sistemas que disponibilizam serviços de e-business na Web, nos componentes relacionados a regras de negócio e integração, conforme a caracterização de sistemas de software na Web apresentados na seção 4.2 . 
O softgoal Disponibilidade [Funcionalidade, Negócio], através da aplicação do método SistemaSoftwareWebDisponibilidadeComponenteViaComponentes pode ser decomposto da seguinte forma:

AND (\{Disponibilidade [Balanceador de Carga], Disponibilidade [Servidor Web], Disponibilidade [Componente Servidor de Aplicação Funcionalidade]\}) SATISFAZEM Disponibilidade [Funcionalidade, Negócio]

O tópico apresentado no softgoal Disponibilidade[Componente Servidor de Aplicação Funcionalidade] representa o módulo responsável pelo processamento da funcionalidade no servidor de aplicação. De acordo com as definições apresentadas na seção 4.2, o softgoal Disponbilidade (Funcionalidade, Componente Servidor de Aplicação Funcionalidade) pode ser decomposto da seguinte forma, através do método SistemaSoftwareWebDisponibilidadeComponenteViaComponentes:

AND (\{Disponibilidade [Aplicativos Funcionalidade],

Disponibilidade [Middleware], Disponibilidade [Software Servidor de Aplicacao],

Disponibilidade [Sistema Operacional SA]\})

SATISFAZEM Disponibilidade [Componente Servidor de Aplicação Funcionalidade]

Os softgoals resultantes das duas últimas decomposições relacionadas a componentes responsáveis pelo processamento de regras de negócio podem ser representados como na Figura 29. 


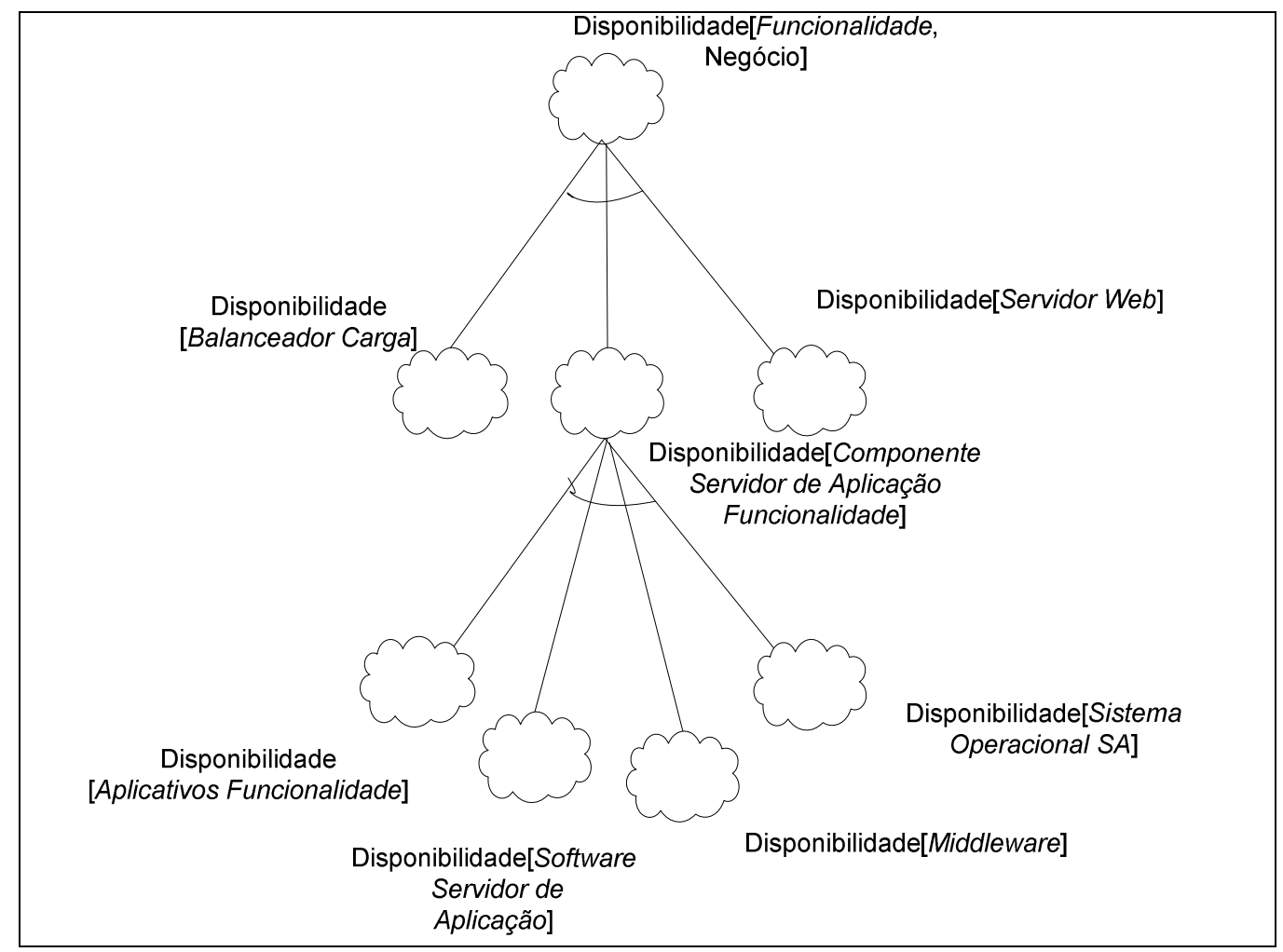

Figura 29 - Decomposição por tópico relacionada à camada de regra de negócio

Em relação à camada de integração, o método SistemaSoftwareWebDisponibilidadeComponenteViaComponente pode ser aplicado na decomposição por tópico a partir de outros componentes. A primeira aplicação do método gera o seguinte refinamento, representado conforme a notação proposta:

AND (\{Disponibilidade [Servidor Base de Dados Funcionalidade],

Disponibilidade [Serviços Externos] \})

SATISFAZEM Disponibilidade [Funcionalidade, Integração]

O softgoal Disponibilidade [Servidor Base de Dados Funcionalidade] pode ser decomposto por meio da decomposição SistemaSoftwareWebDisponibilidadeComponenteViaComponente, sendo esta decomposição representada conforme a seguinte notação:

AND (\{Disponibilidade [Procedimentos Armazenados Funcionalidade],

Disponibilidade [SGBD], Disponibilidade [Sistema Operacional BD]\})

SATISFAZEM Disponibilidade [Servidor Base de Dados Funcionalidade] 
A Figura 30 representa 0 resultado de aplicações do método SistemaSoftwareWebDisponibilidadeComponenteViaComponente ao componente que representa a camada de integração.

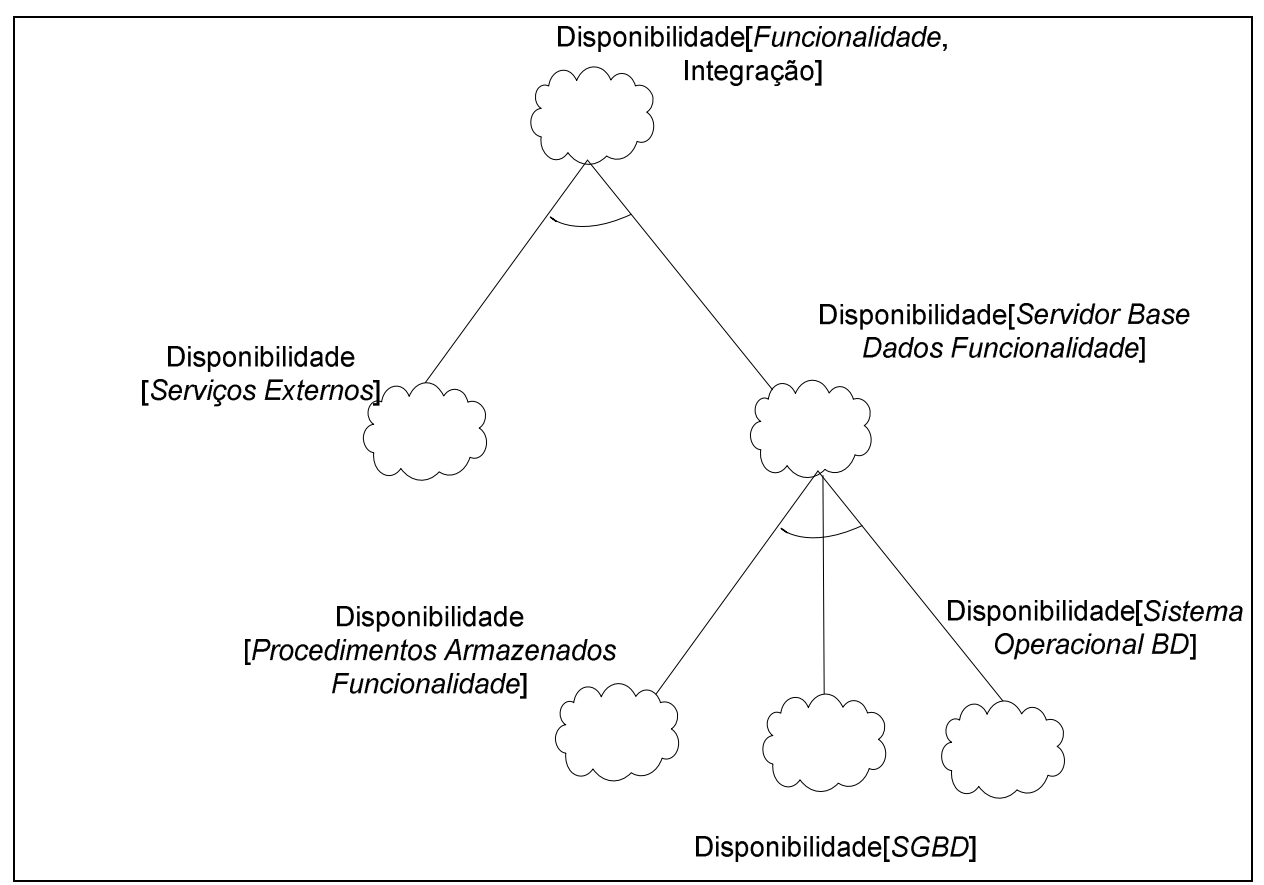

Figura 30 - Decomposição por tópico relacionada a camada de integração

Outro método de decomposição por tópico através da estruturação de sistemas lida com situações de fluxos alternativos de processamento de componentes independentes na execução dos serviços. Nestas situações, um mesmo serviço de um componente pode ser executado através da interação entre conjuntos diferentes de sub-componentes, e adota-se a premissa de que a disponibilidade de serviços de um componente depende da disponibilidade dos sub-componentes utilizados em um determinado fluxo, ou da disponibilidade dos sub-componentes que realizam um fluxo alternativo. Para representar fluxos alternativos, utiliza-se uma decomposição por tópico, na qual o softgoal que representa a disponibilidade de um serviço de um componente pode ser decomposto, por meio de uma combinação $O R$, em softgoals que representem a disponibilidade dos sub-componentes que são responsáveis pela execução dos fluxos alternativos. Um exemplo desta situação pode ser visto na Figura 31. A Figura 31(a) representa uma situação na qual um determinado serviço pode ser executado ou por meio do componente $\mathrm{C} 1$, ou por meio do componente C2. A Figura 31(b) exemplifica a contribuição $O R$ adotada no refinamento. Esta 
decomposição

recebe

0

nome

de

SistemaSoftwareWebDisponibilidadeComponenteViaComponenteFluxoAlternativo e pode ser representado conforme a notação definida no Capítulo 2 para contribuições $O R$ :

OR (\{Disponibilidade [Componentes]\}) SATISFAZEM Disponibilidade [Componente]

De acordo com esta notação, o exemplo presente na Figura 29(b) pode ser representado por meio da seguinte notação:

OR (\{Disponibilidade [C1], Disponibilidade [C2]\}) SATISFAZ Disponibilidade [C]

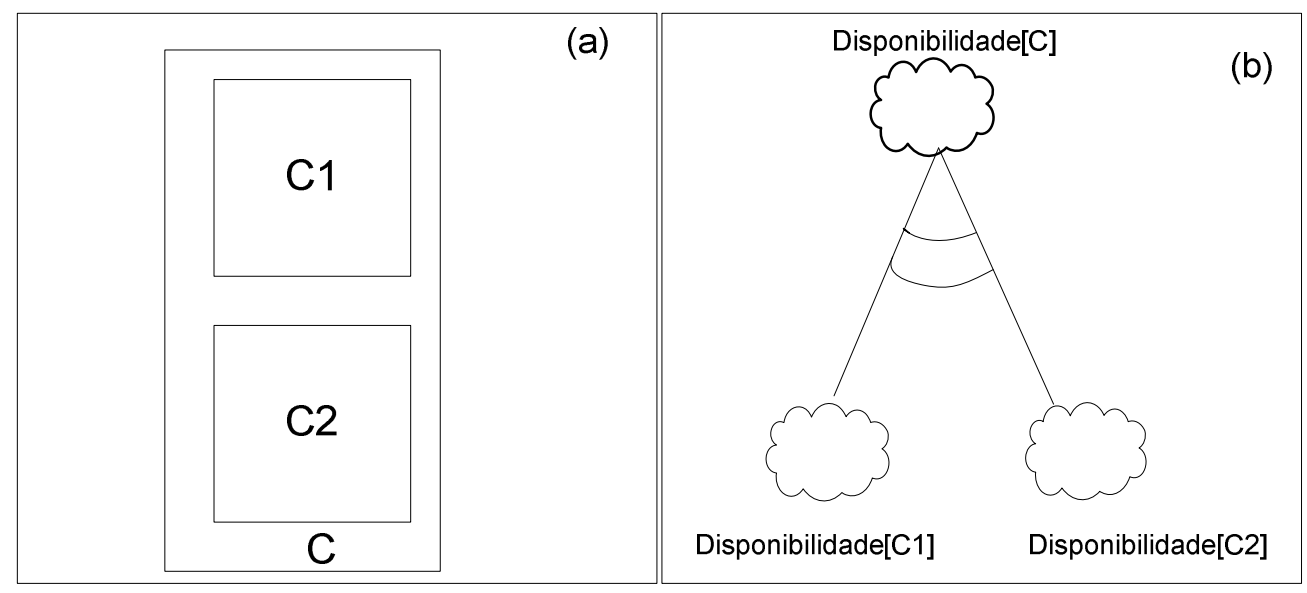

Figura 31 - Decomposição por tópico - Fluxo Alternativo

Cabe ressaltar que esta decomposição somente pode ser aplicada em situações em que os componentes responsáveis pela execução dos fluxos alternativos sejam totalmente independentes, ou seja, uma falha em um componente não afeta o comportamento dos demais componentes.

Dada a recursividade da definição presente em (LAPRIE, 1992), aplicações sucessivas dos métodos de decomposição por tópico através de componentes podem ocorrer, até que se obtenham componentes considerados atômicos, seja por impossibilidade de novas decomposições, ou por se atingir um nível de abstração desejado dos componentes sob análise.

Conforme definição de (LAPRIE, 1992) a definição de disponibilidade está relacionada a uma medida de entrega correta de um serviço considerando-se a alternância entre um correto serviço e um incorreto serviço. Ainda segundo (LAPRIE, 1992), uma falha corresponde a uma ameaça de dependabilidade que consiste em 
uma transição de um serviço correto para um serviço incorreto. Portanto, para se aumentar a disponibilidade de um sistema de software, existem duas possibilidades: minimizar a ocorrência de falhas no sistema, aumentando assim o tempo de fornecimento de serviço correto, ou minimizar o tempo de serviço incorreto, sendo necessário um tempo de recuperação mínimo para a detecção da falha e da tomada de ações para fazer com que novamente o serviço seja disponibilizado de forma correta. Portanto, percebe-se uma relação entre o atributo disponibilidade e a ameaça falha. Devido a esta relação, existe a necessidade de representação de falhas na técnica ADSSW. No framework NFR não existe a definição de falhas, portanto existe a necessidade de criação de um novo elemento para a representação de ameaças de dependabilidade. Como o conceito de softgoal está relacionado aos objetivos a serem alcançados em um sistema, este conceito não pode ser utilizado para representar ameaças de dependabilidade, uma vez que ameaças, por definição, não correspondem a objetivos a serem alcançados. Portanto propõe-se no método ADSSW a criação de um novo elemento, o elemento ameaça de dependabilidade. Conforme definição de (LAPRIE, 1992), existem três tipos de ameaças de dependabilidade: defeito, erro e falha. Na técnica proposta, cada ameaça é representada por uma elipse, com uma letra identificando cada tipo de ameaça. As letras D, E e F representam defeito, erro e falha, respectivamente, conforme notação exibida na Figura 32. Na técnica aqui proposta, os elementos que representam ameaças a disponibilidade, assim como softgoals de requisitos nãofuncionais, também apresentam uma descrição Tipo [Tópico], na qual Tipo representa uma ameaça de dependabilidade descrita em (LAPRIE, 1992) e (AVIŽIENIS et al., 2004), e Tópico, corresponde ao elemento associado a ameaça descrita pelo Tipo.

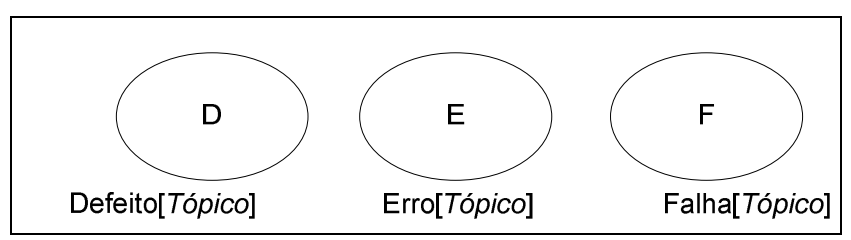

Figura 32 - Representação de ameaças de dependabilidade no método

$\mathrm{Na}$ técnica proposta, as relações de interdependência entre softgoals presentes no framework NFR são utilizadas para representação de interdependências entre 
ameaças, e relações entre ameaças e softgoals que representam requisitos nãofuncionais. Dentre as relações de interdependência, destacam-se as contribuições examinadas no capítulo 2: AND, OR, ALGO-, FERE, QUEBRA, ALGO+, AUXILIA e REALIZA. Na técnica ADSSW as notações utilizadas para descrever sintaticamente estas contribuições envolvendo ameaças assemelham-se às notações utilizadas para as contribuições entre softgoals de requisitos não-funcionais, com as ameaças sendo representadas na notação de forma similar a softgoals de requisitos nãofuncionais.

Segundo a definição de (LAPRIE, 1992), atributos de dependabilidade são afetados pelas ameaças de dependabilidade. A ocorrência de falhas contribui negativamente para o atributo de qualidade disponibilidade. Falhas no comportamento de um componente causam uma diminuição do nível de disponibilidade deste componente, podendo trazer impactos negativos à sua disponibilidade. Baseado nesta premissa, o método proposto irá adotar o inter-relacionamento entre o conceito de falhas e o requisito não-funcional disponibilidade através de uma contribuição ALGO-. A utilização de uma contribuição $A L G O$ - baseia-se em duas premissas. A primeira premissa consiste no fato de que a ocorrência de uma falha em um tópico pode causar efeitos negativos em relação ao softgoal de disponibilidade deste tópico. A segunda premissa está relacionada à intensidade da contribuição, que pode variar dependendo do nível de severidade da falha representada. Falhas que apresentam um nível de severidade menor em um determinado tópico podem realizar contribuições do tipo FERE em softgoals que representam a disponibilidade deste tópico, uma vez que o softgoal de disponibilidade afetado pode ser considerado insatisfatório, mas não necessariamente o será, uma vez que possíveis operacionalizações associadas a meios de tolerância a defeitos apresentados no capítulo 3 podem fazer com que o softgoal de disponibilidade que apresente a falha seja considerado satisfatório. No entanto, falhas com um nível de severidade maior podem realizar contribuições do tipo QUEBRA em softgoals de disponibilidade, uma vez que a ocorrência destas falhas pode ser suficiente para que o softgoal de disponibilidade que recebe a contribuição seja considerado insatisfatório, independentemente de possíveis operacionalizações. 
Com base na descrição sintática da contribuição ALGO- examinada no capítulo 2 deste trabalho, a contribuição $A L G O$ - entre falha e softgoal de disponibilidade pode ser representada conforme a seguinte notação:

\section{Falha [Tópico] ALGO- Disponibilidade [Tópico]}

A Figura 33 ilustra a contribuição $A L G O$ - que relaciona falha associada a um determinado tópico com um softgoal que representa a disponibilidade associada ao tópico em questão.

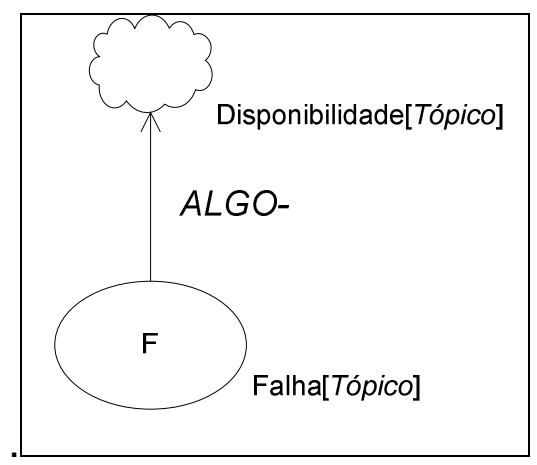

Figura 33 - Contribuição $A L G O$ - de Falha para disponibilidade

Em (AVIŽIENIS et al., 2004), existe uma definição de possíveis modos de falha do sistema. Esta definição permite que se caracterizem os tipos de falha que podem ocorrer no fornecimento de um serviço do sistema de software (ou de algum componente que compõe o sistema). Na técnica proposta existe a possibilidade de se definir um catálogo de tipos de falhas. O catálogo pode ser semelhante ao catálogo de requisitos não-funcionais utilizado em (CHUNG et al., 2000). A Figura 34 representa o catálogo de falhas utilizado na técnica.

$\mathrm{Na}$ Figura 34 nota-se a presença de características de falhas, representadas em itálico e em um tamanho menor na figura. Estas características assemelham-se a características de requisitos não-funcionais, definidas em (CHUNG et al., 2000), utilizadas na criação de catálogos de tipos de requisitos não-funcionais. As características de requisitos não-funcionais não representam tipos de requisitos nãofuncionais, mas são características que podem modificar ou especializar o significado de um tipo de requisito não-funcional. De forma similar, características de falhas não correspondem a tipo de falhas no sistema, e correspondem a 
características que podem modificar ou especializar o significado de um tipo de falha.

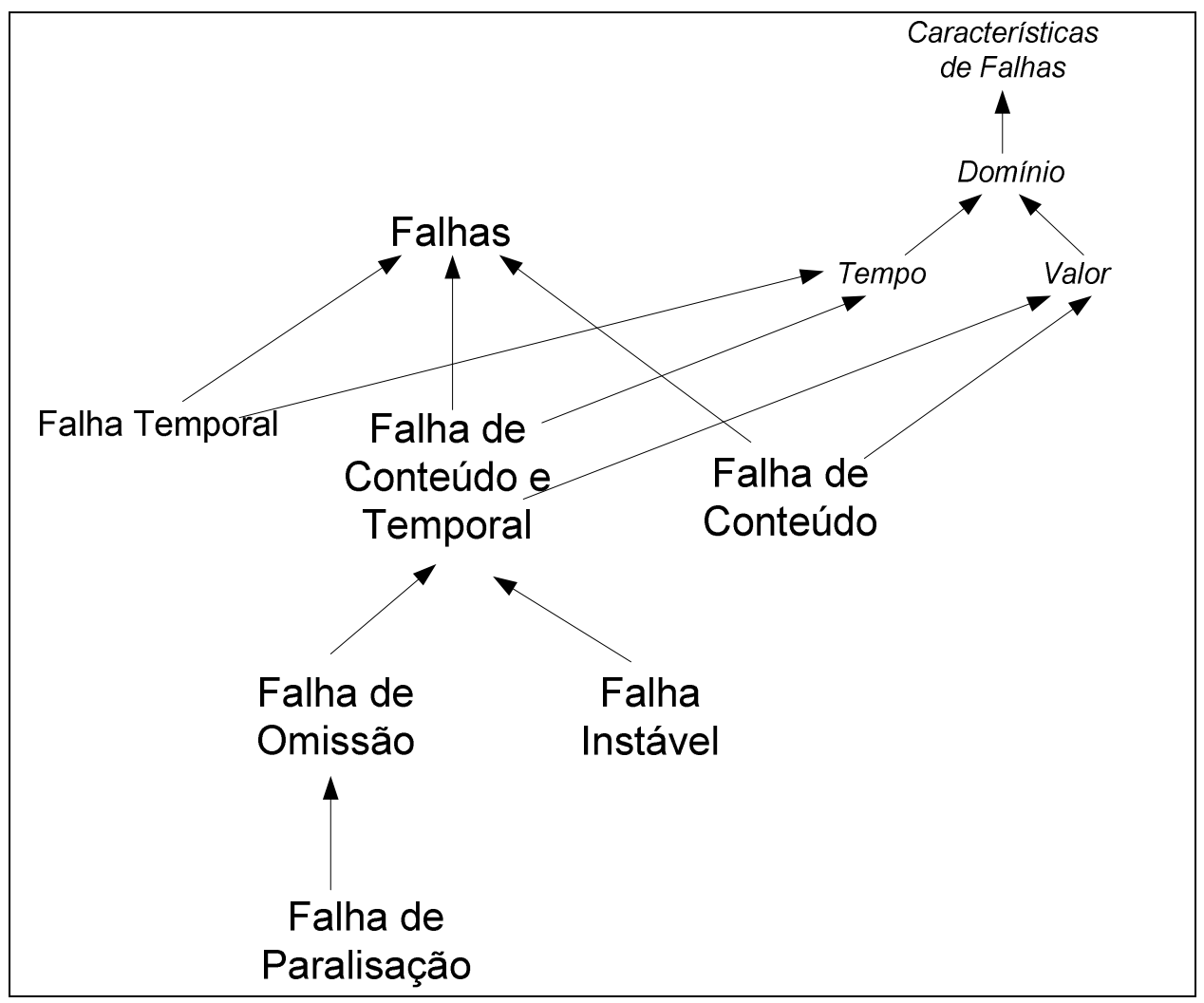

Figura 34 - Catálogo de tipos de falhas definido na técnica ADSSW

$\mathrm{Na}$ técnica proposta, a característica de falha considerada é o domínio de falha, conforme descrito em (LAPRIE, 1992) e abordado no capítulo 3 deste trabalho, em que as falhas podem ser classificadas de acordo com seu domínio. Como pode ser visto na Figura 34, a característica domínio está associada com dois valores possíveis: tempo e valor. A característica domínio influencia a definição de tipos de falhas. Com base no domínio de falhas, são definidos os seguintes tipos de falhas no catálogo:

- Falhas de conteúdo: neste tipo de falha, o valor do serviço disponibilizado não está de acordo com a especificação. Este tipo de falha se caracteriza quando o único domínio associado a esta falha é o valor;

- Falhas temporais: neste tipo de falha, o tempo de resposta relacionado ao serviço não está de acordo com a especificação. Este tipo de falha se caracteriza quando o único domínio associado a esta falha é o valor; 
- Falhas de Conteúdo e Temporal: este tipo de falha se caracteriza quando os domínios tempo e valor estão associados à falha. Conforme (AVIŽIENIS et al., 2004), quando ocorrem falhas tanto no conteúdo quando no tempo, existem duas classes de falhas em relação ao domínio, também representadas no catálogo da Figura 34:

- falhas por paralisação (com um caso especial de falhas por omissão)

○ falhas de instabilidade.

Com base no catálogo representado na Figura 34, a técnica ADSSW propõe a utilização de métodos de decomposição por tipo aplicados em softgoals de requisitos não-funcionais para a decomposição de falhas.

Uma decomposição por tipo de falhas que compõe a técnica recebe o nome de FalhaViaDominio, que decompõe a falha relacionada a um determinado tópico em possíveis modos de falhas de acordo com o domínio. Esta decomposição utiliza uma contribuição $O R$, pois uma falha, de acordo com o seu domínio, pode ser classificada como somente temporal, ou somente de conteúdo, ou temporal e de conteúdo. A ocorrência de uma destas três condições de falha em um tópico é condição suficiente para que se caracterize uma falha em relação a este tópico. Por esta razão utiliza-se a contribuição $O R$ nesta decomposição por tipo. A representação da decomposição por tipo FalhaViaDominio utiliza a mesma notação utilizada para representação da decomposição por tipo de softgoals de requisitos não-funcionais. Portanto, o método FalhaViaDominio pode ser representado conforme a seguinte notação:

OR (\{Falha de Conteúdo [Tópico], Falha Temporal[Tópico],

Falha de Conteúdo e Temporal[Tópico]\})

SATISFAZ Falha [Tópico]

Outra decomposição por tipo corresponde à classificação das falhas de conteúdo e temporal presente no catálogo de falhas. Esta decomposição também utiliza uma decomposição $O R$, pois dentre as falhas de omissão e intermitentes, a ocorrência de um destes tipos de falhas é condição suficiente para se caracterizar uma falha de conteúdo e temporal. Esta decomposição recebe o nome de 
FalhaConteudoTemporalViaCaracteristica, e assim como o método FalhaViaDominio, segue a seguinte notação:

\section{OR (\{Falha de Paralisação [Tópico], Falha Instável [Tópico]\}) \\ SATISFAZ Falha de Conteúdo e Temporal[Tópico]}

No catálogo de falhas representado na Figura 34, verifica-se que falha de omissão é um tipo de falha de paralisação. Como conseqüência desta relação entre falha de omissão e falha de paralisação, a ocorrência de uma falha de omissão, por definição, caracteriza uma falha de paralisação. Na técnica ADSSW considera-se que uma falha de omissão contribui positivamente para a caracterização de falhas de paralisação, e a ocorrência de uma falha de omissão é condição suficiente para caracterizar uma falha de paralisação. Portanto, o inter-relacionamento entre falhas de omissão e falhas de paralisação na técnica proposta é uma contribuição REALIZA. Esta contribuição é representada por meio da seguinte notação:

Falha de Omissão [tópico] REALIZA Falha de Paralisação [tópico]

A Figura 35 ilustra as decomposições FalhaViaDominio e FalhaConteudoTemporalViaCaracteristica, além da contribuição REALIZA entre falha de omissão e falha de paralisação.

Segundo (LAPRIE, 1992), uma falha temporal pode ser classificada em dois tipos de falhas: falha por antecipação ou falha por atraso. Na técnica proposta, esta classificação pode ser representada através de uma decomposição por tipo que utiliza uma contribuição $O R$. No caso de falha por antecipação, esta ocorre devido ao tempo de resposta ser menor do que o valor mínimo especificado, enquanto que o segundo caso ocorre devido ao tempo de resposta ser maior do que o valor máximo especificado. A decomposição de falhas temporais em falhas por antecipação ou falhas por atraso recebe no método o nome de FalhaTemporalViaCaracteristica, e pode ser representada seguindo a notação a seguir:

OR (\{Falha de Antecipação [tópico], Falha por Atraso [tópico]\})

SATISFAZ Falha Temporal [tópico] 


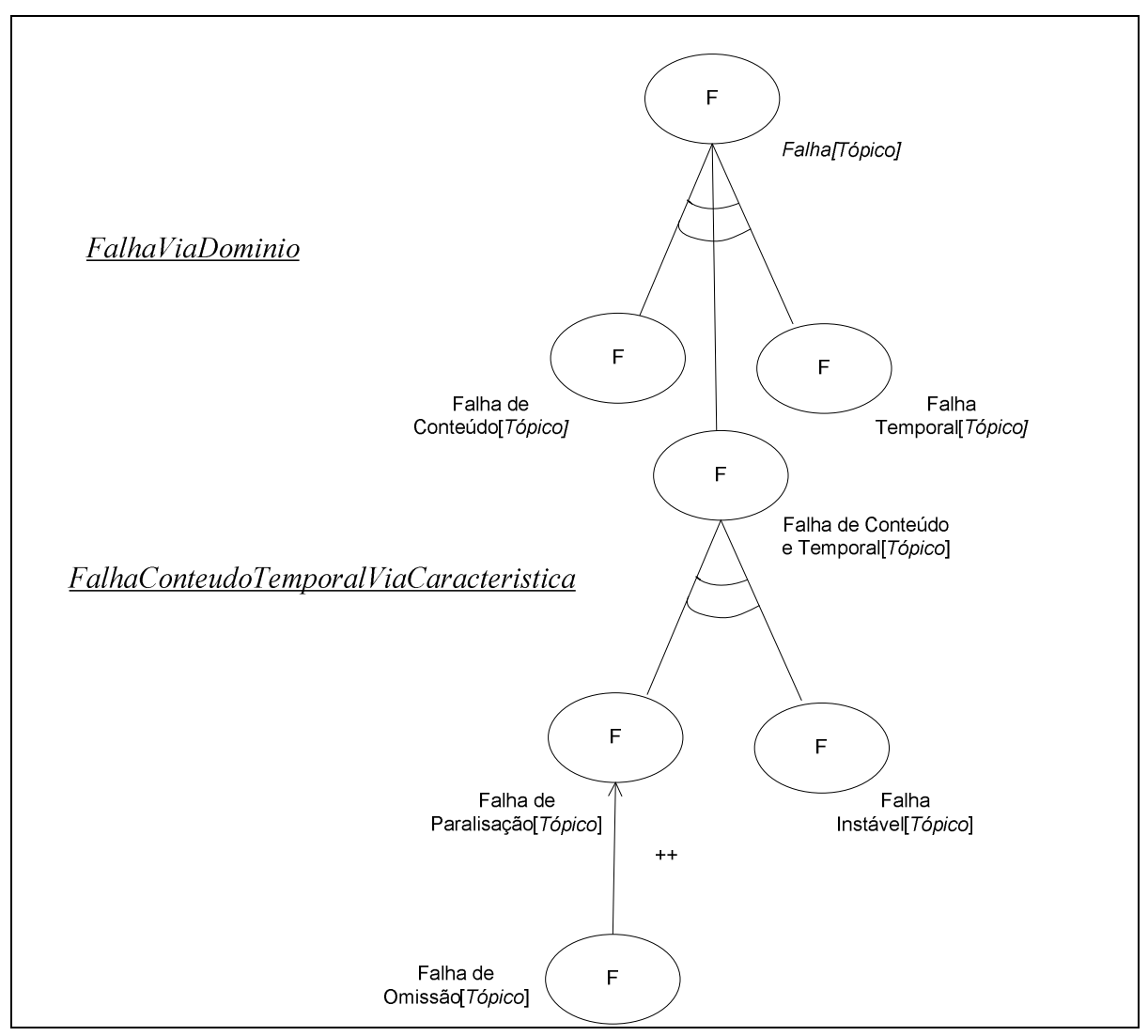

Figura 35 - Decomposição por tipo de falhas

Falhas temporais, por definição, estão relacionadas ao requisito não-funcional desempenho, por meio do atributo tempo de resposta. Uma monitoração do tempo de resposta do tópico que está sob análise corresponde a uma monitoração de um possível ponto de falha, sendo esta falha detectada quando o tempo de resposta deste tópico não está de acordo com os limites estabelecidos na especificação do tópico considerado. Em situações de falha por antecipação, esta se caracteriza quando o tempo de resposta apresentado pelo tópico analisado apresenta um valor menor que o valor mínimo especificado. Já em situações de falha por atraso, esta ocorre devido ao tempo de resposta do componente ultrapassar um valor limite máximo especificado. Portanto, falhas temporais contribuem negativamente para que sejam atingidos níveis desejados de tempo de resposta, sendo o tempo de resposta um dos atributos que caracterizam o requisito não-funcional desempenho. A relação entre falha temporal e tempo de resposta é representada através de uma contribuição ALGO-. A Figura 36 representa a decomposição por tipo e a contribuição de falhas temporais em relação ao tempo de resposta de um determinado tópico. A relação entre tempo de resposta e desempenho, assim como 
a representação de atributos inerentes ao desempenho foi extraída de (CHUNG et al., 2000).

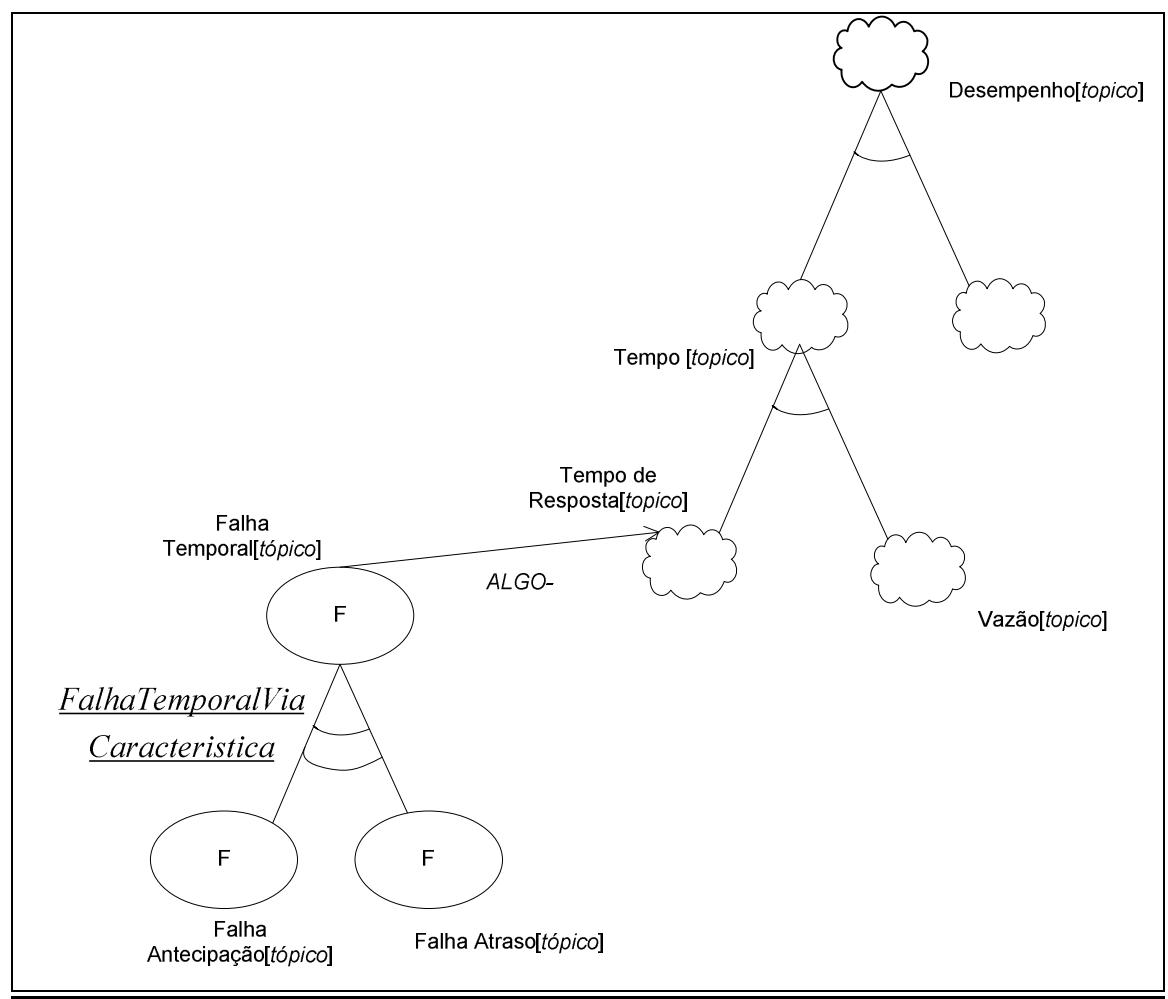

Figura 36 - Representação de Falha Temporal com refinamentos e contribuições

Falhas de conteúdo podem ser detectadas através da informação retornada pelo serviço disponibilizado por um componente. Segundo (AVIŽIENIS et al., 2004), podem ocorrer problemas em valores numéricos, alfanuméricos, conteúdos gráficos, cores, e conteúdos sonoros. A falha de conteúdo em um componente ou funcionalidade se manifesta através da informação retornada pelo componente ou serviço, ocorrendo a falha neste caso quando a informação disponibilizada pelo serviço difere da informação considerada correta. Esta relação será representada no método proposto, por meio de uma operação de decomposição por tópico, onde a falha de conteúdo de um tópico pode ser refinada em uma falha de conteúdo da informação provida por este tópico. A contribuição caracterizada nesta situação corresponde a uma contribuição $R E A L I Z A$, pois a ocorrência de falhas de conteúdo em um componente é condição suficiente para se caracterizar a ocorrência de falhas de conteúdo na informação disponibilizada por este componente. A contribuição REALIZA entre falhas de componente e a falhas de informação disponibilizadas por um componente pode ser representada conforme a seguinte notação: 
Falha de Conteúdo [Componente] REALIZA Falha de Conteúdo

[Informacao_Componente]

A contribuição REALIZA entre falhas de componente e a falhas de informação disponibilizadas por um componente pode ser representada graficamente no diagrama da Figura 37 (a). Existem relações entre falhas de conteúdo e o requisito não-funcional acurácia. A ISO 9126 (ISO, 2001) define acurácia como a capacidade de um sistema gerar resultados precisos e dentro do esperado. Em (CHUNG et al., 2000) este requisito não-funcional é refinado em elementos do framework NFR para lidar com características de acurácia. Os tipos de requisitos de acurácia são mapeados em tipos de softgoals de acurácia. Os softgoals de acurácia utilizam como tópico informações relacionadas ao sistema de software analisado, considerando fluxo de informações presentes neste sistema. Em (CHUNG et al., 2000) também são descritos métodos de operacionalização relacionados à acurácia, categorizados de acordo com seu propósito em: métodos de operacionalização por precaução, utilizados para reduzir as chances de ocorrência ou recorrência de itens de informação imprecisos; métodos de operacionalização preventivos, que têm como objetivo a detecção de possíveis imprecisões em um item de informação e visam prevenir que estas informações se espalhem por todo o sistema; e métodos curativos, que visam recuperar possíveis fontes de informações imprecisas.

A relação entre falhas de conteúdo e acurácia é representada no método proposto. Falhas de conteúdo relacionadas a uma informação fornecida por um componente ou funcionalidade contribuem negativamente com a acurácia desta informação. Considera-se no método proposto que uma falha de conteúdo é suficiente para negar a acurácia de uma determinada configuração, constituído uma contribuição do tipo QUEBRA. Esta relação pode ser representada com a mesma descrição sintática utilizada para a representação de contribuições QUEBRA apresentada no capítulo 2, e é representada a seguir. Esta relação também pode ser representada graficamente no diagrama da Figura 37 (b). 


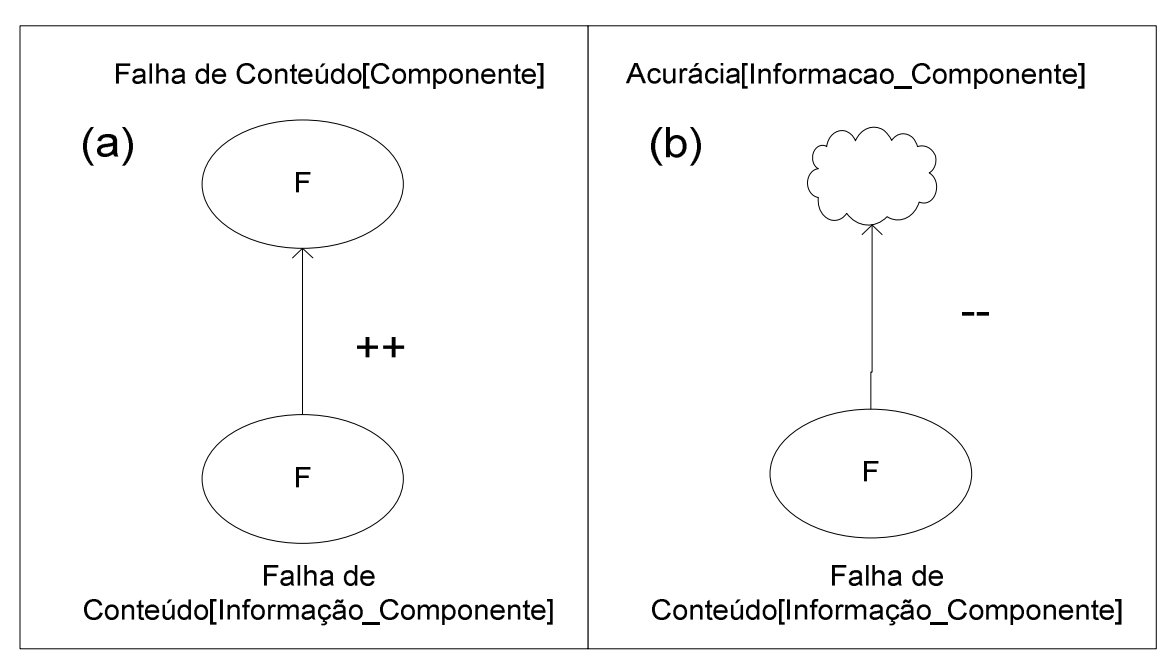

Figura 37 - Refinamentos e contribuições associadas a falhas de conteúdo

(LAPRIE, 1992) e (AVIŽIENIS et al., 2004) estabeleceram uma cadeia fundamental de ameaças de dependabilidade, indicando mecanismos de criação e de manifestação das ameaças. De forma resumida, defeitos ativam erros em um componente, que se propagam em falhas na interfaces deste componente, que pode causar defeitos sob a óptica de um outro componente. Esta cadeia fundamental de ameaças será representada na técnica proposta por meio de contribuições $A U X I L I A$, uma vez que a ocorrência de uma ameaça contribui positivamente para o ocorrência de outra ameaça encadeada, mas o encadeamento pode ser evitado com a adoção de meios de tolerância a defeitos. A Figura 38 representa o encadeamento entre defeitos, erros e falhas no método, com um exemplo de contribuições decorrentes deste encadeamento. No exemplo, um defeito em relação ao componente "Componente_A" ativa um erro no "Componente_A", que se propaga pela interface do componente, caracterizando uma falha no "Componente_A". No exemplo, considera-se que a falha no "Componente_A" pode causar um defeito no “Componente_B”.

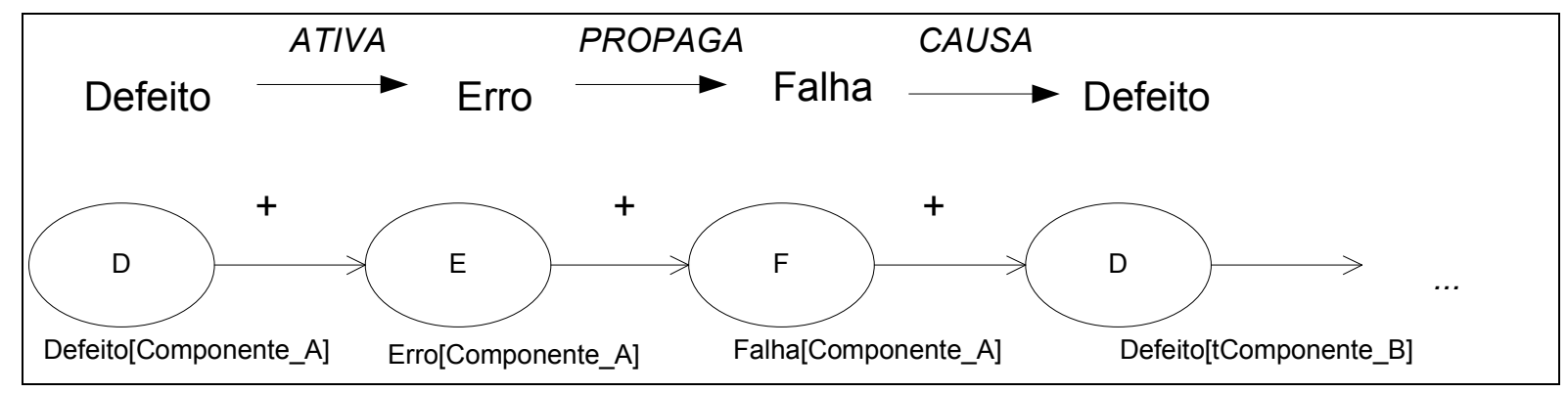

Figura 38 - Representação de encadeamento entre defeitos, erros e falhas na técnica 
O encadeamento presente na Figura 38 pode ser representado através das notações:

\author{
Defeito [Componente_A] AUXILIA Erro [Componente_A] \\ Erro [Componente_A] AUXILIA Falha [Componente_A] \\ Falha [Componente_A] AUXILIA Defeito [Componente_B]
}

Na técnica proposta, a análise de ameaças à dependabilidade do sistema de software se inicia com a análise de possíveis falhas que podem afetar os serviços oferecidos por componentes atômicos no sistema. Em um primeiro momento, não são modelados os possíveis erros e os possíveis defeitos que resultaram na falha do serviço fornecido pelo componente atômico. Como exemplo desta característica da técnica, considera-se uma situação na qual um componente responsável pelo processamento de uma regra de negócio apresenta uma falha de conteúdo devido ao fato de que um parâmetro com valor inválido foi digitado por um usuário do sistema. Nesta situação, pode-se considerar, por exemplo, que o defeito foi provocado na fase de desenvolvimento do componente, uma vez que o componente deveria alertar o usuário de que um valor inválido foi informado, e não processar a regra e informar um valor incorreto. Na técnica ADSSW, não será considerado o defeito de desenvolvimento, mas somente a falha de conteúdo associada ao componente atômico em questão. $O$ tratamento a defeitos e erros que podem vir a provocar falhas em componentes atômicos poderá ser incorporado na técnica em trabalhos futuros.

Como o componente atômico pertence ao contexto de um sistema de software, uma das etapas do método é verificar quais os efeitos das falhas em relação ao sistema de software como um todo. Para que isto seja possível, a conceituação de encadeamento de ameaças presente no método possui um papel fundamental, em que a falha do serviço de um componente atômico pode ser considerada um defeito de outro componente, que podem ativar erros neste outro componente, e propagarse em falhas no serviço oferecido por este outro componente. Estas falhas, por sua vez, contribuem negativamente para a disponibilidade deste outro componente.

$\mathrm{Na}$ técnica proposta, considera-se que a falha seja a única ameaça que se relaciona diretamente com softgoals associados a atributos de dependabilidade. Defeitos e erros não se relacionam diretamente com estes atributos, pois não necessariamente 
resultam em serviços incorretos, e os atributos de qualidade possuem características relacionadas a fornecimento de serviços corretos e incorretos.

Uma classificação de erros, segundo (AVIŽIENIS et al., 2004), pode ser descrita de forma semelhante à terminologia utilizada para a descrição de falhas de serviço que estes podem provocar. Desta forma, na técnica proposta os erros são classificados de acordo com o domínio das falhas que sua propagação pode causar.

Conforme descrito anteriormente neste trabalho, a técnica ADSSW tem como objetivo auxiliar a geração de cenários de disponibilidade. Uma etapa posterior à geração de cenários de disponibilidade corresponde à identificação de possíveis táticas arquitetônicas relacionadas a meios de tolerância a defeitos, que têm como objetivo atingir a resposta desejada associada ao cenário identificado. Para que a técnica ADSSW possa prover um suporte à geração de táticas arquitetônicas relacionadas aos cenários identificados, existe a necessidade de incorporar à técnica elementos que permitam representá-las, identificar as conseqüências das aplicações destas táticas em atributos de dependabilidade, e identificar as conseqüências destas táticas em relação a outros requisitos não-funcionais. Em trabalhos futuros, na técnica ADSSW existe a possibilidade de inclusão de elementos de operacionalização descritos no framework NFR. Conforme descrição apresentada no capítulo 2, operacionalizações no framework NFR correspondem a técnicas de desenvolvimento e decisões de projeto utilizadas para satisfazer determinados requisitos não-funcionais, sendo representados através de softgoals de operacionalização. (CHUNG et al., 2000) descrevem elementos que permitem correlacionar softgoals de operacionalização com softgoals de requisitos nãofuncionais.

\subsection{Técnica ADSSW}

$\mathrm{Na}$ seção anterior, foram descritos os elementos da técnica proposta. Conforme visto na seção 4.3, a técnica ADSSW utiliza elementos presentes no framework NFR (CHUNG et al., 2000) para a representação de conceitos de dependabilidade descritos em (LAPRIE, 1992) e (AVIŽIENIS et al., 2004). O conceito de modelagem hierárquica de disponibilidade em sistemas e-business proposta em (KAÂNICHE; KANOUN; RABAH, 2001) contribui para a definição de decomposições por tópico 
presentes na técnica. Por fim, a técnica provê a geração de cenários de disponibilidade, cuja definição está presente em (BASS; CLEMENTS; KAZMAN, 2003).

De forma resumida, a técnica é composta pelos seguintes elementos:

1. Catálogo de softgoals de requisitos não-funcionais, que podem representar atributos de dependabilidade;

2. Entidades que representam ameaças a disponibilidade (defeitos, erros e falhas);

3. Catálogo de métodos de refinamento, composto por:

a) Decomposição por tipo de softgoals, em que a dependabilidade do sistema de software pode ser decomposta em atributos de dependabilidade;

b) Priorização da disponibilidade percebida por um determinado perfil de usuário;

c) Priorização da disponibilidade de uma determinada funcionalidade do sistema;

d) Métodos de decomposição por tópico de softgoals de disponibilidade, composto por:

- Decomposição do sistema de software por perfil operacional de usuário;

- Decomposição do sistema de software em funcionalidades, sendo estas associadas ou não a um determinado perfil;

- Decomposição da funcionalidade do sistema em componentes responsáveis por prover a funcionalidade;

- Decomposição do componente em outros componentes, que interagem para determinar o comportamento do componente original.

e) Decomposição por tipo para falhas; 
f) Contribuição entre falhas e softgoals de disponibilidade;

g) Contribuição entre falhas temporais e softgoal de tempo de resposta;

h) Contribuição entre falhas de conteúdo e softgoal de acurácia;

i) Contribuições entre defeitos, erros e falhas.

Para auxiliar a geração de cenários de disponibilidade propõe-se a aplicação da técnica ADSSW em duas etapas principais. A primeira etapa corresponde à geração do grafo de disponibilidade relacionado ao sistema de software sob análise. A construção deste grafo se baseará nos elementos descritos anteriormente. A segunda etapa corresponde a aplicação de um procedimento de avaliação no grafo gerado na etapa anterior. Como resultado do procedimento de avaliação, obtém-se uma tabela contendo as ameaças identificadas, com softgoals de disponibilidade afetados por cada ameaça. Esta tabela será utilizada para a geração de cenários de disponibilidade para o sistema de software sob análise.

\subsubsection{Primeira Etapa - Geração do Grafo}

A primeira etapa consiste nos seguintes passos:

1. Para a avaliação da dependabilidade do sistema como um todo, aplicar a decomposição por tipo SistemaSoftwareWebDependabilidadeViaSubTipo. Esta aplicação gera o softgoal relacionado à disponibilidade do sistema de software.

2. Caso seja relevante para o sistema avaliar a disponibilidade percebida pelo perfil do usuário, a decomposição SistemaSoftwareWebDisponibilidadeViaPerfil deve ser aplicada para a criação de softgoals que permitam que se avalie isoladamente a disponibilidade relacionada a perfis de usuários distintos.

3. Caso algum perfil operacional apresente uma necessidade maior de disponibilidade do sistema, devem ser gerados softgoals que indiquem a priorização de softgoals que representam a disponbilidade percebida por esse perfil operacional. 
4. Caso os passos 2 e 3 não tenham sido executados, deve ser aplicada a decomposição SistemaSoftwareWebDisponibilidadeViaFuncionalidade para a decomposição do sistema de software, visando a análise de cada funcionalidade oferecida pelo sistema. Caso contrário, deve ser aplicado a decomposição SistemaSoftwareWebDisponibilidadePerfilViaFuncionalidade, em que cada softgoal relacionado a um perfil operacional deve ser decomposto em softgoals que representem as funcionalidades às quais esse perfil operacional sob análise tem acesso.

5. Caso alguma funcionalidade apresente uma necessidade maior de disponibilidade em relação às demais funcionalidades do sistema, devem ser gerados softgoals que indiquem a priorização de softgoals que representem a disponibilidade associada a essa funcionalidade.

6. Aplicação da decomposição por tópico SistemaSoftwareWebDisponibilidadeFuncViaCamada, em que cada funcionalidade é decomposta em três componentes distintos: componente responsável por disponibilizar serviços relacionados a camada de apresentação, componente responsável por disponibilizar serviços relacionados ao processamento de regras de negócio do sistema de software, e componente de integração, responsável por efetuar acesso a dados do sistema e a serviços externos.

7. Esta etapa do método pode ser realizada mais de uma vez sucessivamente, consistindo na aplicação da decomposição por tópico SistemaSoftwareWebDisponibilidadeComponenteViaComponente. Baseado no principio de que um componente pode ser subdividido em outros componentes, cada softgoal gerado apresenta como tópicos os componentes resultantes da subdivisão do componente analisado anteriormente. Esta etapa pode ser repetida até restarem somente componentes considerados atômicos, ou seja, quando não existe a possibilidade ou a necessidade de se dividir os componentes. 
8. Uma vez identificados os componentes considerados atômicos no sistema, estes serão analisados, verificando-se as possíveis falhas que possam ocorrer nos serviços disponibilizados por eles.

9. Neste passo, cada falha deve ser caracterizada, sendo explicitadas as relações entre falhas e requisitos não-funcionais.

10. Neste passo deve ser representada a contribuição negativa que possa ocorrer entre falhas dos componentes atômicos e a disponibilidade do componente atômico.

11. A partir das falhas dos componentes atômicos, deve-se verificar quais ameaças à dependabilidade podem ser conseqüências da ocorrência de falhas em relação a outros componentes que utilizem os serviços dos componentes atômicos. Neste passo, serão representadas as contribuições entre ameaças de dependabilidade em componentes.

12. À medida que falhas forem identificadas em componentes do sistema, quando estas afetam a disponibilidade de um determinado componente, deverão ser representadas no grafo as contribuições negativas em relação ao softgoal de disponibilidade associado a este componente.

Com a aplicação dos passos citados, obtém-se um grafo de disponibilidade do sistema de software. Neste grafo estão dispostas as relações entre ameaças à dependabilidade e atributos de qualidade a serem considerados na análise do sistema. Efetuada esta etapa, o próximo passo corresponde à aplicação do procedimento de avaliação.

\subsubsection{Segunda etapa - Aplicação do procedimento de avaliação}

O procedimento de avaliação é um conceito do framework NFR que determina o impacto de decisões de projeto no atendimento aos requisitos não-funcionais (CHUNG et al., 2000). Dado um grafo, completo ou incompleto, o procedimento de avaliação determina se cada softgoal ou interdependência no grafo é considerado satisfatório. A segunda etapa da técnica baseia-se no procedimento de avaliação 
descrito no framework NFR aplicado ao grafo de interdependências obtido. O objetivo é avaliar qualitativamente o relacionamento entre falhas, isto é, estímulos de cenários de disponibilidade, e as possíveis respostas do sistema associadas aos softgoals de disponibilidade. Na técnica proposta, considera-se que falhas de componentes servirão como estímulos para a geração de cenários de disponibilidade. Como falhas de componentes podem ser monitoradas, os resultados da monitoração constituem respostas do sistema na ocorrência daqueles estímulos. Desse modo, existe a possibilidade de se relacionar, para cada possível falha identificada, quais são os componentes, perfis operacionais e funcionalidades que podem ter o nível de disponibilidade afetado. Os relacionamentos identificados permitem o estabelecimento de níveis desejados de disponibilidade na ocorrência dos estímulos, resultando em cenários de disponibilidade. Por outro lado, os softgoals que representam a disponibilidade associada aos perfis operacionais, funcionalidades e componentes são relacionados a esses estímulos. Em suma, a segunda etapa corresponde à aplicação de um procedimento de avaliação, visando a criação de uma tabela que reúna todos os elementos utilizados na geração de cenários de disponibilidade para o sistema analisado.

O procedimento de avaliação no framework NFR baseia-se na associação de rótulos a softgoals presentes no SIG. Antes de se analisar possíveis valores associados aos rótulos, são apresentados conceitos importantes no framework NFR: satisficed, satisficeable, denied e deniable ${ }^{3}$. Quando o desenvolvedor considera que um softgoal é considerado satisfatório em limites aceitáveis interpretados qualitativamente, diz-se que o softgoal é considerado satisficed. Caso o softgoal seja considerado qualitativamente insatisfatório, o softgoal é considerado denied. Se o softgoal for considerado potencialmente satisfatório, diz-se que o softgoal é satisficeable. Se em contrapartida o softogal for considerado potencialmente insatisfatório em limites aceitáveis interpretados qualitativamente, diz-se que 0 softgoal é considerado deniable.

A razão pela qual os termos satisficeable e deniable são adotados no framework NFR explica-se pelo fato de que um determinado softgoal pode receber tanto contribuições negativas quanto contribuições positivas de outros softgoals. Um

\footnotetext{
${ }^{3}$ Como foi dito em uma nota anterior, neste trabalho serão mantidos os nomes originais em inglês para aqueles cuja tradução em português não seja trivial.
} 
softgoal considerado satisficeable pode ser considerado satificed caso não receba contribuição negativa de nenhum softgoal de operacionalização. Caso seja aplicado um softgoal de operacionalização que impacte negativamente o softgoal sob análise, o softgoal antes satisficeable pode ser considerado insatisfatório. Portanto, é necessário distinguir satisficeable de satisficed e deniable de denied.

No framework NFR, o procedimento de avaliação é útil na seleção entre decisões alternativas de projeto, em que o desenvolvedor pode utilizar o procedimento para avaliar o impacto de uma seleção em particular em determinados requisitos nãofuncionais representados por softgoals. Se uma seleção de uma decisão impacta negativamente softgoals importantes, o desenvolvedor pode rejeitá-la, escolhendo outra possível solução e novamente utilizar o procedimento de avaliação para verificar o impacto de suas escolhas. Com a repetição do processo, os desenvolvedores podem realizar a escolha de decisões de forma a obter soluções com prejuízos mínimos. No framework NFR as decisões de projetos são representadas por softgoals de operacionalização, geralmente localizadas em níveis inferiores no grafo. As decisões de aceitar ou rejeitar alternativas se dão através da associação de rótulos aos respectivos softgoals de operacionalização. Rótulos também podem ser associados a softgoals de requisitos não-funcionais e softgoals de argumentação localizados em níveis inferiores do SIG. O procedimento de avaliação presente no framework NFR utiliza rótulos para avaliar o impacto de decisões em outros softgoals, inclusive em softgoals localizados na parte superior do grafo.

O procedimento de avaliação do framework NFR associa os seguintes rótulos aos softgoals para análise de decisões (CHUNG et al., 2000):

- Satisficed ( $\checkmark$ ou S) se o softgoal for considerado satisficeable e não denied;

- Denied (X ou D) se o softgoal for considerado deniable, mas não satisficeable;

- Conflitante (pode ser representado graficamente pela figura de um raio no SIG, ou pela letra C) se um softgoal for considerado simultaneamente satisficeable e deniable;

- Indeterminado (representado por um caractere $U$ ou por um softgoal sem nenhuma marcação) se o softgoal não for considerado nem satisficeable e 
nem denied. Ao se introduzir um softgoal em um grafo, este softgoal assume automaticamente este rótulo;

- Fracamente positivo (do termo em inglês weak positive, representado pela sigla $\mathrm{W}^{+}$) representando uma situação na qual existe um suporte positivo inconclusivo em relação ao softgoal que recebe uma contribuição;

- Fracamente negativo (do termo em inglês weak negative, representado pela sigla $W^{-}$) representando uma situação na qual existe um suporte negativo inconclusivo em relação ao softgoal que recebe uma contribuição.

Os dois últimos rótulos (fracamente positivo e fracamente negativo) representam situações nas quais um determinado softgoal apresenta evidências inconclusivas em relação à adoção de um rótulo satisficed ou denied.

Quando um rótulo é associado a um softgoal presente no SIG, o procedimento de avaliação é ativado, iniciando-se a propagação de rótulos de softgoals que estão em um nível inferior para softgoals que estão em um nível superior. Esta propagação ocorre em duas etapas. Na primeira etapa, para um determinado softgoal presente no SIG, o procedimento inicialmente determina o impacto individual de cada interdependência associada a este softgoal. Em uma segunda etapa, os impactos individuais de todas as interdependências são combinados em um único rótulo que deverá ser associado ao softgoal.

A primeira etapa da propagação de rótulos no procedimento de avaliação determina o impacto individual de interdependências entre softgoals. Para cada interdependência descrita no framework NFR, existem regras para se determinar os resultados da propagação de rótulos. Para contribuições $A N D$ e $O R$, são definidas em (CHUNG et al., 2000) as seguintes regras:

IF sub-softgals_1 AND sub-softgals_2 ... AND sub-softgals_n SATISFAZEM softgoal THEN rótulo $($ softgoal $)=\min _{i}($ rótulo $($ sub-softgoals $)$ )

IF sub-softgals_1 OR sub-softgals_2 ... OR sub-softgals_n SATISFAZEM softgoal THEN rótulo $($ softgoal $)=\max _{\mathrm{i}}\left(\right.$ rótulo $\left(\right.$ sub-softgoals $\left.\left.\mathrm{s}_{\mathrm{i}}\right)\right)$

Estas regras indicam que para a contribuição do tipo $A N D$, o softgoal em questão recebe o rótulo mínimo dentre os softgoals que realizam uma contribuição sobre ele. Para contribuição do tipo $O R$, o softgoal em questão recebe o rótulo máximo dentre os softgoals que realizam uma contribuição sobre ele. 
Para o estabelecimento de valores mínimo e máximo para a aplicação da regra citada, o framework NFR utiliza a seguinte ordenação de rótulos:

$$
\mathrm{X} \leq \mathrm{U} \approx \mathrm{C} \leq \checkmark
$$

Percebe-se que rótulo mínimo é o rótulo $X$ e o rótulo $\checkmark$ é o rótulo máximo para análise de contribuições AND e OR. Na definição de (CHUNG et al., 2000) para a primeira etapa, considera-se que não existe uma ordenação específica entre os rótulos $\mathrm{U}$ e $\mathrm{C}$, que são considerados maiores que o rótulo rótulos $\mathrm{X}$ e menores que $\mathrm{o}$ rótulo $\checkmark$. A presença dos rótulos $U$ e $C$ podem requerer intervenção do desenvolvedor para análise.

Para a avaliação de contribuições individuais em relação a possíveis valores de rótulos, são definidas as seguintes regras no procedimento de avaliação:

- REALIZA: esta contribuição propaga rótulos $\checkmark$ e X para o softgoal que recebe a contribuição;

- QUEBRA: esta contribuição converte o rótulo $\checkmark$ de quem realiza a contribuição para um rótulo $X$ no softgoal que recebe esta contribuição. Se o softgoal que contribui apresenta um rótulo $\mathrm{X}$, o rótulo para o softgoal que recebe a contribuição corresponde a $\mathrm{W}^{+}$. De acordo com (CHUNG et al., 2000), isto ocorre seguindo a premissa de que a não ocorrência de algo negativo pode ser útil, mas não necessariamente resulta em um resultado positivo;

- $A U X I L I A$ : esta contribuição mantém a mesma natureza do rótulo associado ao softgoal que efetua a contribuição, mas diminui sua intensidade. Isto significa que $\circ$ rótulo $\checkmark$ é propagado como $\mathrm{W}^{+}$para o softgoal que recebe a contribuição, enquanto que o rótulo $X$ é propagado como $W^{-}$;

- FERE: esta contribuição inverte a natureza do rótulo associado ao softgoal que efetua a contribuição, diminuindo a sua intensidade. Isto significa que o rótulo $\checkmark$ é propagado como $W^{-}$para o softgoal que recebe a contribuição, enquanto que o rótulo $\mathrm{X}$ é propagado como $\mathrm{W}^{+}$;

- ALGO+: esta contribuição considera os resultados decorrentes das contribuições $A U X I L I A$ e REALIZA, e utiliza o rótulo que apresenta a menor intensidade como resultado; 
- ALGO-: esta contribuição considera os resultados decorrentes das contribuições FERE e QUEBRA, e utiliza o rótulo que apresenta menor intensidade como resultado.

Segundo (CHUNG et al., 2000), o rótulo C propaga-se como C, e o rótulo U propaga-se como $U$, independentemente da contribuição.

As combinações de rótulos associados aos softgoals resultantes das contribuições individuais presentes no framework NFR são apresentadas na Tabela 5, extraída de (CHUNG et al., 2000).

Tabela 5 - Impacto de contribuições individuais segundo o procedimento de avaliação presente no framework NFR

\begin{tabular}{|c|c|c|c|c|c|c|}
\hline Rótulo & \multicolumn{6}{|c|}{ Rótulo associado ao softgoal que recebe a contribuição } \\
\hline $\begin{array}{l}\text { associado } \\
\text { ao softgoal } \\
\text { que realiza } \\
\text { a } \\
\text { contribuição }\end{array}$ & QUEBRA & ALGO- & FERE & $A U X I L I A$ & $A L G O+$ & $R E A L I Z A$ \\
\hline $\mathrm{X}$ & $\mathrm{W}^{+}$ & $\mathrm{W}^{+}$ & $\mathrm{W}^{+}$ & $\mathrm{W}^{-}$ & $\mathrm{W}^{-}$ & $\mathrm{X}$ \\
\hline $\mathrm{C}$ & $\mathrm{C}$ & $\mathrm{C}$ & $\mathrm{C}$ & $\mathrm{C}$ & $\mathrm{C}$ & $\mathrm{C}$ \\
\hline $\mathrm{U}$ & $\mathrm{U}$ & $\mathrm{U}$ & U & U & $\mathrm{U}$ & $\mathrm{U}$ \\
\hline$\checkmark$ & $X$ & $\mathrm{~W}^{-}$ & $\mathrm{W}^{-}$ & $\mathrm{W}^{+}$ & $\mathrm{W}^{+}$ & $\checkmark$ \\
\hline
\end{tabular}

Fonte: (CHUNG et al., 2000)

$\mathrm{Na}$ Tabela 5 nota-se que os rótulos $\mathrm{W}^{+}$e $\mathrm{W}^{-}$não são utilizados como rótulos associados aos softgoals que realizam a contribuição. A razão pela qual isto ocorre justifica-se pelo fato de que na segunda etapa do procedimento de avaliação recomenda-se a eliminação desses valores. Segundo a descrição do procedimento apresentada em (CHUNG et al., 2000), os rótulos $\mathrm{W}^{+}$e $\mathrm{W}^{-}$podem ser combinados na segunda etapa em um ou mais rótulos $\checkmark, X, C$ e U. Normalmente rótulos do tipo $W^{+}$isolados podem resultar em rótulos $\checkmark$ ou $U$, enquanto que rótulos do tipo $W$ isolados podem resultar em rótulos $\mathrm{X}$ ou $\mathrm{U}$. Uma situação na qual ocorre um mistura de rótulos $\mathrm{W}^{+} \mathrm{e} \mathrm{W}^{-}$pode resultar em um rótulo $\checkmark, \mathrm{X}$ ou $\mathrm{C}$. 
Uma vez definidos os valores dos rótulos resultantes de contribuições para um dado softgoal, aplica-se uma segunda etapa da avaliação, na qual um único rótulo é associado. Todos os rótulos resultantes das contribuições são agrupados em uma coleção ${ }^{4}$. Conforme descrito anteriormente, caso existam rótulos $\mathrm{W}^{+}$e $\mathrm{W}^{-}$, estes são combinados pelo desenvolvedor que realiza a análise em um ou mais rótulos de outros tipos $(\checkmark, X, C$ e U). Após a realização desta combinação, a coleção de rótulos é combinada em um único rótulo mínimo resultante desta combinação. Sua determinação decorre da seguinte ordenação:

\section{$\mathrm{C} \leq \mathrm{U} \leq \mathrm{X} \approx \checkmark$}

Se ambos os valores $\checkmark$ e $X$ estiverem presentes, e não existirem contribuições do tipo $A L G O+$ e $A L G O$-, o rótulo resultante será o rótulo de conflito (C). Na descrição da segunda etapa de avaliação, não existe uma ordenação específica entre os rótulos $X$ e $\checkmark$, e são os valores máximos que um rótulo pode assumir.

$\mathrm{Na}$ descrição do procedimento de avaliação do framework NFR, é ressaltada a possibilidade de a equipe que aplica o procedimento de avaliação utilizar sua experiência e conhecimento sobre o domínio da aplicação para a resolução de conflitos. Esta possibilidade existe em possíveis substituições de rótulos $C$ por valores que a equipe possa vir a considerar adequados, e em situações de eliminação de rótulos $W^{+}$e $W^{-}$na segunda etapa. Em (CHUNG et al., 2000) os autores citam uma extensão do procedimento de avaliação, que mantém rótulos $\mathrm{W}^{+}$ e W` na segunda etapa de análise do softgoal, possibilitando que estes rótulos sejam considerados no decorrer do procedimento de avaliação. Para que esta extensão seja possível, existe a necessidade de se associar regras de propagação de rótulos para os rótulos $\mathrm{W}^{+}$e $\mathrm{W}^{\text {. }}$.

$\mathrm{Na}$ técnica ADSSW, é adotado um procedimento de avaliação que tem como objetivo relacionar ameaças à dependabilidade com softgoals de disponibilidade. Este procedimento de avaliação baseia-se no procedimento de avaliação do framework NFR. Inicialmente, existe a necessidade de se rotular os elementos que representam ameaças à dependabilidade. Basicamente existe a necessidade de dois rótulos: um que indique a ocorrência da ameaça, e outro que indique a não-

\footnotetext{
${ }^{4}$ Cabe ressaltar que esta coleção não é um conjunto, uma vez que permite itens duplicados, diferentemente de um conjunto.
} 
ocorrência, ou ausência destas ameaças. Com o intuito de se manter as regras de propagação de rótulos presentes no procedimento de avaliação do framework NFR, são utilizados os seguintes rótulos:

- Satisficed ( $\checkmark$ ou S): quando este rótulo é associado a uma ameaça à dependabilidade, significa a ocorrência da ameaça;

- Denied (X ou D) quando este rótulo é associado a uma ameaça à dependabilidade, significa a ausência da ameaça.

A adoção destes rótulos para representar a ocorrência de falhas assemelha-se à utilização deles para aceitar ou rejeitar softgoals de operacionalização no procedimento de avaliação do framework NFR. Enquanto que o objetivo principal do procedimento de avaliação do framework NFR é o de avaliar o impacto de decisões de projeto em softgoals de requisitos não-funcionais, o objetivo do procedimento da técnica ADSSW é o de avaliar quais softgoals relacionados ao requisito nãofuncional disponibilidade são afetados pela ocorrência de ameaças à dependabilidade.

Diferentemente de softgoals que apresentam como valor inicial o rótulo $U$, o valor inicial associado a ameaças à dependabilidade é o rótulo $X$. Ao se inserir no grafo um elemento de ameaça a dependabilidade, este assume este valor, indicando que a análise da ocorrência da ameaça representada não foi efetuada. Portanto, na técnica proposta, uma ameaça que não apresenta graficamente um rótulo associado pode ser considerada uma ameaça denied.

Para cada ameaça a ser analisada, marca-se com o rótulo $\checkmark$ o elemento que a representa no grafo. A propagação de rótulos segue as regras definidas no framework NFR. Ou seja, para contribuição do tipo $O R$, o rótulo resultante é o rótulo máximo, e para contribuições $A N D$ considera-se o rótulo mínimo como o rótulo resultante. Ao se avaliar o impacto de contribuições individuais entre softgoals e ameaças, observa-se na descrição da técnica apresentada na seção anterior que:

- Os softgoals de requisitos não-funcionais (disponibilidade, desempenho, representado por tempo de resposta e acurácia) recebem somente contribuições individuais negativas, decorrentes de ameaças a dependabilidade representadas na técnica; 
- As ameaças à dependabilidade representadas na técnica recebem somente contribuições individuais positivas, decorrentes do encadeamento de ameaças definidos de acordo com (LAPRIE, 1992).

Como pode ser observado, não existem situações de conflito em casos de contribuição individual; softgoals que representam requisitos não-funcionais recebem somente contribuições individuais negativas, enquanto que ameaças recebem contribuições positivas. Isto ocorre porque decisões arquitetônicas que poderiam impactar positivamente em softgoals de requisitos não-funcionais, e negativamente em ameaças (através de técnicas de prevenção de sua ocorrência, por exemplo) não são consideradas inicialmente na técnica ADSSW. Estas decisões não são consideradas porque a técnica inicialmente se restringe à elicitar cenários de disponibilidade e não avaliar táticas arquitetônicas relacionadas aos cenários. Como não existem conflitos em contribuições na técnica ADSSW, não se utilizam os rótulos $W^{+}$e $W^{-}$, uma vez que estes rótulos são utilizados para a resolução de possíveis situações de conflitos. Desta forma, enquanto o procedimento de avaliação inicialmente descrito no framework NFR elimina os rótulos somente na segunda etapa de análise do softgoal, o procedimento de avaliação descrito na técnica ADSSW não os utiliza, empregando o rótulo $\checkmark$ em situações nas quais o resultado da contribuição resulta no rótulo $\mathrm{W}^{+}$, e o rótulo $\mathrm{X}$ em situações nas quais o resultado da contribuição resulta no no rótulo $W^{-}$. Portanto, o resultado das contribuições individuais no procedimento de avaliação adotado na técnica da ADSSW pode ser sumarizado na Tabela 6. Observa-se que o conteúdo desta tabela assemelha-se ao conteúdo da Tabela 5, ocorrendo a substituição somente dos rótulos $\mathrm{W}^{+}$e W: 
Tabela 6 - Impacto de contribuições individuais segundo o procedimento de avaliação presente na técnica ADSSW

\begin{tabular}{|c|c|c|c|c|c|c|}
\hline $\begin{array}{c}\text { Rótulo } \\
\text { associado ao } \\
\text { softgoal que } \\
\begin{array}{c}\text { realiza a } \\
\text { contribuição }\end{array}\end{array}$ & \multicolumn{5}{|c|}{ Rótulo associado ao softgoal que recebe a contribuição } \\
\cline { 2 - 7 } & QUEBRA & ALGO- & FERE & AUXILIA & ALGO+ & REALIZA \\
\hline X & $\checkmark$ & $\checkmark$ & $\checkmark$ & X & X & X \\
\hline C & C & C & C & C & C & C \\
\hline U & U & U & U & U & U & U \\
\hline$\checkmark$ & X & X & X & $\checkmark$ & $\checkmark$ & $\checkmark$ \\
\hline
\end{tabular}

O algoritmo de propagação de rótulos, aplicado de acordo com as interdependências presentes no grafo, permite identificar quais ameaças são encadeadas e quais softgoals de requisitos não-funcionais são afetados pela ameaça. Para cada falha analisada, os softgoals de disponibilidade marcados com o rótulo $\mathrm{X}$ e as ameaças marcadas com o rótulo $\checkmark$ são relacionados à falha analisada. Estas informações são então agrupadas em uma tabela, cujo formato é apresentado no exemplo ilustrado na Tabela 7.

Tabela 7 - Tabela representando falha com softgoals e ameaças relacionadas

\begin{tabular}{|c|c|c|c|}
\hline Estímulos & Softgoals - Disponibilidade & $\mathbf{P}$ & Ameaças encadeadas \\
\hline $\begin{array}{c}\text { Falha } \\
\text { Temporal[ } \\
\text { SGBD] }\end{array}$ & Disponibilidade[Pagamento & Tributos, Camada Integração] & $\begin{array}{c}\text { Erro Temporal } \\
\text { [Pagamento Tributos, } \\
\text { Camada Integração] }\end{array}$ \\
\cline { 2 - 4 } & $\begin{array}{c}\text { Disponibilidade[Pagamento } \\
\text { Tributos] }\end{array}$ & $\checkmark$ & $\begin{array}{c}\text { Falha Temporal } \\
\text { [Pagamento Tributos, } \\
\text { Camada Integração] }\end{array}$ \\
\cline { 2 - 4 } & Disponibilidade[PerfilEspecial] & & \\
\cline { 2 - 4 } & Disponibilidade[PerfilEspecial] & & \\
\cline { 2 - 4 } & & & \\
\hline
\end{tabular}

A primeira coluna (Estímulos) contém possíveis estímulos, representando elementos de falhas do grafo a ser avaliado. A segunda coluna (Softgoals Disponibilidade) contém os softgoals de disponibilidade afetados pelo estímulo, que servirão de base para a definição de respostas do sistema para cenários de 
disponibilidade. A terceira coluna $(\mathrm{P})$ está relacionada diretamente à segunda coluna, e marcações nesta coluna indicam que os softgoals da segunda coluna são marcados como prioritários no grafo. Esta coluna auxilia a priorização de cenários de disponibilidade. Por fim, a quarta coluna contém as ameaças relacionadas à ameaça presente na primeira coluna.

À medida que o procedimento de avaliação é executado no grafo sob análise, informações são adicionadas à tabela. Para cada falha a ser considerada como estímulo, o preenchimento da tabela deve ser realizado da seguinte forma:

- Ao iniciar-se a análise para uma determinada falha a ser considerada como estímulo, deve ser associado um rótulo $\checkmark$ ao elemento que representa a falha no grafo. Ao associar o rótulo $\checkmark$ a um elemento que representa uma falha, a descrição Tipo[Topico] associada à falha rotulada deve ser inserida na primeira coluna da tabela resultante da aplicação da técnica. O conteúdo "Falha Temporal[SGBD]" apresentado na Tabela 7 representa um exemplo de conteúdo inserido.

- Com a propagação de rótulos, as ameaças decorrentes da falha sob análise são marcadas com o rótulo $\checkmark$. Para cada marcação do rótulo $\checkmark$ em cada ameaça encadeada, deve ser inserida na quarta coluna da tabela a descrição Tipo[Topico] associada à ameaça rotulada. A ameaça inserida na tabela deve estar relacionada com a falha da primeira coluna sob análise. O conteúdo "Erro Temporal [Pagamento Tributos, Camada Integração]" apresentado na Tabela 7 (associado ao estímulo "Falha Temporal[SGBD]" presente na primeira coluna) exemplifica o conteúdo inserido.

- Durante a aplicação do procedimento de avaliação, softgoals associados ao requisito não-funcional disponibilidade são marcados com o rótulo $X$. Para cada marcação do rótulo $X$ em cada softgoal, deve ser inserida na segunda coluna a descrição Tipo[Topico] representando o softgoal marcado, e esta descrição deve estar relacionada com a falha da primeira coluna sob análise. O conteúdo "Disponibilidade[Pagamento Tributos]" apresentado na Tabela 7 (associado ao estímulo "Falha Temporal[SGBD]" presente na primeira coluna) exemplifica o conteúdo inserido. Caso o softgoal esteja no grafo com uma indicação de prioridade (acompanhado do caractere '!'), a terceira coluna deve ser marcada com $\checkmark$, indicando que existe uma priorização na tabela. 
Pela notação de priorização adotada na técnica ADSSW, baseada na notação presente do framework NFR, existe uma contribuição AUXILIA associada ao softgoal priorizado. De acordo com a regra definida para contribuição AUXILIA, o rótulo $\mathrm{X}$ deve ser marcado em dois softgoals que representam a disponibilidade associada ao perfil operacional ou funcionalidade. Para fins de simplificação, e com o intuito de facilitar a visualização do conteúdo da tabela resultante, o rótulo $X$ deve ser marcado nos dois softgoals, mas a descrição associada ao softgoal priorizado deve ser inserida somente uma vez na tabela.

O procedimento descrito deve ser aplicado a todas as falhas que serão consideradas como estímulos para cenários de disponibilidade. Para se analisar cada falha isoladamente, todos os elementos devem assumir seu rótulo inicial e inicia-se o procedimento de avaliação com a marcação do rótulo $\checkmark$ na falha sob análise presente no grafo.

Portanto, o resultado da segunda etapa do método é uma tabela com todas as falhas e seus relacionamentos, que será utilizada na geração de cenários de disponibilidade. $O$ arquiteto de software deve utilizar esta tabela na etapa 5 do ATAM para a geração de cenários de disponibilidade, que devem ser priorizados e incluídos na árvore de utilidades do ATAM.

\subsection{Geração de cenários de disponibilidade e integração com o ATAM}

Para a geração dos cenários de disponibilidade a partir da tabela gerada na segunda etapa da técnica ADSSW, primeiramente consideram-se possíveis estímulos. $\mathrm{Na}$ integração da técnica ADSSW com o método ATAM, assume-se a premissa de que falhas nos componentes, representados na primeira coluna da Tabela 7, são estímulos para a geração de cenários de disponibilidade. Com esta premissa, é possível estabelecer uma monitoração do comportamento dos componentes, sendo possível a detecção de possíveis falhas para que a arquitetura seja capaz de produzir uma resposta.

A equipe de avaliação de arquitetura, juntamente com a equipe responsável pelas decisões de projeto, deve estabelecer se todos os estímulos serão considerados para análise, ou se somente alguns destes estímulos serão considerados. Cabe 
ressaltar que se alguma falha estiver relacionada com um softgoal de disponibilidade marcado como prioritário, recomenda-se que esta falha seja considerada para análise.

Após a definição de estímulos para cenários de disponibilidade, o próximo passo corresponde à geração de cenários, através da caracterização de ambientes e respostas possíveis para os estímulos considerados. A caracterização do ambiente deverá seguir o enfoque de (BASS; CLEMENTS; KAZMAN, 2003) para a definição de ambiente em cenários de disponibilidade, considerando diferentes modos de operação do sistema na ocorrência de um estímulo. Na versão atual, a tabela resultante da aplicação da técnica ADSSW não provê elementos que possibilitem a caracterização do ambiente.

Para a definição de possíveis respostas para os estímulos é necessária a análise da segunda coluna da tabela resultante da aplicação da técnica ADSSW. Para cada falha presente na primeira coluna, existem softgoals de disponibilidade que são afetados por esta falha. Para que esses softgoals possam originar cenários de disponibilidade, é necessário que eles estejam associados a valores que permitam quantificar o nível de disponibilidade desejado para um determinado componente, funcionalidade ou perfil operacional. Essa associação, é definida por diretrizes resultantes da etapa 2 do ATAM (apresentação dos objetivos de negócio). Com os níveis desejados de disponibilidade definidos, é necessário o estabelecimento de possíveis respostas na ocorrência das falhas dos componentes. A especificação de respostas para cenários de disponibilidade está relacionada ao tempo máximo de detecção de falhas, ao tempo máximo de recuperação de falhas, à reconfiguração dinâmica com degradação gradual e à probabilidade de um chaveamento com sucesso para um componente sobressalente, entre outras respostas. Dessa forma, ao se determinar respostas para cada falha, devem ser considerados os softgoals afetados pela falha e os níveis de disponibilidade associados aos softgoals. Portanto, a técnica ADSSW relaciona, qualitativamente, falhas com perfis operacionais, componentes e funcionalidades afetados por esta falha. Para a completa caracterização de cenários de disponibilidade, é necessária uma análise quantitativa complementar, visando associar a cada softgoal de disponibilidade medidas tais como disponibilidade assintótica e tempo para reparo. Essa análise 
quantitativa não será detalhada neste trabalho, e poderá ser incluída em trabalhos futuros.

Para uma estruturação de cenários de disponibilidade obtidos com a utilização do catálogo resultante da aplicação da técnica ADSSW, recomenda-se que a árvore de utilidades seja organizada inicialmente conforme descrito em (CLEMENTS; KAZMAN; KLEIN, 2002), com o primeiro nível representando a "utilidade" do sistema, e o segundo nível contendo um nó representando o atributo de qualidade disponibilidade. Sob este nó, recomenda-se que se organizem os cenários de acordo com os estímulos considerados para análise. Portanto, o terceiro nível da árvore de utilidades para disponibilidade deve conter elementos descritos na primeira coluna presente no catálogo gerado pela técnica ADSSW.

Uma vez caracterizados os cenários de disponibilidade, é necessária uma priorização. Esta priorização não deve considerar somente os cenários de disponibilidade, mas também os demais cenários de atributos de qualidade representados na árvore de utilidades. Uma possível estratégia de definição de prioridades é realizar uma classificação preliminar considerando somente cenários de disponibilidade. A técnica ADSSW auxilia essa classificação preliminar baseada na importância do cenário na arquitetura sob análise, com a representação da priorização de softgoals (terceira coluna) na tabela. Após a classificação preliminar, uma priorização posterior se faz necessária, sendo a importância dos cenários de disponibilidade definida de forma relativa em comparação com os cenários relacionados a outros requisitos não-funcionais.

A Figura 39 representa o processo de geração de cenários de disponibilidade com o auxílio da técnica ADSSW na etapa 5 do ATAM: 


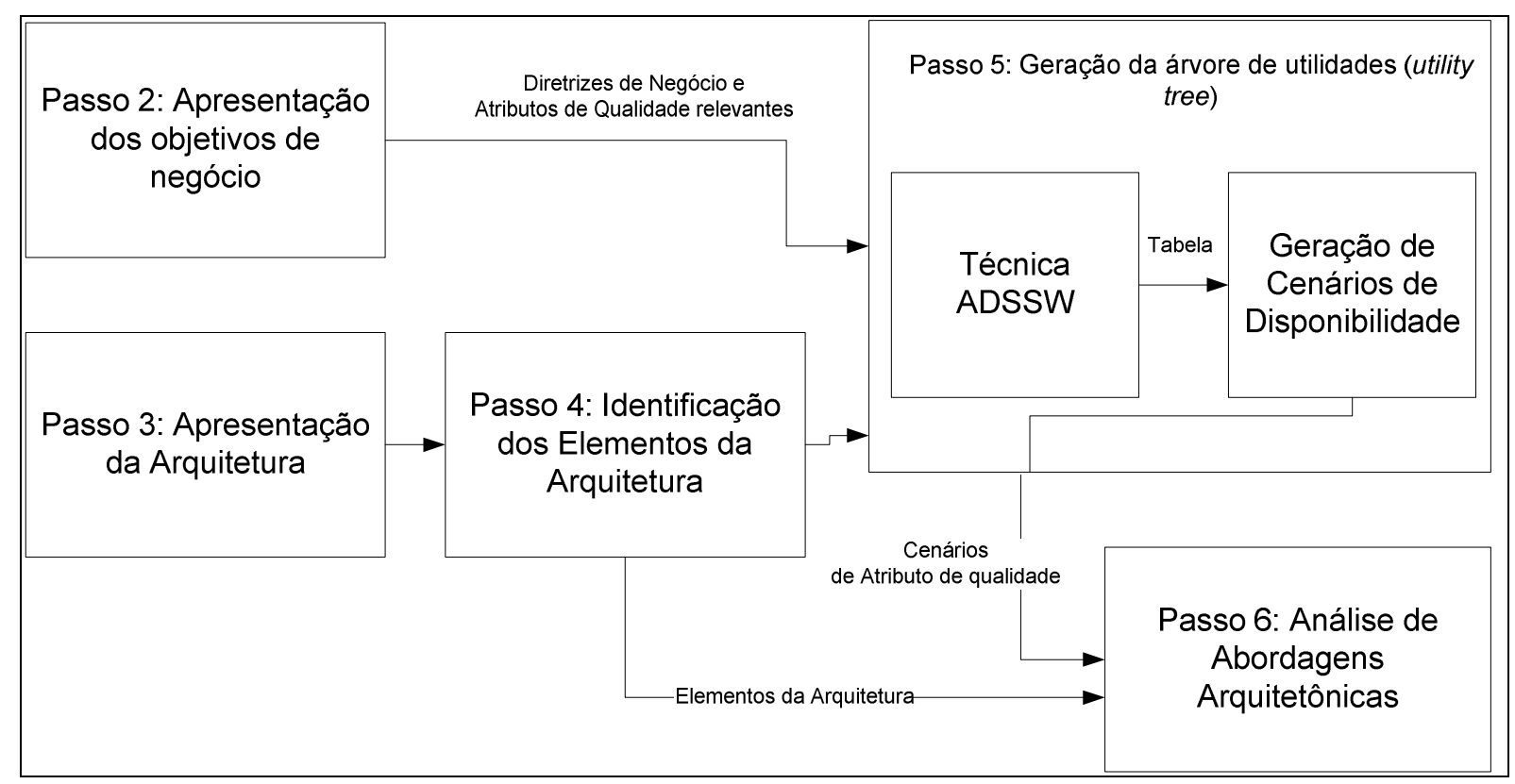

Figura 39 - Geração de Cenários com o auxílio da técnica ADSSW

$\mathrm{Na}$ Figura 39, nota-se que a saída da etapa 4 (identificação de elementos arquitetônicos) é uma das entradas para a aplicação da técnica ADSSW. Elementos arquitetônicos tais como a divisão em camadas, e a utilização de componentes são utilizados na aplicação da técnica ADSSW. Outra entrada para a técnica ADSSW são diretrizes de negócio definidas na etapa 2 do método ATAM. As diretrizes de negócio resultantes da etapa de apresentação dos objetivos de negócio determinam quais perfis operacionais de usuário e funcionalidades são consideradas na aplicação da técnica ADSSW, e também possibilitam que se estabeleçam prioridades em softgoals associados a perfis operacionais e funcionalidades. Após as etapas de construção do grafo de disponibilidade e de aplicação do procedimento de avaliação, a técnica ADSSW gera uma tabela relacionando falhas de componentes com softgoals de disponibilidade associados a componentes, funcionalidades e perfis operacionais. A tabela gerada, juntamente com diretrizes de negócio resultantes da etapa 2 do ATAM, provêem elementos para a geração de cenários de disponibilidade.

Uma vez construída a árvore de utilidades, os cenários gerados com o auxílio da técnica ADSSW considerados mais relevantes são submetidos à etapa 6 do ATAM (análise de abordagens arquitetônicas). Nesta etapa, o modelo descrito na Tabela 3 é utilizado para a análise de abordagens arquitetônicas no cenário de disponibilidade 
gerado. A Tabela 8 representa como elementos pertencentes ao catálogo resultante da técnica ADSSW são mapeados em elementos pertencentes ao modelo de análise de abordagens arquitetônicas em um cenário de disponibilidade.

Tabela 8 - Modelo para análise de abordagens arquitetônicas em cenários de disponibilidade gerados com o auxílio da técnica ADSSW

Cenário: Texto do cenário de disponibilidade pertencente à árvore de utilidades

Atributo: Disponibilidade

Ambiente: Para um cenário de disponibilidade, o ambiente pode ser caracterizado por um modo normal de operação, ou por um modo de operação degradado.

Estímulo: Estímulo a ser considerado para análise, extraído da primeira coluna da tabela resultante da técnica ADSSW.

Resposta: uma declaração precisa da resposta do cenário de disponibilidade. A resposta do cenário de disponibilidade está relacionada aos objetivos relacionados a softgoals associados ao estímulo presente na segunda coluna do catálogo gerado pela técnica ADSSW.

\begin{tabular}{|l|c|c|c|c|}
\multicolumn{1}{|c|}{$\begin{array}{c}\text { Decisões } \\
\text { Arquitetônicas }\end{array}$} & $\begin{array}{c}\text { Pontos de } \\
\text { Sensibilidade }\end{array}$ & $\begin{array}{c}\text { Pontos de } \\
\text { Tradeoff }\end{array}$ & Riscos & $\begin{array}{c}\text { Não- } \\
\text { riscos }\end{array}$ \\
\hline $\begin{array}{l}\text { Lista de decisões } \\
\text { arquitetônicas }\end{array}$ & $\begin{array}{c}\text { Pontos de } \\
\text { sensibilidade } \\
\text { relevantes que afetam a } \\
\text { resposta do cenário de } \\
\text { atributo de qualidade. } \\
\text { cada decisão de } \\
\text { arquitetura no } \\
\text { cenário em } \\
\text { questão }\end{array}$ & $\begin{array}{c}\text { Pontos de } \\
\text { tradeoff } \\
\text { relacionados a } \\
\text { cada decisão, } \\
\text { com o impacto } \\
\text { em relação } \\
\text { aos demais } \\
\text { atributos de } \\
\text { qualidade }\end{array}$ & $\begin{array}{c}\text { Descrições } \\
\text { relacionadas } \\
\text { ao efeito } \\
\text { negativo de } \\
\text { uma decisão } \\
\text { arquitetônica } \\
\text { (ou a ausência } \\
\text { da decisão) no } \\
\text { cenário em } \\
\text { questão }\end{array}$ & $\begin{array}{c}\text { Descriçada } \\
\text { relacionada } \\
\text { s ao efeito } \\
\text { positivo de } \\
\text { uma } \\
\text { decisão } \\
\text { arquitetônic } \\
\text { a no } \\
\text { cenário em } \\
\text { questão }\end{array}$ \\
\hline
\end{tabular}

Racionalização: racionalização quantitativa e/ou qualitativa indicando as razões pelas quais a lista de decisões arquitetônicas contribuem para afetar cada requisito de atributo de qualidade representado pelo cenário.

Diagramas de Arquitetura: diagrama ou diagramas de visões arquitetônicas que representam informações arquitetônicas que dão suporte à racionalização acima, acompanhados com um texto explicativo caso seja necessário.

Nesta etapa, táticas de arquitetura relacionadas aos meios de dependabilidade podem ser aplicadas na análise, gerando riscos, não-riscos, pontos de sensibilidade e tradeoff. Decisões arquitetônicas que a princípio não visam atender ao atributo de qualidade disponibilidade, mas que podem trazer conseqüências em relação ao requisito representado no cenário, devem ser identificadas. Nesta etapa de análise, meios de previsão de defeitos podem ser utilizados para analisar o impacto de decisões arquitetônicas nos cenários de disponibilidade considerados. 
Os cenários gerados com o auxílio da técnica ADSSW podem ter sua priorização revista na etapa 7 do método ATAM, com o envolvimento de mais stakeholders em um brainstorming. Cabe ressaltar que o objetivo da técnica ADSSW não é esgotar todas as possibilidades de se gerar cenários de disponibilidade, mas sim prover elementos que auxiliem a sua geração. Portanto, nas etapas 5 e 7 do ATAM existe a possibilidade de que stakeholders criem cenários de disponibilidade com elementos que não estejam presentes no catálogo gerado pela técnica.

Existe a possibilidade de desenvolvimento de uma ferramenta de apoio para a aplicação da técnica ADSSW. Para a aplicação da primeira etapa da técnica, a ferramenta poderia disponibilizar uma interface para a construção do grafo, com a inclusão de softgoals, ameaças e seus inter-relacionamentos e a automatização dessa construção. O usuário informaria pelo menos: os perfis operacionais de acesso ao sistema de software, as funcionalidades associadas a cada perfil operacional, os componentes necessários para que a funcionalidade seja disponibilizada e as ameaças relacionadas a estes componentes. O procedimento de avaliação realizado na segunda etapa da técnica também pode ser automatizado, com a implementação do algoritmo de propagação de rótulos descrito na seção 4.4.2. Como resultado da aplicação da técnica ADSSW, pode ser obtido a tabela que relaciona falhas identificadas com softgoals de disponibilidade.

A ferramenta de apoio para a técnica ADSSW pode ser uma base para a construção de uma ferramenta responsável pela geração de cenários de disponibilidade no ATAM. Os autores de (BABAR; CAPILLA, 2008) argumentam que enquanto abordagens para a elicitação de cenários de atributos de qualidade auxiliam a elicitação e a especificação de atributos de qualidade, não existe atualmente uma ferramenta de apoio para capturar e gerenciar o conhecimento sobre atributos de qualidade para um domínio particular, e capaz de armazenar toda a racionalização que justifique a escolha de decisões arquitetônicas. Em (BABAR; GORTHON, 2007), é descrita a ferramenta PAKME (Process-centric Architecture Knowledge Management Environment), que corresponde a uma ferramenta que tem como objetivo prover um gerenciamento de conhecimento no processo de avaliação de arquitetura de software. Esta ferramenta disponibiliza um modelo para a inclusão de cenários gerais de atributos de qualidade, que podem ser instanciados durante o procedimento de avaliação de arquitetura. Existe a possibilidade de um trabalho 
futuro que implemente uma ferramenta que permite a automatização da geração de cenários relacionados ao requisito não-funcional disponibilidade, seguindo os passos descritos na técnica ADSSW e utilizando a tabela resultante da técnica como base para a geração dos cenários, com falhas identificadas sendo adotadas como estímulo e softgoals de disponibilidade sendo utilizados como base para a definição de possíveis respostas para cada falha. A possibilidade de se gerar cenários de disponibilidade com a utilização de uma ferramenta de apoio, além de auxiliar a avaliação de uma arquitetura de software, possibilita que os cenários sejam catalogados para análises de decisões de arquitetura e que possam ser utilizados de modo integrado a ferramentas como a ferramenta PAKME. 


\section{APLICAÇÃo dA TÉCNICA ADSSW}

Neste capítulo é descrito um exemplo de aplicação da técnica ADSSW em um sistema de software bancário na Web simplificado, para fins ilustrativos. No exemplo, a aplicação será realizada em um nível de abstração envolvendo módulos e componentes, sem entrar no mérito de tecnologias utilizadas e sem considerar configurações de hardware e software específicas.

O exemplo aqui elaborado é uma evolução do exemplo apresentado em (VASCONCELLOS NETO; MUNIZ SILVA, 2009). São considerados dois perfis operacionais: um perfil que será referenciado como perfil simples, composto por usuários que têm acesso a funcionalidades elementares, tais como transferência de valores, pagamento de tributos e consulta de saldos; e um perfil que será referenciado como perfil especial, composto por usuários que têm acesso às mesmas funcionalidades disponíveis para o perfil simples, mas com acesso à funcionalidade de investimentos. No sistema sob análise, considera-se que a disponibilidade para o perfil especial deve ser considerada com uma prioridade maior em relação à disponibilidade para um perfil simples.

No exemplo, cada funcionalidade acessa um ou mais serviços externos. Este serviço externo deve ser acessível a cada canal de distribuição bancário, por isto são considerados serviços externos que devem ser acionados por cada canal de distribuição específico (inclusive o canal de distribuição Internet). São definidos os seguintes serviços externos:

- Serviço de consulta de saldos - retorna os saldos relacionados a contas;

- Serviço de pagamento de tributos - realiza operações de pagamentos de tributos, interligadas com órgãos governamentais;

- Serviço de autenticação - utilizado nas operações de pagamento de tributos e transferência de valores, permitindo que o usuário se autentique para a efetivação de determinadas operações;

- Serviço de transferência de valores - realiza operações de transferência de valores; 
- Serviço de investimentos - realiza operações de investimentos, retirando quantias financeiras da conta corrente do usuário e aplicando-as em fundos de investimento.

As quatro funcionalidades (transferência de valores, pagamento de tributos, consulta de saldos e investimentos) são fornecidas aos usuários através de uma arquitetura de software baseada em três camadas como a descrita no capítulo 4, havendo uma distinção entre lógica de apresentação, regras de negócio e integração. Em relação à camada de apresentação, no exemplo não serão considerados aspectos relacionados ao navegador do cliente, nem aspectos relacionados a redes de comunicação que interligam o cliente ao sistema de software do servidor, devido à heterogeneidade de condições de rede e de máquinas do cliente. A aplicação da técnica se dará somente em aspectos relacionados após a chegada da requisição ao servidor e antes do envio da página de resposta ao cliente.

A camada responsável pelo processamento de regras de negócio apresentará os elementos destacados na seção 4.1: balanceador de carga, servidor Web e servidores de aplicação. Em relação ao servidor de aplicação, componentes de software específicos do aplicativo devem ser executados em um software de servidor de aplicação, utilizando um middleware para comunicação com a camada de integração. A camada de integração, por sua vez, além de contemplar aspectos relacionados aos serviços externos associados às funcionalidades oferecidas, contempla uma base de dados contendo informações associadas relacionadas aos clientes que acessam o site e configurações relacionadas ao serviço de pagamento de tributos. Para a obtenção e manipulação dessas informações, são utilizadas stored procedures (procedimentos armazenados) localizadas no sistema gerenciador de base de dados.

A aplicação do exemplo na técnica se dá em três seções neste capítulo. Na primeira seção, é descrito um exemplo de construção do grafo. Na segunda seção, ocorre um exemplo de aplicação do procedimento de avaliação para geração da tabela resultante. Por fim, na terceira seção, é descrito um exemplo de como a tabela pode auxiliar a geração de cenários de disponibilidade. 


\subsection{Etapa 1 - Construção do Grafo}

A primeira etapa consiste na aplicação dos passos descritos no capítulo 4 para a geração do grafo contendo softgoals, ameaças a dependabilidade e interrelacionamentos entre estes elementos. A análise inicia-se no softgoal Dependabilidade [SistemaSoftwareBancarioWeb], que representa a dependabilidade do sistema de software analisado no exemplo. A primeira decomposição realizada neste exemplo, como visto na seção 4.4 , é a decomposição SistemaSoftwareWebDependabilidadeViaSubTipo, na qual ocorre a decomposição de Dependabilidade em atributos de dependabilidade. Para esta decomposição serão considerados os atributos de dependabilidade identificados como relevantes, de acordo com (OFFUTT, 2002), em sistemas de software de e-business. A Figura 40 representa esta decomposição.

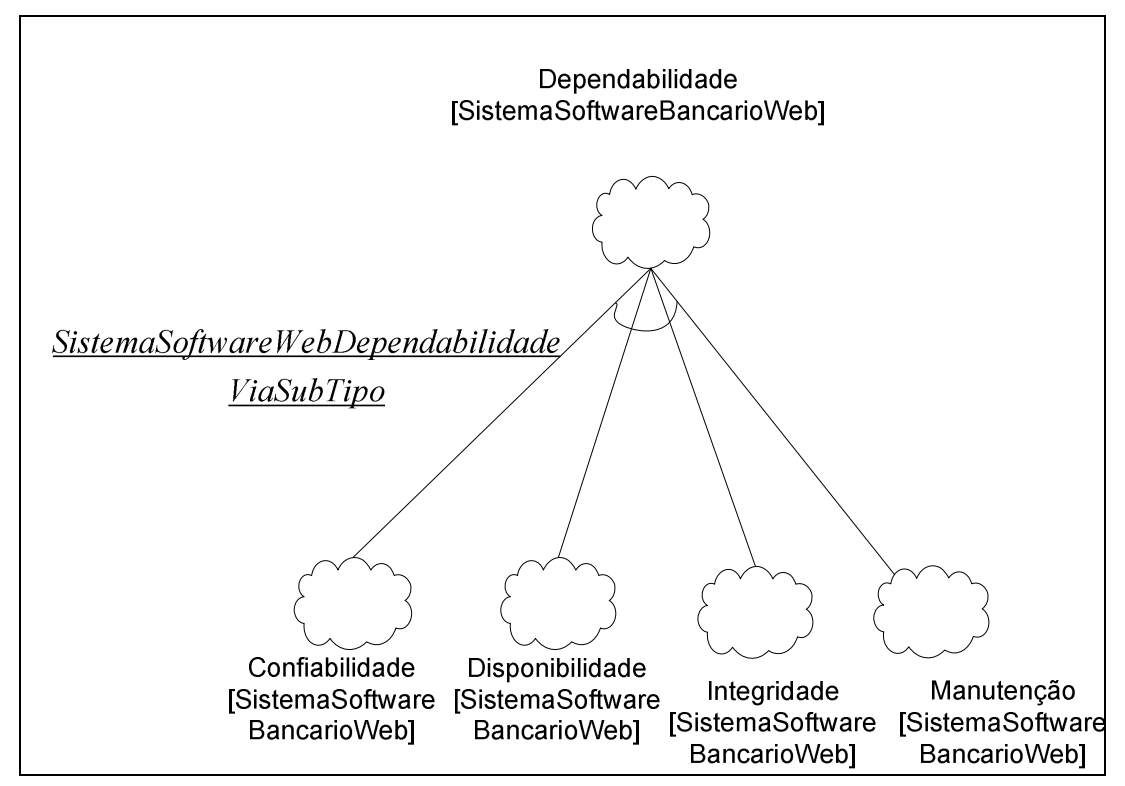

Figura 40 - Aplicação da decomposição

SistemaSoftwareWebDependabilidadeViaSubTipo

O segundo passo da aplicação da técnica aplica a decomposição SistemaSoftwareWebDisponibilidadeViaPerfil, que ocorre no softgoal que representa a disponibilidade do perfil operacional. No exemplo são descritos dois perfis operacionais: perfil simples e perfil especial. A Figura 41 representa esta decomposição. 


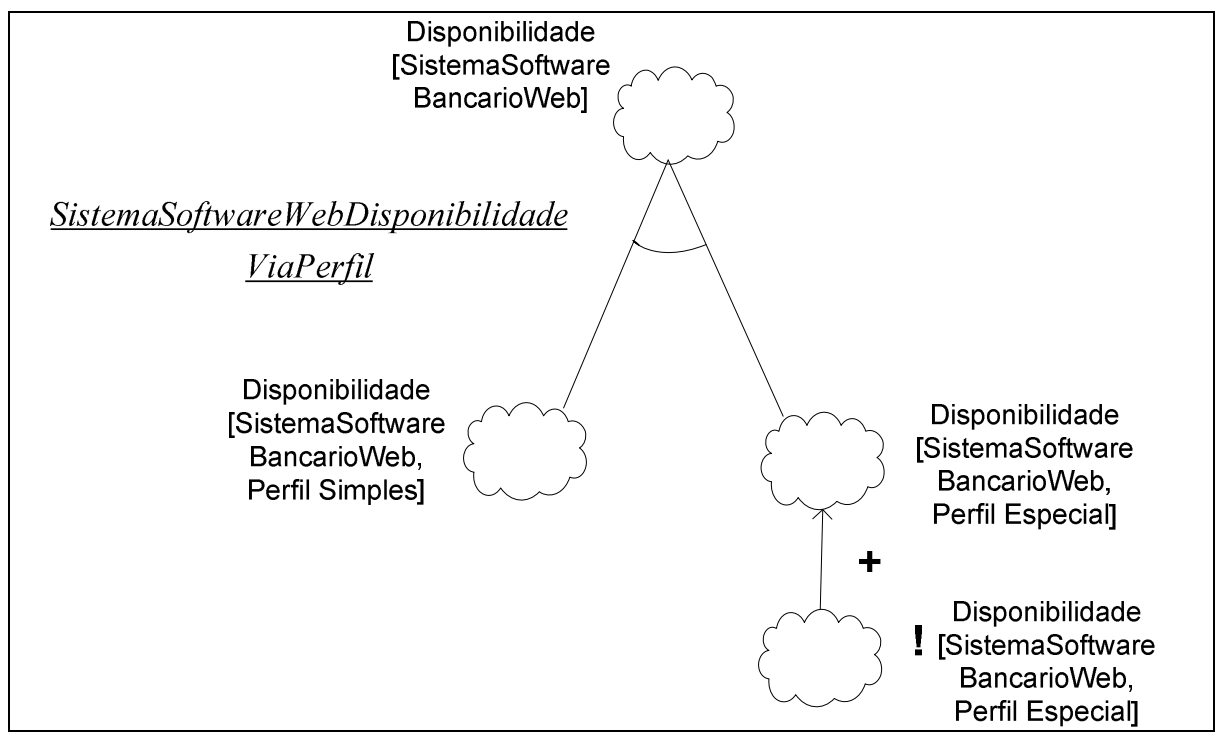

Figura 41 - Aplicação da decomposição SistemaSoftwareWebDisponibilidadeViaPerfil

Como resultado desta decomposição, são representados softgoals que representam a disponibilidade associada aos dois perfis operacionais considerados no exemplo. $\mathrm{Na}$ Figura 41 é representada a marcação de priorização do softgoal de disponibilidade para o perfil especial, de acordo com a notação utilizada no framework NFR.

O terceiro passo da aplicação na técnica para a construção do grafo consiste na decomposição SistemaSoftwareWebDisponibilidadeViaFuncionalidade, em que cada softgoal relacionado a um perfil operacional deve ser decomposto em softgoals que representem as funcionalidades às quais este perfil operacional tem acesso. A decomposição SistemaSoftwareWebDisponibilidadeViaFuncionalidade pode ser representada na Figura 42. 


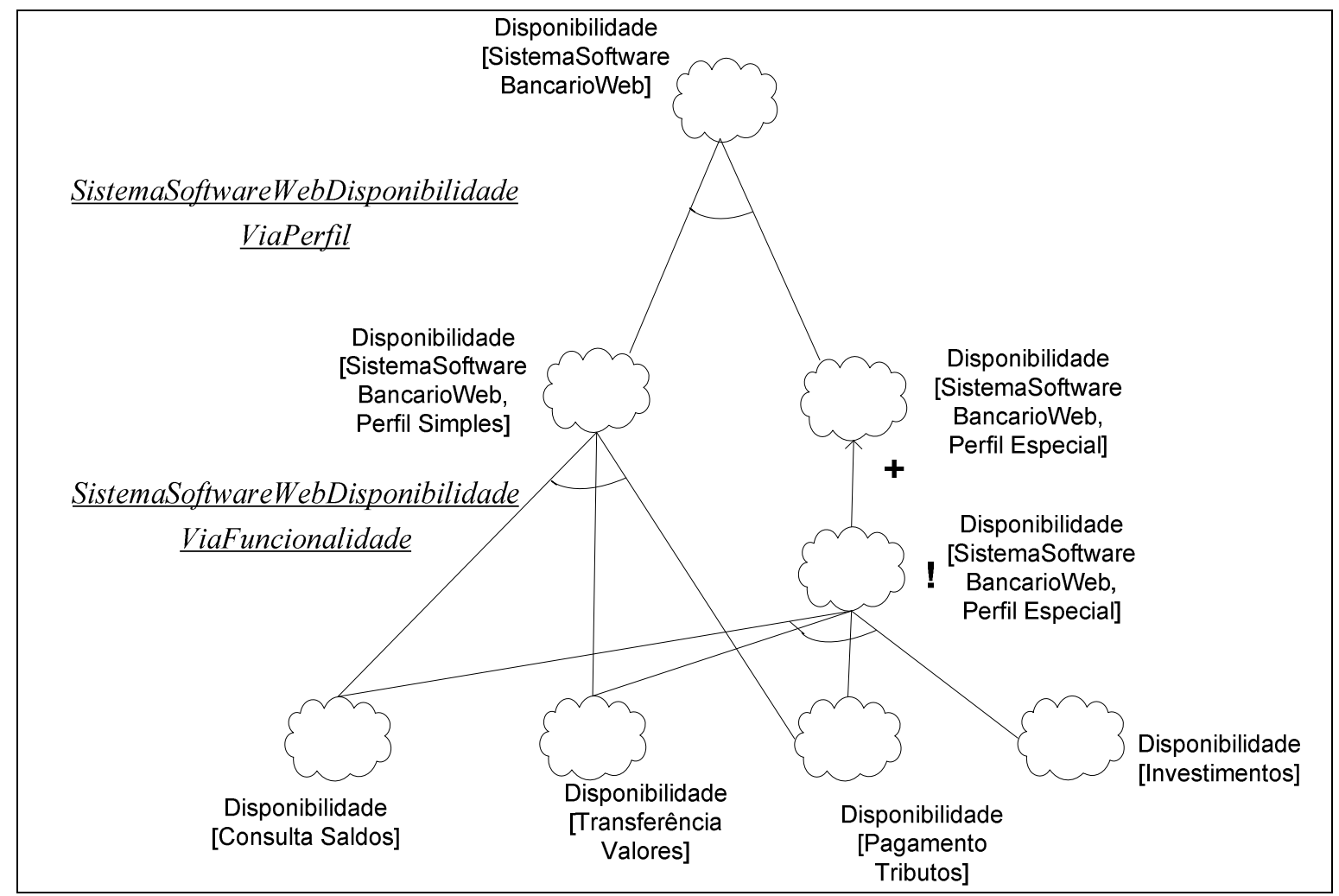

Figura 42 - Aplicação da decomposição SistemaSoftwareWebDisponibilidadeViaFuncionalidade

Para cada softgoal que representa a disponibilidade associada a uma determinada funcionalidade, deve ser aplicada, como visto no capítulo 4, a decomposição SistemaSoftwareWebDisponibilidadeFuncViaCamada. Esta decomposição tem como objetivo estruturar a análise de disponibilidade de funcionalidade em função dos componentes que interagem entre si para fornecê-la, segundo a estruturação em camadas presente no exemplo. Um exemplo desta decomposição pode ser representado graficamente na Figura 43. No exemplo, o softgoal do tipo disponibilidade com um tópico Pagamento Tributos é decomposto em softgoals de disponibilidade que apresentam tópicos componentes de apresentação, componentes de negócio e componentes de integração relacionados à funcionalidade Pagamento Tributos. 


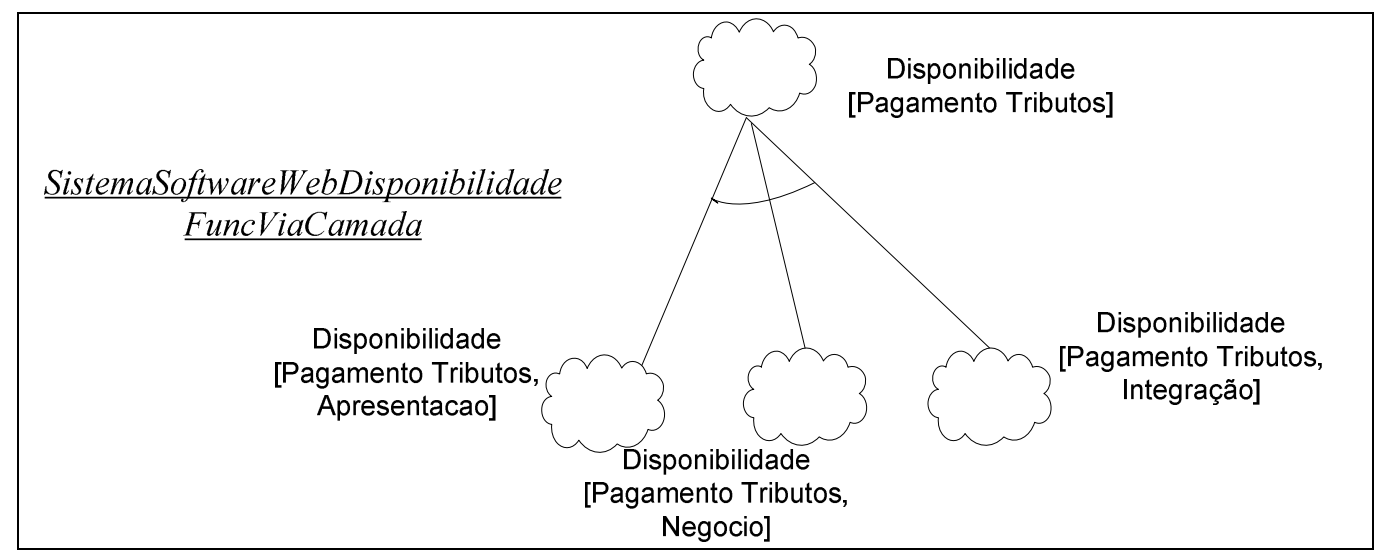

Figura 43 - Aplicação da decomposição SistemaSoftwareWebDisponibilidadeFuncViaCamada

O próximo passo engloba aplicações sucessivas da decomposição SistemaSoftwareWebDisponibilidadeComponenteViaComponentes, onde analisa-se a disponibilidade de componentes. No exemplo, o softgoal Disponibilidade [Pagamento Tributos, Negócio], através da aplicação da decomposição SistemaSoftwareWebDisponibilidadeComponenteViaComponentes pode ser decomposto da seguinte forma:

AND (\{Disponibilidade [Balanceador de Carga], Disponibilidade [Servidor Web],

Disponibilidade [Componente Servidor de Aplicação Pagamento Tributos]\}) SATISFAZEM Disponibilidade [Pagamento Tributos, Negócio]

O softgoal Disponibilidade [Balanceador de Carga] representa a disponibilidade associada ao balanceador de carga. $\mathrm{Na}$ arquitetura proposta no exemplo, o balanceador de carga é compartilhado por diversas funcionalidades do sistema. Portanto, este softgoal pode ser utilizado na análise de outras funcionalidades do sistema além da funcionalidade de Pagamento Tributos. Raciocínio similar se aplica ao softgoal Disponibilidade [Servidor Web]. O softgoal Disponibilidade [Componente Servidor de Aplicação - Pagamento Tributos] considera o tópico "Componente Servidor de Aplicação - Pagamento Tributos" como um componente responsável pelo processamento de regras de negócio no servidor de aplicações.

De acordo com as definições apresentadas na seção 4.4, o softgoal Disponibilidade [Componente Servidor de Aplicação - Pagamento Tributos] pode ser decomposto da 
seguinte

forma,

através

do

método

SistemaSoftwareWebDisponibilidadeComponenteViaComponentes:

AND (\{Disponibilidade [Aplicativo Pagamento Tributos],

Disponibilidade [Middleware], Disponibilidade [Software Servidor de Aplicação],

Disponibilidade [Sistema Operacional SA]\})

SATISFAZEM Disponibilidade [Componente Servidor de Aplicação - Pagamento Tributos]

O tópico do softgoal Disponibilidade [Aplicativo Pagamento Tributos] representa a disponibilidade relacionada ao aplicativo de pagamento de tributos, ou seja, um aplicativo responsável por prover o comportamento específico necessário para a funcionalidade de pagamento de tributos, envolvendo aspectos tais como processamento de regras de negócio e validação de sessão.

Os softgoals resultantes das duas últimas decomposições relacionadas a componentes responsáveis pelo processamento de regras de negócio podem ser representados como na Figura 44.

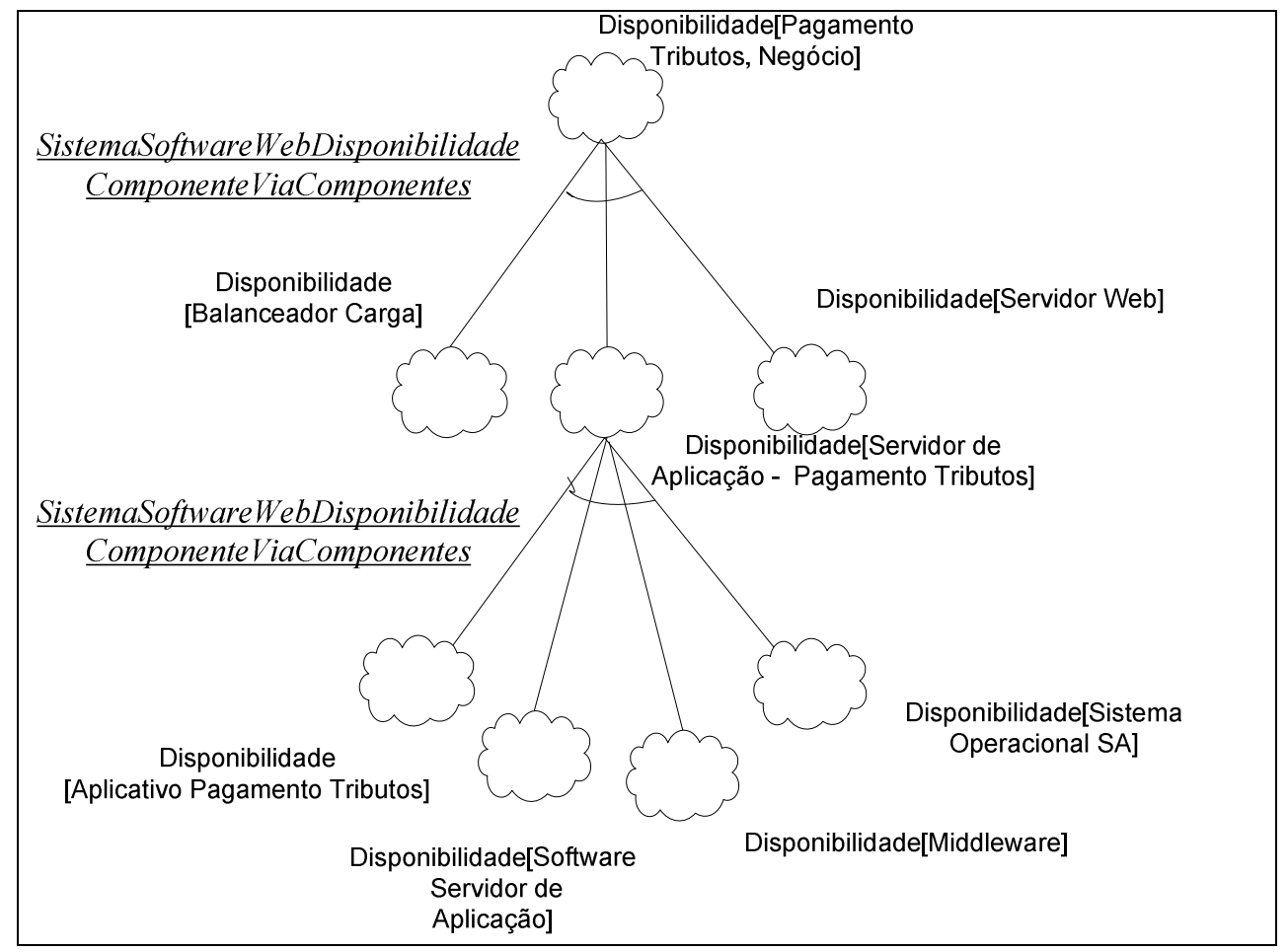

Figura 44 - Decomposição por tópico relacionada à camada de negócio no exemplo - Funcionalidade Pagamento de Tributos 
Em relação à camada de integração, o método SistemaSoftwareWebDisponibilidadeComponenteViaComponente pode ser aplicado. No exemplo, a funcionalidade de pagamento de Tributos realiza acesso a banco de dados e acesso a dois serviços externos: um serviço externo de pagamento de tributos, responsável por interligar o sistema bancário com órgãos governamentais, e um serviço de autenticação, que permite que o usuário se autentique para efetivação da operação. Para fins de análise, todo o acesso e operações realizadas na base de dados serão encapsulados em um componente "Servidor Banco Dados Tributos". A aplicação do método gera o seguinte refinamento para a funcionalidade Pagamento de Tributos, representado conforme a notação proposta:

AND (\{Disponibilidade [Servidor Banco Dados Tributos],

Disponibilidade [Serviço Externo de Pagamento de Tributos],

Disponibilidade [Serviço Externo de Autenticação]\})

SATISFAZEM Disponibilidade [Pagamento de Tributos, Integração]

O softgoal Disponibilidade [Servidor Banco Dados Tributos] pode ser decomposto através da decomposição SistemaSoftwareWebDisponibilidadeComponenteViaComponente, sendo esta decomposição representada conforme a seguinte notação:

AND (\{Disponibilidade [Procedimento Armazenado Tributos], Disponibilidade [SGBD], Disponibilidade [Sistema Operacional BD]\}) SATISFAZEM Disponibilidade [Servidor Banco Dados Tributos]

A Figura 45 representa 0 resultado de aplicações da decomposição SistemaSoftwareWebDisponibilidadeComponenteViaComponente no componente que representa a camada de integração relacionada à funcionalidade Pagamento de Tributos. 


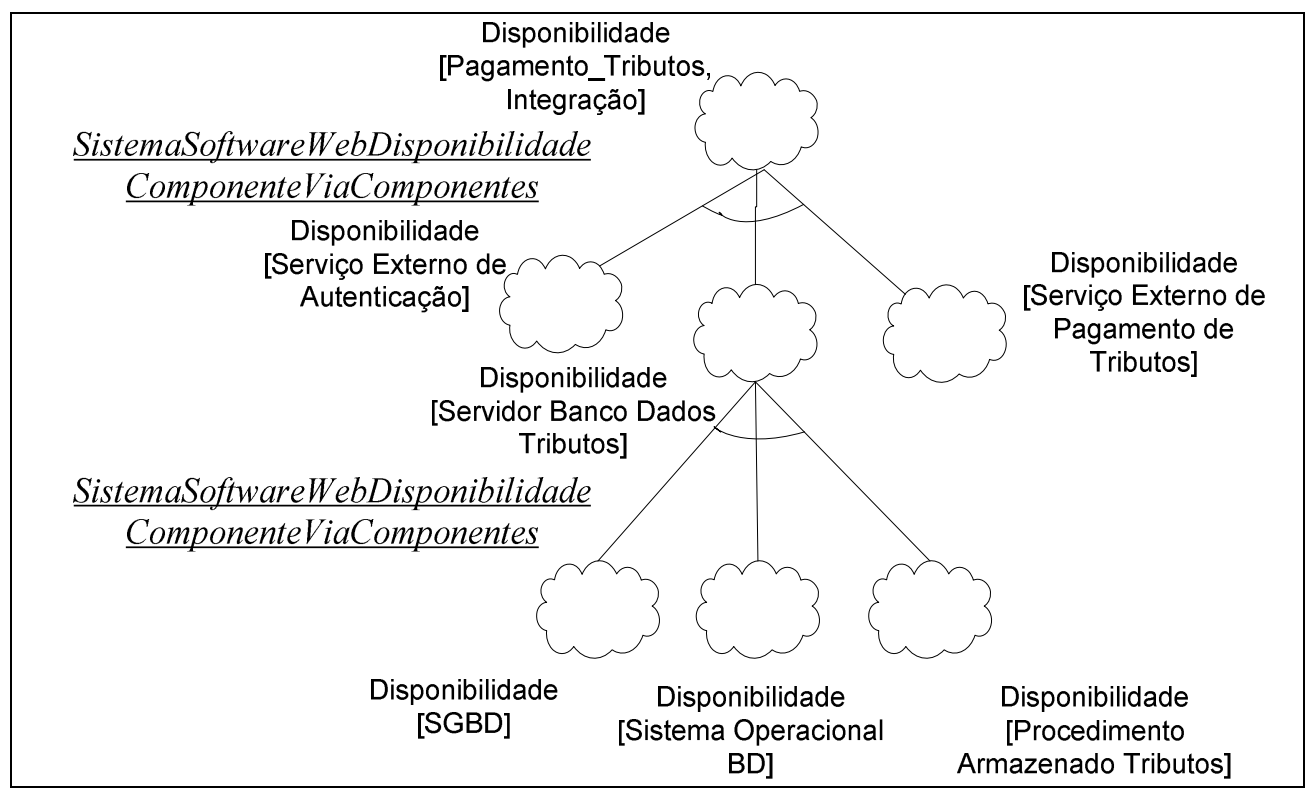

Figura 45 - Decomposição por tópico relacionada à camada de integração no exemplo - Funcionalidade Pagamento de Tributos

Uma vez identificados os softgoals de disponibilidade associados a componentes considerados atômicos, o próximo passo é identificar quais falhas são inerentes a estes componentes. No exemplo, o componente analisado corresponde ao Sistema Gerenciador de Banco de Dados (SGBD), em que os erros são tratados de forma geral, sem considerar falhas específicas de um gerenciador de banco de dados de uma determinada marca. No exemplo, consideram-se dois tipos de falhas:

- Falha de Conteúdo: considera-se que um Sistema Gerenciador de Base de Dados pode apresentar falhas no conteúdo de suas tabelas. Este tipo de falha pode apresentar diferentes defeitos como possíveis causas, dentre os quais podem ser citados defeitos operacionais, nos quais usuários podem se desconectar de uma instância de uma forma anormal, sem a realização adequada de operações de commit e rollback, causando assim inconsistência nos dados presentes nas tabelas gerenciadas pelo Sistema Gerenciador de Banco de Dados. Outro possível defeito que pode ocasionar este tipo de falha está na classe de defeitos de hardware, constituindo assim defeitos em dispositivos de armazenamento provocando assim falhas de conteúdo no Sistema Gerenciador de Banco de Dados.

- Falha Temporal: neste caso, consideram-se falhas por atraso, nas quais possíveis operações de consulta e armazenamento são executadas em um 
tempo maior que o tempo máximo estabelecido. Dentre os possíveis defeitos que podem causar esta falha, podem ser defeitos que se originam no projeto na base de dados, no qual não são considerados índices para a realização de consultas, ou defeitos operacionais, causados devido a não execução de um procedimento periódico de exclusão de dados, por exemplo.

$\mathrm{Na}$ técnica ADSSW inicialmente proposta neste trabalho não são representados os defeitos que possam ser considerados como causas de falhas. O objetivo da técnica proposta consiste em determinar o impacto da ocorrência de falhas na disponibilidade de um sistema de software, e não em determinar a causa de determinadas falhas.

$\mathrm{Na}$ técnica ADSSW, as falhas podem ser representadas com as ameaças "Falha de Conteúdo [SGBD]" e "Falha Temporal [SGBD]". A ocorrência destas falhas é suficiente para caracterizar uma falha no Sistema Gerenciador de Banco de Dados. Segundo a classificação de falhas por domínio definida em (LAPRIE, 1992), tem-se a decomposição FalhaViaDominio da ameaça Falha [SGBD] representada graficamente na Figura 46.

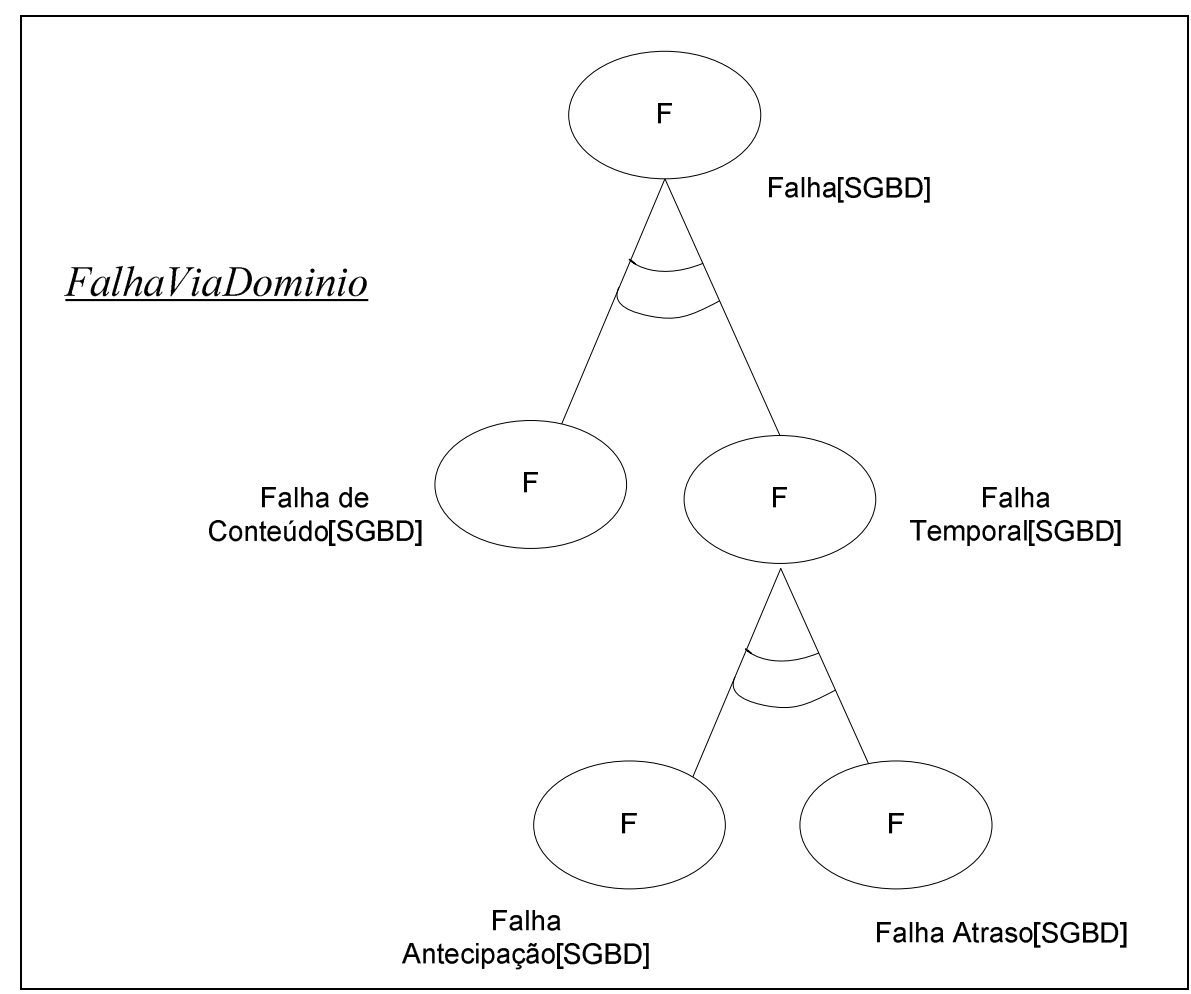

Figura 46 - Representação de possíveis falhas relacionadas ao componente Sistema Gerenciador de Banco de Dados 
Para uma melhor caracterização das falhas relacionadas ao Sistema Gerenciador de Banco de Dados, o próximo passo na técnica consiste em explicitar as relações entre as falhas presentes no modelo e softgoals associados a requisitos nãofuncionais. Conforme descrição da técnica ADSSW presente no capítulo 4, falhas temporais associadas a um determinado tópico contribuem negativamente para o tempo de resposta associado a este tópico. No caso do exemplo, considera-se uma contribuição negativa QUEBRA entre a falha temporal e o softgoal tempo de resposta, pois em caso de ocorrência de falha temporal, o tempo de resposta associado ao tópico $S G B D$ não é considerado suficientemente satisfatório. Raciocínio análogo aplica-se à falha de conteúdo. A falha de conteúdo associada ao Sistema Gerenciador de Banco de Dados, como pode ser visto na seção 4.3, contribui com uma contribuição REALIZA para a falha de conteúdo associada à informação retornada pelo Sistema Gerenciador de Banco de Dados, pois a ocorrência de falhas em um Sistema Gerenciador de Banco de Dados é condição suficiente para caracterizar a ocorrência de falhas de conteúdo na informação retornada por um Sistema Gerenciador de Banco de Dados. Esta falha, por sua vez, como pode ser visto na seção 4.3, realiza uma contribuição QUEBRA no softgal que representa a acurácia desta informação, pois uma falha de conteúdo associada à informação retornada por um Sistema Gerenciador de Banco de Dados é suficiente para negar a acurácia desta informação. Estas contribuições entre falhas e softgoals de requisitos não-funcionais podem ser representadas graficamente na Figura 47.

Conforme descrito anteriormente, faz-se necessário, na técnica, associar falhas de componentes com softgoals que representam a disponibilidade associada a estes componentes. Trata-se de contribuições do tipo ALGO-, que indica que as falhas contribuem de forma negativa para que o softgoal não seja considerado suficientemente satisfatório. No caso do componente Sistema Gerenciador de Base de Dados, esta contribuição pode ser representada graficamente na Figura 48. 


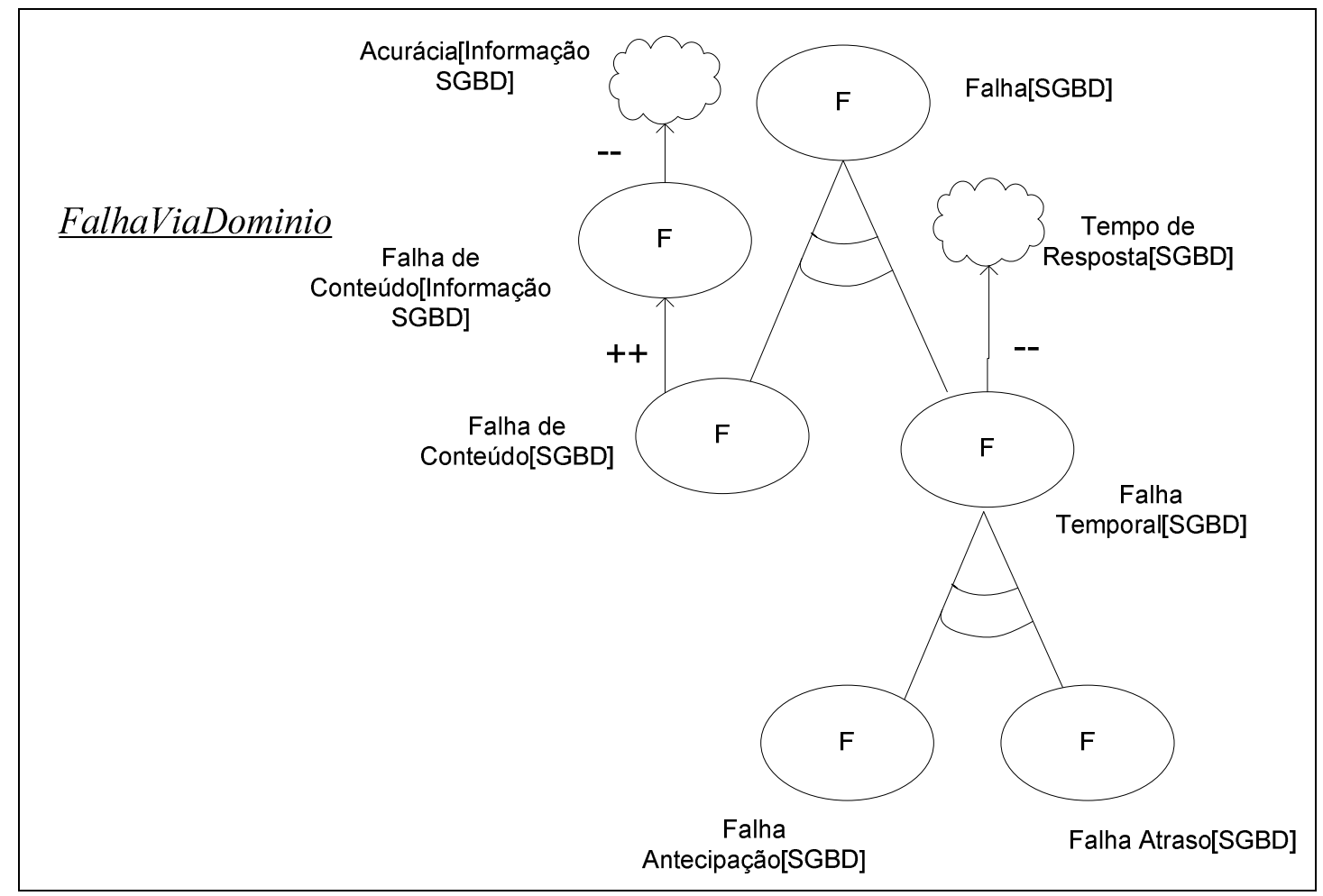

Figura 47 - Representação entre falhas e softgoals de acurácia e tempo de resposta

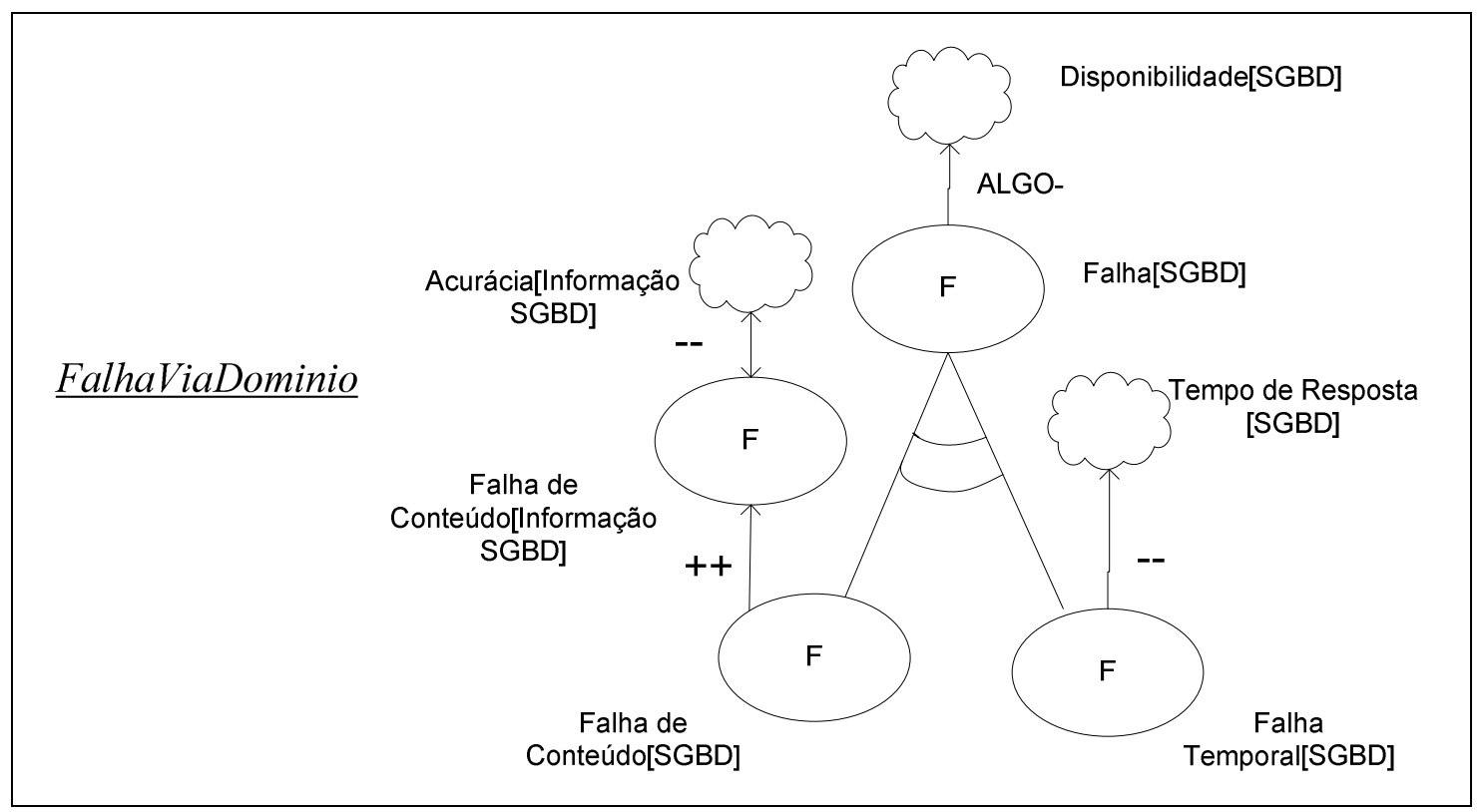

Figura 48 - Representação da contribuição entre falha e softgoal de disponibilidade associado ao componente SGBD

Identificadas as falhas em todos os componentes atômicos, assim como as respectivas contribuições em relação aos respectivos softgoals de disponibilidade, o próximo passo é considerar o encadeamento de ameaças de disponibilidade presentes nos respectivos componentes. No exemplo, consideram-se inicialmente 
as falhas inerentes ao Sistema Gerenciador de Base de Dados. Conforme descrito anteriormente, o Sistema Gerenciador de Banco de Dados compõe, entre outros componentes, o componente "Servidor Banco de Dados Tributos". Portanto falhas temporais do componente Sistema Gerenciador de Banco de Dados podem ser defeitos sob o ponto de vista do componente "Servidor Banco de Dados Tributos". Este defeito, se não tratado corretamente, pode causar um erro temporal no componente "Servidor Banco de Dados Tributos". Este erro, se não for aplicado um tratamento para sua recuperação, pode propagar-se em uma falha temporal do componente "Servidor Banco de Dados Tributos". Raciocínio similar pode ser aplicado em relação ao componente que corresponde à camada de integração da funcionalidade Pagamento de Tributos. Uma falha temporal do componente "Servidor Banco de Dados Tributos" pode ser considerada defeito sob o ponto de vista do componente que corresponde à camada de integração da funcionalidade Pagamento de Tributos. Este defeito pode causar um erro, que pode propagar-se em uma falha para este componente. Nesta propagação, à medida que falhas são identificadas, é necessário representar, no grafo, a contribuição da falha deste componente em relação ao respectivo softgoal. A Figura 49 representa graficamente o encadeamento descrito no exemplo.

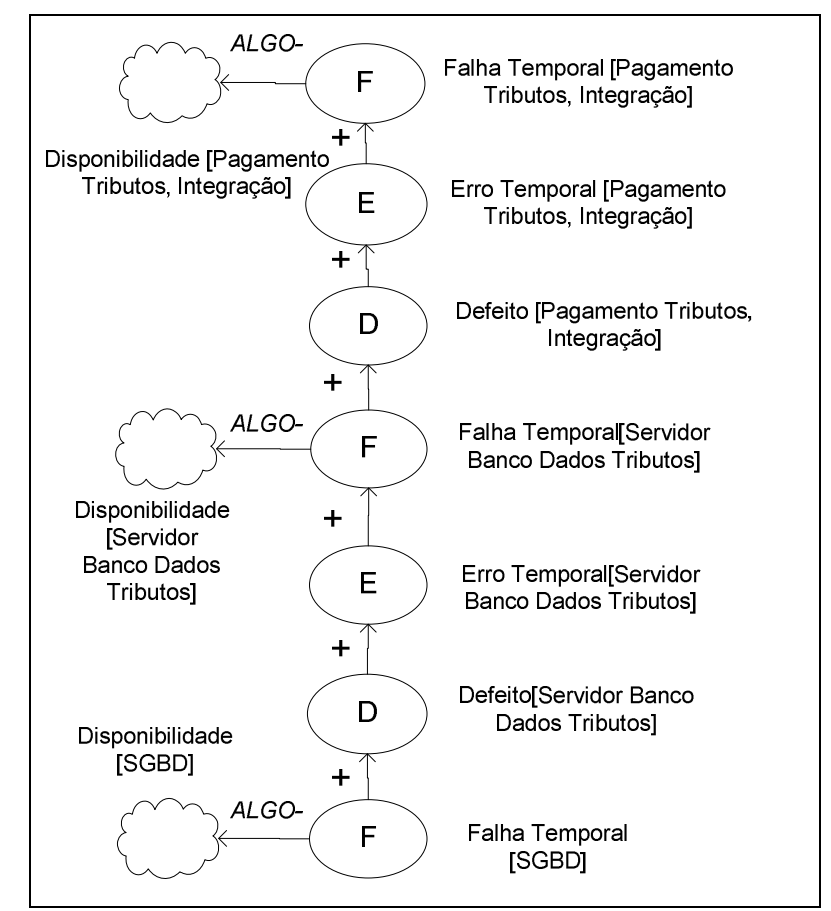

Figura 49 - Exemplo de Encadeamento de ameaças a dependabilidade, com respectivas contribuições 


\subsection{Etapa 2 - Aplicação do procedimento de avaliação}

A seção anterior exemplificou a aplicação dos passos da etapa de geração de grafo de disponibilidade do sistema, que relaciona ameaças a dependabilidade com softgoals de requisitos não-funcionais. A segunda etapa da técnica ADSSW avalia o grafo gerado segundo o procedimento de avaliação descrito no framework NFR para a geração de uma tabela com elementos que auxiliam a criação de cenários de disponibilidade.

Cabe ressaltar que falhas de componentes serão considerados estímulos para cenários de disponibilidade. Portanto, a segunda etapa da técnica inicia-se identificando os possíveis estímulos. Para cada estímulo identificado, devem ser identificados os softgoals afetados e as ameaças encadeadas. A seguir é descrita a aplicação do procedimento de avaliação no grafo gerado para o exemplo sob análise:

1. Inicialmente, seleciona-se um possível estímulo para a geração de cenários de disponibilidade. No exemplo, será considerada inicialmente como estímulo a ameaça "Falha por Atraso [SGBD]", considerando situações em que o tempo para o atendimento de uma requisição para o Sistema Gerenciador de Base de Dados supera o tempo limite máximo estabelecido. Para o estímulo a ser representado, marca-se com um rótulo $\checkmark$ a ameaça, conforme pode ser visto na Figura 50 considerada, e insere-se uma linha na tabela com a descrição "Falha por Atraso [SGBD]", conforme exemplificado na Tabela 9. 


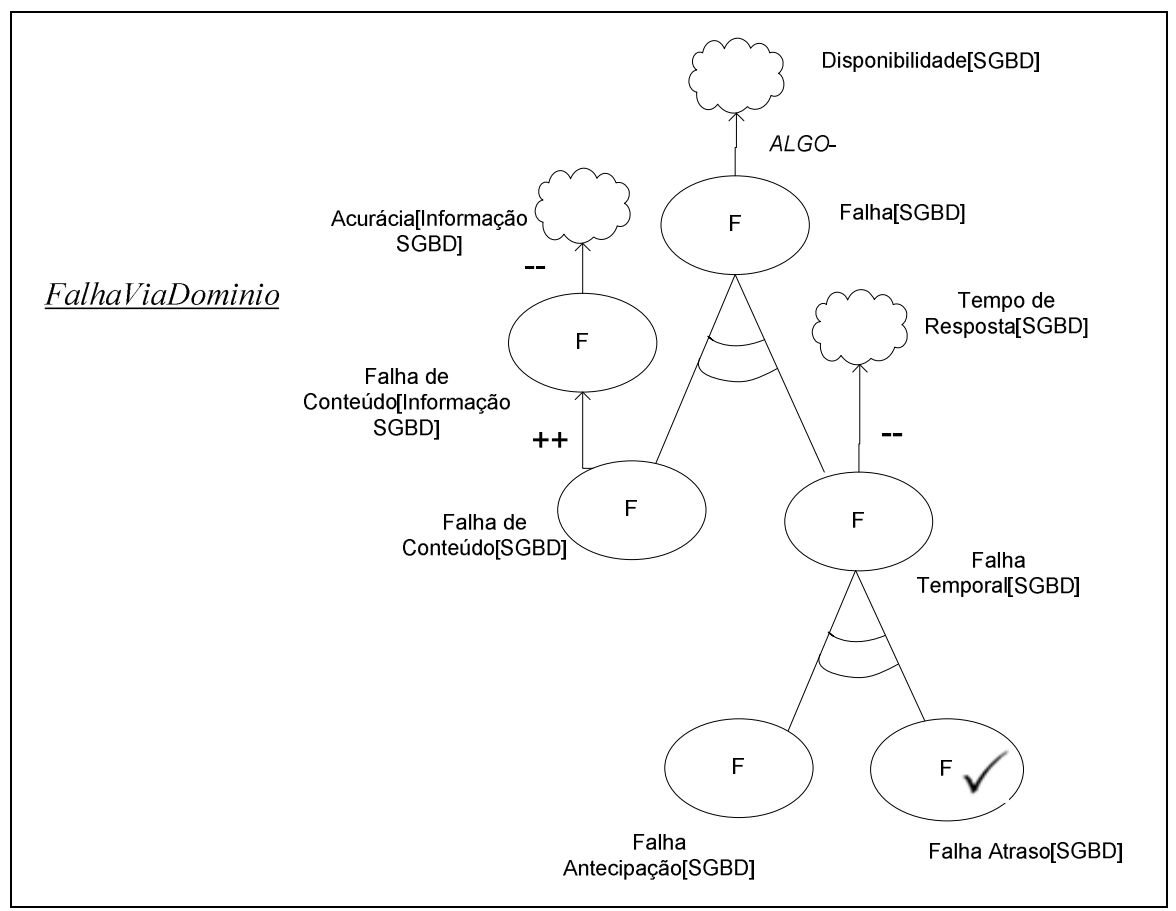

Figura 50 - Inserção de rótulo no estímulo a ser considerado

Tabela 9 - Início de procedimento - inserção de falha no catálogo

\begin{tabular}{|c|c|c|c|}
\hline Estímulos & $\begin{array}{c}\text { Softgoals - } \\
\text { Disponibilidade }\end{array}$ & $\mathbf{P}$ & Ameaças encadeadas \\
\hline $\begin{array}{c}\text { Falha Por Atraso } \\
{[\text { SGBD }]}\end{array}$ & & & \\
\hline
\end{tabular}

2. Com a marcação do rótulo, inicia-se o algoritmo de propagação de rótulos. Como a falha por atraso e a falha por antecipação foram decompostos através de uma contribuição $O R$, a ocorrência da falha por atraso é condição suficiente para que o rótulo $\checkmark$ seja propagado para a falha "Falha Temporal [SGBD]", uma vez que o rótulo $\checkmark$ apresenta o maior valor possível, e conforme visto na seção 4.4.2, um softgoal que recebe uma contribuição $O R$ apresenta o valor máximo dentre os rótulos associados aos softgoals que realizam a contribuição. Raciocínio análogo se aplica para propagação do rótulo $\checkmark$ para a ameaça "Falha [SGBD]". A ocorrência de uma falha temporal no Sistema Gerenciador de Banco de Dados é condição suficiente para caracterizar uma falha no Sistema Gerenciador de Banco de Dados. A Figura 51 representa o resultado da propagação destes rótulos. 


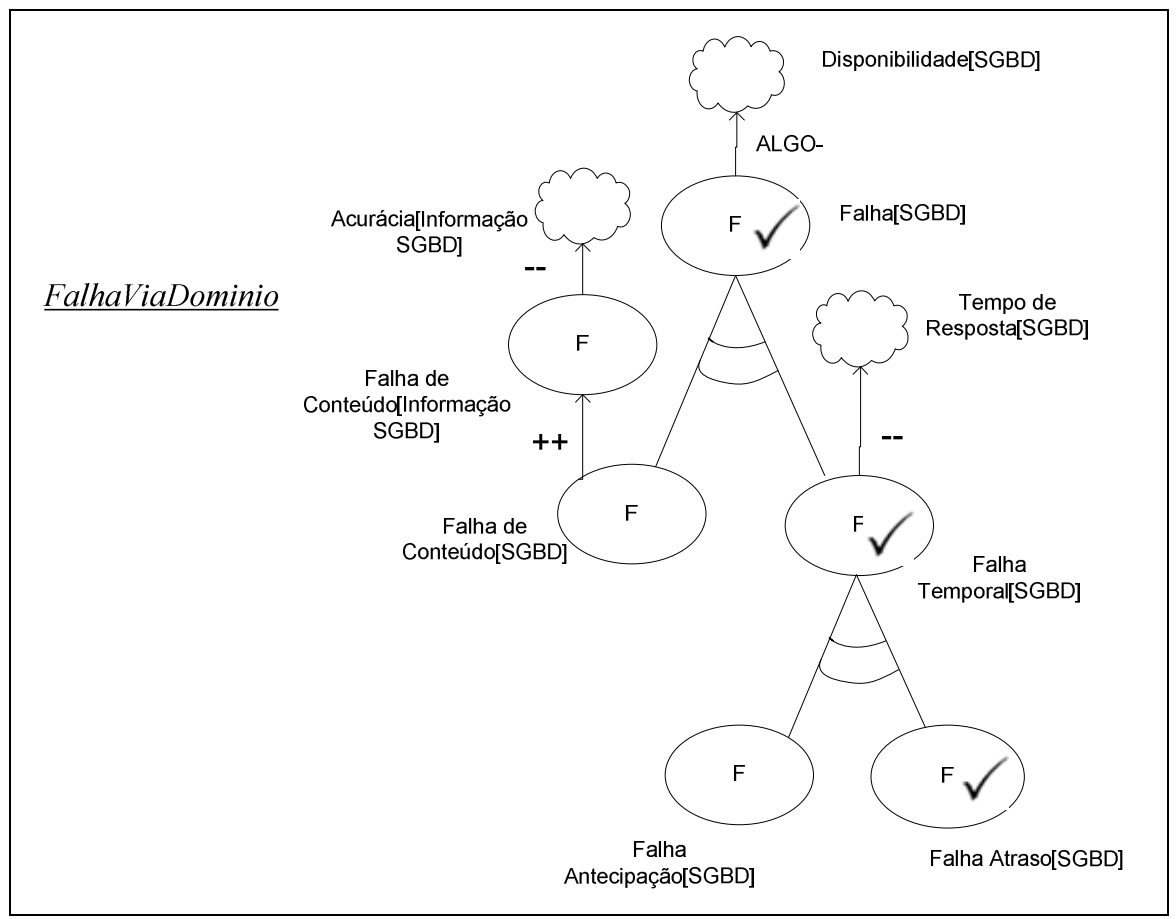

Figura 51 - Representação de propagação de rótulos

3. A ameaça Falha Temporal [SGBD] apresenta um encadeamento de ameaças, conforme descrito na construção do grafo do exemplo, representado através de contribuições AUXILIA. Como não são representadas contribuições negativas relacionadas às ameaças encadeadas, os rótulos $\checkmark$ são propagados através das contribuições, de acordo com as regras de propagação de rótulos presentes na Tabela 6. A Figura 52 exemplifica a propagação de rótulos entre as ameaças encadeadas. A Tabela 10 exemplifica a inclusão das ameaças marcadas com $o$ rótulo $\checkmark$ na quarta coluna da tabela. 


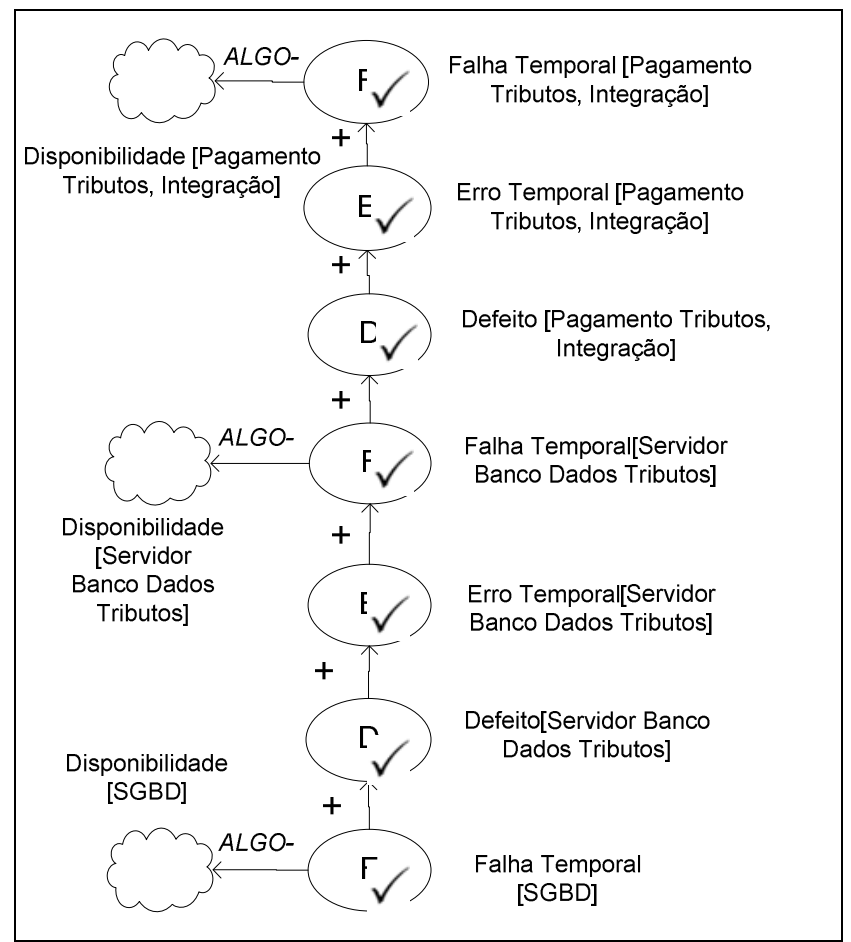

Figura 52 - Propagação de rótulos para ameaças encadeadas

Tabela 10 - Inserção de ameaças encadeadas

\begin{tabular}{|c|c|c|c|}
\hline Estímulos & $\begin{array}{c}\text { Softgoals - } \\
\text { Disponibilidade }\end{array}$ & $\mathbf{P}$ & Ameaças encadeadas \\
\hline \multirow{7}{*}{$\begin{array}{l}\text { Falha Por Atraso } \\
\text { [SGBD] }\end{array}$} & & & Falha Temporal [SGBD] \\
\hline & & & Defeito [Servidor Banco Dados Tributos] \\
\hline & & & $\begin{array}{c}\text { Erro Temporal [Servidor Banco Dados } \\
\text { Tributos] }\end{array}$ \\
\hline & & & $\begin{array}{c}\text { Falha Temporal [Servidor Banco Dados } \\
\text { Tributos] }\end{array}$ \\
\hline & & & $\begin{array}{c}\text { Defeito [Pagamento Tributos, } \\
\text { Integração] }\end{array}$ \\
\hline & & & $\begin{array}{c}\text { Erro Temporal [Pagamento Tributos, } \\
\text { Integração] }\end{array}$ \\
\hline & & & $\begin{array}{c}\text { Falha Temporal [Pagamento Tributos, } \\
\text { Integração] }\end{array}$ \\
\hline
\end{tabular}

4. Ao aplicar o algoritmo, nota-se que existe uma contribuição $A L G O$ - entre a ameaça "Falha [SGBD]" e o softgoal "Disponibilidade [SGBD]". De acordo com o algoritmo de propagação de rótulos, como não existe nenhuma outra contribuição positiva relacionada ao softgoal sob análise, o rótulo $X$ é associado ao softgoal e este é inserido na segunda coluna do catálogo. A 
propagação de rótulos é exemplificada na Figura 53 e a inserção do softgoal é exemplificada na Tabela 11.

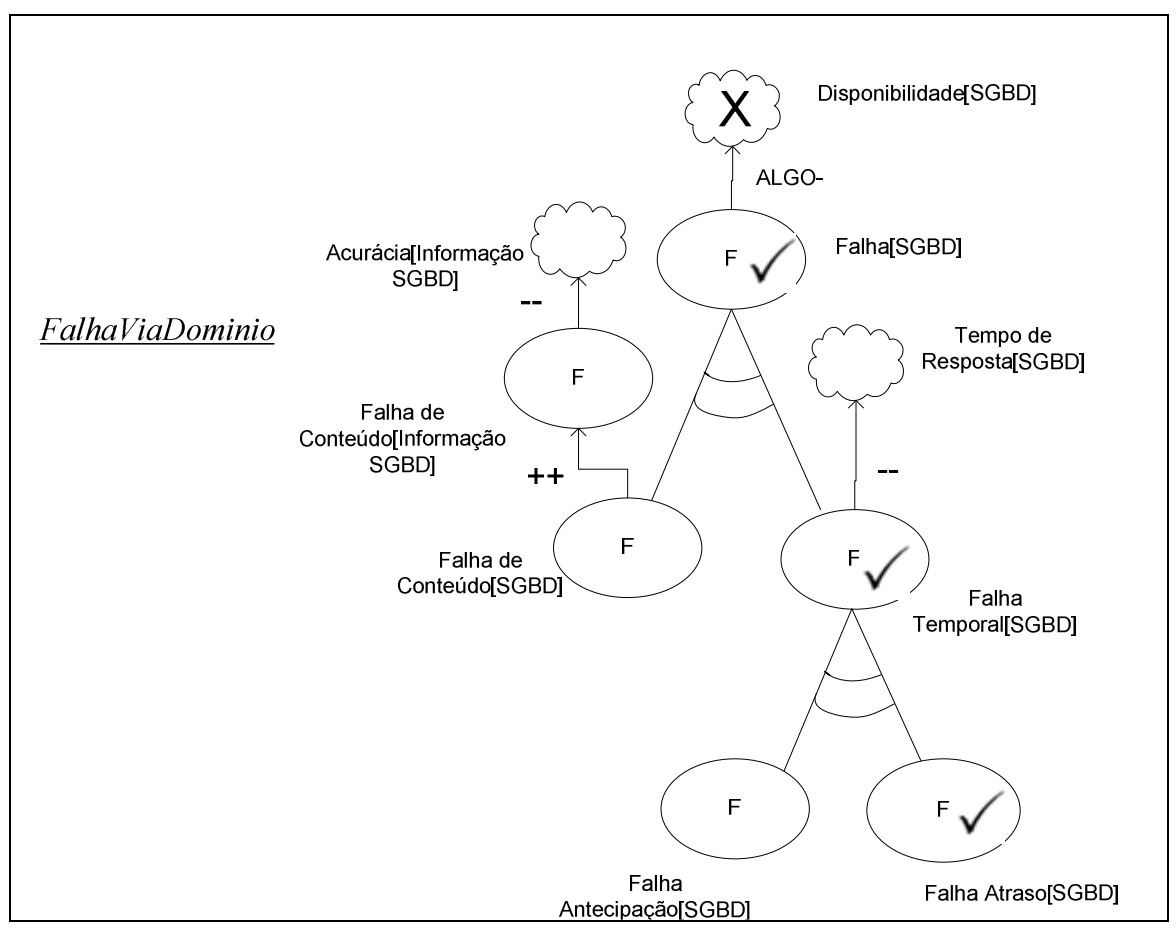

Figura 53 - Marcação do softgoal Disponibilidade [SGBD]

Tabela 11 - Inserção do softgoal Disponibilidade [SGBD]

\begin{tabular}{|c|c|c|c|}
\hline Estímulos & $\begin{array}{c}\text { Softgoals - } \\
\text { Disponibilidade }\end{array}$ & $\mathbf{P}$ & Ameaças encadeadas \\
\hline \multirow[t]{7}{*}{$\begin{array}{l}\text { Falha Por Atraso } \\
\text { [SGBD] }\end{array}$} & $\begin{array}{l}\text { Disponibilidade } \\
\text { [SGBD] }\end{array}$ & & Falha Temporal [SGBD] \\
\hline & & & Defeito [Servidor Banco Dados Tributos] \\
\hline & & & $\begin{array}{c}\text { Erro Temporal [Servidor Banco Dados } \\
\text { Tributos] }\end{array}$ \\
\hline & & & $\begin{array}{c}\text { Falha Temporal [Servidor Banco Dados } \\
\text { Tributos] }\end{array}$ \\
\hline & & & $\begin{array}{c}\text { Defeito [Pagamento Tributos, } \\
\text { Integração] }\end{array}$ \\
\hline & & & $\begin{array}{c}\text { Erro Temporal [Pagamento Tributos, } \\
\text { Integração] }\end{array}$ \\
\hline & & & $\begin{array}{c}\text { Falha Temporal [Pagamento Tributos, } \\
\text { Integração] }\end{array}$ \\
\hline
\end{tabular}

5. O algoritmo de propagação continua a ser aplicado. O softgoal "Disponibilidade [SGBD]", conforme descrito no exemplo, é resultante da decomposição do softgoal "Disponibilidade [Servidor Banco Dados de Tributos]". Esta decomposição ocorre através de uma decomposição AND. Conforme verificado na seção 4.4.2, um rótulo $\mathrm{X}$ em uma contribuição $A N D$ é 
condição suficiente para negar a condição de suficientemente satisfatório do softgoal decomposto. Portanto, o softgoal recebe 0 rótulo $\mathrm{X}$, conseqüentemente, é inserido na segunda coluna do catálogo. O mesmo critério se aplica no softgoal "Disponibilidade [Pagamento de Tributos, Integração]", no qual a negação do softgoal "Disponibilidade [Servidor Banco Dados de Tributos]" é suficiente para que o softgoal decomposto também seja negado. A propagação de rótulos é exemplificada na Figura 54 e a inserção dos softgoals é exemplificada na Tabela 12.

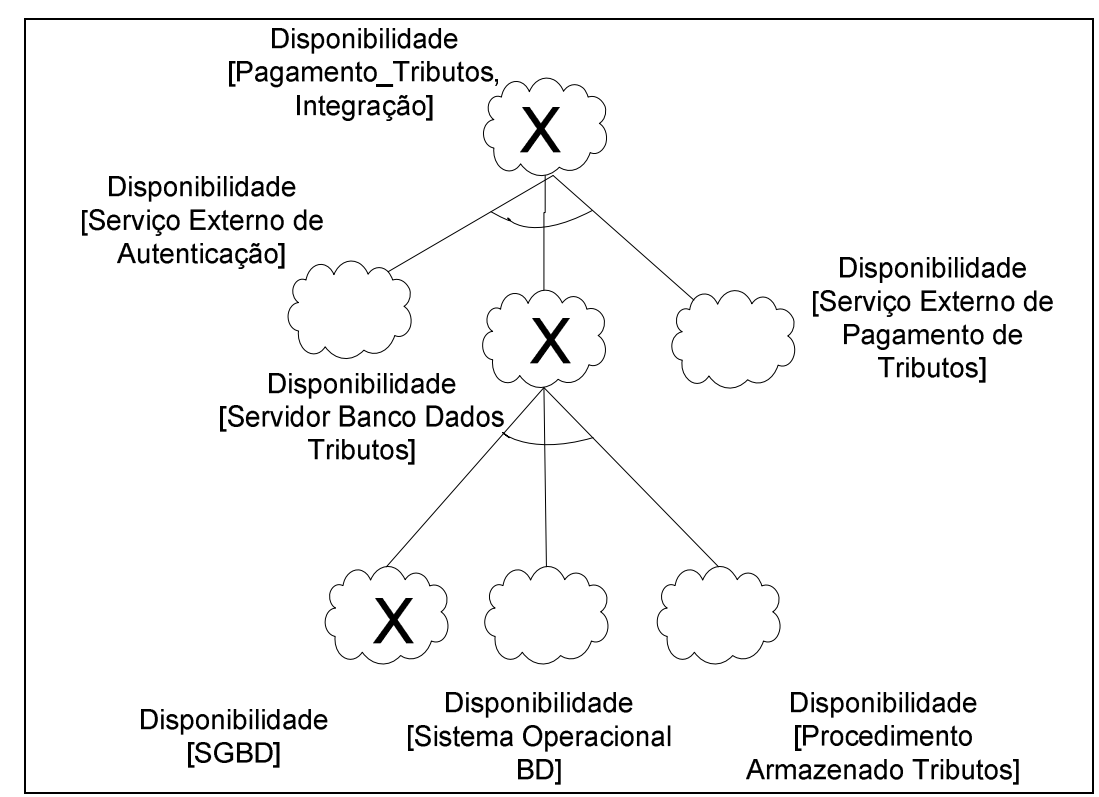

Figura 54 - Propagação de rótulos nos componentes da camada de integração

Tabela 12 - Inserção de softgoals associados a componentes da camada de integração

\begin{tabular}{|c|c|c|c|}
\hline Estímulos & Softgoals - Disponibilidade & $\mathbf{P}$ & Ameaças encadeadas \\
\hline \multirow{7}{*}{$\begin{array}{c}\text { Falha Por } \\
\text { Atraso } \\
\text { [SGBD] }\end{array}$} & Disponibilidade [SGBD] & & Falha Temporal [SGBD] \\
\hline & $\begin{array}{c}\text { Disponibilidade } \\
\text { [Servidor Banco Dados Tributos] }\end{array}$ & & $\begin{array}{l}\text { Defeito [Servidor Banco Dados } \\
\text { Tributos] }\end{array}$ \\
\hline & $\begin{array}{c}\text { Disponibilidade } \\
\text { [Pagamento Tributos, Integração] }\end{array}$ & & $\begin{array}{c}\text { Erro Temporal [Servidor Banco } \\
\text { Dados Tributos] }\end{array}$ \\
\hline & & & $\begin{array}{c}\text { Falha Temporal [Servidor Banco } \\
\text { Dados Tributos] }\end{array}$ \\
\hline & & & $\begin{array}{l}\text { Defeito [Pagamento Tributos, } \\
\text { Integração] }\end{array}$ \\
\hline & & & $\begin{array}{l}\text { Erro Temporal [Pagamento } \\
\text { Tributos, Integração] }\end{array}$ \\
\hline & & & $\begin{array}{c}\text { Falha Temporal [Pagamento } \\
\text { Tributos, Integração] }\end{array}$ \\
\hline
\end{tabular}


A próxima decomposição na qual será aplicado o algoritmo de propagação corresponde à decomposição SistemaSoftwareWebDisponibilidadeFuncViaCamada. Como se trata também de uma contribuição $A N D$, a associação do rótulo $\mathrm{X}$ ao softgoal "Disponibilidade [Pagamento Tributos, Integração]" é suficiente para a propagar o rótulo X para o softgoal "Disponibilidade [Pagamento Tributos]". A propagação de rótulos é exemplificada na Figura 55 e a inserção do softgoal é exemplificada na Tabela 13.

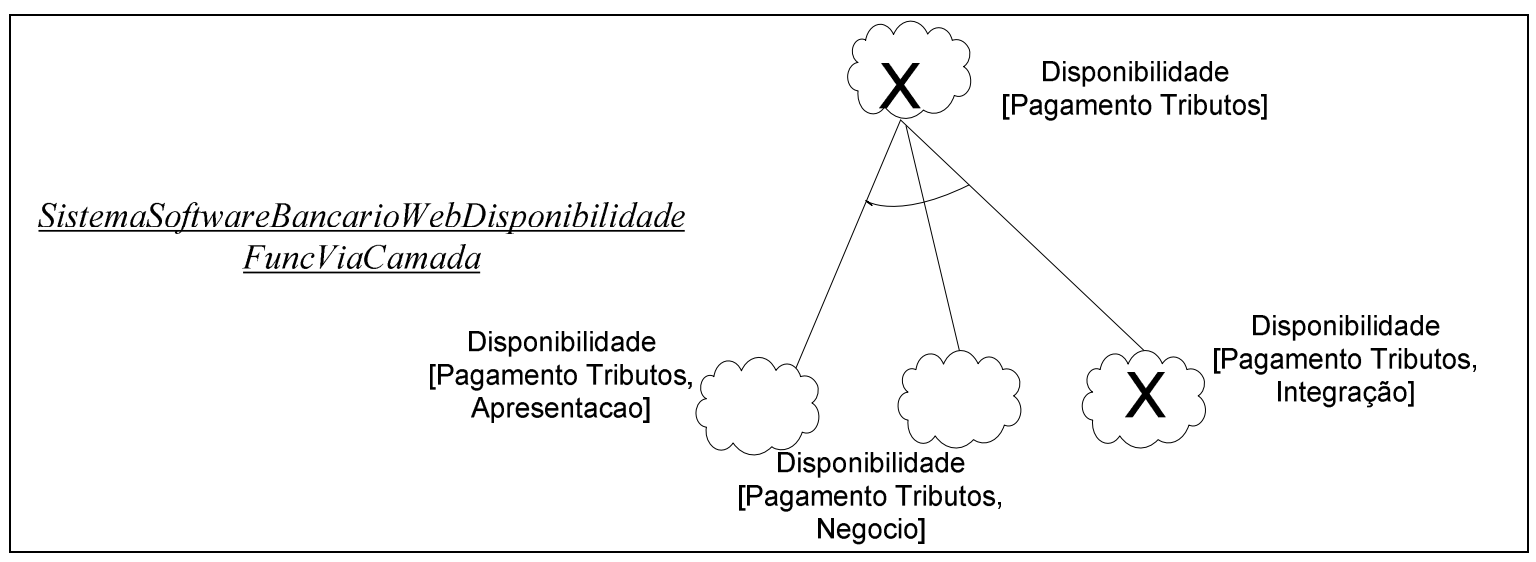

Figura 55 - Marcação do rótulo associado ao softgoal relacionado à funcionalidade de Pagamento de Tributos

Tabela 13 - Inclusão de softgoal relacionado à funcionalidade de Pagamento de Tributos

\begin{tabular}{|c|c|c|c|}
\hline \multirow{4}{*}{ Estímulos } & $\begin{array}{c}\text { Softgoals - } \\
\text { Disponibilidade }\end{array}$ & $\mathbf{P}$ & Ameaças encadeadas \\
\hline $\begin{array}{c}\text { Falha Por Atraso } \\
\text { [SGBD] }\end{array}$ & Disponibilidade [SGBD] & & Falha Temporal [SGBD] \\
\cline { 2 - 4 } & $\begin{array}{c}\text { Disponibilidade } \\
\text { [Servidor Banco Dados } \\
\text { Tributos] }\end{array}$ & $\begin{array}{c}\text { Defeito [Servidor Banco Dados } \\
\text { Tributos] }\end{array}$ \\
\cline { 2 - 4 } & $\begin{array}{c}\text { Disponibilidade } \\
\text { [Pagamento Tributos, } \\
\text { Integração] }\end{array}$ & $\begin{array}{c}\text { Erro Temporal [Servidor Banco } \\
\text { Dados Tributos] }\end{array}$ \\
\cline { 2 - 4 } & $\begin{array}{c}\text { Disponibilidade } \\
\text { [Pagamento Tributos] }\end{array}$ & $\begin{array}{c}\text { Falha Temporal [Servidor Banco } \\
\text { Dados Tributos] }\end{array}$ \\
\cline { 2 - 4 } & $\begin{array}{c}\text { Defeito [Pagamento Tributos, } \\
\text { Integração] }\end{array}$ \\
\cline { 2 - 4 } & & $\begin{array}{c}\text { Erro Temporal [Pagamento } \\
\text { Tributos, Integração] }\end{array}$ \\
\cline { 2 - 3 } & & $\begin{array}{c}\text { Falha Temporal [Pagamento } \\
\text { Tributos, Integração] }\end{array}$ \\
\hline
\end{tabular}


6. A próxima decomposição na qual será aplicado o algoritmo de propagação corresponde

SistemaSoftwareWebDisponibilidadeViaFuncionalidade. Como se trata também de uma contribuição $A N D$, a associação do rótulo $\mathrm{X}$ ao softgoal "Disponibilidade [Pagamento Tributos]" é condição suficiente para a negação dos softgoals "Disponibilidade [SistemaSoftwareBancarioWeb, Perfil Simples]" e "Disponibilidade [SistemaSoftwareBancarioWeb, Perfil Especial]". Nota-se que este softgoal está marcado com uma notação de priorização. De acordo com o algoritmo do procedimento de avaliação, a marcação de negação deve propagar-se através da contribuição que indica a priorização, e o softgoal marcado como prioritário deve ser associado ao estímulo somente uma vez no catálogo, sendo inserido um valor $\checkmark$ na terceira coluna, que indica priorização. Por fim, o algoritmo de propagação é aplicado na decomposição SistemaSoftwareWebDisponibilidadeViaPerfil. Como os dois perfis apresentam um rótulo de negação, o softgoal "Disponibilidade [SistemaSoftwareBancarioWeb]" deve ser inserido no catálogo. A propagação de rótulos é exemplificada na Figura 56 e a inserção dos softgoals é exemplificada na Tabela 14.

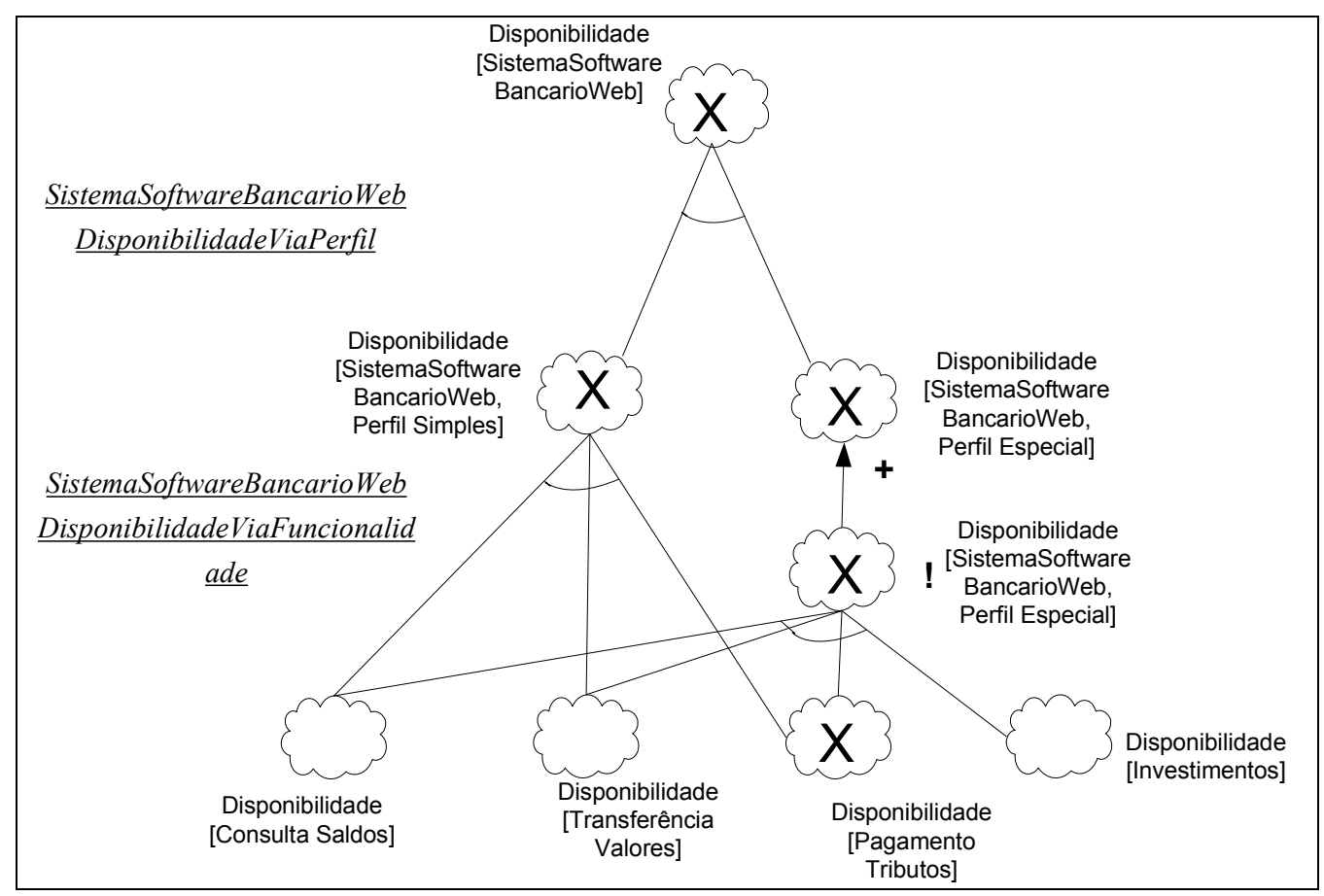

Figura 56 - Marcação de rótulos associados aos softgoals relacionados a perfis operacionais e ao sistema de software como um todo 
Tabela 14 - Inserção de softgoals relacionados a perfis operacionais e ao sistema de software como um todo, com marcação de priorização

\begin{tabular}{|c|c|c|c|}
\hline \multirow{1}{*}{ Estímulos } & $\begin{array}{c}\text { Softgoals - } \\
\text { Disponibilidade }\end{array}$ & $\mathbf{P}$ & Ameaças encadeadas \\
\hline $\begin{array}{c}\text { Falha Por Atraso } \\
\text { [SGBD] }\end{array}$ & Disponibilidade [SGBD] & Falha Temporal [SGBD] \\
\cline { 2 - 3 } & $\begin{array}{c}\text { Disponibilidade } \\
\text { [Servidor Banco Dados } \\
\text { Tributos] }\end{array}$ & $\begin{array}{c}\text { Defeito [Servidor Banco Dados } \\
\text { Tributos] }\end{array}$ \\
\cline { 2 - 4 } & $\begin{array}{c}\text { Disponibilidade } \\
\text { [Pagamento Tributos, } \\
\text { Integração] }\end{array}$ & $\begin{array}{c}\text { Erro Temporal [Servidor Banco } \\
\text { Dados Tributos] }\end{array}$ \\
\cline { 2 - 4 } & $\begin{array}{c}\text { Disponibilidade } \\
\text { [Pagamento Tributos] }\end{array}$ & $\begin{array}{c}\text { Falha Temporal [Servidor Banco } \\
\text { Dados Tributos] }\end{array}$ \\
\cline { 2 - 4 } & $\begin{array}{c}\text { Disponibilidade } \\
\text { [SistemaSoftwareBancari } \\
\text { oWeb, Perfil Simples] }\end{array}$ & $\begin{array}{c}\text { Defeito [Pagamento Tributos, } \\
\text { Integração] }\end{array}$ \\
\cline { 2 - 3 } & $\begin{array}{c}\text { Disponibilidade } \\
\text { [SistemaSoftwareBancari } \\
\text { oWeb, Perfil Especial] }\end{array}$ & $\checkmark$ & $\begin{array}{c}\text { Erro Temporal [Pagamento } \\
\text { Tributos, Integração] }\end{array}$ \\
\cline { 2 - 3 } & $\begin{array}{c}\text { Disponibilidade } \\
\text { [SistemaSoftwareBancari } \\
\text { oWeb] }\end{array}$ & Falha Temporal [Pagamento \\
& Tributos, Integração] \\
\hline
\end{tabular}

O procedimento deve ser aplicado a todos os estímulos a serem considerados na geração de cenários de disponibilidade. Ao final do procedimento, o resultado será uma tabela contendo possíveis falhas a serem consideradas na avaliação da arquitetura de software. Para cada falha identificada, a tabela permite que se identifique quais softgoals de disponibilidade estão relacionados com esta falha, e quais ameaças à dependabilidade esta ameaça pode encadear. A tabela visa auxiliar a geração de cenários de disponibilidade para o método de avaliação de arquitetura ATAM, minimizando riscos relacionados à não identificação de possíveis ocorrências de falhas e possibilitando que se identifiquem quais as conseqüências destas ocorrências.

\subsection{Geração de cenários de disponibilidade}

O conteúdo parcial presente na Tabela 14 será utilizado para exemplificar como a tabela gerada pela técnica ADSSW pode ser utilizada para auxiliar a geração de cenários de disponibilidade. Conforme descrito na técnica ADSSW, a primeira coluna da tabela corresponde a falhas que correspondem a estímulos para a 
construção de cenários de disponibilidade. Conforme descrito anteriormente, os valores presentes nesta coluna são utilizados para organizar cenários de disponibilidade, sendo correspondente ao terceiro nível da árvore de utilidades. O primeiro nível da árvore de utilidades (equivalente à raiz da árvore) corresponde à utilidade do sistema como um todo e o segundo nível corresponde aos requisitos não-funcionais a serem considerados no sistema sob análise. A Figura 57 representa a inclusão da falha por atraso no SGBD na árvore de utilidades.

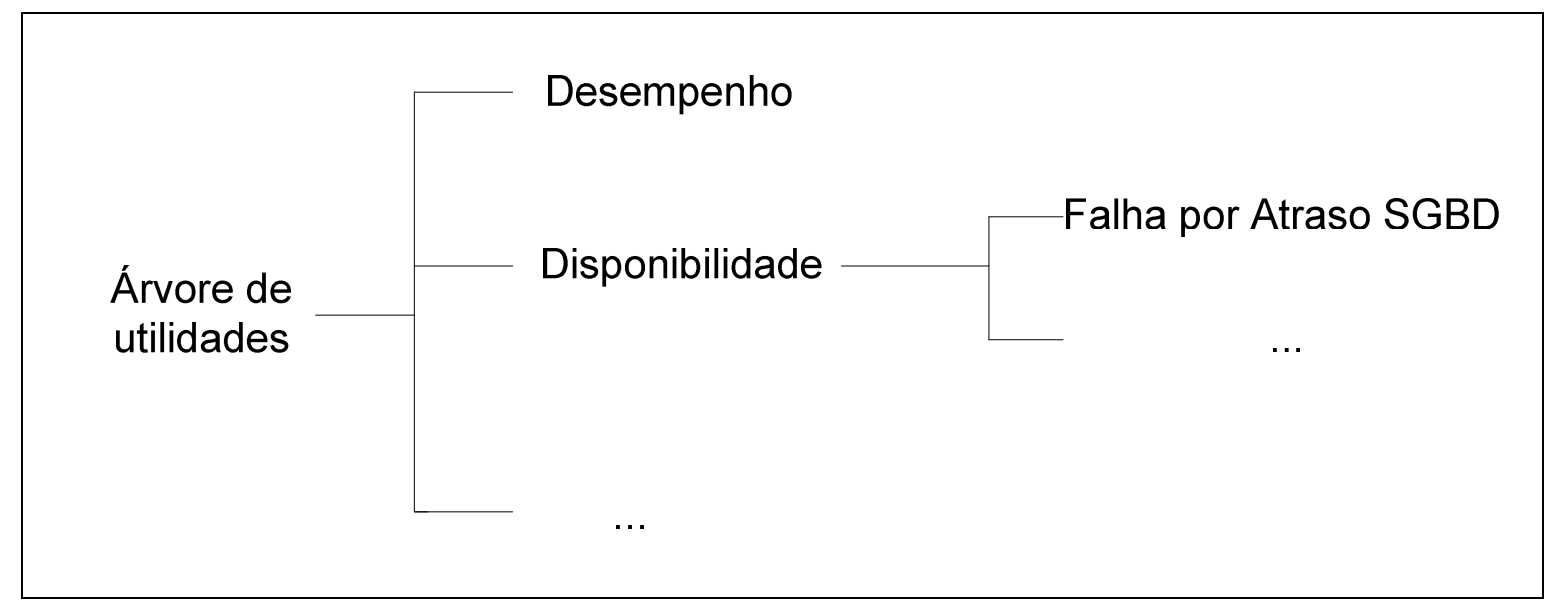

Figura 57 - Inclusão de nó correspondente a falha temporal no Sistema Gerenciador de Banco de Dados na árvore de utilidades

A falha por atraso é considerada um possível estímulo para cenários de disponibilidade. $O$ sistema de software deve ser capaz de responder a este estímulo de forma que atenda os requisitos de disponibilidade estabelecidos. Para se ter esta resposta, questiona-se: qual funcionalidade é afetada pela ocorrência desta falha? Quais usuários podem ser afetados por esta falha? Esta falha pode provocar outra ocorrência de falhas? Em decorrência da complexidade dos sistemas de software que disponibilizam serviços na Web, existe um risco de que os participantes envolvidos na avaliação de arquitetura podem não ser capazes de solucioná-los de maneira satisfatória. Falhas podem não ser consideradas, ou, caso sejam consideradas, existe um risco de que suas conseqüências não sejam mapeadas corretamente. O catálogo gerado pela técnica ADSSW visa minimizar os riscos citados, pois relaciona as falhas sob análise com softgoals associados ao requisito não-funcional disponibilidade.

O conteúdo da Tabela 14 possibilita a identificação de possíveis softgoals afetados pela falha em questão:

- Disponibilidade [SGBD] 
- Disponibilidade [Servidor Banco Dados Tributos]

- Disponibilidade [Pagamento Tributos, Integração]

- Disponibilidade [Pagamento Tributos]

- Disponibilidade [SistemaSoftwareBancarioWeb, Perfil Simples]

- Disponibilidade [SistemaSoftwareBancarioWeb, Perfil Especial]

- Disponibilidade [SistemaSoftwareBancarioWeb]

A presença destes softgoals pode auxiliar a levantar questões que visam auxiliar a caracterização de possíveis respostas dos cenários. As questões associadas ao softgoal "Disponibilidade [SGBD]" e "Disponibilidade [Servidor Banco Dados Tributos]" estão relacionadas a situações mais comumente relacionadas ao estímulo falha por atraso, tais como:

- Qual a disponibilidade assintótica relacionada ao Sistema Gerenciador de Banco de Dados?

- Qual o tempo máximo de reparo para o Sistema Gerenciador de Banco de Dados na ocorrência de uma falha por atraso?

Outras questões exigem um conhecimento maior da arquitetura de software como um todo. Questões associadas a funcionalidades, como, por exemplo, relacionadas ao softgoal "Disponibilidade [Pagamento Tributos]":

- Qual a disponibilidade assintótica relacionada à funcionalidade Pagamento de Tributos?

- Existe algum período específico (pode ser durante o dia, ou um período durante um determinado mês ou ano) no qual a funcionalidade Pagamento de Tributos deve estar disponível?

- A funcionalidade Pagamento de Tributos possui modos de operação diferenciados, utilizando recursos de hardware e software de acordo com as condições do ambiente?

- Para a funcionalidade Pagamento de Tributos existe alguma redundância de informação prevista para o caso de falha por atraso no Sistema Gerenciador de Banco de Dados?

Outras questões estão relacionadas a perfis operacionais. No caso da falha em questão no exemplo, existem questões relacionadas ao softgoal "Disponibilidade 
[SistemaSoftwareBancarioWeb, Perfil Simples]" e "Disponibilidade [SistemaSoftwareBancarioWeb, Perfil Especial]":

- Existem períodos específicos nos quais os perfis simples e especiais devem estar com a aplicação disponível?

- Qual o nível de disponibilidade associado a um determinado perfil operacional?

- Para cada usuário pertencente aos perfis simples e especial, em caso de indisponibilidade da funcionalidade Pagamento de Tributos, existe alguma funcionalidade (que não utilize o Sistema Gerenciador do Banco de Dados) que possa ser oferecida para que o usuário para que este não tenha maiores prejuízos?

- Caso o aplicativo tenha de operar em um modo de operação reduzido, qual perfil operacional teria uma prioridade no acesso às funcionalidades que acessam o Sistema Gerenciador de Banco de Dados?

As respostas para as questões levantadas são decorrentes da etapa 2, nas quais são apresentadas as diretrizes de negócio. Exemplos de diretrizes relacionadas ao sistema de exemplo são descritas a seguir:

- A funcionalidade Pagamento de Tributos não deve ficar indisponível ao usuário por mais de 1 minuto.

- A funcionalidade Pagamento de Tributos deve ser priorizada em relação às demais funcionalidades do sistema em caso de utilização excessiva de recursos do sistema.

Analisando-se o softgoal Disponibilidade [Pagamento Tributos], e com base nas diretrizes de negócio descritas, podem ser gerados os seguintes cenários, identificados por D1 e D2:

D1: Caso ocorra falha temporal no Sistema Gerenciador de Banco de Dados e o sistema de software estiver em modo normal de operação, após no máximo 1 minuto após a ocorrência da falha, deve-se permitir o acesso ao banco de dados somente para a funcionalidade Pagamento de Tributos por um período de 5 minutos, ocorrendo assim uma degradação do sistema eliminando uma possível causa para ocorrência da falha.

D2: Caso ocorra falha temporal no Sistema Gerenciador de Banco de Dados e o sistema de software estiver em modo degradado de operação, com somente a 
funcionalidade Pagamento de Tributos estiver funcional, o sistema deve chavear requisições para uma nova instância do Sistema Gerenciador do Banco de Dados. O período de sincronização de informações e reinício do novo módulo não deve ultrapassar o período de um minuto.

Os cenários D1 e D2 são incluídos no quarto nível da árvore de utilidades, representada na Figura 58.

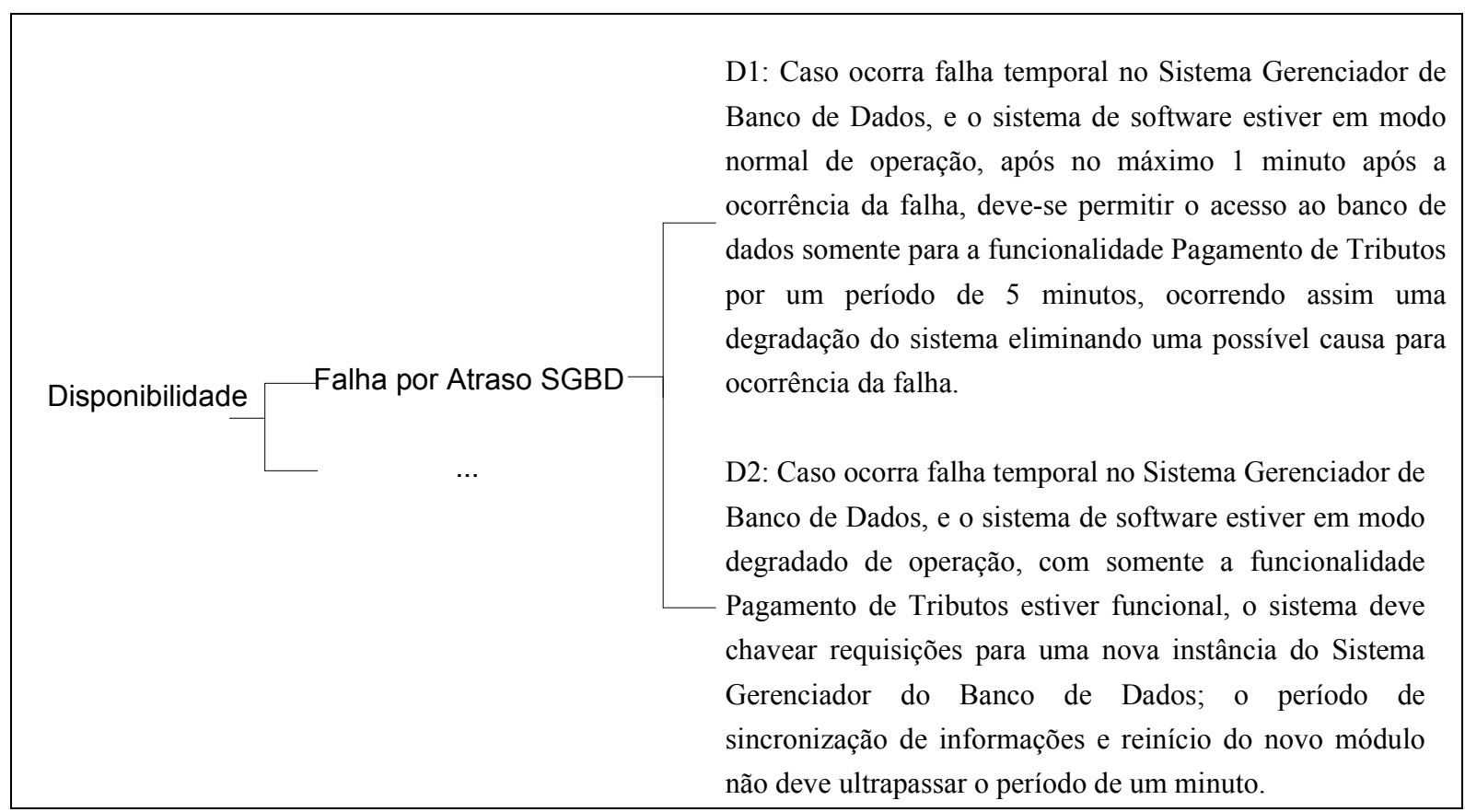

Figura 58 - Árvore de utilidades em seu quarto nível - com inserção dos cenários D1 e D2

As respostas presentes nos cenários D1 e D2 só foram possíveis devido ao fato de que a falha por atraso no Sistema Gerenciador de Banco de Dados foi associada à funcionalidade Pagamento de Tributos. Caso esta associação não fosse detectada pela equipe de avaliação de arquitetura, a avaliação de possíveis respostas para a falha em questão estaria comprometida. Cabe ressaltar que objetivos de negócio relacionados a softgoals de disponibilidade são fatores determinantes para a determinação da resposta ao estímulo.

Uma vez inseridos na árvore de utilidades, os cenários são priorizados de acordo com dois critérios: a importância do cenário, e a complexidade na obtenção da resposta definida no cenário. Ao final da etapa 5 do ATAM, o resultado consiste na árvore de utilidades com todos os cenários priorizados. 
Na etapa 6, os cenários considerados mais relevantes são submetidos à avaliação de abordagens arquitetônicas, sendo identificados, para cada cenário, quais os pontos de sensibilidade, tradeoffs, riscos e não-riscos. A Tabela 15 representa o cenário D1 no modelo definido para a etapa 6 do método, e a Tabela 16 representa o cenário D2.

Tabela 15 - Modelo para análise do cenário D1

Cenário: Cenário D1 - resposta com degradação

Atributo: Disponibilidade

Ambiente: Modo normal de operação.

Estímulo: ocorrência de falha por atraso no Sistema Gerenciador de Banco de Dados.

Resposta: Após no máximo 1 minuto após a ocorrência da falha, deve-se permitir o acesso ao banco de dados somente para a funcionalidade Pagamento de Tributos por um período de 5 minutos, ocorrendo assim uma degradação do sistema, eliminando uma possível causa para ocorrência da falha.

\begin{tabular}{|l|c|c|c|c|}
\multicolumn{1}{|c|}{$\begin{array}{c}\text { Decisões } \\
\text { Arquitetônicas }\end{array}$} & $\begin{array}{c}\text { Pontos de } \\
\text { Sensibilidade }\end{array}$ & $\begin{array}{c}\text { Pontos de } \\
\text { Tradeoff }\end{array}$ & Riscos & $\begin{array}{c}\text { Não- } \\
\text { riscos }\end{array}$ \\
\hline $\begin{array}{l}\text { Lista de decisões } \\
\text { arquitetônicas } \\
\text { relevantes que afetam a } \\
\text { resposta do cenário de } \\
\text { atributo de qualidade. }\end{array}$ & $\begin{array}{c}\text { Pontos de } \\
\text { sensibilidade } \\
\text { associados a } \\
\text { cada decisão de } \\
\text { arquitetura no } \\
\text { cenário em } \\
\text { questão }\end{array}$ & $\begin{array}{c}\text { Pontos de } \\
\text { tradeoff } \\
\text { relacionados a } \\
\text { cada decisão, } \\
\text { com o impacto } \\
\text { em relação } \\
\text { aos demais } \\
\text { atributos de } \\
\text { qualidade }\end{array}$ & $\begin{array}{c}\text { Descrições } \\
\text { relacionadas } \\
\text { ao efeito } \\
\text { negativo de } \\
\text { uma decisão } \\
\text { arquitetônica } \\
\text { (ou a ausência } \\
\text { da decisão) no no } \\
\text { cenário em } \\
\text { questão }\end{array}$ & $\begin{array}{c}\text { Descriçada } \\
\text { relacionada } \\
\text { saofitivo de } \\
\text { uma } \\
\text { decisão } \\
\text { arquitetônic } \\
\text { a no } \\
\text { cenário em } \\
\text { questão }\end{array}$ \\
\hline
\end{tabular}

Racionalização: racionalização quantitativa e/ou qualitativa indicando as razões pelas quais a lista de decisões arquitetônicas contribuem para afetar cada requisito de atributo de qualidade representado pelo cenário.

Diagramas de Arquitetura: diagrama ou diagramas de visões arquitetônicas que representam informações arquitetônicas que dão suporte à racionalização acima, acompanhados com um texto explicativo caso seja necessário. 
Tabela 16 - Modelo para análise de cenário D2

Cenário: Cenário D2 - resposta com degradação

Atributo: Disponibilidade

Ambiente: Modo degradado de operação (somente a funcionalidade Pagamento de Tributos possui acesso ao Sistema Gerenciador de Banco de Dados)

Estímulo: ocorrência de falha por atraso no Sistema Gerenciador de Banco de Dados.

Resposta: o sistema deve chavear requisições para uma nova instância do Sistema Gerenciador do Banco de Dados; o período de sincronização de informações e reinício do novo módulo não deve ultrapassar o período de um minuto.

\begin{tabular}{|l|c|c|c|c|}
\multicolumn{1}{|c|}{$\begin{array}{c}\text { Decisões } \\
\text { Arquitetônicas }\end{array}$} & $\begin{array}{c}\text { Pontos de } \\
\text { Sensibilidade }\end{array}$ & $\begin{array}{c}\text { Pontos de } \\
\text { Tradeoff }\end{array}$ & Riscos & $\begin{array}{c}\text { Não- } \\
\text { riscos }\end{array}$ \\
\hline $\begin{array}{l}\text { Lista de decisões } \\
\text { arquitetônicas } \\
\text { relevantes que afetam a } \\
\text { resposta do cenário de } \\
\text { atributo de qualidade. }\end{array}$ & $\begin{array}{c}\text { Pontos de } \\
\text { sensibilidade } \\
\text { associados a } \\
\text { cada decisão de } \\
\text { arquitetura no } \\
\text { cenário em } \\
\text { questão }\end{array}$ & $\begin{array}{c}\text { Pontos de } \\
\text { tradeoff } \\
\text { relacionados a } \\
\text { cada decisão, } \\
\text { com o impacto } \\
\text { em relação } \\
\text { aos demais } \\
\text { atributos de } \\
\text { qualidade }\end{array}$ & $\begin{array}{c}\text { Descrições } \\
\text { relacionadas } \\
\text { ao efeito } \\
\text { negativo de } \\
\text { uma decisão } \\
\text { arquitetônica } \\
\text { (ou a ausência } \\
\text { da decisão) no no } \\
\text { cenário em } \\
\text { questão }\end{array}$ & $\begin{array}{c}\text { Descriçes } \\
\text { relacionada } \\
\text { sao efeito } \\
\text { positivo de } \\
\text { uma } \\
\text { decisão } \\
\text { arquitetônic } \\
\text { a no } \\
\text { cenário em } \\
\text { questão }\end{array}$ \\
\hline
\end{tabular}

Racionalização: racionalização quantitativa e/ou qualitativa indicando as razões pelas quais a lista de decisões arquitetônicas contribuem para afetar cada requisito de atributo de qualidade representado pelo cenário.

Diagramas de Arquitetura: diagrama ou diagramas de visões arquitetônicas que representam informações arquitetônicas que dão suporte à racionalização acima, acompanhados com um texto explicativo caso seja necessário. 


\section{Considerações FinaIS}

\subsection{Conclusão}

Este trabalho teve como objetivo a proposição de uma técnica que, de forma organizada e detalhada, seja capaz de prover elementos para auxiliar a geração de cenários de disponibilidade no método de avaliação de arquitetura ATAM (Architecture Tradeoff Analysis Method - Método de Análise de Compromissos de Arquitetura) em sistemas de software que fornecem serviços através da Internet.

Para cumprir o objetivo, foi proposta a técnica ADSSW (Análise de Disponibilidade de Sistemas de Software na Web). Esta técnica não visa cobrir todas as possibilidades de geração de cenários de disponibilidade, mas sim propiciar, de forma detalhada e estruturada, a criação de um catálogo que possibilite a identificação e caracterização de falhas que possam afetar a disponibilidade do sistema, e que permita uma identificação de possíveis conseqüências na ocorrência destas falhas.

A técnica faz uso de conceitos de dependabilidade, estruturados com elementos presentes no framework NFR e utilizando uma hierarquia para a modelagem de disponibilidade em sistemas de e-business. Uma das contribuições da técnica proposta é o mapeamento dos conceitos de atributos de dependabilidade e ameaças à dependabilidade em elementos do framework NFR.

A técnica apresentada inicialmente pode ser aplicada somente em arquiteturas de software baseadas em componentes e em sistemas de software que disponibilizem serviços na Internet. A restrição existe devido ao fato de que a técnica apresenta métodos de decomposição que se baseiam em uma hierarquia de perfis operacionais, funcionalidades e componentes aplicados em sistemas de software que disponibilizam serviços na Web baseados na arquitetura aqui descrita, mas não necessariamente em sistemas de software baseados em outros estilos arquitetônicos ou em outras plataformas tecnológicas.

O trabalho apresentou os elementos da técnica, tais como softgoals de requisitos não-funcionais, ameaças à dependabilidade e um catálogo de métodos que 
possibilitam que se construam interdependências entre os itens citados. Detalhou os passos necessários para sua aplicação, com duas etapas principais: a primeira englobando a construção de um grafo contendo softgoals, ameaças e interrelacionamentos entre estes elementos; e a segunda aplicando um procedimento de avaliação baseado no procedimento de avaliação do framework NFR, que visa avaliar o impacto da ocorrência de ameaças na disponibilidade associada a componentes, funcionalidades e perfis operacionais. Cabe ressaltar que a versão inicial da proposta ADSSW considera somente aspectos relacionados à elicitação de cenários de disponibilidade. Portanto, nesta versão optou-se por não representar decisões arquitetônicas relacionadas aos meios de dependabilidade.

O resultado da aplicação da técnica é uma tabela contendo falhas utilizadas como estímulos para a caracterização de cenários de disponibilidade, com os softgoals afetados por sua ocorrência. Com esta tabela, existe a possibilidade de que sejam gerados cenários que representem requisitos de disponibilidade.

Foram também descritos, de modo sucinto, trabalhos que abordam a geração de cenários de atributos de qualidade para o método de avaliação de arquitetura ATAM. Em (BASS; CLEMENTS; KAZMAN, 2003) são descritos elementos para a geração de cenários gerais, relacionados a atributos de qualidade, que devem ser instanciados para a geração de cenários de atributos de qualidade específicos para a arquitetura de software sob avaliação. No método QAW (BARBACCl et al., 2003), cenários são elicitados inicialmente com a interação de stakeholders em um processo de brainstorming, no qual cada stakeholder define cenários considerados relevantes para a avaliação da arquitetura. Em seguida, os cenários são priorizados, de acordo com uma votação realizada pelos stakeholders. Os cenários considerados de maior relevância são refinados, adequando-os à estrutura de cenários de atributos de qualidade apresentada em (BASS; CLEMENTS; KAZMAN, 2003).

No ATAM, existem duas abordagens para a geração de cenários na avaliação. Em um primeiro momento, na etapa 5 , um grupo menor de stakeholders gera cenários de atributos de qualidade, com a geração da árvore de utilidades. Em um segundo momento, na etapa 7, um grupo maior de stakeholders participa da geração de cenários numa atividade de brainstorming, além de rever a priorização adotada nos cenários elicitados na etapa 5. De forma geral, a geração de cenários de atributos de qualidade baseia-se em interações com stakeholders e a equipe de avaliação de 
arquitetura de software estrutura estes cenários de tal forma que estejam coerentes com a estruturação de cenários de atributos de qualidade proposta em (BASS; CLEMENTS; KAZMAN, 2003).

Cabe ressaltar que a técnica ADSSW não tem por objetivo substituir o processo de elicitação de cenários apresentado no método de avaliação de arquitetura ATAM, com interações envolvendo stakeholders. A técnica proposta tem como objetivo auxiliar a geração de cenários de disponibilidade para sistemas de software que disponibilizam serviços na Web, provendo um suporte com o objetivo de minimizar riscos em relação à avaliação do requisito não-funcional disponibilidade na arquitetura de software sob análise. A principal motivação para a proposição da técnica é a constatação de que, durante o procedimento de elicitação de cenários de disponibilidade, existem riscos tais como a não identificação de possíveis estímulos e de suas conseqüências, especialmente em casos de sistemas de software que apresentam uma complexa infra-estrutura distribuída de software, como é o caso da arquitetura típica para sistemas Web analisada.

No presente trabalho, existem evidências de que a técnica proposta cumpriu seu objetivo, uma vez que o procedimento definido na técnica ADSSW possibilita que sejam identificadas, de uma forma detalhada e organizada, quais são as ameaças a serem consideradas ao se analisar disponibilidade em uma arquitetura de software. A tabela resultante da aplicação da técnica permite que a equipe de avaliação visualize quais componentes, funcionalidades e perfis operacionais são afetados pela ocorrência das ameaças identificadas.

No capítulo 5 deste trabalho, aplicou-se a técnica ADSSW em um exemplo de sistema de software simplificado. Este exemplo teve como objetivo principal propiciar um melhor entendimento dos elementos e do procedimento definidos na técnica.

A técnica ADSSW apresenta uma base conceitual fundamentada, principalmente, na conceituação de dependabilidade apresentada em (LAPRIE, 1992) combinada com o framework NFR (CHUNG et al., 2000), que dá suporte à análise de requisitos nãofuncionais na área de engenharia de software. Com a aplicação da técnica em um exemplo, existem evidências que os elementos apresentados na técnica auxiliam a geração de cenários de disponibilidade, identificando de modo detalhado e sistemático estímulos para a geração dos cenários, embora esta percepção não pôde ser comprovada neste trabalho devido à ausência de um estudo de caso real. 
A aplicação da técnica ADSSW em um estudo de caso é uma possibilidade de trabalho futuro relacionado ao conteúdo apresentado neste trabalho.

O presente trabalho também concentrou-se na descrição dos elementos da técnica, justificando a presença de cada elemento. No entanto, não foi descrita uma ferramenta de apoio para a aplicação da técnica ADSSW, apenas apresentado, ao final do capítulo 4 , seus objetivos gerais. O desenvolvimento de uma ferramenta de apoio para aplicação da técnica é outra possibilidade de trabalho futuro.

\subsection{Trabalhos futuros}

A aplicação da técnica ADSSW em um estudo de caso é um dos trabalhos futuros vislumbrados relacionados ao conteúdo apresentado no presente trabalho. O estudo de caso deverá contemplar a aplicação da técnica na avaliação de uma arquitetura de software com características similares às apresentadas neste trabalho e também deverá verificar os resultados de sua aplicação. Para a realização do estudo de caso, existe a necessidade de se determinar as variáveis que permitam caracterizar a eficiência da aplicação da técnica e critérios para se avaliar esta eficiência. Além disso, o estudo de caso deve mostrar a quantidade de cenários de disponibilidade gerados e um modo de se verificar a relevância destes cenários.

Outra possibilidade de trabalho futuro está relacionada ao desenvolvimento de uma ferramenta de apoio para a aplicação da técnica proposta. A ferramenta deve possibilitar a construção do grafo, com informações fornecidas pelo usuário da ferramenta, tais como perfis operacionais, funcionalidades disponibilizadas pelos perfis operacionais e componentes que provêem a funcionalidade, assim como as possíveis ameaças associadas aos componentes. Ela deve automatizar o procedimento de avaliação da técnica ADSSW, implementando o algoritmo de propagação de rótulos definido na descrição do procedimento de avaliação. A ferramenta deve também possibilitar, a partir de interações requeridas para decidir aspectos de satisfação durante o procedimento de avaliação, a geração da tabela que relaciona as falhas identificadas com softgoals afetados por elas.

Outra possibilidade de trabalho futuro seria a extensão da técnica, através da inclusão de novos elementos, como, por exemplo, a caracterização de defeitos que desencadeiem a ocorrência de falhas em componentes atômicos. Outra possível 
extensão seria a inclusão de softgoals de operacionalização. Conforme visto em (CHUNG et al., 2000), softgoals de operacionalização são utilizados para a representação de decisões de projeto (design) que afetam positiva ou negativamente softgoals de requisitos não-funcionais. Nessa extensão, os softgoals de operacionalização poderiam ser utilizados para representar táticas arquitetônicas relacionadas a meios de tolerância a defeitos. Tal inclusão possibilitaria verificar qual o impacto dessas decisões em requisitos não-funcionais considerados na avaliação da arquitetura de software, abrindo a possibilidade para que a técnica ADSSW seja aplicada não somente na etapa de geração de cenários de disponibilidade, mas também em etapas de avaliação de decisões arquitetônicas nos cenários identificados. Por fim, outra possível extensão da técnica seria a possibilidade de se analisar outros atributos de dependabilidade em arquiteturas de software, tais como confiabilidade e segurança (safety), além de atributos de segurança (security). 


\section{REFERÊNCIAS}

AL-KHATEEB, W. F.; AL-IRHAYIM, S.; AL-KHATEEB, K. A. Reliability objectives in next-generation internet. In: Asia-Pacific Conference on Communications - APCC, 9., 2003, Penang, Malaysia. Anais... Penang, Malaysa: APCC, 2003. v. 1. p. 192197.

AVIŽIENIS, A. et al. Basic concepts and taxonomy of dependable and secure computing. IEEE Transactions on Dependable and Secure Computing, v. 1, n. 1, p. 11-33, Jan./Mar. 2004.

BABAR, M.A.; CAPILLA, R. Capturing and using quality attributes knowledge in software architecture evaluation process. In: International Workshop on Managing Requirements Knowledge, 1., 2008, Catalunya, Spain. Anais... Catalunya, Spain: Mark, 2008. p. 53-62.

BABAR, M.A.; GORTHON, I. A tool for managing software architecture knowledge. In: Workshop on Sharing and Reusing Architectural Knowledge - Architecture, rationale, and Design Intent, 29., 2007, Minneapolis, USA. Anais... Minneapolis, USA: IEE Computer Society, 2007. 11 p.

BACHMANN, F. et al. Designing software architectures to achieve quality attribute requirements. IEEE Proceedings on Software, v. 152, n. 4, p. 153-165, Aug. 2005.

BARBACCI, M. et al. Quality Attributes. Pittsburg: Software Engineering Institute, Dec. 1995. (Technical Report CMU/SEI-95-TR-021).

Quality attribute workshops (QAWs). $3^{\text {th }}$ ed. Pittsburgh: Software Engineering Institute, Aug. 2003. (Technical Report CMU/SEI-2003-TR-016).

BASS, L.; CLEMENTS, P.; KAZMAN, R. Software architecture in practice. $2^{\text {nd }}$ ed. Boston, USA: Addison-Wesley Professional, 2003.

BASS, L.; KLEIN, M.; BACHMANN F. Quality attribute design primitives. Pittsburgh: Software Engineering Institute, Dec. 2000. (Technical Report CMU/SEI2000-TN-017). 
. Quality attribute design primitives and the attribute driven design method. In: International Workshop on Software Product-Family Engineering, 4., 2001. Proceedings... London, UK: Springer-Verlag, 2001. p. 323-328.

BASS, L.; KLEIN, M.; MORENO, G. Applicability of general scenarios to the architecture tradeoff analysis method. Pittsburgh: Software Engineering Institute, Oct. 2001. (Technical Report CMU/SEI-2001-TR-014).

$\mathrm{BOOCH}, \mathrm{G}$. Object solutions: managing the object-oriented project. Boston, USA: Addison-Wesley Longman Publishing Co., 1996.

BREWER, E.A. Lessons from giant-scale services. IEEE Internet Computing, v. 4, n. 4, p. 46-55, 2001.

CHUNG, L. et al. Non-functional requirements in software engineering. Norwell, USA: Kluwer Academic Publishers, 2000.

CLEMENTS, P.; KAZMAN, R.; KLEIN, M. Evaluating software architectures: methods and case studies. Boston, USA: Addison-Wesley Professional, 2002.

CYSNEIROS, L. M.; LEITE, J. C. S. P. Nonfunctional requirements: from elicitation to conceptual models. IEEE Transactions on Software Engineering, v. 30, n. 5, p. 328-350, 2004.

CYSNEIROS, L. M.; LEITE, J. C. S. P.; SABAT NETO, J. M. A framework for integrating non-functional requirements into conceptual models. Requirements Engineering Journal, v. 6, n. 2, p. 97-115, 2001.

DOBRICA, L.; NIEMELIÄ, E. A survey on software architecture analysis methods. IEEE Transactions on Software Engineering, v. 28, n. 7, p. 638-653, 2002.

FORTUNA, E. Mercado financeiro produtos e serviços. 17. ed. Rio de Janeiro: QualityMark, 2008.

GORBENKO, A. et al. F(I)MEA - technique of web services analysis and dependability ensuring. In: BUTLER, M. J. et al. (Eds.). Rigorous development of complex fault-tolerant systems. Heidelberg: Springer Berlin, 2006. p. 153-168. 
GUERRA, P. A. C.; RUBIRA, C.; DE LEMOS, R.: A fault-tolerant software architecture for component-based systems. In: DE LEMOS, R.; ISSARNY, V.; ROMANOVSKY, A. Architecting dependable systems. Heidelberg: Springer Berlin, 2003. p. 129-149.

IEEE. IEEE Std 830: IEEE recommended practice for software requirements specifications. New York, USA: The Institute of Electrical and Electronics Engineers, 1998. (Software Engineering Standards Collection).

IEEE. IEEE Std 1471: recommended practice for architectural description of software-intensive systems. New York, USA: The Institute of Electrical and Electronics Engineers, 2000.

ISO. ISO 9126-1: software engineering - product quality - part 1: quality model. Geneve: International Standardization Organization, 2001.

JOHNSON, B. W. The design and analysis of fault-tolerant digital systems. Boston, USA: Addison- Wesley Professional, 1989.

KAÂNICHE, M.; KANOUN K.; RABAH M. A framework for modeling the availability of e-Business Systems. In: International Conference on Computer Communications and Networks, 10., 2001, Scothdale-AZ, USA. Anais... Scothdale-AZ, USA: World Academy of Science, Engineering and Technology, 2001. p. 40-45.

KAZMAN, R.; CARRIÈRE, S. J.; WOODS, S. G. Toward a discipline of scenariobased architectural engineering. Annals of Software Engineering, v. 9, n. 1-4, p. 533, 2000.

KAZMAN, R.; KLEIN, M. Attribute-based architectural styles. Pittsburgh: Software Engineering Institute, Oct. 1999. (Technical Report CMU/SEI-99-TR-022).

KAZMAN, R.; KLEIN, M.; CLEMENTS, P. ATAM: method for architecture evaluation. Pittsburgh: Software Engineering Institute, Aug. 2000. (Technical Report CMU/SEI2000-TR-004).

LAPRIE, J. C. (Ed.).Dependability: basics concepts and terminology in English, French, German, Italian and Japanese. London, UK: Spring-Verlag. 1992. 
LOOKER, N.; MUNRO, M.; XU, J. Increasing web service dependability through consensus voting. In: Annual International Computer Software and Applications Conference, 29., 2005, Edinburgh, Scotland. Proceedings... Washington, DC, USA: IEEE Computer Society, 2005. v. 2. p. 66-69.

MISHRA, K.; TRIVEDI, K. S. Model based approach for autonomic availability management. In: WALTER, M.; TRINITIS, C.; TOEROE, M. Service availability. Heidelberg: Springer Berlin, 2006. p. 1-16.

OFFUTT, J. Quality attributes of web software applications. IEEE Software, v. 19, n. 2, p. 25-32, 2002.

OPPENHEIMER, D.; PATTERSON, D. A. Architecture and dependability of largescale internet services. IEEE Internet Computing, v. 6, n. 5, p. 41-49, 2002.

OZKAYA, I. et al. Making practical use of quality attribute information. IEEE Software, 2008, v. 25, n. 2, p. 25-33, 2008.

PEACOCK, R. Distributed architecture technologies. IT Professional IEEE, v. 2, n. 3, p. 58-60, 2000.

PEÑALOZA, W. ERP a savior or slayer of enterprise competitiveness. Switzerland, France: Université de Laussane, 2003. (Working Paper 0305, ERP: Cisco Case Study).

SHAW M.; GARLAN, D. Software architecture: perspectives on an emerging discipline. Upper Saddle River, USA: Prentice Hall, 1996.

VASCONCELLOS NETO, O. C.; MUNIZ SILVA, P. S. A technique for the generation of availability scenarios in the ATAM. Conferência Latino-americana de Informática (CLEI), 35., 2009, Pelotas, Brasil, 2009. Anais... Pelotas, Brasil: CLEI, 2009. A ser publicado nos anais da conferência.

ZHU, Y.; HUANG, G.; MEI, H. Quality attribute scenario based architectural modeling for self-adaptation supported by architecture-based reflective middleware. In: AsiaPacific Software Engineering Conference (APSEC'04), 11., 2004, Busan, Korea. Proceedings... Los Alamitos, USA: IEEE Computer Society, 2004. p. 2-9. 